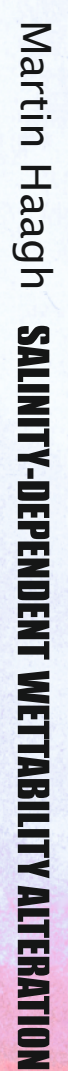

\title{
SALINITY-DEPENDENT WETTABILITY ALTERATION
}

Mimicking Low Salinity Water Flooding with Model Systems of Varying Complexity

Martin Haagh

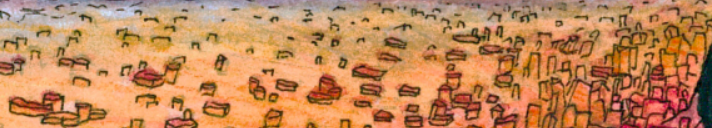

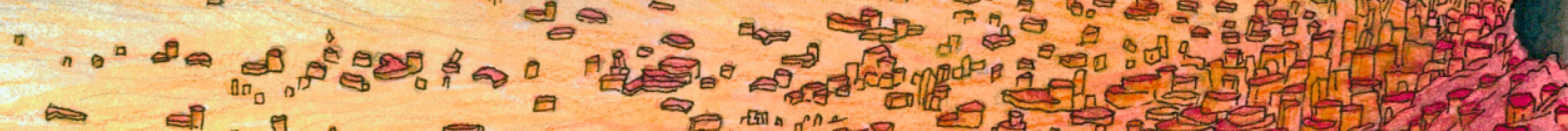

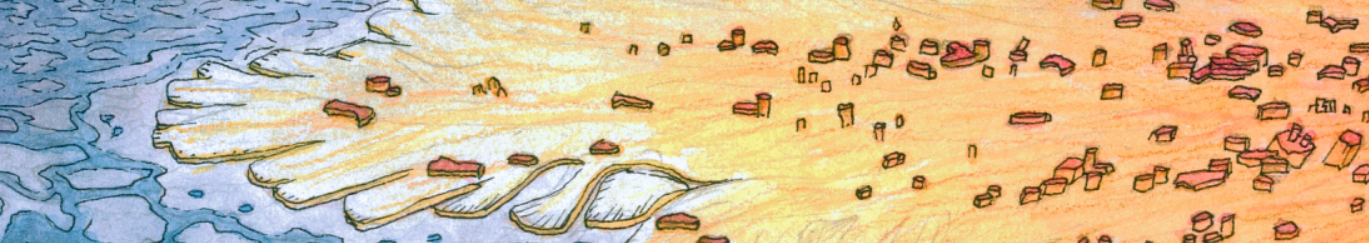

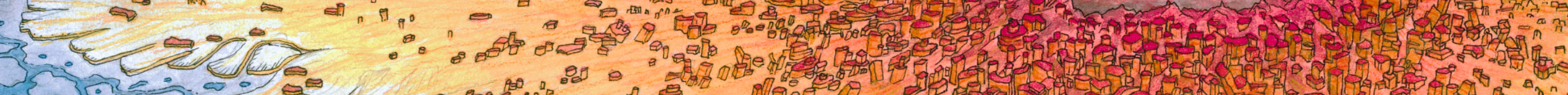

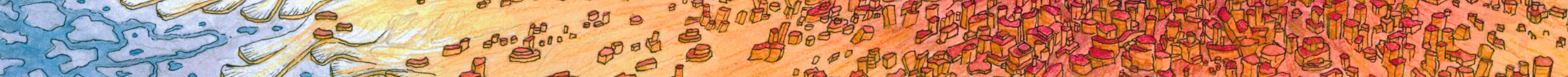

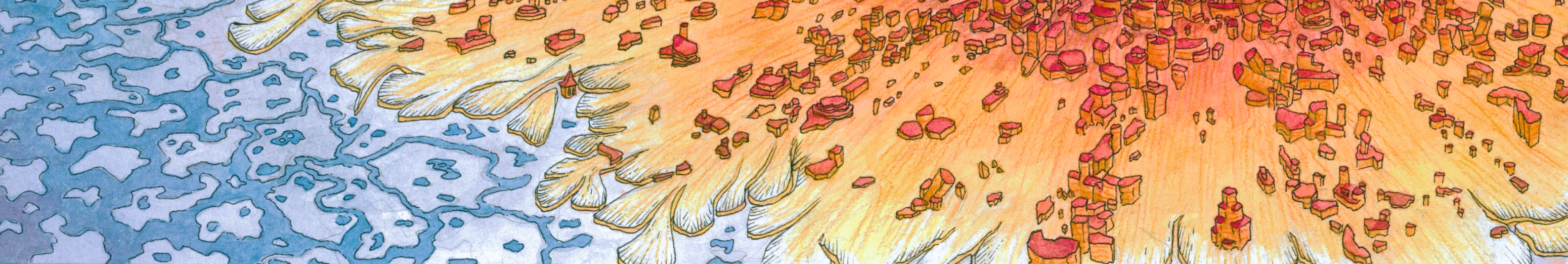




\section{SALINITY-DEPENDENT WETTABILITY ALTERATION \\ Mimicking Low Salinity Water Flooding with Model Systems of Varying Complexity}

\section{DISSERTATION}

to obtain

the degree of doctor at the Universiteit Twente, on the authority of the rector magnificus,

Prof.dr. T.T.M. Palstra, on account of the decision of the graduation committee to be publicly defended on Friday 28 February 2020 at 16.45

by 
This dissertation has been approved by:

Supervisors

Prof. dr. F.G. Mugele

Prof. dr. M.H.G. Duits

Cover design \& layout:

Martin Haagh

Printed by:

Gildeprint B.V.

ISBN:

978-90-365-4949-3

DOI:

$10.3990 / 1.9789036549493$

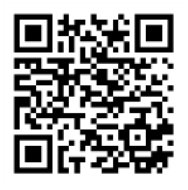

(c) 2020 Martin Haagh, The Netherlands.

All rights reserved. No parts of this thesis may be reproduced, stored in a retrieval system or transmitted in any form or by any means without permission of the author.

Alle rechten voorbehouden. Niets uit deze uitgave mag worden vermenigvuldigd, in enige vorm of op enige wijze, zonder voorafgaande schriftelijke toestemming van de auteur. 


\section{Graduation committee:}

Chairman / secretary

Supervisors:

Committee Members: prof. dr. J.L. Herek

prof. dr. F. Mugele

dr. M.H.G. Duits

prof. dr. N.E. Benes

prof. dr. J.G.E. Gardeniers

em. prof. dr. M.A. Cohen Stuart

dr. I.R. Collins

prof. dr. M.D. Jackson

The research described in this thesis was performed at:

Physics of Complex Fluids

Faculty of Science and Technology

University of Twente

P.O. Box 217

7500 AE Enschede

The Netherlands

\section{UNIVERSITY | MESA+ \\ OF TWENTE. INSTITUTE}

This work is part of the research program Rock-on-a-Chip with project number i40, which is co-financed by the Netherlands Organization for Scientific Research (NWO) and by the Exploratory Research (ExploRe) program of BP plc. BP Exploration Operating Company Limited are thanked for permission to publish this paper. 



\section{SUMMARY}

Low salinity water flooding is a technique where, by injecting reduced salinity seawater, oil recovery can be significantly improved in some sandstone reservoirs. It has been generally agreed upon that this works predominantly by improving the water wettability of the reservoir rock. However, the mechanisms that underlie this salinity-induced water wettability alteration are still poorly understood, largely because of the high degree of complexity of these reservoir systems. This is found in the variety of the oil, brine, and mineral phase contents; in the multiscale porous system, and in the high temperatures and pressures involved.

In designing an experiment to find the underlying wettability mechanisms one must therefore either include a high degree of complexity to get realistic, but difficult to interpret results, or greatly simplify the system to gain insight into very specific mechanisms, which are however not guaranteed to be relevant under more realistic conditions. A wealth of literature exists largely on the more complex side of these experiments, and, since recently, much has been done using highly simplified systems. In this work, I aimed to bridge some of the mechanistic insights gained from simplified systems with the current knowledge of low salinity water flooding at realistic conditions. Therefore, I opted to look into systems of low-to-intermediate complexity. This work is set-up such that each chapter adds a degree of complexity, starting with single-salt brine/oil/mineral systems at room temperature, and ending with complex multi-component brine/crude oil/oil-aged mineral systems at elevated temperatures. The general form of these experiments has been kept constant: a single droplet of either oil ( $n$-decane with fatty acids, or crude oil) or brine, in an ambient phase of the other kind, deposited onto a mineral substrate, usually mica. I measured the wettability response of the systems by registering the contact angles of the droplets, and how these depend on the conditions of the system. In some cases I also looked into the physico-chemical properties of the substrates, to study the underlying mechanisms in further detail. 
In Chapter 2 I discuss the most simple setup, at room temperature, in which it was found that the wettability of the system was completely dominated by the concentration of divalent cations in the brine, and not by the total ionic strength. The divalent cations seemed to be able to bridge fatty acids from the oil phase to the substrate, thereby creating a patchy hydrophobic monolayer structure. In fact, if the monovalent cation concentration was very high compared to the divalent concentration, the water wettability actually goes up again, likely due to competitive adsorption with the divalent cations. I could also mimic a highly simplified form of low salinity water flooding in this system, by first depositing a high divalent cation content droplet, which reaches high contact angles (low water wettability), and then exchanging its ionic content. In this way, water wettability could be improved by introducing low salinity brine, or brines high in monovalent cation content, but not if the invading brine was high in divalent cation content.

Changing the temperature of the system had strong effects on the wettability of these simplified systems, as investigated in Chapter 3: at temperatures above $40^{\circ} \mathrm{C}$ the divalent cation content, although still important, was no longer the sole factor dominating the wettability effects. Instead the presence of just $2 \mathrm{mM}$ of bicarbonate, as it occurs in seawater, now caused the water contact angles of up to $160^{\circ}$ to be reached, whereas only $60^{\circ}$ could be reached without it. In Chapter 4 I looked into this remarkable effect in more detail, and found that the underlying structure on the substrate was altered from a patchy monolayer to a dense hydrophobic multilayer. It was established that this multilayer forms at the three-phase contact line, and likely consists of alternating fatty acid bilayers bound together by $\mathrm{CaCO}_{3}$.

Lastly, in Chapter 5, measurements using real crude oil are introduced, with substrates aged with a thin brine film and the same oil. There I found that all substrates were fully covered in organic layers, likely consisting mostly of asphaltenic aggregates. Therefore, during wettability measurement, there was no direct contact between mineral substrate and the oil and brine phases. The nature of this organic layer was shown to be critical to the eventual wettability effects, and it was 
found that the aging conditions (mostly the brine content) of the substrate were therefore very influential in this regard. Even here the divalent cation content was found to be one of the most important factors determining the wettability response of the system.

Moving forward in gaining understanding in the wettability alteration mechanisms that underlie low salinity water flooding, it will be very important to investigate these pre-adsorbed organic layers: how they are formed and how they affect the macroscopic wettability and its dependence on ionic content. 



\section{SAMENVATTING}

Waterinjectie met laag zoutgehalte is een techniek waarmee oliewinning van zandsteenreservoirs significant verhoogd kan worden. De algemene consensus is dat dit effect grotendeels veroorzaakt wordt door een vergrote waterbevochtiging van het gesteente. De onderliggende mechanismes van de zoutgehalte-afhankelijke bevochtigingsverandering worden echter nog steeds niet goed begrepen. Dit komt waarschijnlijk hoofdzakelijk door de grote complexiteit van het reservoir systeem: er is grote variatie in de samenstelling van de olie-, de zout water-, en mineraalfases; hoge complexiteit in de multischaalporositeit van het gesteente; en hoge aanwezige druk en temperatuur.

Om een experiment te ontwerpen voor het vinden van de relevante onderliggende bevochtigingsmechanismes moet men enerzijds rekening houden met de hoge complexiteit om realistische, maar moeilijk te interpreten resultaten te behalen, anderzijds is het nuttig om een sterk vereenvoudigd systeem te ontwerpen om specifieke inzichten te behalen, maar zonder garantie dat deze ook relevant zijn bij realistischere omstandigheden. De huidige literatuur biedt hoofdzakelijk een grote hoeveelheid informatie over complexere systemen, en er is sinds kort ook veel werk verricht met sterk vereenvoudigde systemen. Dit werk heeft tot doel om de inzichten in de mechanismes uit de versimpelde systemen te vertalen naar wat er bekend is van de relatie tussen bevochtiging en zoutgehalte uit realistische systemen. Daarom heb ik ervoor gekozen om te werken met system van een lage tot gemiddelde complexiteit. Dit werk is zo opgesteld dat er met elk hoofdstuk een stap aan complixiteit wordt toegevoegd: we beginnen met simpele zoutoplossing/olie/mineraal systemen bij kamertemperatuur, en eindigen met complexe zout water/ruwe olie/in-olie-voorbereide mineraal systemen bij hoge temperatuur. Wat alle experimenten gemeen hebben is de algemene vorm: een enkele druppel van of olie ( $n$-decaan met vetzuren, of ruwe olie) of zout water, in een omgeving van de andere fase, neergelegd op een mineraalsubstraat, meestal muscoviet. Hierin meten we de 
contacthoek om zo de bevochting van het systeem te bepalen. In sommige gevallen bestuderen we ook de microscopische eigenschappen van het substraat zelf, om hieruit meer inzicht te krijgen in de onderliggende mechanismes van geobserveerde bevochtegingsveranderingen.

In Hoofdstuk 2 neem ik het meest eenvoudige systeem door, bij kamertemperatuur, waarvan is ontdekt dat de bevochtiging compleet gedomineerd wordt door de concentratie divalente kationen, en niet door de totale ionische sterkte. Deze divalente kationen lijken de vetzuren uit te olie te kunnen binden aan het substraat, hierdoor vormt zich een fragmentarische hydrofobe monolaagstructuur. Het is zelfs zo, dat als de concentratie monovalente kationen zeer hoog is vergelijken met die van de divalente kationen, het systeem meer door water wordt bevochtigd. Dit gebeurt waarschijnlijk door competetieve adsorptie van de verschillende ionen. In dit systeem heb ik ook een sterk vereenvoudigde vorm van waterinjectie met laag zoutgehalte uitgevoerd, door eerst een druppel met hoge divalente kationconcentratie neer te leggen, welke een hoge contacthoek aanneemt, en vervolgens de ionische inhoud van deze druppel te veranderen door injectie met een andere oplossing. Zo kon de waterbevochtiging van het systeem verhoogd worden wanneer er een oplossing werd geïnjecteerd met een laag zoutgehalte, of een oplossing met een hoge concentratie monovalent kationen, maar niet met een oplossing met hoge concentratie divalente kationen..

De bevochtigingseigenschappen van het systeem werden ook sterk beïnvloed wanner de temperatuur verhoogd werd, zoals onderzocht in Hoofdstuk 3: boven de $40^{\circ} \mathrm{C}$ waren de divalente kationen niet langer de enige belangrijke component voor het bepalen van de contacthoek. In plaats daarvan was het de aanwezigheid van slechts $2 \mathrm{mM}$ bicarbonaat, zoals het ook in zeewater voorkomt, die ervoor zorgde dat contacthoeken tot aan $160^{\circ}$ bereikt konden worden, in plaats van de $60^{\circ}$ zonder bicarbonaat. In Hoofdstuk 4 heb ik dit bijzondere effect in meer detail bestudeerd, waar ik gevonden heb dat er zich op het substraat geen fragmentarische monolaag meer vormt, maar een dichte multilaag. Deze laag vormt zich bij de drie-fase-contactlijn, en bestaat 
waarschijnlijk uit afwisselende lipide dubellagen, bij elkaar gehouden door $\mathrm{CaCO}_{3}$.

In Hoofdstuk 5 laat ik experimenten zien die gedaan zijn met ruwe olie, op substraten die enkele dagen in contact waren geweest met een dunne laag zout water en ondergedompeld in dezelfde ruwe olie. Deze substraten bleken op deze manier compleet bedekt te zijn in een stabiele organische laag, voornamelijk bestaande uit asfaltenische aggregaten. Hierdoor waren de olie- en waterfases tijdens de contacthoekmetingen niet meer in direct contact met het mineraal zelf. De eigenschappen van de organische laag bleken kritiek te zijn voor de bevochtingseigenschappen tijdens de metingen. Als gevolg daarvan, waren de condities (voornamelijk de ionische samenstelling van de zoutoplossing) tijdens de voorbereiding van het substraat van groter belang dan tijdens de meting zelf. Ook in dit geval weer bleken juist de divalent kationen de belangrijkste component met grote invloed op de uiteindelijke bevochtigingseigenschappen.

Om verdere stappen te nemen om de invloed van zoutgehalte op de bevochtiging van soortgelijke systemen beter te begrijpen, zal het in de toekomst belangrijk zijn om juist deze van tevoren geadsorbeerde laag verder te onderzoeken: hoe deze gevormd wordt en op welke manier het reageert op de ionische samenstelling van de waterfase. 



\section{TABLE OF CONTENTS}

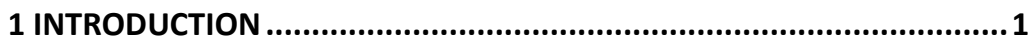

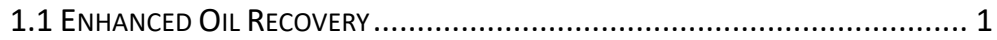

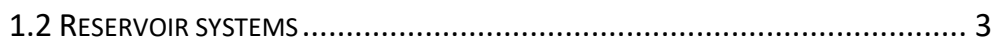

1.3 LoW SALINITY WATER FLOOdING MECHANISMS..................................... 8

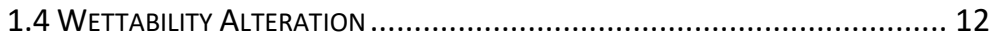

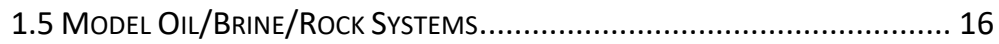

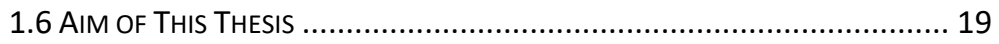

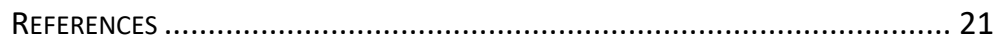

2 CATION-DEPENDENT WETTABILITY ALTERATION...........................27

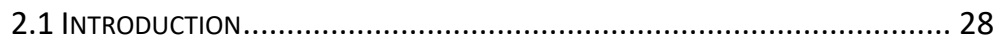

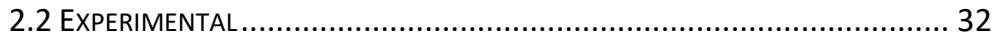

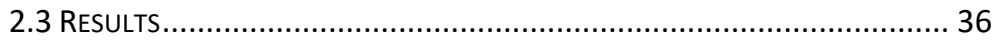

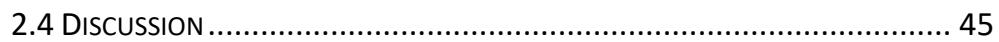

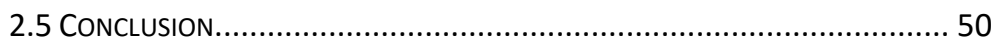

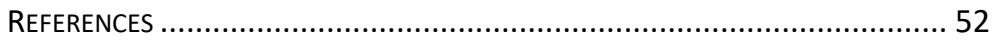

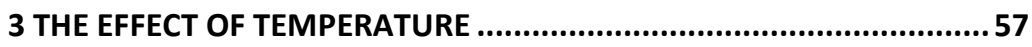

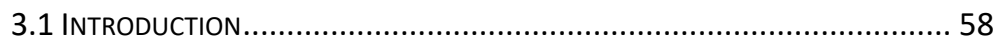

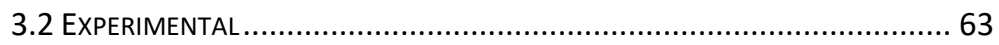

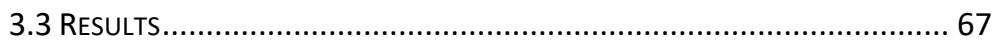

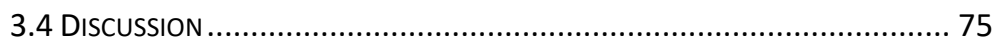

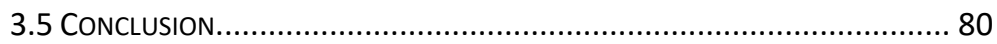

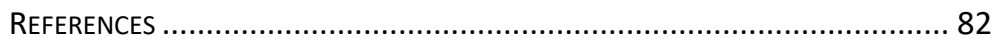

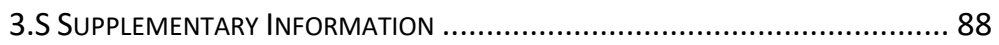

4 CARBONATE EFFECT AT ELEVATED TEMPERATURE ............................89

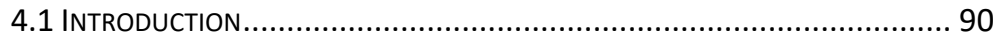

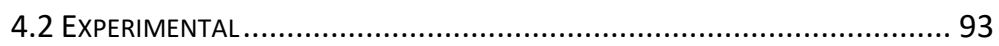

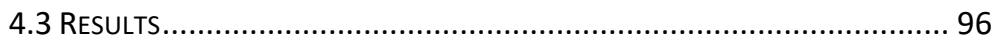

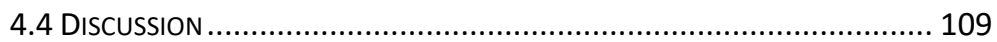

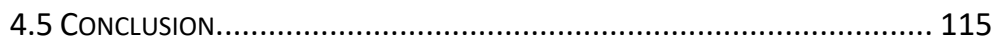

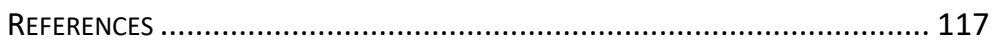


5 CRUDE OIL SYSTEMS AND THE EFFECTS OF AGING

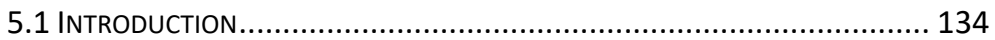

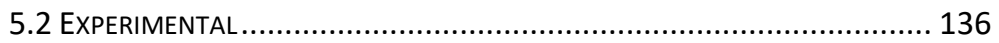

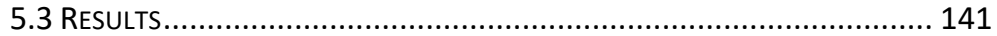

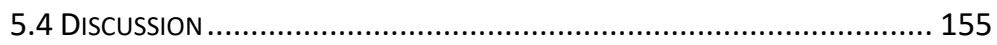

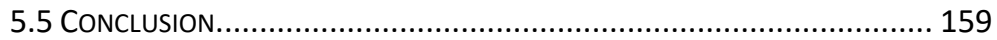

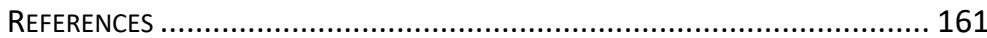

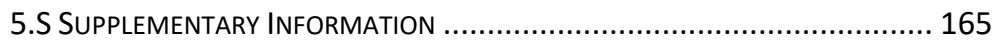

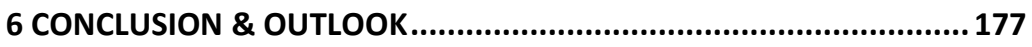

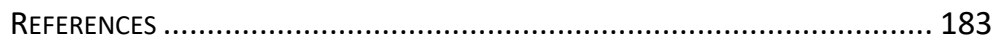




\section{INTRODUCTION}

\subsection{Enhanced Oil Recovery}

The production of crude oil from reservoirs is performed in several stages, as shown in Fig. 1.1. The first, primary recovery stage happens due to the overpressure of the oil in the reservoir, supplemented by other natural driving forces such as expanding gas and adjacent aquifer water flows. ${ }^{1}$ This stage tends to be very inefficient, ${ }^{2}$ which is why additional fluid, usually seawater, is often injected to increase the reservoir pressure, this is known as secondary oil recovery. After some years the production of oil will become unfeasible with these 'conventional' methods, and is ceased. Reservoirs worldwide exploited in this manner to their economically feasible limit typically still have $40-80 \%$ of their original oil content. ${ }^{3}$ Some of this large amount of residual oil can still be recovered by using an injection fluid that can alter the physical and/or chemical properties of the reservoir. This is the tertiary recovery category, and is known as enhanced oil recovery (EOR). This stage can produce another $5-10 \%$ of oil, but will often require additional infrastructure to be built. Economic feasibility is critical for EOR. Therefore, it is important to make the predictions required to judge whether or not its employment is sensible.

Traditional EOR techniques involve either gas injection or the addition of chemicals to the injected water. Gas injection works mainly on the pore-scale. By substituting injected water for gas, the interfacial tension between the injected phase and oil is reduced, thereby decreasing the influence of capillary forces, causing some of the residual oil trapped by capillary effects to be released. On the macroscopic displacement scale however, the relatively low viscosity and density of the gas reduces the production efficiency through gravity and viscous fingering effects. ${ }^{4,5}$ Overall, this type of EOR therefore has a low efficiency and is only economically viable in very large fields, in regions without a viable market for the natural gases required as injection phase. $^{3}$ To counteract some of the inefficiencies of this 
technique, the gas can be injected simultaneously or alternating with water. This technique is the most widely applied and successful style of EOR. $^{6}$
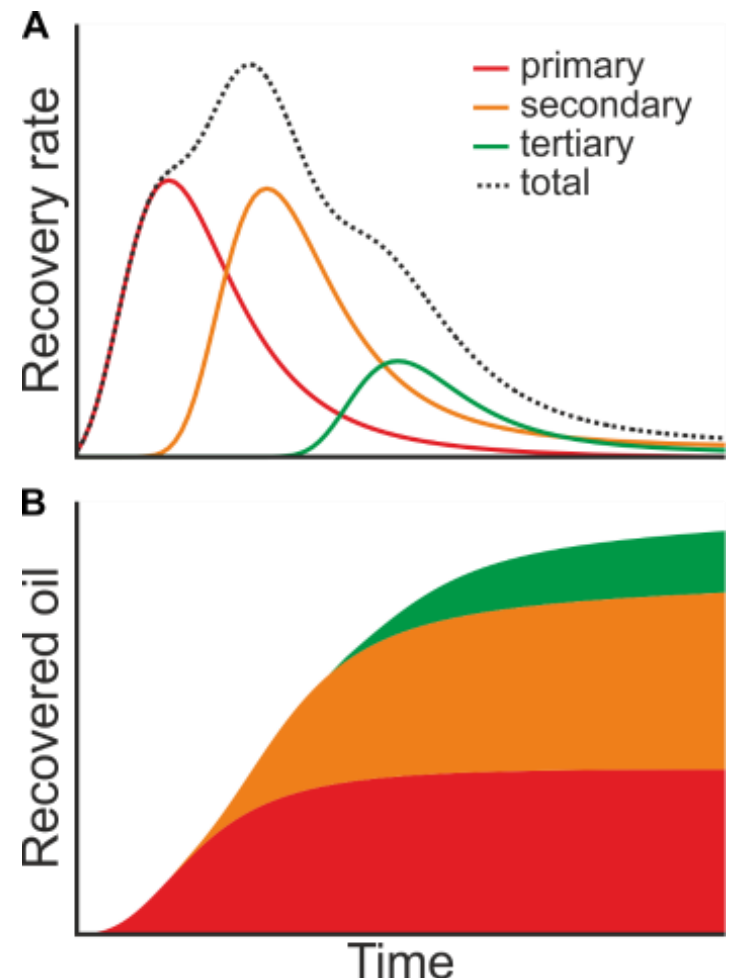

Figure 1.1. Examples of primary, secondary, and tertiary recovery rates $(A)$ and cumulative production (B) over time.

Water flooding with added chemicals is usually also aimed at reducing the interfacial tension (through surfactants), but it can also be used to reduce viscous fingering (through polymers). ${ }^{7}$ Polymer flooding can also help with redirecting the flow of the injected fluid by blocking already accessed high-permeability zones through gel formation with added cross-linkers. This particular technique is only applicable in 
specific reservoirs as it requires identification and isolation of these specific zones. ${ }^{8}$

These conventional EOR techniques have been successful in many cases, but rely on a high oil price to be economically feasible. Therefore, there has been increased interest in alternative EOR methods, that bring lower costs. One promising method, and the subject of this work, is low salinity water flooding (LSWF), which utilizes desalinized seawater as the injected fluid. The exact mechanism by which this works is still disputed, but relies on the nanometer-scale interactions of the rock/water and oil/water interfaces, see section 1.3 for a further discussion. The idea of LSWF has been explored since the $1950 \mathrm{~s},{ }^{9}$ but has gained much attention due to positive experimental observations only in the $90 \mathrm{~s},{ }^{10,11,12,13}$ and reservoir-scale results in the 2000s. ${ }^{14,15,16}$ Many more investigations have been made into the effects of LSWF, and research is still on-going, but as mentioned above, a unified understanding of the underlying mechanisms is still lacking. This thesis aims to address some of the shortcomings in the existing knowledge on the effects of salinity on the nanometer scale interactions relevant for sandstone reservoirs. But before I go into detail on these interactions, I will first describe the reservoir systems itself more comprehensively.

\subsection{Reservoir systems}

Practically all petroleum reservoirs are found in sedimentary rock formations, consisting of either sandstone or carbonate rock. ${ }^{17}$ Although LSWF has seen some experimental success for both rock types, the mechanisms by which it can mobilize oil are likely not the same, due to the different surface chemistries of these rock types. This thesis is focused on sandstone reservoirs, which is the most common type outside the Middle East. ${ }^{18}$ The rock consists mainly of quartz grains, in the range of micro- to millimeters, which over millions of years have been cemented together through mechanical and chemical processes under high temperature and pressure in a process called diagenesis. Organic matter buried underneath the sediments also undergoes diagenesis to form what is known as kerogen: a solid state of 
organic matter that is essentially an insoluble polymer. Over time, the kerogen will break down into smaller molecules if the temperatures are high enough (roughly $>100^{\circ} \mathrm{C}$ ) and form liquid petroleum and natural gas, which through buoyancy rise upward to more permeable sandstone structures, displacing water in the process, and forming a sandstone reservoir. ${ }^{17}$

The reservoir is therefore a three-phase multi-scale porous system of rock, oil, and brine. The cemented grains of the sandstone rock form a porous network on the millimeter scale (see Fig. 1.2A) where the pores are filled with oil and brine in varying ratios, depending on the history of the reservoir and the physico-chemical properties of the rock. The permeability (the ease at which fluid flows through it) of this network is the most important macroscopic characteristic for oil recovery. This property is largely determined by the porosity of the rock (volume fraction of fluids), and the sizes and shapes of the pores. Due to the rough and stratified nature of sedimentary rock, heterogeneity of these properties within the reservoir is high. On a larger scale the way the areas of differing permeability are connected, as well as the presence of macroscopic features such as fractures, will also be important to oil recovery. ${ }^{17}$ Conventional recovery will mostly mobilize the oil from highly connected regions of good permeability, forming conduits for the oil to flow through. This is one of the most important reasons that, as noted above, so much oil remains in the reservoirs after secondary recovery, as it is 'trapped' in low permeable and poorly connected regions. In these areas, capillary-, rather than viscous forces, dominate the flow behavior. In order to access these particular regions with EOR, the nano- to micrometer-scale properties need to be modified. This requires a proper understanding of the chemistries of the rock, oil, and brine phases, where most phases show a compositional complexity.

A highly schematic sketch of the reservoir at the nanometer scale is shown in Fig. 1.2B. As noted above, the rock phase of the reservoir consists mainly of quartz grains, but a considerable (in the order of $10 \%)^{19}$ fraction of the surface area is accounted for by clay minerals. The former consist of silica, mostly in a crystalline quartz phase but at 
the surface a nanometer scale, amorphous layer is often found.$^{20} \mathrm{Clay}$ minerals are phyllosilicates, i.e. fine-grained hydrated crystals consisting of stacked silica and alumina sheets. Two basic forms of clay minerals exist, depending on their silica:alumina sheet ratio, and how these are stacked: there are 1:1-clays with alternating sheets, and 2:1clays where every sheet of alumina is sandwiched between two silica sheets. ${ }^{21}$ Due to their small size $(\approx 1 \mathrm{um})$, planar geometry, and their tendency to coat the silica surface, they make up a considerable fraction of the surface areas of most sandstone reservoirs. Amorphous silica at the quartz surface can be negatively charged due to deprotonation of $\mathrm{SiOH}$ groups at higher than neutral $\mathrm{pH} .{ }^{22}$ A similar charging can happen on clays where their silica sheets are exposed; predominantly around the edges where most imperfections occur. ${ }^{23}$ 1:1-clays can also have their alumina sheets exposed; these typically have a positive surface charge, but can also be negatively charged due to local defects. ${ }^{24}$ Isomorphous substitution of ions in the lattice is a common feature of 2:1-clays, and can cause them to also acquire a permanent surface charge on their basal planes, independent of $\mathrm{pH}$. The most common substitutions are $\mathrm{Al}^{3+}$ for $\mathrm{Si}^{4+}$, and $\mathrm{Mg}^{2+}$ for $\mathrm{Al}^{3+}$, both resulting in a net gain of negative charge. ${ }^{21}$ These charging characteristics combined with a large surface area make clays excellent targets for the adsorption of organics from the oil, and of cations from the brine. 


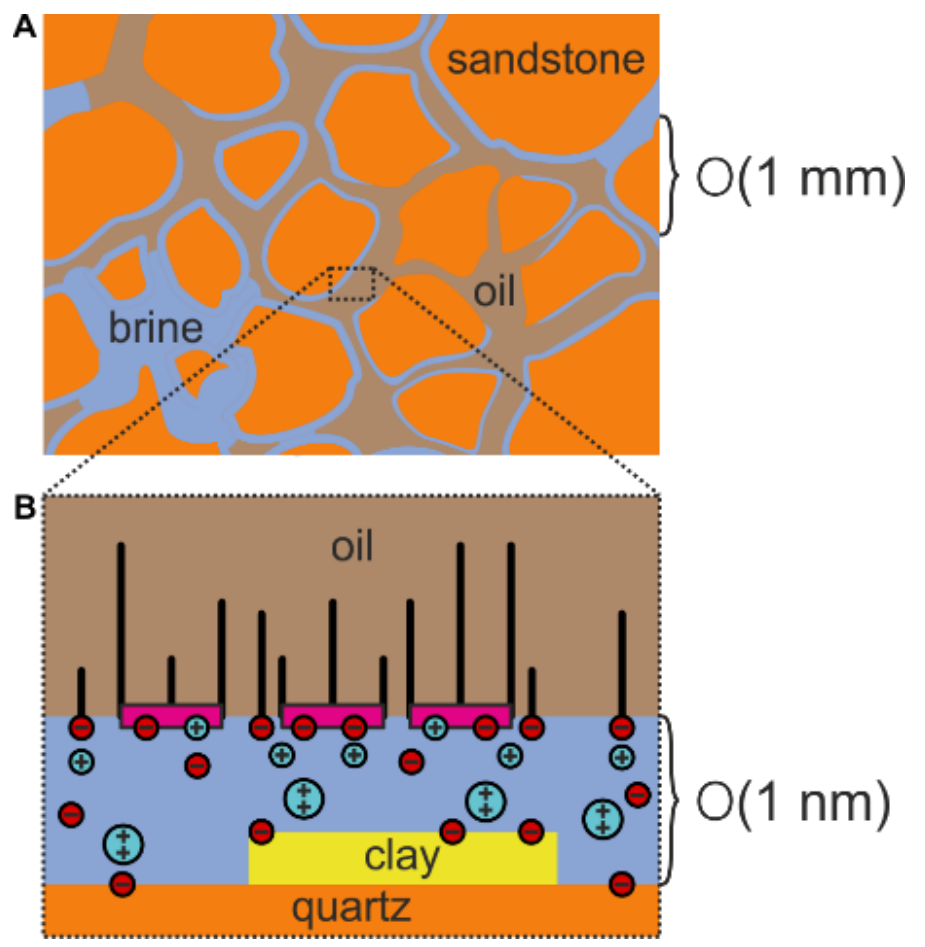

Figure 1.2. Schematic representation of the sandstone reservoir on $(A)$ the pore-scale showing the individual sand-grains with variable wetting states; $(B)$ on the molecular scale, showing the interactions between organic components and the mineral surface, through a thin brine film.

The crude oil phase has a very complex, history dependent chemical composition, through the diagenetic processes described above. The organic contents vary from simple alkanes to bulky phenolic structures. The non-volatile part of the organics is conventionally separated into in four fractions based on their mass and polarizability, in a chromatographic process called saturate, aromatic, resin and asphaltene (SARA)-analysis. The saturates are the non-polar fraction, consisting of linear, cyclic, and branched alkanes. This is typically the largest fraction by weight, ${ }^{25}$ and the most important one for gasoline. ${ }^{26}$ The aromatic fraction is of comparable molecular weight, but more 
polarizable due to the presence of aromatic rings. The remaining two fractions are the bulkier molecules usually containing multiple aromatic rings, and are solid or highly viscous in their pure form. The distinction between them is defined by their solubility in heptane, with resins being the soluble-, and asphaltenes being the insoluble fraction. The latter are the largest molecules present in petroleum. They have a high propensity for adsorption due to their amphiphilic nature and are therefore likely the most important fraction when considering the surface interactions within the porous sandstone network. The general architecture of asphaltenes comprises one or more graphitic sheet structures, with branching alkane tails, and often include carboxylate or amine groups, see Fig. 1.3. ${ }^{27,28,29}$ Therefore, asphaltenes are sometimes considered to behave similar to proteins, engaging in complex, ion-mediated interactions with other asphaltenes and the rock. ${ }^{30}$

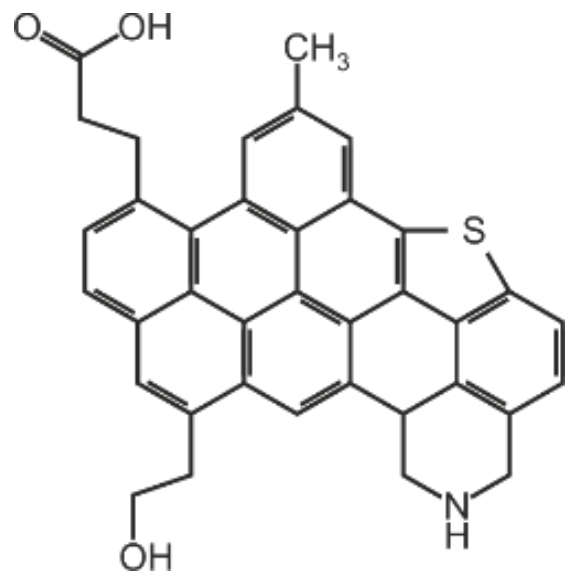

Figure 1.3. Typical chemical structure of an asphaltene molecule, based on several proposed structures. ${ }^{27,28,29}$

The brines present in the reservoir, known as formation water, show strong compositional differences between reservoirs, in relation to their different geological environments and histories. All brines originate from seawater, which mainly contains $\mathrm{Na}^{+}, \mathrm{Mg}^{2+}, \mathrm{Ca}^{2+}$, and $\mathrm{K}^{+}$cations (in that order). $\mathrm{Cl}^{-}$is the principal anion present, but small amounts of 
$\mathrm{CO}_{3}{ }^{2-}, \mathrm{SO}_{4}{ }^{2-}$, and derived species are also present. Over time, dissolution of minerals, mixing with other brines or fresh-water, evaporation and related precipitation of minerals (evaporates), and redox reactions with minerals, all cause changes in brine composition. ${ }^{31}$ As a result, formation brines are often very dissimilar to seawater. Therefore, secondary oil recovery, which introduces seawater into the reservoir, already strongly alters the salinity and composition of the aqueous phase to which the rock is exposed.

The complexity of these three phases means that a large variety of interactions is possible. These occur at the rock/brine, rock/oil, and oil/water interfaces. On a microscopic scale, the rock/oil interface likely consists of a combination of the other two interfaces, as shown in Fig. $1.2 \mathrm{~B}$, where all three phases are involved in binding the oil to the rock. ${ }^{32}$ It is self-evident that, from this high complexity, it is difficult to identify what interactions are relevant to oil recovery, and how they are influenced by LSWF to release oil from the low permeability rocks.

\subsection{Low Salinity Water Flooding Mechanisms}

It is generally agreed upon that one of the main mechanisms by which LSWF promotes oil recovery, is to improve the water wettability of the reservoir rock. ${ }^{32,33}$ Exact definitions of wettability vary (see section 1.4) but in general it relates to the tendency of the rock to maintain contact with either the brine- (water-wet) or the oil-phase (oil-wet). Most reservoir rock is mixed-wet, meaning it has areas retaining mostly oil, and others retaining mostly water. If the overall reservoir is brought to a more water-wet state, it would also be in a less oil-wet state, meaning some oil must be released. This has been observed in many laboratoryscale tests (called core flooding experiments) where first a high salinity, and next a low salinity brine are pushed through a rock sample. Exactly how a lowered salinity of the brine phase helps to produce additional oil, remains disputed, as much apparently conflicting evidences exist. Empirically, some experiments have shown enhanced recovery under low salinity conditions, but also many reports exist of experiments where LSWF does not seem to improve oil recovery at all. ${ }^{33}$ These different findings could be due to a large variety in the experimental 
conditions, mainly in the differences in oil, brine, and rock compositions. It seems plausible that for systems with different chemical properties, different salinity responsive mechanisms are at play. Many specific mechanisms have been suggested, but none have been found to hold true for all conditions.

The earliest suggested mechanism has been that the low salinity water promotes the swelling and detachment of clays from the rock surface, a process known as fines migration. ${ }^{34}$ The released 'fines' can block part of the pores, reducing permeability, increasing the pressure drop, and diverting the flow to remove oil that was not accessed earlier. Another suggestion on how fines migration could improve oil recovery has been that these clays, which, as noted above, readily adsorb organic components, tend to be more oil-wet, and when released reveal the intrinsically water-wet silica below, thereby improving the overall water-wettability of the system. ${ }^{35}$ The mobilization of fines has been observed in some experimental cases by flushing low salinity water through sandstone cores, and a correlation with increased recovery has also been observed. This correlation is far from obvious though, as many contrary results also exist: many core floods without observed fines migration exist, ${ }^{33}$ as well as evidence for improved recovery without any clays being present at all. ${ }^{36}$ The migration of fines also has a downside: it is a known source of formation damage, which can even lead to a decreased recovery through the blocking of oil-laden pore space. $^{37}$

It has also been suggested that the $\mathrm{pH}$ increase that is sometimes induced by LSWF, promotes the formation of surfactants. ${ }^{15}$ This would work by saponification of acidic molecules from the crude oil at high $\mathrm{pH}$. The underlying mechanism would then be similar to that of surfactant injection as discussed in section 1.1: reduction of the interfacial tension rather than altering the physico-chemical properties of the rock surface. A reduced salinity has indeed been correlated with reduced interfacial tension, but there no correlation was found between crude oil acid content and improved oil recovery by low salinity. ${ }^{33}$ Also, a $\mathrm{pH}$ of higher than 9 would be required for substantial saponification to take place, and these conditions are unlikely to occur in reservoir 
conditions due to buffering by $\mathrm{CO}_{2}$ and carbonate species present even in many sandstone reservoirs.

A more direct way in which the salinity can influence the wettability of the system is through thin-film interactions. Since the clay and silica surfaces of the rock are intrinsically water-wet, a nanometer-scale thin brine film can exist between the rock and oil phases at high salinity conditions, stabilized by the counteracting forces of attractive van der Waals interactions and repulsive electrostatic interactions between the two charged interfaces, ${ }^{38}$ as schematically shown in Fig. 1.4A. Even though the rock would be directly in contact with the water phase, the overall system is oil-wet on macroscopic length scales, since oil is bound to the surface. When low salinity water is introduced, the concentration of cations in the brine film must go down, and the electrostatic screening of the two interfaces will be reduced. As the two interfaces repel each other more strongly, a double layer expansion (DLE) will take place. The thicker water film on microscopic length scales translates to a macroscopically more water-wet system (see section 1.4). This is a popular explanation of the wettability alteration via LSWF. It is supported by the fact that reduction of divalent cations, which contribute more strongly to the ionic strength of the brine, improves the oil production more strongly than the removal of monovalent cations. This explanation is however not fully satisfactory since it assumes that significant differences exist between electrostatic forces at realistic high- and low-salinity conditions. However, even low salinity brines typically have an ionic strength of around $100 \mathrm{mM}$, while the range of electrostatic forces typically will only increase significantly for ionic strengths well below $100 \mathrm{mM} .{ }^{39}$ Adhesion tests between crude oil droplets and mineral substrates in brine have also been inconsistent in this regard, sometimes showing the expected reduced-, but in other cases showing an increased adhesion..$^{40,41}$ 

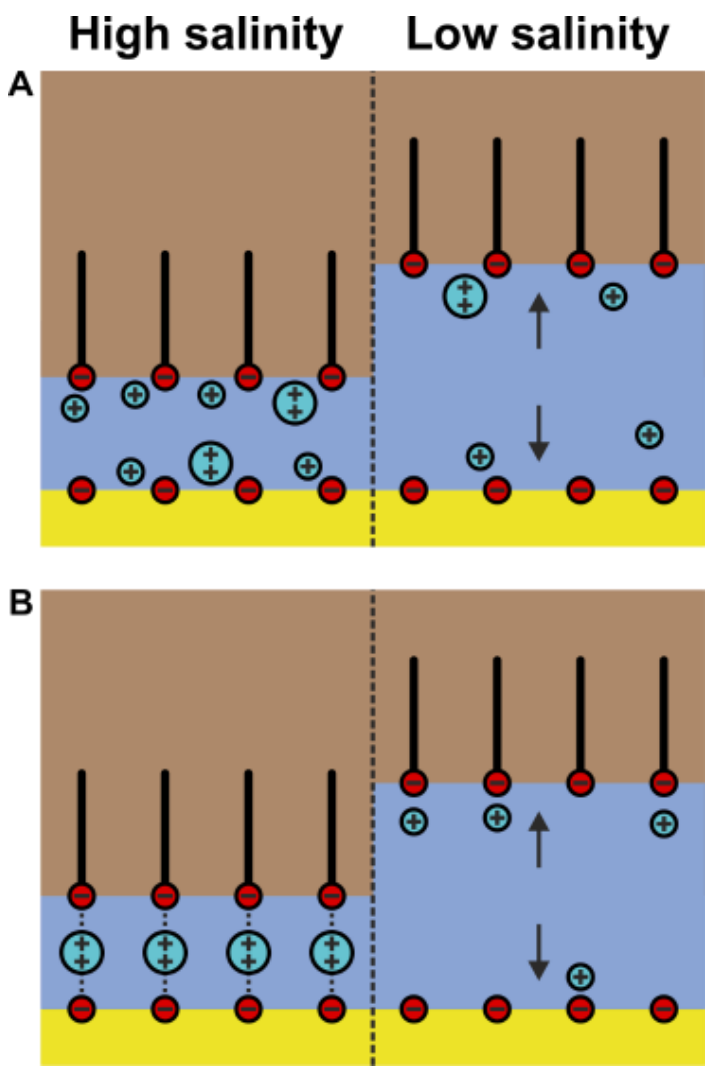

Figure 1.4. Schematic representations of two proposed microscopic mechanisms underlying wettability alteration in LSWF: DLE (A), and MIE (B).

Since it is known that in some cases, the effects of LSWF depend on the specific ions that are depleted, mainly concerning divalent cations, it is likely that specific ion interactions play an important role in LSWF. Another popular suggested mechanism, usually termed multi-component ion exchange (MIE), posits that divalent cations bind anionic amphiphilic molecules from the oil to the reservoir rock, thereby providing a hydrophobic layer on its surface, see Fig. 1.4B. When low salinity water is introduced, these cations desorb, thereby causing the hydrophobic layer to dissolve back into the oil, and 
exposing the water-wet sandstone surface. This mechanism has been proposed by Lager et al. after they found that for sandstone cores rich in clays, the reduction in divalent cation content (rather than overall salinity) correlated with oil recovery. ${ }^{42}$ Similar effects have been found in other field- and laboratory tests.

Alternatively, Austad et al. have suggested that the polar organic compounds are directly bound to the rock, not via the divalent cations but through hydrogen bridging. ${ }^{43}$ In their explanation, the divalent cations are exchanged with protons during LSWF, thereby raising the $\mathrm{pH}$, deprotonating the carboxylic acid or amine groups of the adsorbed organic compounds, as well as making the surfaces more negatively charged, leading to a desorption of organic compounds. As discussed above, the bulk pH increase of reservoir brines is rarely observed due to $\mathrm{CO}_{2}$ buffering, so the proposed effect can only pertain to a 'local $\mathrm{pH}$ ': i.e. a surface enhanced $\mathrm{OH}^{-}$concentration.

Overall, it seems that fines migration and $\mathrm{pH}$ increase may hold true as underlying mechanisms in some specific cases, but in general it seems more likely that it's the alteration (directly via salinity) of nanometer scale interactions at the oil/rock/brine interfaces that primarily controls the macroscopic wettability in most cases. The mechanism of EDL expansion seems unlikely from a physical standpoint, but the fact that a minimal change in electrostatic forces could be enough to bring about macroscopic wettability alteration cannot be rejected. Mugele et al. have tried to model the thin film interactions governing salinity dependent wettability alteration using DLVO theory, but found that additional short-range forces were indeed necessary to explain the known wettability behavior. ${ }^{44}$ Some form of MIE is likely to play a part in many cases, due to the large variety of surface-active organic components and cations present in the system. It is clear that still more insight into these molecular scale mechanisms is required.

\subsection{Wettability Alteration}

There are multiple definitions of wettability. In petroleum literature it often refers to an empirical property, commonly measured by what is 
known as the Amott test. ${ }^{45}$ It tests the spontaneous imbibition and forced displacement of oil and a water through a rock sample, and yields an estimate of the ability of the sample to hold either of these phases. In physics and chemistry, wettability is generally based on the contact angle of the three-phase system, see Fig. 1.5A. This angle is arrived at through a minimization of the total interfacial energy (i.e. the sum of contributions from the oil/water, solid/oil, and solid/water interfaces, for which the energies per area are given by $\gamma, \gamma_{s o}$, and $\gamma_{s w}$ respectively), or the balance of surface tensions, resulting in the Young-Dupré equation: ${ }^{46}$

$$
\gamma_{s o}-\gamma_{s w}=\gamma \cos \theta
$$

Where $\theta$ is the contact angle, in this case through the water phase. The equation is valid as long as there is partial wetting of the surface: i.e. a droplet is formed because the difference between $\gamma_{s o}$ and $\gamma_{s w}$ is smaller than $\gamma$. If it is larger, the surface will be entirely covered with either the oil- (for $\gamma_{s o}-\gamma_{s w}<-\gamma$ ), or the water phase (for $\gamma_{s o}-\gamma_{s w}>$ $\gamma)$. This is known as complete wetting. The Amott wettability index is related with the contact angles of the substrate, but it also involves other, more macroscopic qualities such as pore geometry and flow properties. Since this thesis work focusses on local, microscopic mechanisms I will only use the Young's angle to describe the wettability.

We have so far discussed two wetting configurations: complete and partial wetting. As noted above, the mechanisms which underlie wettability alteration in LSWF are likely occurring in thin water films, these occur in a third type of wetting configuration called pseudo-partial wetting, where a macroscopic droplet and a microscopically thin film coexist (see Fig. 1.5B). ${ }^{47}$ In this case, what appears macroscopically as the solid/oil interface, is actually a thin water film through which the solid/water and oil/water interfaces interact. Its surface energy (per unit area) can then be expressed as:

$$
\gamma_{s o}=\gamma_{s w}+\gamma+\varphi(d)
$$


Where $\varphi(d)$ is the interaction potential per unit area between the interfaces, as a function of the film thickness $d$. A pseudo-partial wetting configuration is stable if this potential has a form such as shown in Fig. $1.5 \mathrm{C}$. The state at finite thickness $d=d_{e q}$ (the film state) can coexists with the one at $d \rightarrow \infty$ (the bulk or droplet state) because these two states correspond to the same pressure. Substituting $\gamma_{s o}$ in Eq. 1.1 with Eq. 1.2, using $\varphi_{e q}=\varphi\left(d_{e q}\right)$ yields the extended Young-Dupré equation for the pseudo-partial wetting configurations:

$$
1+\frac{\varphi_{e q}}{\gamma}=\cos \theta
$$

The negative derivative of the interaction potential per unit area is known as the disjoining pressure, which can be positive or negative (see Fig. 1.5C). It now becomes immediately obvious that there are indeed two stable configurations, where this pressure is 0 : at $d_{e q}$ and $d \rightarrow \infty$. The form of $\varphi(d)$ required for drop-film coexistence arises naturally in the case of two charged interfaces of the same sign, where an attractive van der Waals force is opposed by a repulsive electrostatic force as sketched in Fig. $1.5 \mathrm{C}$ (in reality there will always be additional short-range forces, which were left out here for simplicity, but are known to be important). One can now see how, if the electrostatic forces are increased, the minimum at $d_{e q}$ is pushed further away to the right, i.e. reduced electrostatic screening results in thicker water films. If the electrostatic repulsion becomes strong enough to overcome any minimum potential, the film will expand, resulting in a complete waterwetting configuration.

In reality, the forces occurring within the thin water film cannot be adequately described with the simple textbook expressions for electrostatic and van der Waals forces (as was done in Fig. 1.5C). These forces are only approximate, due to assumptions like: i) the medium is a continuum, and ii) ions behave as an ideal gas of point-like particles. These assumptions do no longer hold at distances of $\mathrm{O}(1 \mathrm{~nm})$, or at relatively high $(>100 \mathrm{mM}$ ) ionic strengths, both of which are typical for realistic brine films. ${ }^{44}$ Also, the oil phase will hold many surface active molecules, which also bring their own, molecular scale interactions. 
Therefore non-DLVO interactions should also be considered, which is precisely what the MIE interpretation of LSWF attempts to do. Charged groups at the oil/water interface can form complexes with cations residing near the solid/water interface. This kind of interaction can be interpreted as an additional contribution to $\varphi(d)$ in the form of a potential of mean force (PMF), as has been done by Kobayashi et al. for fatty acids interacting with a mineral surface through different cations. ${ }^{48}$ They have demonstrated that the form of such a potential strongly depends on the specific cations that are involved in the complexation.

When these surface-active molecules formed at the oil-brine interface subsequently get deposited onto the solid, the droplet is forced to reach higher contact angles. This process has been termed 'autophobing' because the contact line retraction is facilitated by the droplet itself. A trace of desposited surfactant is left behind in the oil phase. Using the PMF interpretation of interactions across a thin water film, the presence of surfactants introduces an additional attractive interaction potential. This would shift $\varphi_{e q}$ to more negative values, which, according to Fig. $1.5 \mathrm{C}$ would cause a thinner film, and according to Eq. 1.3 would indeed result in a higher water contact angle. An alternative interpretation is that the adsorbed organic monolayer, with the hydrophobic tails sticking into the fluid phase, essentially forms a new hydrophobic surface. In this interpretation the presence of a thin water film is not necessary, as it might break up during the autophobing process. That is not to say that the water plays no role, as it will likely always be present as long as cations are involved, since hydration is known to be an important factor in the adsorption and complexation of ions. ${ }^{49,} 50$ 


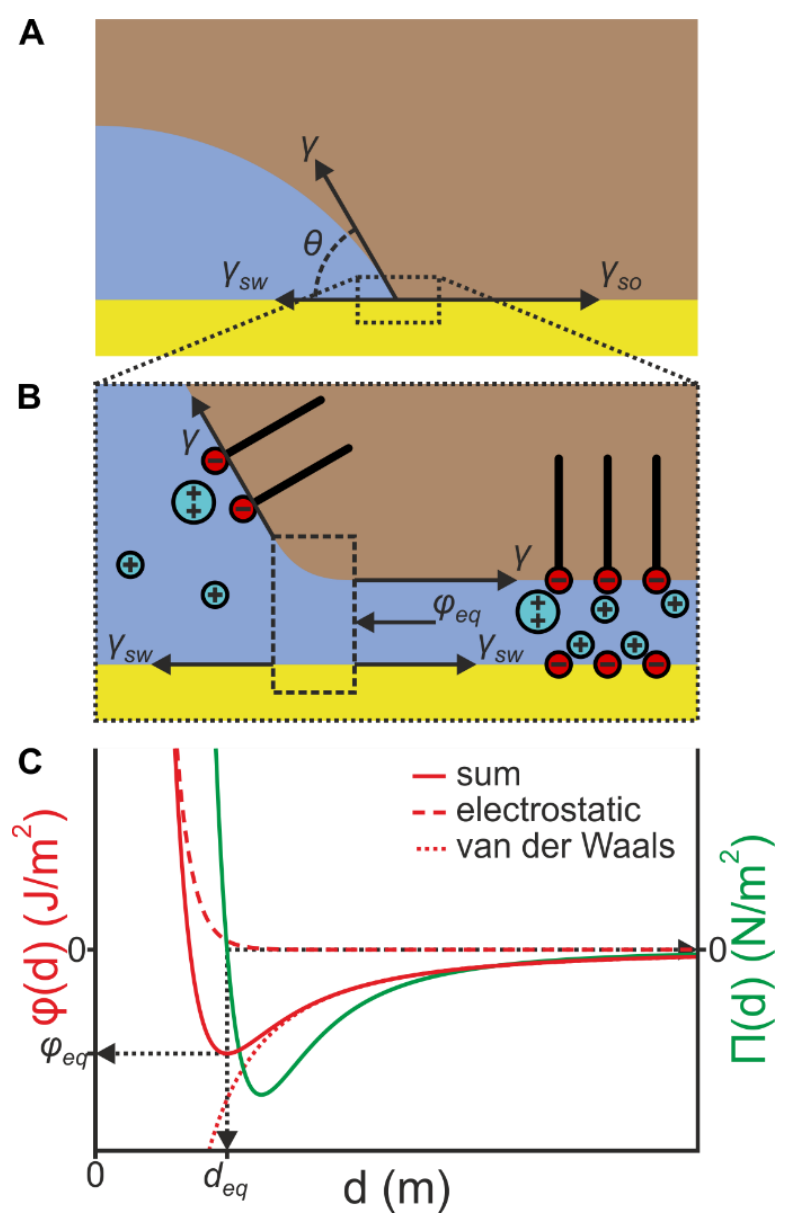

Figure 1.5. Schematic representation showing the link between macroscopic wettability (A), and microscopic thin film interactions (B), as well as the general form of the interaction potential $\varphi(d)$ and disjoining pressure $\Pi(d)$ in a pseudo-partial wetting configuration $(C)$.

\subsection{Model Oil/Brine/Rock Systems}

When investigating the underlying mechanisms of wettability alteration in LSWF, a main challenge is to find an appropriate experimental 
system. The mechanisms at play in a real reservoir operate across many length-scales, ranging from chemical interactions on a (sub-) nanometer scale, to complex porous fluidic systems on millimeter to meter scales, and up to kilometer scale rock heterogeneities. For a comprehensive understanding, detailed knowledge of the system on each of these length-scales would be required. As stated above, in this work I shall focus on the smallest length-scales and their influence on wetting properties. However, even with this limited scope, drastic simplifications are required and not one ideal model system exists. As explained above, real reservoir systems have a highly complex chemistry and geometry, and conditions and compositions vary widely between and even within reservoirs.

The arguably most realistic type of laboratory scale model system is the core flooding experiment, where crude oil and realistic brines can be pumped through real reservoir rock at high pressures and temperatures. As shown in section 1.3 though, these types of experiments are not often consistent across different rock and oil types, and the actual interacting interfaces are inaccessible making microscopic characterization impossible. They are therefore ill-suited to examine exact mechanisms, but still helpful to assess specific rock/oil types and judge common trends. Another approach is to use highly simplified model systems, e.g. by using one specific mineral, looking into the effects of specific salt solutions, and/or organic components. These types of systems can be examined in much more detail, as all parameters can be tightly controlled. The major drawback is that, since the conditions are far from those of a real reservoir system, there is no direct way to ascertain whether any mechanisms identified for the model system are actually relevant to (or even dominant in) the real systems. Therefore, in order to gain a meaningful understanding of the wettability effects of LSWF, experiments might be needed across the entire 'spectrum' of complexity, ranging from simplified model systems to real rock/oil core flooding and even field tests. In that way, any possible relevant mechanisms found in simplified experiments can be validated by more complex variations. 
The current state of relevant literature still has plenty of gaps in this regard, predominantly in experiments of intermediate complexity, between highly simplified systems and realistic reservoir condition experiments. On the complex end, many studies exist but, as described above, many of these results appear to depend on the specific details of the oil, rock, and brines investigated. The general trends allude to the importance of divalent cation depletion in LSWF and often the presence of clays also plays a role in the strength of its effects (see above).

Simplified model oil/brine/rock systems typically consist of an oil phase with added surfactants to represent the crude oil and its amphiphilic components, a water droplet with dissolved salts, and a smooth mineral surface to represent the rock phase. Mica is often used for this purpose due to its chemical similarity to 2:1 clays, and the ease at which it can be cleaved to provide a clean, highly smooth surface. ${ }^{51}$ Bera et al. have performed contact angle measurements in such a threephase system using single salt aqueous solution droplets and pure decane as the ambient oil phase. ${ }^{52}$ Even in this highly simplified system, salinity effects were found (including slight but significant specific ion effects), with divalent cations yielding the highest contact angles (up to $\approx 10^{\circ}$, so still rather water-wet), likely due to improved thin film interactions in a pseudo-partial wetting configuration as described above. When fatty acids were added to the oil phase, to simulate the amphiphilic molecules in crude oil, autophobing through the deposition of organic layers was observed, but only if divalent cations were present in the brine phase (yielding contact angles up to $\left.60^{\circ}\right) .^{52}$ Kumar et al. formed similar monolayers using Langmuir-Blodgett transfer onto mica and silica, and observed that these layers were most stable when $\mathrm{Ca}^{2+}$ was present during transfer, and that these layers could be disrupted when brought in contact with water low in $\mathrm{Ca}^{2+}{ }^{53}$ Wang et al. used quart crystal microbalance measurements to quantify the effects of $\mathrm{Ca}^{2+}$ on fatty adsorption and found, at neutral $\mathrm{pH}$, a strongly enhanced adsorption on silica and even a slight enhancement for alumina surfaces. ${ }^{54}$ All of these results indicate that divalent cations facilitate the interactions between fatty acids and several minerals, which at first glance seems in line with MIE interpretation of LSWF effects. There is 
however no evidence that suggests that these interactions are still relevant at reservoir conditions, including enhanced temperatures, multi-component brines, and more complex oils.

Contact angle measurements with crude oil at more realistic temperature and pressure conditions, and for more realistic oil and brine compositions, have also been performed. The interpretation and execution of such experiments has proven to be difficult, since often crude oil does not adhere by itself to many mineral substrates. Buckley et al. found that the oil must be a poor solvent for its asphaltenes to facilitate adhesion. ${ }^{55}$ Crude oil wettability experiments on rough clay, or sandstone rock have shown improved water-wettability with low salinity brines. ${ }^{56,57,58}$ But opposite effects have also been observed by Drummond and Israelachvili. ${ }^{59}$ It should however be noted, that in the latter experiments only monovalent cations were present in the brine phase. Adhesion measurements by atomic force microscopy (AFM) using alkane-functionalized tips have also shown that, largely, lower salinities reduce the adhesion of oil to sandstone rock. ${ }^{60,61}$

In general, the simplified and more complex experiments seem to be aligned regarding the link between wettability and salinity, and both indicate that divalent cations and clays are important factors to the low salinity effect (although less consistently in the more complex experiments). There is however no guarantee that the mechanisms described in the simpler systems, are the same that act in the more complex experiments. When the overall wettability results are compared with the even more complex system of core flooding, many apparent inconsistencies arise (see section 1.3), possibly due to the more complex geometry, but likely also in part due to wettability differences. This indicates that there must be more to the simple 'divalent cation bridging' mechanisms that makes its effects less explicit in more complex systems, underlining a need for more in-depth study.

\subsection{Aim of This Thesis}

In order to close the aforementioned 'complexity gap', I present in this work several studies where wettability effects of salinity in increasingly 
complex systems were investigated. I start with simple fatty acid systems, and subsequently introduce the effects of multi component brines (including realistic formation brines and seawater), higher temperatures, and eventually also crude oils. I aim to supplement the current understanding of the relevant underlying mechanisms in wettability alteration through LSWF. A secondary aim in this is to provide feedback about what ingredients and conditions are necessary to create a simplified model system that can provide both mechanistic explanations and predictive results. Such model systems could contribute a useful addition to exploratory core flood tests.

In the next chapter, I will describe oil/brine/mineral systems consisting of $n$-decane and fatty acids, multiple salt solutions, and mica, as well as silica substrates. These simple systems were used to investigate the effects of specific cations, and the competition between them. I simulated the effects of LSWF by a gradual in-situ exchange of the brine droplet with water. Following that, in chapter 3, I studied a similar system at elevated temperatures. In that chapter another anion, bicarbonate, is also introduced, which, in combination with the elevated temperatures, causes very high contact angles to be reached. In chapter 4 I investigated the underlying causes for this intensified hydrophobization effect in more detail. Lastly, I also investigated more realistic oil/brine/mineral systems in chapter 5 . There, crude oil was used as the droplet phase, on substrates also aged in crude oil. 


\section{References}

1. Ahmed, T. Chapter 11 - Oil Recovery Mechanisms and the Material Balance Equation. In Reservoir Engineering Handbook (Fourth Edition), Ahmed, T., Ed.; Gulf Professional Publishing: Boston, 2010, pp 733-809.

2. Ahmed, T. Chapter 14 - Principles of Waterflooding. In Reservoir Engineering Handbook (Fourth Edition), Ahmed, T., Ed.; Gulf Professional Publishing: Boston, 2010, pp 909-1095.

3. Muggeridge, A.; Cockin, A.; Webb, K.; Frampton, H.; Collins, I.; Moulds, T.; Salino, P. Recovery Rates, Enhanced Oil Recovery and Technological Limits. Philosophical Transactions of the Royal Society A: Mathematical, Physical and Engineering Sciences 2014, 372 (2006), 20120320.

4. Claridge, E. Prediction of Recovery in Unstable Miscible Flooding. Society of Petroleum Engineers Journal 1972, 12 (02), 143-155.

5. Blackwell, R.; Rayne, J.; Terry, W. Factors Influencing the Efficiency of Miscible Displacement. 1959.

6. Awan, A. R.; Teigland, R.; Kleppe, J. A Survey of North Sea EnhancedOil-Recovery Projects Initiated During the Years 1975 to 2005. SPE Reservoir Evaluation \& Engineering 2008, 11 (03), 497-512.

7. Gogarty, W.; Tosch, W. Miscible-Type Waterflooding: Oil Recovery with Micellar Solutions. Journal of Petroleum Technology 1968, 20 (12), 1,4071,414 .

8. Sydansk, R. D.; Seright, R. S. When and Where Relative Permeability Modification Water-Shutoff Treatments Can Be Successfully Applied. In SPE/DOE Symposium on Improved Oil Recovery; Society of Petroleum Engineers: Tulsa, Oklahoma, USA, 2006, p 15.

9. Wagner, O.; Leach, R. Improving Oil Displacement Efficiency by Wettability Adjustment. Transactions of the AIME 1959, 216 (01), 65-72.

10. Jadhunandan, P. P.; Morrow, N. R. Spontaneous Imbibition of Water by Crude Oil/Brine/Rock Systems. In Situ 1991, 15 (4), 319-345.

11. Jadhunandan, P. P.; Morrow, N. R. Effect of Wettability on Waterflood Recovery for Crude-Oil/Brine/Rock Systems. SPE Reservoir Engineering (Society of Petroleum Engineers) 1995, 10 (1), 40-46.

12. Yildiz, H. O.; Morrow, N. R. Effect of Brine Composition on Recovery of Moutray Crude Oil by Waterflooding. Journal of Petroleum Science and Engineering 1996, 14 (3-4), 159-168. 
13. Tang, G. Q.; Morrow, N. R. Salinity, Temperature, Oil Composition, and Oil Recovery by Waterflooding. SPE Reservoir Engineering 1997, 12 (04), 269-276.

14. Webb, K. J.; Black, C. J. J.; Al-Ajeel, H. Low Salinity Oil Recovery - LogInject-Log. In SPE/DOE Symposium on Improved Oil Recovery; Society of Petroleum Engineers: Tulsa, Oklahoma, 2004, p 7.

15. McGuire, P. L.; Chatham, J. R.; Paskvan, F. K.; Sommer, D. M.; Carini, F. H. Low Salinity Oil Recovery: An Exciting New Eor Opportunity for Alaska's North Slope. Society of Petroleum Engineers, 2005.

16. Seccombe, J.; Lager, A.; Jerauld, G.; Jhaveri, B.; Buikema, T.; Bassler, S.; Denis, J.; Webb, K.; Cockin, A.; Fueg, E. Demonstration of Low-Salinity Eor at Interwell Scale, Endicott Field, Alaska. In SPE Improved Oil Recovery Symposium; Society of Petroleum Engineers: Tulsa, Oklahoma, USA, 2010, $p$ 12.

17. Bjørlykke, K. Introduction to Petroleum Geology. In Petroleum Geoscience: From Sedimentary Environments to Rock Physics, Bjørlykke, K., Ed.; Springer Berlin Heidelberg: Berlin, Heidelberg, 2015, pp 1-29.

18. Bjørlykke, K.; Jahren, J. Sandstones and Sandstone Reservoirs. In Petroleum Geoscience: From Sedimentary Environments to Rock Physics, Bjørlykke, K., Ed.; Springer Berlin Heidelberg: Berlin, Heidelberg, 2015, pp 119-149.

19. Wooldridge, L. J.; Worden, R. H.; Griffiths, J.; Utley, J. E. How to Quantify Clay-Coat Grain Coverage in Modern and Ancient Sediments. Journal of Sedimentary Research 2019, 89 (2), 135-146.

20. Worden, R. H.; French, M. W.; Mariani, E. Amorphous Silica Nanofilms Result in Growth of Misoriented Microcrystalline Quartz Cement Maintaining Porosity in Deeply Buried Sandstones. Geology 2012, 40 (2), 179182.

21. Barton, C. Clay Minerals. In: Rattan Lal, comp., ed. Encyclopedia of Soil Science. New York, New York: Marcel Dekker: 187-192. 2002.

22. Goloub, T. P.; Koopal, L. K.; Bijsterbosch, B. H.; Sidorova, M. P. Adsorption of Cationic Surfactants on Silica. Surface Charge Effects. Langmuir 1996, 12 (13), 3188-3194. 
23. Kumar, N.; Zhao, C.; Klaassen, A.; van den Ende, D.; Mugele, F.; Siretanu, I. Characterization of the Surface Charge Distribution on Kaolinite Particles Using High Resolution Atomic Force Microscopy. Geochimica et Cosmochimica Acta 2016, 175, 100-112.

24. Klaassen, A.; Liu, F.; van den Ende, D.; Mugele, F.; Siretanu, I. Impact of Surface Defects on the Surface Charge of Gibbsite Nanoparticles. Nanoscale 2017, 9 (14), 4721-4729.

25. Fan, T.; Wang, J.; Buckley, J. S. Evaluating Crude Oils by Sara Analysis. In SPE/DOE Improved Oil Recovery Symposium; Society of Petroleum Engineers: Tulsa, Oklahoma, 2002, p 7.

26. Bjørlykke, K. Source Rocks and Petroleum Geochemistry. In Petroleum Geoscience: From Sedimentary Environments to Rock Physics, Bjørlykke, K., Ed.; Springer Berlin Heidelberg: Berlin, Heidelberg, 2015, pp 361-372.

27. Joonaki, E.; Buckman, J.; Burgass, R.; Tohidi, B. Water Versus Asphaltenes; Liquid-Liquid and Solid-Liquid Molecular Interactions Unravel the Mechanisms Behind an Improved Oil Recovery Methodology. Scientific reports 2019, 9 (1), 11369-11369.

28. Yaseen, S.; Mansoori, G. A. Asphaltene Aggregation Due to Waterflooding (a Molecular Dynamics Study). Journal of Petroleum Science and Engineering 2018, 170, 177-183.

29. Schuler, B.; Meyer, G.; Peña, D.; Mullins, O. C.; Gross, L. Unraveling the Molecular Structures of Asphaltenes by Atomic Force Microscopy. Journal of the American Chemical Society 2015, 137 (31), 9870-9876.

30. Yang, X.; Verruto, V. J.; Kilpatrick, P. K. Dynamic Asphaltene-Resin Exchange at the Oil/Water Interface: Time-Dependent W/O Emulsion Stability for Asphaltene/Resin Model Oils. Energy \& Fuels 2007, 21 (3), 13431349.

31. Dresel, P. E.; Rose, A. W. Chemistry and Origin of Oil and Gas Well Brines in Western Pennsylvania. 2010.

32. Myint, P. C.; Firoozabadi, A. Thin Liquid Films in Improved Oil Recovery from Low-Salinity Brine. Current Opinion in Colloid \& Interface Science 2015, 20 (2), 105-114.

33. Jackson, M.; Vinogradov, J.; Hamon, G.; Chamerois, M. Evidence, Mechanisms and Improved Understanding of Controlled Salinity Waterflooding Part 1: Sandstones. Fuel 2016, 185, 772-793. 
34. Bernard, G. G. Effect of Floodwater Salinity on Recovery of Oil from Cores Containing Clays. Society of Petroleum Engineers, 1967.

35. Tang, G.-Q.; Morrow, N. R. Influence of Brine Composition and Fines Migration on Crude Oil/Brine/Rock Interactions and Oil Recovery. Journal of Petroleum Science and Engineering 1999, 24 (2-4), 99-111.

36. Du, Y.; Xu, K.; Mejia, L.; Zhu, P.; Balhoff, M. T. Microfluidic Investigation of Low-Salinity Effects During Oil Recovery: A No-Clay and TimeDependent Mechanism. SPE Journal 2019, Preprint (Preprint), 18.

37. Sharma, M. M.; Yortsos, Y. Fines Migration in Porous Media. AlChE Journal 1987, 33 (10), 1654-1662.

38. Hirasaki, G. J. Wettability: Fundamentals and Surface Forces. 1991.

39. Israelachvili, J. N. 14 - Electrostatic Forces between Surfaces in Liquids. In Intermolecular and Surface Forces (Third Edition), Israelachvili, J. N., Ed.; Academic Press: Boston, 2011, pp 291-340.

40. Buckley, J. S.; Morrow, N. R. Characterization of Crude Oil Wetting Behavior by Adhesion Tests. In SPE/DOE Enhanced Oil Recovery Symposium; Society of Petroleum Engineers: Tulsa, Oklahoma, 1990, p 7.

41. Drummond, C.; Israelachvili, J. Fundamental Studies of Crude OilSurface Water Interactions and Its Relationship to Reservoir Wettability. Journal of Petroleum Science and Engineering 2004, 45 (1), 61-81.

42. Lager, A.; Webb, K.; Black, C.; Singleton, M.; Sorbie, K. Low Salinity Oil Recovery-an Experimental Investigation. Petrophysics 2008, 49 (01).

43. Austad, T.; Rezaeidoust, A.; Puntervold, T. Chemical Mechanism of Low Salinity Water Flooding in Sandstone Reservoirs. Society of Petroleum Engineers, 2010.

44. Mugele, F.; Bera, B.; Cavalli, A.; Siretanu, I.; Maestro, A.; Duits, M.; Cohen-Stuart, M.; van den Ende, D.; Stocker, I.; Collins, I. Ion AdsorptionInduced Wetting Transition in Oil-Water-Mineral Systems. Scientific Reports 2015, 5, 10519.

45. Amott, E. Observations Relating to the Wettability of Porous Rock. 1959.

46. De Gennes, P. G. Wetting: Statics and Dynamics. Reviews of Modern Physics 1985, 57 (3), 827-863.

47. Silberzan, P.; Leger, L. Evidence for a New Spreading Regime between Partial and Total Wetting. Physical review letters 1991, 66 (2), 185. 
48. Kobayashi, K.; Liang, Y.; Murata, S.; Matsuoka, T.; Takahashi, S.; Amano, K.-i.; Nishi, N.; Sakka, T. Stability Evaluation of Cation Bridging on Muscovite Surface for Improved Description of Ion-Specific Wettability Alteration. The Journal of Physical Chemistry C 2017, 121 (17), 9273-9281.

49. Pintea, S.; de Poel, W.; de Jong, A. E. F.; Vonk, V.; van der Asdonk, P.; Drnec, J.; Balmes, O.; Isern, H.; Dufrane, T.; Felici, R.; Vlieg, E. Solid-Liquid Interface Structure of Muscovite Mica in Cscl and Rbbr Solutions. Langmuir 2016, 32 (49), 12955-12965.

50. van Lin, S. R.; Grotz, K. K.; Siretanu, I.; Schwierz, N.; Mugele, F. IonSpecific and Ph-Dependent Hydration of Mica-Electrolyte Interfaces. Langmuir 2019, 35 (17), 5737-5745.

51. de Poel, W.; Pintea, S.; Drnec, J.; Carla, F.; Felici, R.; Mulder, P.; Elemans, J. A. A. W.; van Enckevort, W. J. P.; Rowan, A. E.; Vlieg, E. Muscovite Mica: Flatter Than a Pancake. Surface Science 2014, 619, 19-24.

52. Bera, B.; Kumar, N.; Duits, M.; Cohen Stuart, M.; Mugele, F. Cationic Hofmeister Series of Wettability Alteration in Mica-Water-Alkane Systems. Langmuir 2018, 34 (45), 13574-13583.

53. Kumar, N.; Wang, L.; Siretanu, I.; Duits, M.; Mugele, F. Salt Dependent Stability of Stearic Acid Langmuir-Blodgett Films Exposed to Aqueous Electrolytes. Langmuir 2013, 29 (17), 5150-5159.

54. Wang, L.; Siretanu, I.; Duits, M. H. G.; Stuart, M. A. C.; Mugele, F. Ion Effects in the Adsorption of Carboxylate on Oxide Surfaces, Studied with Quartz Crystal Microbalance. Colloids and Surfaces A: Physicochemical and Engineering Aspects 2016, 494, 30-38.

55. Buckley, J. S.; Liu, Y.; Xie, X.; Morrow, N. R. Asphaltenes and Crude Oil Wetting - the Effect of Oil Composition. SPE Journal 1997, 2 (02), 107-119. 56. Alotaibi, M. B.; Nasralla, R. A.; Nasr-El-Din, H. A. Wettability Studies Using Low-Salinity Water in Sandstone Reservoirs. SPE Reservoir Evaluation \& Engineering 2011, 14 (06), 713-725.

57. Mahani, H.; Berg, S.; Ilic, D.; Bartels, W.-B.; Joekar-Niasar, V. Kinetics of the Low Salinity Waterflooding Effect Studied in a Model System. In SPE Enhanced Oil Recovery Conference; Society of Petroleum Engineers: Kuala Lumpur, Malaysia, 2013, p 14.

58. Berg, S.; Cense, A.; Jansen, E.; Bakker, K. Direct Experimental Evidence of Wettability Modification by Low Salinity. Petrophysics 2010, 51 (05). 
59. Drummond, C.; Israelachvili, J. Fundamental Studies of Crude OilSurface Water Interactions and Its Relationship to Reservoir Wettability. Journal of Petroleum Science and Engineering 2004, 45 (1-2), 61-81.

60. Hilner, E.; Andersson, M.; Hassenkam, T.; Matthiesen, J.; Salino, P.; Stipp, S. The Effect of Ionic Strength on Oil Adhesion in Sandstone-the Search for the Low Salinity Mechanism. Scientific reports 2015, 5.

61. Matthiesen, J.; Bovet, N.; Hilner, E.; Andersson, M. P.; Schmidt, D. A.; Webb, K. J.; Dalby, K. N.; Hassenkam, T.; Crouch, J.; Collins, I. R.; Stipp, S. L. S. How Naturally Adsorbed Material on Minerals Affects Low Salinity Enhanced Oil Recovery. Energy \& Fuels 2014, 28 (8), 4849-4858. 


\section{2}

\section{CATION-DEPENDENT WETTABILITY ALTERATION}

The contents of this chapter have also been published as:

'Salinity-Dependent Contact Angle Alteration in Oil/Brine/Silicate Systems: the Critical Role of Divalent Cations'

M. E. J. Haagh, I.. Siretanu, M.H.G. Duits, and F. Mugele; Langmuir 2017, 33, 14, 3349-3357

In this chapter, we use macroscopic contact angle goniometry in highly idealized model systems to evaluate how brine salinity affects the balance of wetting forces and to infer the microscopic origin of the resulting contact angle alteration. We focus in particular on two competing mechanisms debated in the literature, namely double layer expansion and divalent cation bridging. Our experiments involve aqueous droplets with a variable content of chloride salts of $\mathrm{Na}^{+}, \mathrm{K}^{+}$, $\mathrm{Ca}^{2+}$ and $\mathrm{Mg}^{2+}$, wetting surfaces of mica and amorphous silica, and an environment of ambient decane containing small amounts of fatty acids to represent polar oil components. By diluting the salt content in various manners, we demonstrate that the water contact angle on mica, but not on silica, decreases by up to $25^{\circ}$ as the divalent cation concentration is reduced from typical concentrations in sea water to zero. Decreasing the ionic strength at constant divalent ion concentration, however, has a negligible effect on the contact angle. We discuss the consequences for the interpretation of core flooding experiments and the identification of a microscopic mechanism of low salinity water flooding. 


\subsection{Introduction}

Standard water flooding oil recovery from geological reservoirs is a complex multi-scale process with a rather low overall efficiency, typically leaving between half and two thirds of the oil in the ground by the end of the economic life time of a reservoir. ${ }^{1}$ This poor macroscopic efficiency is caused to an important extent by the microfluidic twophase flow processes that arise when oil is displaced by the injected brine on the pore scale. Given the large surface-to-volume ratios on the pore scale and the low capillary numbers typically involved in oil recovery, it is clear that these two-phase flows are controlled to a large extent by the wettability of oil and water in the complex geometry of the porous rock material: the distribution of local contact angles in combination with the pore geometry provide the complex energy landscape, in which the distribution of oil and water typically evolves typically under quasi-static conditions driven by the externally applied pressure gradient. Numerous experiments, simulations, and theoretical models on different levels of complexity have demonstrated that the resulting final saturation of a porous medium with the displaced phase (i.e. the oil in oil recovery) after invasion of the second immiscible phase (i.e. the injection water) depends very sensitively on the relative wettability of the two phases on the solid matrix. ${ }^{2,3}$ For instance, a recent study combining experiments with packed beads and numerical simulations consistently demonstrates a substantial increase of the displacement efficiency as the contact angle of the displacing phase is decreased from somewhat above to somewhat below $90^{\circ} .4$ Hence, wettability alteration is a very efficient process to improve the recovery of crude oil in enhanced oil recovery (EOR) processes.

It is important to point at the outset of any discussion to an ambiguity in terminology between physical chemists and the petroleum engineering community in this context: in physical chemistry 'wettability' describes a qualitative measure of the contact angle; 'wettability alteration' is therefore equivalent to 'contact angle alteration'. In contrast, petroleum engineers use the term 'wettability' to express the retention capability of a porous medium in a two-phase flow displacement experiment such as an Amott wettability test; 
'wettability' in that sense is therefore a much more complex quantity that is affected by the properties of the aforementioned complex energy landscape and by details of the process parameters such as sample history and flow rates. Throughout this work, we will stick to the generic terminology of physical chemistry, where 'wettability' describes equilibrium contact angle.

Since the mid to late 1990s, empirical evidence has grown that water flooding oil recovery with brines of reduced salinity gives rise to significant increases in recovery. ${ }^{5,6,7}$ Various mechanisms have been proposed throughout the years to explain the success of this Low Salinity Water Flooding (LSWF) process, including the mobilization of fines, ${ }^{8,9}$ mineral dissolution, ${ }^{8}$ emulsification at elevated $\mathrm{pH},{ }^{10,11}$ and wettability alteration. ${ }^{12}$ In fact, in more recent years wettability alteration from more oil-wet towards more water-wet has become the predominant paradigm in the literature. ${ }^{6,7}$ The microscopic mechanisms causing the wettability alteration, however, are also under debate. While the situation in carbonate reservoirs is particularly complex due to the strong chemical activity of the rock, ${ }^{13,}{ }^{14}$ the discussion for sandstone reservoirs largely focuses on two specific competing mechanisms: double layer expansion (DLE) upon reducing salinity, ${ }^{8,15}$, ${ }^{16}$ and multicomponent ion exchange (MIE)/complex formation. ${ }^{17,}{ }^{18}$ In the MIE mechanism, divalent cations play a prominent role because they are believed to promote binding of acidic oil components to negatively charged rock surfaces. Empirical correlations of the success of LSWF with clay content suggest that amongst the rock components, clay is particularly important for these surface reactions. ${ }^{8}$

Despite the facts that (i) recovery factors obtained in core flooding experiments are affected by much more complex factors than local contact angles and (ii) local contact angles are not measured in core flooding experiments, it has become customary to discuss the alleged contact angle variation in terms of very specific models based on DLVO theory and extensions of it involving specific chemical binding mechanisms. An early overview of the physical ingredients of these models was given by Hirasaki. ${ }^{19}$ Such models provide direct predictions for the variation of the equilibrium contact angle on flat surfaces. One 
key element of such models is a thin wetting film of brine with a thickness in the nanometer range that is expected to cover most of the solid surface in a partial wetting situation. The thickness of such a wetting film is governed by a balance of repulsive short-range and/or electrostatic forces and attractive long range dispersion forces. ${ }^{19}$ In view of the intrinsically hydrophilic character of the rock material, the existence of a such a water film is very plausible. However, its existence in experiments is usually only inferred from indirect evidence such as sample history and pretreatment. Direct proof for the existence of these layers has been provided only in very few cases either by neutron reflectivity ${ }^{20}$ or by imaging ellipsometry in model systems. ${ }^{21}$

Experiments aiming to demonstrate the effect of brine composition on wettability with model surfaces, crude oils and brines of variable composition and at variable temperature provided mixed evidence. ${ }^{22,23,}$ ${ }^{24}$ To a certain extent, inconsistencies in macroscopic experiments are not completely surprising given the complexity of both the types of surfaces and oils employed in different experimental studies. Nevertheless, such inconsistencies raise the question whether the basic underlying assumptions regarding the competing candidate mechanisms are at all justified. This question prompted a series of experiments in our laboratory in recent years to verify one by one the validity of each individual steps involved in the competing multicomponent ion exchange and in the double layer expansion mechanisms. On the microscopic scale, we verified the preferential adsorption of divalent as compared to monovalent cations to mineral surfaces using atomic force microscopy and ellipsometry. ${ }^{21,25}$ On the macroscopic scale, we showed that this adsorption process of divalent cations $\left(\mathrm{Ca}^{2+}, \mathrm{Mg}^{2+}\right)$ induces partial water wetting in idealized decane/brine/mica systems. ${ }^{21}$ This transition could be correlated to a reversal of the mica/water interfacial charge from negative to positive, leading to attractive electrostatic contribution in the DLVO forces governing the stability of the oil/water film/mica system. At the same time, monovalent cations $\left(\mathrm{Na}^{+}, \mathrm{K}^{+}\right)$always lead to a repulsive electrostatic contribution to the total disjoining pressure and hence to near-zero contact angles. A quantitative DLVO model provided a 
consistent description of the contact angle alteration with the brine composition-dependent variation of the interfacial charges.

We also performed measurements where small amounts of stearic acid were added to the oil phase, as a model to represent interfacially active acidic oil components. ${ }^{26}$ The combination of stearic acid and divalent cations demonstrated a massive synergistic effect boosting the range of the observed wettability alteration from approximately $10^{\circ}$ to more than $60^{\circ}$. Atomic force microscopy and ellipsometry imaging revealed that this boost in wettability alteration was caused by the formation of a self-assembled monolayer of stearate rendering the mica surface substantially more hydrophobic. ${ }^{26,} 27$ These experiments suggested that divalent cations act indeed as a glue attaching acidic oil components to the mineral surface, as suggested in the MIE model of LSWF. ${ }^{17}$ The fact that the simultaneous presence of the acidic additive and the divalent cations was essential for the formation of these layers is consistent with our earlier observations demonstrating the stability of Langmuir-Blodgett films of stearic acid under water depends strongly on the presence of divalent cations during the preparation process of these layers. ${ }^{27}$ While supporting the idea of divalent ion-mediated binding of stearate to the surface, the fact that the preparation conditions displayed an important effect on the ultimate stability of the layers raises questions regarding the kinetic and the equilibration of the adsorption/desorption processes in these systems.

All these preceding studies thus consistently point to an essential role of divalent cations in increasing water contact angles by binding polar oil components. Yet, these studies were mostly carried out with brines containing only a single species of salt. In the present work, we extend the scope of our macroscopic wettability alteration tests by allowing for the simultaneous presence of both monovalent and divalent cations. Thereby, we allow for competition between different cations for complexation both to the surface and to the carboxylate group of the stearate. This extension is important because it allows us to vary independently the concentration of divalent cations and the overall salinity of the brine. As a consequence, we are able to discriminate between the two proposed mechanisms of DLE and MIE 
by analyzing the contact angle as we vary either the total ionic strength or the concentration of divalent cations while keeping either the other factor constant. In addition, we established an in-situ fluid exchange protocol to vary the salinity of a sessile brine drop while in touch with the solid substrate in ambient oil. This allows us to address important issues regarding the reversibility of the formation of the hydrophobizing stearate layers upon reducing the ionic strength or the divalent ion content in the brine drop. Experiments are carried out in parallel on mica and silica surfaces to represent the main components of sandstone rock, with large flat mica surfaces representing the clay component.

\subsection{Experimental}

\section{Materials}

Anhydrous $n$-decane was used as the oil phase in all experiments. It was passed five times through a $5 \mathrm{~cm}$ long column of aluminum oxide powder to reduce the presence of surface active impurities. ${ }^{28}$ In this oilphase, fatty acids were dissolved to a concentration of $100 \mu \mathrm{M}$. In nearly all cases octadecanoic acid (stearic acid) was used as the fatty acid; the exception was a fluid exchange experiment where a 1:1 molar combination of 12-phenyl-dodecanoic acid and stearic acid was used. For the brine phases we used purified water (Millipore, resistivity 18.2 $\mathrm{M} \Omega \mathrm{cm}$ ) in which different combinations of the following salts were dissolved: $\mathrm{NaCl}, \mathrm{KCl}, \mathrm{CaCl}_{2} \cdot 2 \mathrm{H}_{2} \mathrm{O}$, and $\mathrm{MgCl}_{2} \cdot 6 \mathrm{H}_{2} \mathrm{O}$. Additionally, small amounts of $\mathrm{NaOH}$ were added in case the $\mathrm{pH}$ needed to be increased. All chemicals used were purchased from Sigma Aldrich. For the solid substrates we used mica (muscovite) slides (B \& M Mica Co., Inc.) as well as silicon wafers that were coated with a $30 \mathrm{~nm}$ amorphous, thermally grown, silicon oxide layer (Okmetic Oyj).

Two types of brines were prepared: binary salt solutions and artificial seawater variations. Binary salt solutions were prepared from one monovalent and one divalent cation chloride salt, in the following combinations: $\mathrm{Na}^{+}$and $\mathrm{Ca}^{2+} ; \mathrm{Na}^{+}$and $\mathrm{Mg}^{2+} ; \mathrm{K}^{+}$and $\mathrm{Ca}^{2+}$. For the artificial seawater variations, we used all four aforementioned salts at their typical concentrations in seawater, ${ }^{29}$ to prepare so-called 
simplified artificial seawater (ASW) (Table 1). Three series of ASW variations were investigated. Firstly, a simple dilution series (DIL), where all salt concentrations are reduced evenly. Secondly, a series at constant ionic strength (cIS), where we reduced the concentration of $\mathrm{CaCl}_{2}$ and $\mathrm{MgCl}_{2}$ while adding $\mathrm{NaCl}$ and $\mathrm{KCl}$ to compensate for the loss of ionic strength $\left(I S=\frac{1}{2} \sum_{i} z_{i}^{2} c_{i}\right.$; where $c_{i}$ and $z_{i}$ are the concentration and valence of $i$-th ionic species respectively). And thirdly, a series at constant divalent cation concentration (cDIV), where we reduced only the concentration of $\mathrm{NaCl}$ and $\mathrm{KCl}$. The concentration ratios of $\mathrm{Na}^{+}: \mathrm{K}^{+}$and $\mathrm{Ca}^{2+}: \mathrm{Mg}^{2+}$ are the same for all these samples.

Table 2.1. Brine compositions and their ionic strength used in the experiments with artificial seawater.

\begin{tabular}{|c|c|c|c|c|c|}
\hline \multirow{2}{*}{ Brine name } & \multicolumn{4}{|c|}{ Salt concentration (mM) } & \multirow{2}{*}{$\begin{array}{c}I S \\
(m M)\end{array}$} \\
\hline & $\mathrm{NaCl}$ & $\mathrm{KCl}$ & $\mathrm{CaCl}_{2}$ & $\mathrm{MgCl}_{2}$ & \\
\hline ASW $100 \%$ & 485 & 10.3 & 10.8 & 55.5 & 694 \\
\hline DIL $50 \%$ & 243 & 5.2 & 5.4 & 27.8 & 347 \\
\hline DIL $10 \%$ & 48.5 & 1.0 & 1.1 & 5.6 & 69 \\
\hline DIL $0 \%$ & 0 & 0 & 0 & 0 & 0 \\
\hline cIS $50 \%$ & 582 & 12.4 & 5.4 & 27.8 & 694 \\
\hline cIS $10 \%$ & 660 & 14.0 & 1.1 & 5.6 & 694 \\
\hline cIS $0 \%$ & 680 & 14.4 & 0 & 0 & 694 \\
\hline cDIV $50 \%$ & 242.5 & 5.2 & 10.8 & 55.5 & 447 \\
\hline cDIV $10 \%$ & 48.5 & 1.0 & 10.8 & 55.5 & 248 \\
\hline cDIV $0 \%$ & 0 & 0 & 10.8 & 55.5 & 199 \\
\hline
\end{tabular}

\section{Wettability Measurements}

Brine droplets with a volume of $\approx 2 \mu \mathrm{l}$ were deposited on the solid substrate in oil by gently lowering the needle from which they were hanging. After contact with the substrate was achieved, lifting the 
needle was sufficient to release the droplet. Side-view images of droplets were captured using an optical contact angle goniometer (OCA20L) (Fig. 2.1B). The contact angles were extracted from these images by applying a circle fitting to the droplet contour, using the SCA20 software (both hardware and software from DataPhysics Instruments $\mathrm{GmbH}$ ). For each experimental condition the contact angle was averaged over 20 measurements consisting of two sets of 10 measurements, where each set was performed with freshly prepared brine. Typically the standard errors of these measurements have values between 2 and $5^{\circ}$.

\section{Single Droplet Fluid Exchange}

Muscovite slides were first pretreated to be fully covered by a hydrophobic monolayer of fatty acids. This was achieved by first depositing a $200 \mu \mathrm{ASW}$ droplet on a slide submerged in a solution of fatty acid in $n$-decane. Care was taken to ensure that the droplet covered the entire slide. After a dwell time of 5 minutes the brine fluid was extracted, using a needle and a syringe pump operated at $50 \mu \mathrm{l} / \mathrm{min}$. This procedure should result in the deposition of a hydrophobic layer via the receding contact line as explained in detail in ref ${ }^{30}$. Briefly, after deprotonation of the fatty acid, complexation with a metal cation takes place at the oil-water interface. ${ }^{31}$ The positively charged metal-fatty acid complex gets transferred to the negatively charged solid substrate, ${ }^{26}$ somewhat similar to a Langmuir-Blodgett transfer. The coated substrate was kept in the oil.

In the next step of the protocol, a brine droplet of $18.6 \pm 1.3 \mu 1$ was pipetted on the pretreated substrate. The mean and standard deviation of this droplet volume $(V)$ were obtained by weighing 20 droplets on an analytical mass balance. Two glass capillaries (100 $\mu \mathrm{m}$ inner-, $170 \mu \mathrm{m}$ outer diameter; VitroCom) were inserted in the deposited droplet after they had been connected to a Legato $270 \mathrm{push} /$ pull syringe pump (KD Scientific) as illustrated in Fig. 2.1B. Connecting the inlet to a reservoir with the brine of interest, allowed exchanging the contents of the droplet while maintaining a constant volume. This exchange was done at a rate of $10 \mu \mathrm{l} / \mathrm{min}$. 
It turned out that most droplets did not maintain a spherical cap shape when deposited on the pretreated substrate; this was visible as a left-right asymmetry in side view images, and as an irregular, noncircular, contact line in bottom views. These imperfections are ascribed to heterogeneities in the deposited layer; from previous studies on brine droplets under oil with stearic acid, ${ }^{26}$ and on exposure of dried Langmuir-Blodgett layers to brine, ${ }^{27}$ it is known that inhomogeneous patterns are formed. To obtain the best representative contact angle, we measured the droplet/mica interfacial area, using the bottom-view camera. A pixel-counting script was used to measure the area, which was averaged over 9 measurements for each condition. The effective contact angle $\left(\theta_{\text {eff }}\right)$ was then calculated by using the relation between area $(A)$, volume $(V)$ and contact angle $(\theta)$ for a spherical cap:

$$
V=\frac{A^{\frac{3}{2}}}{3 \sqrt{\pi} \sin ^{3} \theta}\left(\cos ^{3} \theta-3 \cos \theta+2\right)
$$

Measurement of droplet contact angles with the side-view camera, before and after fluid exchange, indicated that the two types of measurements corresponded to each other, within the error margins (before: $58.9 \pm 13.7^{\circ}$ for the bottom view, $69.7 \pm 14.5^{\circ}$ for the side view; after: $27.8 \pm 2.6^{\circ}$ for the bottom view, $30.6 \pm 10.7^{\circ}$ for the side view). 


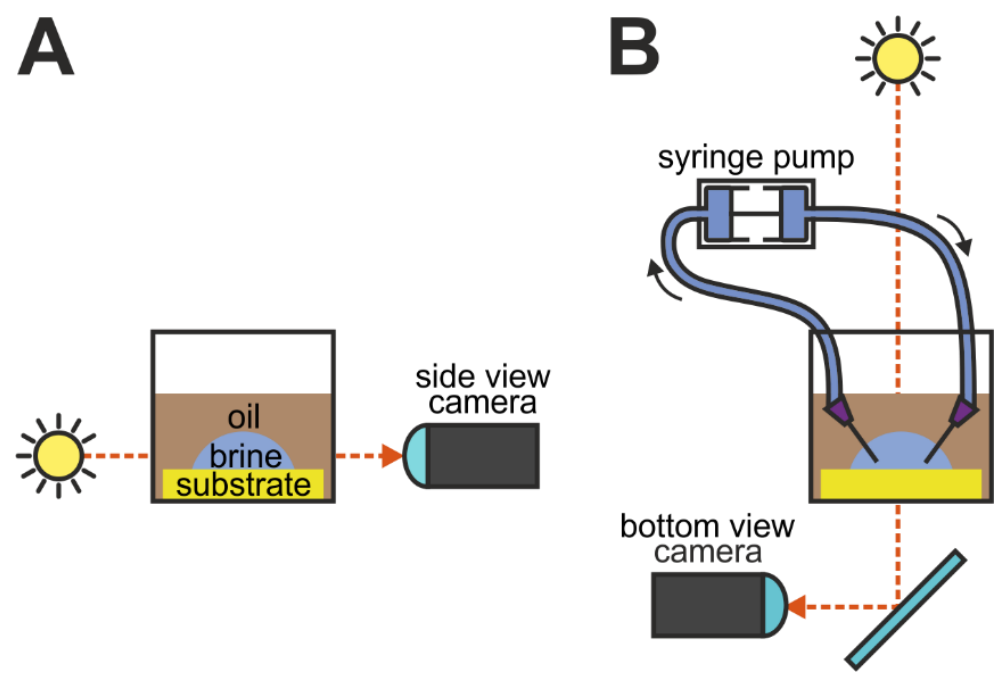

Figure 2.1. Schematic of the experimental setups used for contact angle measurements after droplet deposition (A) and during fluid exchange (B).

\subsection{Results}

\section{General Behavior}

After deposition on mica substrates, most brine droplets showed, after a short phase of rapid spreading, a significant amount of retraction. The latter process was slow enough to measure it via the contact angle. Fig. 2.2A show the kinetics of the relaxation of the contact angle during this phase. This behavior, which has been termed autophobing, ${ }^{30}$ is believed to originate from a metal-stearate transfer from the oil/water interface onto the mica. ${ }^{26}$ This hydrophobic monolayer formed at the contact line then forces the droplet to a higher contact angle. ${ }^{30}$ The time needed for the droplets to reach a constant contact angle ranged from 10 seconds to 3 minutes, depending on brine composition and $\mathrm{pH}$. Thereafter the contact angle remained stable for at least 15 minutes. We will therefore denote it as the final contact angle $\left(\theta_{f}\right)$.

Fig. 2.2B illustrates the impact of the valence of the cations in the solution on the contact angle. Raising the concentration of $\mathrm{Na}^{+}$from 0 to $500 \mathrm{mM}$ increases the contact angle only slightly, from about $2^{\circ}$ to 
$5^{\circ}$. But when $\mathrm{Ca}^{2+}$ is used instead of $\mathrm{Na}^{+}$, the contact angle increases to $55^{\circ}$. Even $20 \mathrm{mM} \mathrm{Ca}^{2+}$ already leads to a contact angle of $25^{\circ}$. This underlines relevance of the type of cation for the wetting behavior of solutions of individual species of salts.
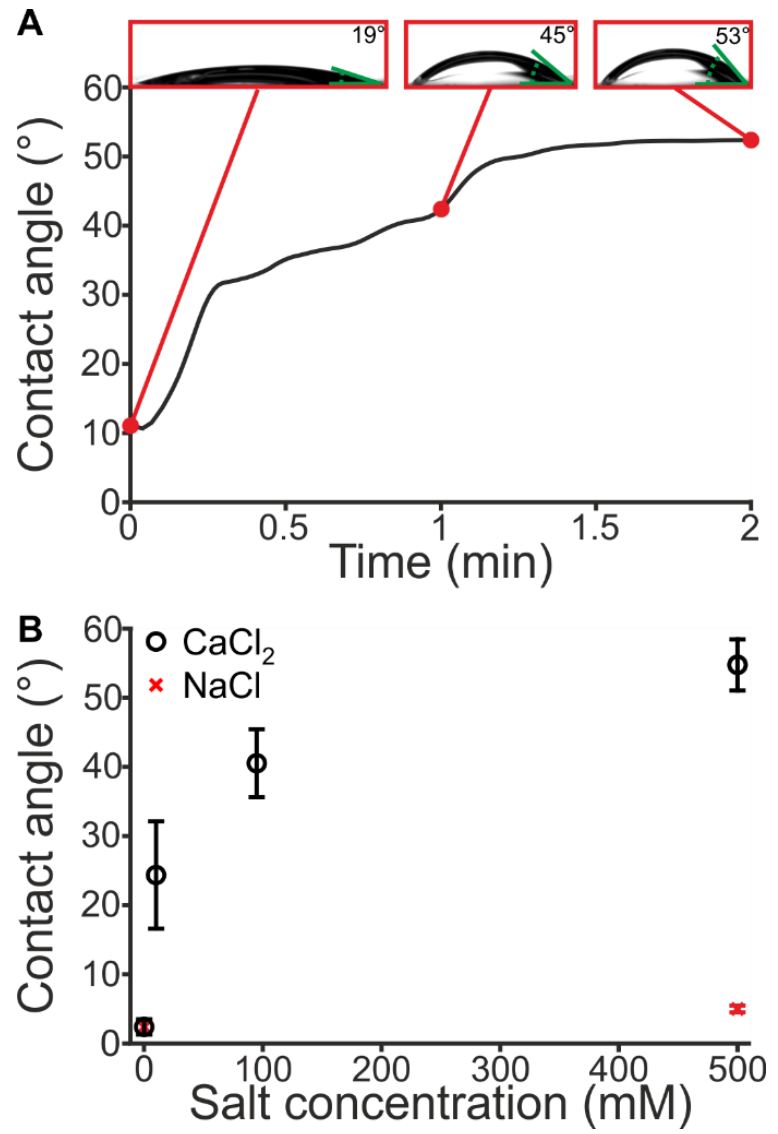

Figure 2.2. Contact angles of brine droplets at $\mathrm{pH} 8$ in an $n$-decane $+100 \mu \mathrm{M}$ stearic acid solution on mica: A) typical behavior of a $500 \mathrm{mM} \mathrm{CaCl}$ drop receding over time, $B$ ) final contact angles versus salt concentration for $\mathrm{CaCl}_{2}$ and $\mathrm{NaCl}$. 


\section{Binary Salt Solutions}

Building on our previous studies with individual salts ${ }^{26}$ we performed contact angle measurements with droplets containing solutions of binary mixtures of cations on the same type of mica surfaces in $n$ decane in the presence of stearic acid. All experiments were carried out at $\mathrm{pH} 8$, to ensure near-complete stearic acid deprotonation $(\mathrm{pKa}=$ 4.75)..$^{32}$

Combinations of $\mathrm{NaCl}$ and $\mathrm{CaCl}_{2}$ solutions display an intermediate behavior between pure $\mathrm{NaCl}$ and pure $\mathrm{CaCl}_{2}$ solutions with high $\left[\mathrm{Ca}^{2+}\right]:\left[\mathrm{Na}^{2+}\right]$ ratios promoting $\mathrm{Ca}^{2+}$-like behavior including autophobing and vice versa (Fig. $2.3 \& 2.4 \mathrm{~A}$ ). For $\left[\mathrm{Ca}^{2+}\right]$ of $100 \mathrm{mM}$ and higher, $\theta_{f}$ turned out to be independent of $\left[\mathrm{Na}^{+}\right]$up to $0.5 \mathrm{M}$. At 10 $\mathrm{mM} \mathrm{Ca}{ }^{2+}$, however, a $\left[\mathrm{Na}^{+}\right]$of $0.5 \mathrm{M}$ was enough to reduce $\theta_{f}$ down to $\approx 5^{\circ}$. Which is the same value as that of a pure $\mathrm{NaCl}$ solution (Fig. 2.2B).

To explore the general validity of these observations, we tested different combinations of common cations $\left(\mathrm{Na}^{+}, \mathrm{K}^{+}, \mathrm{Ca}^{2+}, \mathrm{Mg}^{2+}\right)$ in seawater. Contact angles of $\mathrm{Na}^{+} / \mathrm{Mg}^{2+}$ droplets (Fig. 2.4B) display trends very similar to those of $\mathrm{Na}^{+} / \mathrm{Ca}^{2+}$, except that the contact angles are overall slightly higher for the same concentrations. In particular, even in the presence of $0.5 \mathrm{M} \mathrm{Na}^{+}$, a finite value of $\approx 30^{\circ}$ is observed at $10 \mathrm{mM} \mathrm{Mg}^{2+}$. Surprisingly, even a $\left[\mathrm{Mg}^{2+}\right]$ as low as $1 \mathrm{mM}$ still induces a substantial contact angle of $\approx 20^{\circ}$ at high $\left[\mathrm{Na}^{+}\right]$. Interestingly, at this $\left[\mathrm{Mg}^{2+}\right], \theta_{f}$ was found to vary in a non-monotonic manner with increasing $\left[\mathrm{Na}^{+}\right]$.

The $\mathrm{K}^{+} / \mathrm{Ca}^{2+}$ system (Fig. 2.4C) showed a behavior that is very different from that of $\mathrm{Na}^{+} / \mathrm{Ca}^{2+}$ (Fig. 2.4A): for all measurements with $\left[\mathrm{K}^{+}\right] \geq 100 \mathrm{mM}$, the droplets reached contact angles of $\approx 25^{\circ}$, after an initial phase of spreading and subsequent autophobing. The $\mathrm{Ca}^{2+}$ content affect the contact angle only at the lowest $\mathrm{K}^{+}$concentration of $10 \mathrm{mM}$. 


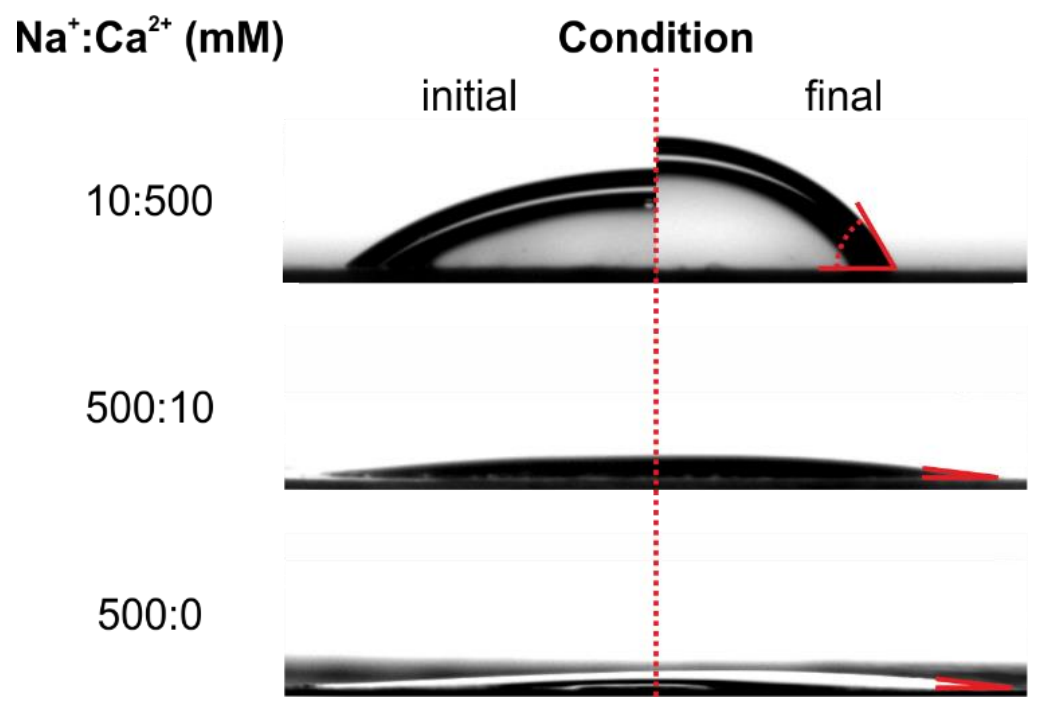

Figure 2.3. Pictures of $\mathrm{NaCl}+\mathrm{CaCl} 2$ brine droplets at $\mathrm{pH} 8$ in $n$-decane $+100 \mu \mathrm{M}$ stearic acid on muscovite, showing the dependence on [Na+] and $[\mathrm{Ca}+]$ right after droplet deposition (left) and after a stable conformation was reached (right) 

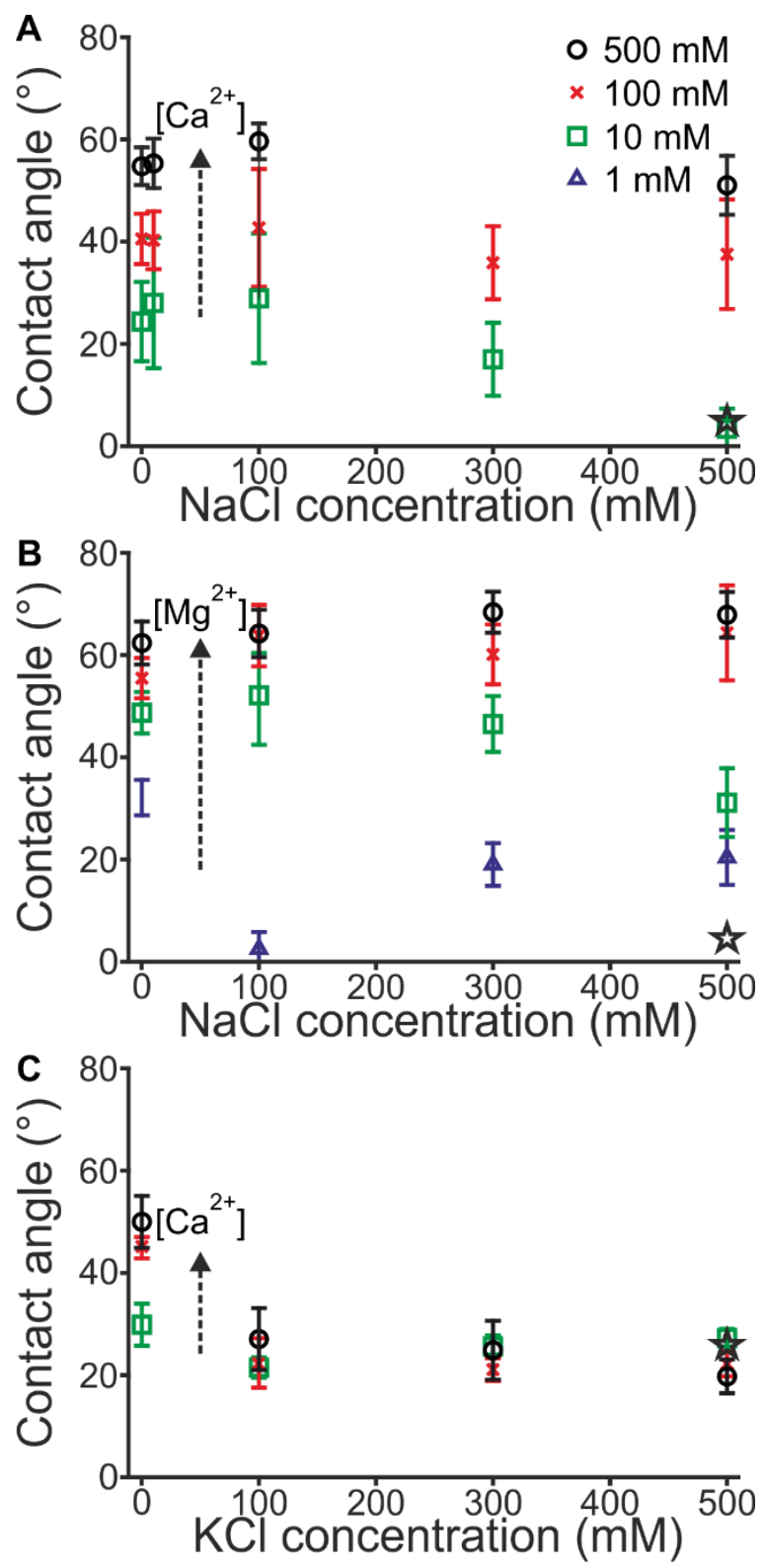
Figure 2.4. (opposite page) Final contact angles of binary salt solution droplets at $\mathrm{pH} 8$ in n-decane $+100 \mu \mathrm{M}$ of stearic acid, on mica: A) $\mathrm{NaCl}$ and $\mathrm{CaCl}_{2}, \mathrm{~B}$ ) $\mathrm{NaCl}$ and $\mathrm{MgCl}$, and $\left.\mathrm{C}\right) \mathrm{KCl}$ and $\mathrm{CaCl}_{2}$. The monovalent cation concentration is shown on the $x$-axis, while the divalent cation concentration is shown in the legend. The black star indicates the contact angle of a pure 500 mM monovalent cation droplet.

\section{Modified Artificial Seawater}

Expanding on the experiments with the binary cation combinations, we also studied the effects of the concentrations of the combined monoand divalent cations, as occurring in ASW. Three types of concentration variations were explored (DIL, cIS and cDIV, Table 2.1). Here the DIL series serves as a reference, representing the simplest way to lower salinity. The cIS series keeps the ionic strength constant while the divalent cation concentration is varied. The cDIV series is complementary: here the divalent cation concentration is kept constant while the ionic strength varies. Together these three series offer a way to examine the relative importance of the possible wetting mechanisms; for example in case of a dominant DLE, the cIS series should produce invariable contact angles while the cDIV experiments would show a variation. If cation bridging were dominant then C2MD should produce constant contact angles while cIS would show a variation. To approach sandstone reservoir surface chemistry, we studied both mica and oxidized silicon substrates, at a close to neutral $\mathrm{pH}$ (6.5).

On mica, the DIL contact angles showed a decrease from $25^{\circ}$ to $2^{\circ}$ (Fig. 2.5A). The cIS contact angles superimpose very well on those of DIL, down to a dilution of $10 \%$ with respect to ASW. The only significant difference between cIS and DIL was found at $0 \%$. Here the droplets of cIS $0 \%$ had an $8^{\circ}$ contact angle, while the pure water droplets of DIL $0 \%$ were at $2^{\circ}$. The cDIV contact angles remained constant at $25^{\circ}$, even though the ionic strength was strongly reduced: from $694.2 \mathrm{mM}$, to $198.9 \mathrm{mM}$.

On silica, at $\mathrm{pH}$ 6.5, no significant wettability alteration was observed in any series, and measurements suffered from large uncertainty (Fig. 2.5B, inset), possibly due to contamination. Therefore, measurements on silica were also performed at $\mathrm{pH} 8$, where silica has 
a stronger negative surface charge (Fig. 2.5B) ${ }^{33}$ Here, a small salinityinduced wettability effect was observed. All three series followed a similar decrease from $19^{\circ}$ to $10-15^{\circ}$, and all contact angles were reached by spreading rather than autophobing.
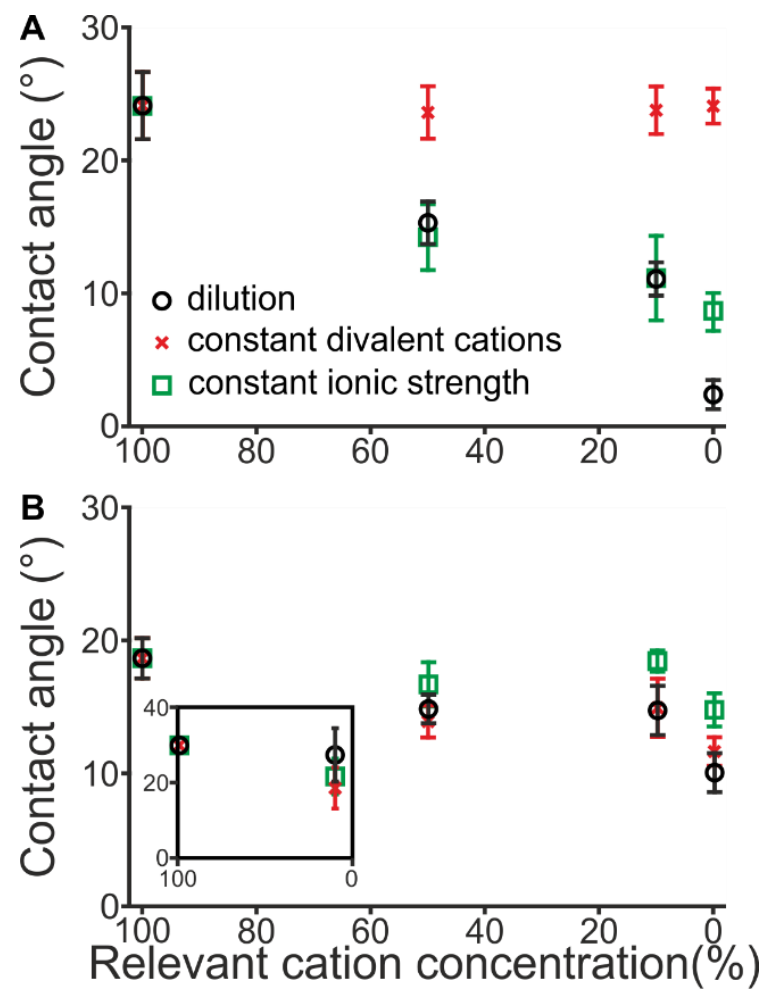

Figure 2.5. Final contact angles of ASW-based droplets measured in n-decane $+100 \mu \mathrm{M}$ stearic acid on A) mica at pH 6.5 and B) silica at $p H 6.5$ (inset) and 8.0 .

\section{Single Droplet Fluid Exchange}

From the trends in $\theta_{f}$ reported in previous sections, it cannot be concluded whether these contact angles are truly equilibrium values. If they are, it should be possible to reverse the autophobing process by 
changing the salt composition of a high $\theta_{f}$ droplet to that of a low $\theta_{f}$ droplet. We tested this hypothesis using the single droplet fluid exchange setup on ASW droplets of $\mathrm{pH} 8$, that were deposited on a mica substrate that was coated with fatty acid (see experimental section). Our aim was to qualitatively reproduce the trends of the DIL, cIS and cDIV series shown in Fig. 2.5A. In analogy to the LSWF process, we exchanged the droplet content with water, cIS $0 \%$, or cDIV $0 \%$ respectively.

From the measured brine/mica interfacial area (Fig, 2.6A) we calculated the effective contact angle (Fig. 2.6B) using Eq. 2.1. For all explored conditions, the observed effective contact angle trends broadly corresponded with the $\theta_{f}$ trends of their respective series. ASW droplets that were flushed with water spread over the course of 10 minutes from an effective contact angle of $60^{\circ}$ to $35^{\circ}$. Droplets flushed with cIS $0 \%$ initially spread following a similar trend. But after 10 minutes the droplets continued to spread, eventually reaching effective contact angles of around $20^{\circ}$. Droplets flushed with a cDIV solution showed no significant spreading.

In the measurements described above stearate is the only polar organic compound, whereas in crude oil many surface active compounds coexist. It is known that stearate monolayers at an air/water interface can be destabilized by additional surface active compounds. ${ }^{34}$ To ensure that our observations do not rely on a uniform monolayer, we also performed measurements where we used a 1:1 molar combination of 12-phenyl-dodecanoic acid and stearic acid. Both have a similar molecular mass ( 284 and $276 \mathrm{~g} / \mathrm{mol}$ respectively) but differ sterically. Flushing ASW droplets with water on this mixed hydrophobic layer caused them to reach a lower final contact angle $\left(20^{\circ}\right)$, about twice as fast as with stearic acid only. 


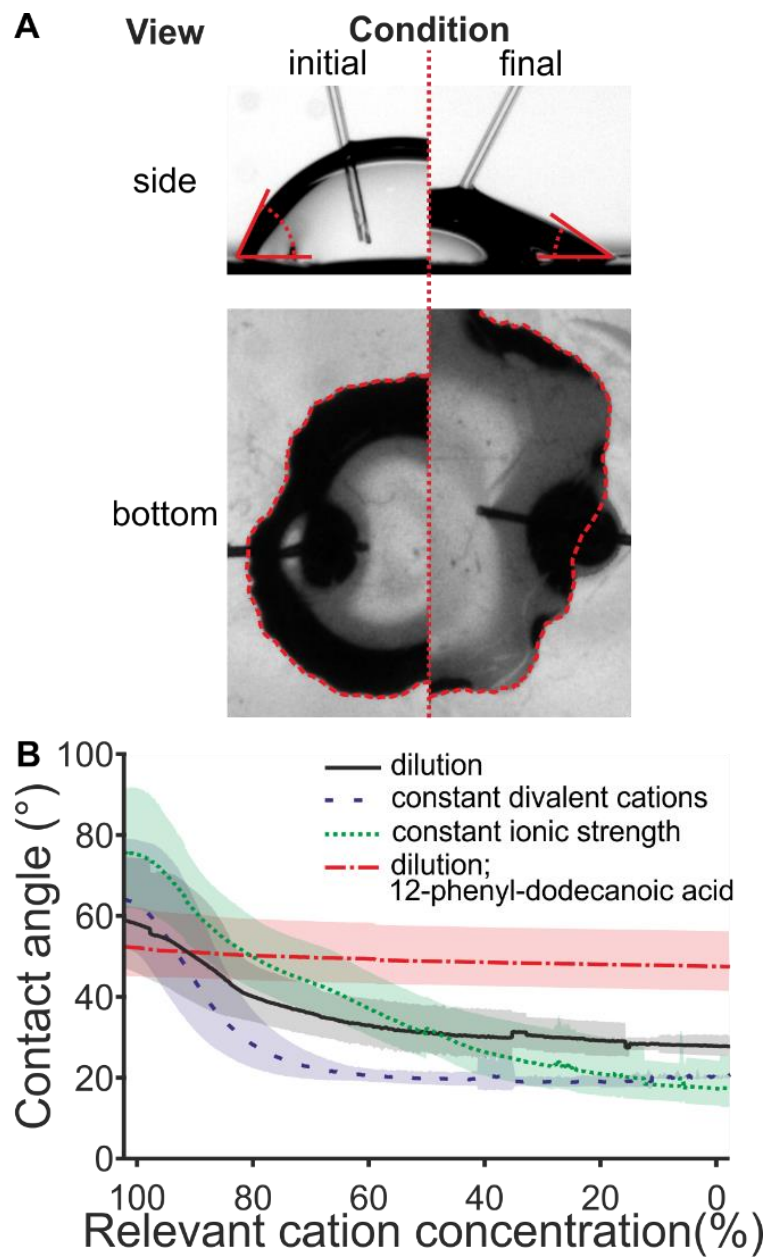

Figure 2.6.. Fluid exchange experiments on $\mathrm{pH} 8 \mathrm{ASW}$ droplets in in $n$-decane on mica pretreated with a stearate layer: A) stills from side-and bottom view videos taken during the initial stable conformation (left) and final video frame after flushing with water (right), B) effective contact angles of spreading droplets. The oil phase contained $100 \mu \mathrm{M}$ stearic acid in all cases except the orange line where 12-phenyl-dodecanoic acid was used. The shaded are represents the standard deviation around the mean of the data. 


\subsection{Discussion}

\section{Ion Adsorption-Controlled Wetting}

On a macroscopic scale, the wettability is governed by the balance of interfacial tensions at the three phase contact line. The present oil/water/mineral systems are well-known to fall in the regime of pseudo-partial wetting, ${ }^{35}, 36$ in which the macroscopic drop is accompanied by a microscopic wetting film covering in equilibrium the entire solid surface (Fig. 2.7). In this case, the equilibrium tension of the substrate-oil interface $\left(\gamma_{s o}\right)$ is determined by the minimum of the thickness-dependent effective interface potential $(\varphi(h))$, where $h$ is the film equilibrium thickness): $\gamma_{s o}(h)=\gamma_{s w}+\gamma+\varphi(h)$, where $\gamma_{s w}$ and $\gamma$ are the solid/water and the oil/water interfacial tensions respectively. Experimentally, the presence of such a film and the dependence of its thickness on the salinity of the brine has been reported recently by our team for a simplified system in the absence of surface active species. ${ }^{21}$ In that work, and in a subsequent theoretical study that included charge regulation, ${ }^{37}$ it was possible to reproduce the experimentally observed salinity-dependent wetting transition within DLVO theory by decomposing $\varphi(h)$ explicitly into its electrostatic, van der Waals and (exponentially decaying) short range hydration contribution by writing $\varphi(h)=\varphi_{e l}(h)+\varphi_{v d W}(h)+\varphi_{h}(h)$ with explicit expressions for each term. $^{21}$ The model, as well as complementary surface charge measurements, confirmed that the alteration of the water contact angle from almost complete water wetting in the presence of $\mathrm{Na}^{+}$or $\mathrm{K}^{+}$to finite contact angles in the presence of $\mathrm{Ca}^{2+}$ or $\mathrm{Mg}^{2+}$ could be attributed to a reversal of the mica/water interfacial charge. Yet, even those studies, as well as follow-up work involving different types of monovalent and divalent cations displaying pronounced specific ion effects, ${ }^{38}$ showed that the choice of the short range interactions plays an crucial role for quantitative results of such models.

The presence of surface active stearates in the present experiments increases the complexity even more. In addition to the adsorption of the ions at the solid surface, complexation reactions between the ions and the carboxylate groups of the fatty acid molecules need to be included. More importantly, however, a prediction of the equilibrium contact 
angle and the equilibrium thickness of the aqueous film would require an explicit model function $\varphi_{\text {bridge }}(h)$ for the contribution of the presumed divalent cation bridge between the solid surface and the adjacent fatty acid molecules at the oil-water interface. To our knowledge, no analytical expression for this function has ever been proposed. Given the complexity of the problem, a numerical statistical approach based on molecular dynamics simulations such as the potentials of mean force used e.g. by Horinek et al. ${ }^{39}$ in the context of ion adsorption to solid surfaces may be the only realistic approach to address this problem.

For the purpose of the present work, we restrain ourselves to a qualitative interpretation of our findings in the context of the extensive literature on the separate interfaces, namely, fatty acid-laden hydrophobic-water interfaces and solid electrolyte interfaces. For both cases, the interaction of the cations studied here with the relevant surface groups, the carboxylate group and the surfaces of mica and silica, have been investigated in great detail. At the near-neutral $\mathrm{pH}$ of the present experiments, it is primarily the interaction with the ions that triggers the deprotonation of the acid group. ${ }^{40}$ It is well-known from the extensive literature on Langmuir monolayers of fatty acids, including in particular stearic acid, that divalent $\mathrm{Mg}^{2+}$ and $\mathrm{Ca}^{2+}$ interact more strongly with the carboxylic acid group of the stearic acid than $\mathrm{Na}^{+}$and $\mathrm{K}^{+}$. 2 , 40, 41 The general consensus in literature is that the binding affinities for these ions with acid groups follows $\mathrm{Ca}^{2+}>\mathrm{Mg}^{2+}>\mathrm{Na}^{+}>\mathrm{K}^{+}$. 41,42 Judging from our binary salt solution contact angle measurements, shown in Fig. 2.4, this binding affinity alone cannot explain wettability trends. Particularly in Fig. 2.4C, where at equal concentrations $\mathrm{K}^{+}$ outcompetes $\mathrm{Ca}^{2+}$ in wettability effects. To explain this observation we should look at interactions between the cations and the charged mica surface. Due to the size of $\mathrm{K}^{+}$being ideal to fit in the mica lattice, where it naturally occurs, it adsorbs more strongly than $\mathrm{Na}^{+}$. This has been confirmed by zeta potential measurements. ${ }^{33,43}$ Park et al. predict, from $\mathrm{X}$-ray resonant anomalous $\mathrm{x}$-ray reflectivity results, that monovalent cations bond more strongly and closer to the mica surface than divalent cations, due to differences in hydration states. ${ }^{44}$ This could help $\mathrm{K}^{+}$ outcompete $\mathrm{Ca}^{2+}$ for adsorption. In our measurements, $\mathrm{Ca}^{2+}$ and $\mathrm{Mg}^{2+}$ 
do however, still outcompete $\mathrm{Na}^{+}$. This is likely an effect of valence, as the divalent cations have the added benefit of being able to ionically bond two anions, and are known to be able to bind anionic molecules such as DNA to mica. ${ }^{45}$

At reservoir conditions, $\mathrm{K}^{+}$and $\mathrm{Na}^{+}$should not affect the wettability significantly, because their concentrations are not high enough. Seawater has about $70 \mathrm{mM}$ of divalent cations, $84 \%$ of which is $\mathrm{Mg}^{2+}$, and about $500 \mathrm{mM}$ of monovalent cations, comprising $98 \%$ sodium. $^{29}$ Formation brines vary highly in their salinity but are often enriched in calcium ions compared to seawater, ${ }^{46}$ which skews the ratio even more in favor of the divalent cation fraction.

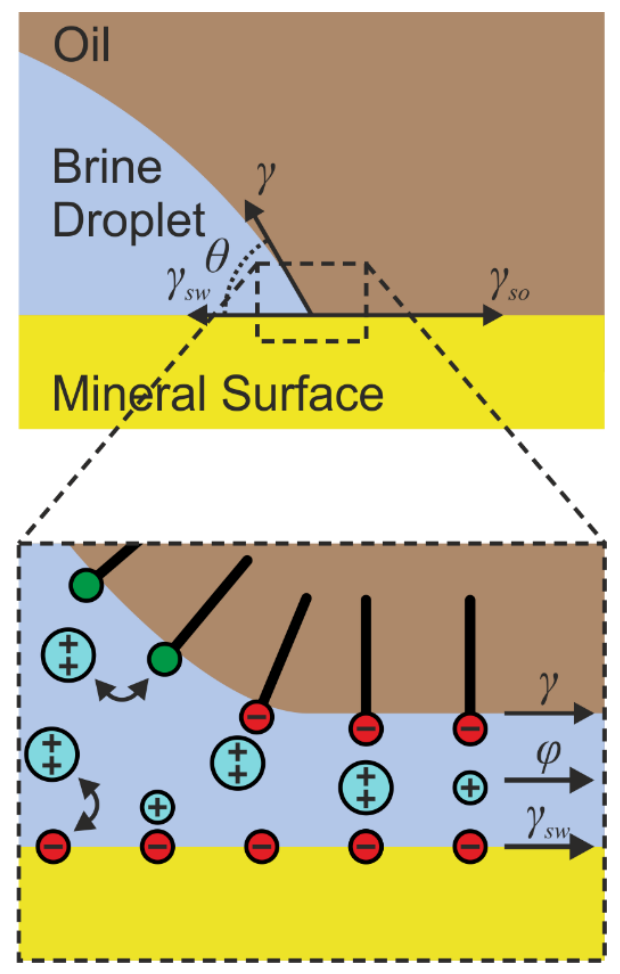

Figure 2.7. Model representation of the molecular scale processes that underlie macroscopic wettability. 


\section{Relevance For Enhanced Oil Recovery}

As already pointed out above, the retention of oil in a porous rock in a core flooding experiment, let alone in an actual oil reservoir, is governed by many more complex factors than the simple variation of the contact angle studied here. These include the complex pore geometry, elevated temperatures and pressures, as well as the chemical composition of rock, oil, and brine. The present experiments are therefore obviously not suitable to derive quantitative predictions regarding enhanced recovery factors. Nevertheless, the experiments clearly demonstrate a few aspects that should enter into any quantitative description of a low salinity EOR process. First of all, our experiments clearly demonstrate that the salinity of the brine can have a strong influence on the wettability of oil-water-mineral systems in the presence of acidic oil components and that contact angle variations can be as large as $60^{\circ}$ upon removal of divalent cations. This is an enormous effect. If inserted into reservoir simulations or other theoretical models of porous media two-phase flows, such variations have an enormous impact on the predicted recovery, in fact exceeding the observed recovery enhancement by far. In oil reservoirs, actual contact angle variations are probably very different and most likely much smaller. The abundance of polar components in crude oils will probably reduce the effect of the contact angle variations as compared to the idealized situation of a single fatty acid component, as reported by various authors. $^{23,24,47}$ On the other hand, the increased temperatures in reservoirs that tend to promote the adsorption of polar organics might increase the effect on water wettability again. ${ }^{48,49}$ In any case, according to reservoir simulations a reduction of the water contact angles of a few degrees is still consistent with recovery enhancements of several percent, as seen in many core flood experiments. ${ }^{3}$

The difference in low salinity response between the mica basal plane and the amorphous silica surfaces shown in Fig. 2.5 is rather striking. While one might have speculated that the adsorption of divalent cations could be even stronger on the amorphous silica surface because of the presence of ionizable silanol groups, the opposite is the case and the formation of salinity-responsive metal stearate layers is 
more favorable on the crystalline mica surface. Notwithstanding differences between the basal plane of mica and other clays typically encountered in oil reservoirs, the strong response on the mica surface is nevertheless consistent with the rather widely reported correlation between clay content and a pronounced low salinity response in core flooding. ${ }^{8}$

Finally, we would like to address the contribution of our results to the ongoing discussion about the relative importance of electric double layer expansion versus divalent cation bridging in low salinity water flooding. For the conditions of the present simple model system, the results are crystal clear. Reducing the divalent ion content improves the water wettability, reducing the ionic strength at constant divalent ion content does not. In the literature, the effect of electric double layer forces is typically discussed in the context of classical DLVO theory using expressions for the electric part of the disjoining pressure that are obtained from Poisson-Boltzmann theory, sometimes even in the linear Debye-Hückel limit. While appropriate up to moderate concentrations of monovalent ions and at low concentrations for divalent ones, it is clear that these models fail at concentrations of ASW or higher, as they frequently occur in connate brines. ${ }^{49}$ For the ionic strengths of the solutions used in this study (see Table 2.1) and for those in low salinity oil recovery tests, the Debye screening length of electrostatic interactions is typically less than $1 \mathrm{~nm}$, for the undiluted ASW it even approaches the diameter of a water molecule. Under these conditions, the classical separation of DLVO forces into van der Waals forces and electrostatic forces no longer holds. Short range chemical forces including hydration effects of both surfaces as well as the individual ions are of crucial importance in that range and the thin water film no longer behaves like a continuous bulk water layer. While the thickness of the Debye layer, according to its formal definition $\lambda_{D}=\sqrt{\frac{\epsilon_{0} \epsilon_{w} k T}{2 N_{A} e^{2} I S}}$, does indeed increase by a factor of three upon reducing the ionic strength by a factor 10 as in many low salinity EOR experiments, it remains in a range where the dominant forces are governed by short range interactions that are not captured by DLVO theory. Attributing 
the success of low salinity water flooding to electric double layer expansion is therefore in our view misleading from a conceptual perspective. In contrast, our present experiments directly demonstrate, without need to invoke any model, that the presence or absence of divalent cations has a pronounced effect on water wettability, presumable mediated by a surface bridging and complexation mechanism.

\subsection{Conclusion}

The main aim of this work was to contribute to the ongoing debate about the microscopic mechanism of LSWF for EOR in sandstone reservoirs, focusing in particular on the competing mechanisms of ion exchange versus double layer expansion. Starting from the assumption that contact angle alteration is the macroscopic manifestation of the relevant microscopic processes controlling the efficiency of LSWF, we analyzed the effect of brine composition on the contact angle of a multicomponent brine droplet. To avoid the poorly understood influences of crude oil components, we performed these experiments in ambient decane with fatty acid on mica and oxidized silicon wafers. While some specific cation effects, beyond valence, were observed, the overall effect of diluting and supplementing cation mixtures resembling those in seawater, turned out to be remarkably simple. Our experimental results in Fig. 2.5 clearly show that for mica substrates, reducing the ionic strength while keeping the divalent cation concentration constant has little effect on the wettability. Vice versa, reducing the divalent cation concentration while keeping the ionic strength constant, decreases the droplets' contact angle by tens of degrees. Straightforward dilution of artificial sea water leads essentially to the same behavior as reducing the divalent cation concentration only. In contrast, for silicon oxide surfaces, little effect of dilution on water wettability is seen. The difference between the two substrate materials is consistent with core flooding experiments that suggest a correlation between the efficiency of LSWF and clay content. The in situ fluid exchange measurements reported in Fig. 2.6 demonstrate that these conclusions hold not only for brine droplets of variable composition 
deposited onto clean solid surface, but also if the composition of a sessile droplet on an already hydrophobized substrate is gradually changed from a high salinity to a low salinity, or low divalent cation condition, in the spirit of EOR by LSWF.

Clearly one should not expect that the presented results translate one-to-one to the conditions in an actual oil reservoir, given the different thermodynamic conditions of elevated temperature and pressure, and, in particular, the much more complex composition of the oil. Nevertheless, regarding the mechanistic details of binding of acidic oil components to mineral surfaces, the present experiments do show that the expansion of the electric double layer is merely a collateral effect but not the cause of the wettability alteration. The latter seems to be driven essentially by the removal of divalent cations. 


\section{References}

1. Cordiner, F. S.; Gordon, D. T.; Jargon, J. R. Determination of Residual Oil Saturation after Waterflooding. Society of Petroleum Engineers, 1972.

2. Herminghaus, S. Universal Phase Diagram for Wetting on Mesoscale Roughness. Physical Review Letters 2012, 109 (23), 236102.

3. Sorbie, K. S.; Collins, I. A Proposed Pore-Scale Mechanism for How Low Salinity Waterflooding Works. Society of Petroleum Engineers, 2010.

4. Jung, M.; Brinkmann, M.; Seemann, R.; Hiller, T.; de la Lama, M. S.; Herminghaus, S. Wettability Controls Slow Immiscible Displacement through Local Interfacial Instabilities. Physical Review Fluids 2016, 1 (7).

5. Jackson, M.; Vinogradov, J.; Hamon, G.; Chamerois, M. Evidence, Mechanisms and Improved Understanding of Controlled Salinity Waterflooding Part 1: Sandstones. Fuel 2016, 185, 772-793.

6. Myint, P. C.; Firoozabadi, A. Thin Liquid Films in Improved Oil Recovery from Low-Salinity Brine. Current Opinion in Colloid \& Interface Science 2015, 20 (2), 105-114.

7. Sheng, J. J. Critical Review of Low-Salinity Waterflooding. Journal of Petroleum Science and Engineering 2014, 120, 216-224.

8. Tang, G.-Q.; Morrow, N. R. Influence of Brine Composition and Fines Migration on Crude Oil/Brine/Rock Interactions and Oil Recovery. Journal of Petroleum Science and Engineering 1999, 24 (2-4), 99-111.

9. Song, W.; Kovscek, A. R. Functionalization of Micromodels with Kaolinite for Investigation of Low Salinity Oil-Recovery Processes. Lab on a Chip 2015, 15 (16), 3314-3325.

10. Jensen, J.; Radke, C. Chromatographic Transport of Alkaline Buffers through Reservoir Rock. SPE reservoir engineering 1988, 3 (03), 849-856.

11. McGuire, P. L.; Chatham, J. R.; Paskvan, F. K.; Sommer, D. M.; Carini, F. H. Low Salinity Oil Recovery: An Exciting New Eor Opportunity for Alaska's North Slope. Society of Petroleum Engineers, 2005.

12. Morrow, N. R.; Tang, G. Q.; Valat, M.; Xie, X. Prospects of Improved Oil Recovery Related to Wettability and Brine Composition. Journal of Petroleum Science and Engineering 1998, 20 (3-4), 267-276.

13. Yousef, A. A.; Al-Saleh, S.; Al-Jawfi, M. S. The Impact of the Injection Water Chemistry on Oil Recovery from Carbonate Reservoirs. Society of Petroleum Engineers, 2012. 
14. Rezaeidoust, A.; Puntervold, T.; Strand, S.; Austad, T. Smart Water as Wettability Modifier in Carbonate and Sandstone: A Discussion of Similarities/Differences in the Chemical Mechanisms. Energy and Fuels 2009, 23 (9), 4479-4485.

15. Ligthelm, D. J.; Gronsveld, J.; Hofman, J.; Brussee, N.; Marcelis, F.; van der Linde, $\mathrm{H}$. Novel Waterflooding Strategy by Manipulation of Injection Brine Composition. Society of Petroleum Engineers, 2009.

16. Hilner, E.; Andersson, M.; Hassenkam, T.; Matthiesen, J.; Salino, P.; Stipp, S. The Effect of Ionic Strength on Oil Adhesion in Sandstone-the Search for the Low Salinity Mechanism. Scientific reports 2015, 5.

17. Lager, A.; Webb, K.; Black, C.; Singleton, M.; Sorbie, K. Low Salinity Oil Recovery-an Experimental Investigation. Petrophysics 2008, 49 (01).

18. Austad, T.; Rezaeidoust, A.; Puntervold, T. Chemical Mechanism of Low Salinity Water Flooding in Sandstone Reservoirs. Society of Petroleum Engineers, 2010.

19. Hirasaki, G. Wettability: Fundamentals and Surface Forces. SPE Formation Evaluation 1991, 6 (02), 217-226.

20. Stocker, I. N.; Miller, K. L.; Welbourn, R. J. L.; Clarke, S. M.; Collins, I. R.; Kinane, C.; Gutfreund, P. Adsorption of Aerosol-Ot at the Calcite/Water Interface - Comparison of the Sodium and Calcium Salts. Journal of Colloid and Interface Science 2014, 418, 140-146.

21. Mugele, F.; Bera, B.; Cavalli, A.; Siretanu, I.; Maestro, A.; Duits, M.; Cohen-Stuart, M.; van den Ende, D.; Stocker, I.; Collins, I. Ion AdsorptionInduced Wetting Transition in Oil-Water-Mineral Systems. Scientific Reports 2015, 5, 10519.

22. Israelachvili, J. N. Intermolecular and Surface Forces: Revised Third Edition; Academic press2011.

23. Lebedeva, E. V.; Fogden, A. Adhesion of Oil to Kaolinite in Water. Environmental Science \& Technology 2010, 44 (24), 9470-9475.

24. Mahani, H.; Berg, S.; llic, D.; Bartels, W.-B.; Joekar-Niasar, V. Kinetics of the Low Salinity Waterflooding Effect Studied in a Model System. Society of Petroleum Engineers, 2013.

25. Siretanu, I.; Ebeling, D.; Andersson, M. P.; Stipp, S. S.; Philipse, A.; Stuart, M. C.; Van Den Ende, D.; Mugele, F. Direct Observation of Ionic Structure at Solid-Liquid Interfaces: A Deep Look into the Stern Layer. Scientific reports 2014, 4, 4956. 
26. Bera, B.; Duits, M. H. G.; Cohen Stuart, M. A.; van den Ende, D.; Mugele, F. Surfactant Induced Autophobing. Soft Matter 2016, 12 (20), 45624571.

27. Kumar, N.; Wang, L.; Siretanu, I.; Duits, M.; Mugele, F. Salt Dependent Stability of Stearic Acid Langmuir-Blodgett Films Exposed to Aqueous Electrolytes. Langmuir 2013, 29 (17), 5150-5159.

28. Goebel, A.; Lunkenheimer, K. Interfacial Tension of the Water/NAlkane Interface. Langmuir 1997, 13 (2), 369-372.

29. Dickson, A. G.; Goyet, C. Physical and Thermodynamic Data. In Handbook of Methods for the Analysis of the Various Parameters of the Carbon Dioxide System in Sea Water., 2 ed.; Oak Ridge National Lab., TN (United States), 1994, pp 11-12.

30. Qu, D.; Suter, R.; Garoff, S. Surfactant Self-Assemblies Controlling Spontaneous Dewetting. Langmuir 2002, 18 (5), 1649-1654.

31. de Ruiter, R.; Tjerkstra, R. W.; Duits, M. H. G.; Mugele, F. Influence of Cationic Composition and $\mathrm{Ph}$ on the Formation of Metal Stearates at OilWater Interfaces. Langmuir 2011, 27 (14), 8738-8747.

32. National Center for Biotechnology Information. Pubchem Compound Database; Cid=5281. https://pubchem.ncbi.nlm.nih.gov/compound/5281 (accessed June 7, 2016).

33. Scales, P. J.; Grieser, F.; Healy, T. W. Electrokinetics of the Muscovite Mica-Aqueous Solution Interface. Langmuir 1990, 6 (3), 582-589.

34. Brzozowska, A. M.; Mugele, F.; Duits, M. H. G. Stability and Interactions in Mixed Monolayers of Fatty Acid Derivatives on Artificial Sea Water. Colloids and Surfaces A: Physicochemical and Engineering Aspects 2013, 433, 200-211.

35. De Gennes, P. G. Wetting: Statics and Dynamics. Reviews of Modern Physics 1985, 57 (3), 827-863.

36. Hirasaki, G. J. Wettability: Fundamentals and Surface Forces. 1991.

37. Cavalli, A.; Bera, B.; van den Ende, D.; Mugele, F. Analytic Model for the Electrowetting Properties of Oil-Water-Solid Systems. Physical Review $E$ 2016, 93 (4), 042606.

38. Bera, B. Ion and Surfactant Induced Wetting Transition. 2016.

39. Horinek, D.; Herz, A.; Vrbka, L.; Sedlmeier, F.; Mamatkulov, S. I.; Netz, R. R. Specific Ion Adsorption at the Air/Water Interface: The Role of Hydrophobic Solvation. Chemical Physics Letters 2009, 479 (4), 173-183. 
40. Kundu, S.; Langevin, D. Fatty Acid Monolayer Dissociation and Collapse: Effect of Ph and Cations. Colloids and Surfaces A: Physicochemical and Engineering Aspects 2008, 325 (1-2), 81-85.

41. Le Calvez, E.; Blaudez, D.; Buffeteau, T.; Desbat, B. Effect of Cations on the Dissociation of Arachidic Acid Monolayers on Water Studied by Polarization-Modulated Infrared Reflection-Absorption Spectroscopy. Langmuir 2001, 17 (3), 670-674.

42. Annapureddy, H. V. R.; Dang, L. X. Molecular Mechanism of Specific Ion Interactions between Alkali Cations and Acetate Anion in Aqueous Solution: A Molecular Dynamics Study. The Journal of Physical Chemistry B 2012, 116 (25), 7492-7498.

43. Wehn, R.; Woermann, D. Modification of the Electric Double Layer Properties of the Interface Mica/Aqueous Solution by Adsorption of Polyelectrolytes. Berichte der Bunsengesellschaft für physikalische Chemie 1986, 90 (2), 121-126.

44. Park, C.; Fenter, P. A.; Nagy, K. L.; Sturchio, N. C. Hydration and Distribution of Ions at the Mica-Water Interface. Physical Review Letters 2006, 97 (1), 016101.

45. Pastré, D.; Piétrement, O.; Fusil, S.; Landousy, F.; Jeusset, J.; David, M.-O.; Hamon, L.; Le Cam, E.; Zozime, A. Adsorption of DNA to Mica Mediated by Divalent Counterions: A Theoretical and Experimental Study. Biophysical journal 2003, 85 (4), 2507-2518.

46. Shaddel, S.; Hemmati, M.; Zamanian, E.; Moharrami, N. N. Core Flood Studies to Evaluate Efficiency of Oil Recovery by Low Salinity Water Flooding as a Secondary Recovery Process. Journal of Petroleum Science and Technology 2014, 4 (1), 47-56.

47. Drummond, C.; Israelachvili, J. Fundamental Studies of Crude OilSurface Water Interactions and Its Relationship to Reservoir Wettability. Journal of Petroleum Science and Engineering 2004, 45 (1-2), 61-81.

48. Alotaibi, M. B.; Nasralla, R. A.; Nasr-El-Din, H. A. Wettability Studies Using Low-Salinity Water in Sandstone Reservoirs. 2011.

49. Yu, L.; Buckley, J. S. Evolution of Wetting Alteration by Adsorption from Crude Oil. 1997. 



\section{3}

\section{THE EFFECT OF TEMPERATURE}

The contents of this chapter have also been published as:

'Salinity-Dependent Contact Angle Alteration in Oil/Brine/Silicate Systems: The Effect of Temperature'

M. E. J. Haagh, N. Schilderink, M.H.G. Duits, I. Siretanu, F. Mugele, and I.R. Collins;

Journal of Petroleum Science and Engineering 2018, 165, 1040-1048

Here, we explore changes of the contact angle of brine droplets on mica in ambient oil ( $\mathrm{n}$-decane plus added fatty acid) at variable temperature as a function of the concentration of mono- and divalent cations. For $20^{\circ} \mathrm{C}$ and $40^{\circ} \mathrm{C}$, we find that the contact angle decreases by up to $30^{\circ}$ with decreasing divalent cation concentration but remains constant upon decreasing the total salinity by removing only monovalent cations, i.e. upon double layer expansion at constant divalent cation concentration. At $60^{\circ} \mathrm{C}$, we find a remarkable increase of the water contact angle of artificial sea water to values of approximately $120^{\circ}$. This value decreases upon dilution to values in the range of $10-40^{\circ} \mathrm{C}$, where the lowest values are again only obtained upon removing the divalent cations. These findings corroborate the conclusion of chapter 2 (at room temperature) that divalent cations play an essential role in controlling the wettability of carboxylic acid groups to mineral surface, presumably in an ion bridging type mechanism. We also demonstrate that the contact angle reduction occurs very quickly upon flushing a sessile droplet of artificial sea water with divalent cation-free or simply diluted brine. Our experiments also demonstrate that, despite the simplicity of the present system, the origins of wettability alteration are rather complex and that synergistic effects can lead to dramatic variations such as the unexpectedly high contact angle at $60^{\circ} \mathrm{C}$. 


\subsection{Introduction}

Secondary oil recovery from subterranean oil reservoirs by water flooding is a complex multiscale process with a rather low overall efficiency. Typically, between half and two-thirds of the original oil in place is left behind by the end of the economic lifetime of the oilfield. This poor recovery efficiency is caused by a number of factors including poor reservoir sweep and pore scale effects. If we focus on the pore scale, it is clear that, given the large surface-to-volume ratios at the pore scale and the low capillary numbers typically involved in oil recovery, the pore scale oil recovery process is controlled largely by the wettability of oil and water in the simulations consistently demonstrate a substantial increase in the displacement efficiency as the contact angle of the displacing phase is decreased from somewhat above to somewhat below $90^{\circ} .1,2$ Hence, wettability alteration is a very efficient process to improve the oil recovery in the complex geometry of the porous rock. At the pore scale, the distribution of local contact angles in combination with the pore geometry provide a complex energy landscape in which the distribution of oil and water evolves under quasi-static conditions driven by the externally applied pressure gradient. Numerous experiments, simulations, and theoretical models at different levels of complexity have demonstrated that the final oil saturation of a porous medium after the invasion of a second immiscible phase (i.e., the injection water) depends very sensitively on the relative wettability of the two phases on the rock surfaces. ${ }^{3,4}$ Optimum oil recovery is usually observed at a neutral Amott wettability index, which yield relatively low water permeability and residual oil saturation. ${ }^{5}$

It is important to point out an ambiguity in terminology between physical chemists and the petroleum engineering community: in physical chemistry, 'wettability' describes a qualitative measure of the contact angle; wettability alteration is therefore equivalent to contact angle alteration. By contrast, petroleum engineers use the term wettability to express the retention capability of a porous medium in a two-phase flow displacement experiment such as the Amott wettability test; wettability in this sense is therefore a much more complex quantity that is affected by the properties of the previously mentioned complex 
energy landscape and the details of the process parameters such as sample history and flow rates. Throughout this work, we will stick to the generic terminology of physical chemistry, where wettability describes the equilibrium contact angle.

Since the mid-1960s, much empirical evidence has been gathered that shows that water flood oil recovery with brines of reduced salinity gives rise to significant increases in recovery. ${ }^{6,7}$ Various mechanisms have been proposed throughout the years to explain the success of low salinity water flooding (LSWF), including the mobilization of fines, ${ }^{8,9}$ mineral dissolution, ${ }^{9}$ surfactant formation at elevated $\mathrm{pH},{ }^{10}$ and wettability alteration. ${ }^{11,12,13}$ These mechanisms are described in more detail in the review of LSWF by Jackson et al. ${ }^{6}$ In more recent years, wettability alteration from an oil-wet state toward more water-wet state has become the predominant paradigm in the literature.6, 7, 14 Many microscopic mechanisms when viewed from a reservoir engineering perspective appear as a wettability modification. However, the actual microscopic mechanisms causing the wettability alteration are still unclear. For sandstone reservoirs, the potential mechanisms largely focus on two specific and potentially synergistic mechanisms: doublelayer expansion (DLE) arising from reducing the brine salinity, $8,15,16$ and multicomponent ion exchange (MIE). ${ }^{17}, 18$ In the MIE mechanism, divalent cations play a prominent role because they are believed to promote the binding of acidic oil components to negatively charged rock surfaces. Empirical correlations of the success of LSWF with the clay content suggest that among the rock components, clay is particularly important for these surface reactions. ${ }^{8}$ These mechanisms are underpinned by an understanding of the potential mechanisms of oil retention in reservoirs as out lined by Buckley et al. ${ }^{19,20,21,22}$ and Rueslatten et al. ${ }^{23}$ These authors suggest that the following crude oil/brine/rock interactions control the rock wettability: polar interactions, surface precipitations, acid/base interactions, and ion-binding. This is complemented by work performed on understanding how organic material is bound to clays in soils and in the rock formations of subterranean reservoirs. ${ }^{24}$ From this literature, it is clear that organic polar materials bind to minerals by four mechanisms: 
- Derjaguin-Landau-Verwey-Overbeek (DLVO) type forces consisting of electrostatic (double layer) forces and van der Waals attraction. Under most reservoir conditions there is repulsion between the two negatively charged interfaces of the oil and the rock, and therefore bonding only occurs under high salinity conditions where the double layer repulsion is suppressed and the forces are attractive.

- Ligand exchange where typically water is eliminated from a hydrolyzed oxide surface by direct bonding of acidic oxygen, or basic nitrogen moieties on the organic material. This results in a covalent bond forming between the organic and the surface.

- Cation bridging whereby a divalent cation acts as a bridge between dissociated hydroxyls groups on the mineral surface and typically carboxyl groups on the organic molecule. Calcium is by far the most potent cation in this process.

- Hydrogen bonding. Under some solution conditions strong hydrogen bonds can form between oxygen atoms on the mineral surface and electropositive hydrogen atoms on the organic molecule.

At a typical reservoir $\mathrm{pH}$ of 7 , Feng et al. find that the relative contributions to bonding at high ionic strength are: ${ }^{25}$ cation bridging > van der Waals $\gg$ ligand exchange $\gg$ hydrogen bonding. It is therefore immediately clear that DLE would lead to release of oil bound by the DLVO mechanism and that MIE would lead to release of oil bound by the cation bridging mechanism. DLE as a mechanism for LSWF has been promoted by Berg et al. ${ }^{13}$ and Ligthelm et al. ${ }^{16}$ and is supported by the work Lee et al. ${ }^{26}$ and Hilner et al. ${ }^{15}$ MIE has been supported predominantly by the work of Lager et al. ${ }^{18}$

Most measurements of the LSWF effect have been performed at temperature $<100^{\circ} \mathrm{C}$. ${ }^{6}, 14$ Early work suggested no temperature limitations to LSWF at these low temperatures. ${ }^{6}$ To the best of our knowledge, only two high temperature $\left(>100^{\circ} \mathrm{C}\right) \mathrm{LSWF}$ studies have been reported in the literature. ${ }^{27,} 28$ The work of Webb et al. ${ }^{27}$ was performed on a clay-rich sandstone reservoir core under reservoir conditions and showed good LSWF recovery whereas the work of 
Aghaeifar et al. ${ }^{28}$ was performed on an illitic sandstone core and showed variable recovery. The latter authors showed no LSWF effect at $\mathrm{T}$ $>100^{\circ} \mathrm{C}$ unless the water flood salinity was reduced to $\approx 23,000 \mathrm{ppm}$. Adsorption of organic polar components on to illite was shown to decrease as the temperature and salinity of the formation brine increases. The literature shows that kaolinite-bearing and illite-bearing sandstones respond to LSWF differently and the interplay of the clay mineralogy with temperature is poorly understood. ${ }^{29}$

The primary challenge in identifying the origin of the success of LSWF is twofold: First, core flood experiments are complex and rather indirect. In addition to surface chemistry, they depend on various other parameters, including in particular the topology of the rock, its heterogeneity and various process parameters. Second, crude oil and reservoir rock are very both complex multicomponent materials. It is therefore likely that more than one of the microscopic mechanisms mentioned above act in parallel. It is therefore very difficult - if at all possible - to identify with certainty whether a specific proposed mechanism is actually at play. In our view, this uncertainty contributes to the wide spread of observations and interpretations. To overcome these difficulties, we chose to work with highly simplified model systems and consisting of flat mica substrates, pure alkanes with a single added acidic polar component, and brines of variable composition. While such experiments cannot directly answer the question whether a proposed mechanism is dominant under condition of actual oil recovery they can at least answer the question whether one or more specific mechanisms are operative at all. A few years ago, we therefore initiated a series of experiments to evaluate the relative importance of monovalent and divalent cations, namely $\mathrm{Na}^{+}$and $\mathrm{K}^{+}$vs. $\mathrm{Mg}^{2+}$ and $\mathrm{Ca}^{2+}$, in controlling surface chemistry and surface charge as well as resulting wettability in oil-brine-mineral systems. The key findings of these experiments were the following: first, divalent cations adsorb more strongly to many mineral surfaces (mica, silica, gibbsite, kaolinite (basal planes)) than the monovalent ones. ${ }^{30,31}$ These results of AFM experiments in our group are in line with various recent $x$-ray reflectivity and surface diffraction measurements as well as numerical 
simulations. ${ }^{32}$, 33, 34 Second, we showed by macroscopic contact goniometry divalent cation adsorption renders the surfaces less water wet and more affine to fatty acids dissolved in ambient oil. ${ }^{30,35,36}$ The latter resulted in a synergetic enhancement of water-in-oil contact angles on mica of up to $70^{\circ}$ that is only observed in the presence of both divalent cations in the brine and fatty acids in the oil. The observation of monolayers of stearate layers on the substrate under these conditions supported the idea that divalent cations act as a 'glue' - presumably an ion bridge - that mediates strong binding between the acids and the mineral surface. A quantitative description of these results in terms of DLVO theory implies the presence of a thin water layer everywhere on the solid-oil interface next to the droplet, as discussed earlier by Hirasaki, ${ }^{37}$ and recently observed experimentally by neutron reflectivity ${ }^{38}$ neutron scattering, ${ }^{26}$ and imaging ellipsometry in model systems. ${ }^{30}$ All these previous experiments together point to a pivotal role of removing divalent cations to enhance water wettability. While the initial experiments all focused on single salt species present in the brine, we recently demonstrated that the same trend also holds for mixtures of chloride salts of mono- and divalent cations. ${ }^{39}$

In the present experiments, we extend our previous studies of macroscopic wettability in mica-brine-decane with stearic acid systems to brines of increased complexity, namely artificial seawater, and to variable temperatures, which we expect to change the thermodynamic equilibria in the system. To test the relative importance of the presence of divalent cations vs. the total salinity of the brine for the wettability, we perform different types of dilution, in which we vary the monovalent and divalent cation concentration independently in a temperature range from $20^{\circ} \mathrm{C}$ to $60^{\circ} \mathrm{C}$. The key question that we address is whether the predominant relevance of divalent cations for the wettability that we demonstrated earlier at room temperature persists at elevated temperatures. Moreover, we will explore whether the enhancement of the water contact angle that is induced by the divalent cation-mediated binding of fatty acids to the substrate is reversible upon removing ions from the brine droplet. 


\subsection{Experimental}

\section{Materials}

We used $n$-decane, with $100 \mu \mathrm{M}$ octadecanoic acid (stearic acid) as the oil phase. To remove most unwanted surface active components, we filtered the $n$-decane five times through a $5 \mathrm{~cm}$ column of aluminum oxide powder prior to adding stearic acid. ${ }^{40}$ The brine phase consisted of purified water (Millipore, resistivity $18.2 \mathrm{M} \Omega \mathrm{cm}$ ) in which we dissolved varying concentrations of $\mathrm{NaCl}, \mathrm{KCl}, \mathrm{CaCl}_{2} \cdot 2 \mathrm{H}_{2} \mathrm{O}$, $\mathrm{MgCl}_{2} \cdot 6 \mathrm{H}_{2} \mathrm{O}$, and $\mathrm{NaHCO}_{3}$. This solution was then brought to $\mathrm{pH} 8$ by adding $\mathrm{NaOH}$. All chemicals used were purchased from Sigma Aldrich. The solid substrate consisted of mica (muscovite) slides (B \& M Mica Co., Inc.).

Three different series of brine solutions, based on artificial seawater (ASW), were tested (Table 3.1). The first was a simple dilution series (DIL) where a 1, 2/3,1/6,1/30, and 0 fraction of ASW was mixed with water to get brines with a total dissolved solids (TDS) content of approximately $30000,20000,5000,1000$, and 0 respectively. In the other two series, the same fractions of ASW were used, but mixed with a different brine solution rather than purified water. In one series, a constant ionic strength $\left(I S=\frac{1}{2} \sum_{i} z_{i}^{2} c_{i}\right.$, where $z_{i}$ and $c_{i}$ are the concentration and valence of the $i$ th ionic species respectively) of 600 $\mathrm{mM}$ was maintained (cIS), while the divalent cation content was reduced in the same proportions as described above. In the other, a constant divalent cation concentration was maintained (cDIV), while the monovalent cations were reduced in the same proportions as in DIL, such that the ionic strength was also reduced. 
Table 3.1. Brine compositions used, and their corresponding ionic strength and total dissolved solids.

\begin{tabular}{|c|c|c|c|c|c|c|c|c|}
\hline \multirow{2}{*}{$\begin{array}{l}\text { Brine } \\
\text { Name }\end{array}$} & \multicolumn{6}{|c|}{ Ion concentration ( $m M)$} & \multirow{2}{*}{$\begin{array}{c}I S \\
(m M)\end{array}$} & \multirow{2}{*}{$\begin{array}{c}\lambda_{D} \\
(m M)\end{array}$} \\
\hline & $\mathrm{Na}+$ & $\mathrm{K}+$ & $\mathrm{Ca} 2+$ & $\mathrm{Mg} 2+$ & $\mathrm{Cl}-$ & $\mathrm{HCO} 3-$ & & \\
\hline ASW & 404 & 10 & 10 & 52 & 536 & 2 & 600 & 0.4 \\
\hline DIL 2/3 & 269 & 6.67 & 6.67 & 34.7 & 357 & 1.33 & 400 & 0.49 \\
\hline DIL $1 / 6$ & 67.3 & 1.67 & 1.67 & 8.67 & 89.3 & 0.33 & 100 & 0.97 \\
\hline DIL 1/30 & 13.5 & 0.33 & 0.33 & 1.73 & 17.9 & 0.07 & 20 & 2.2 \\
\hline DIL 0 & 0 & 0 & 0 & 0 & 0 & 0 & 0 & $>300$ \\
\hline $\operatorname{cIS} 2 / 3$ & 465 & 11.5 & 6.67 & 34.7 & 556 & 2.3 & 600 & 0.4 \\
\hline cIS $1 / 6$ & 555 & 13.7 & 1.67 & 8.67 & 587 & 2.75 & 600 & 0.4 \\
\hline cIS $1 / 30$ & 580 & 14.3 & 0.33 & 1.73 & 595 & 2.87 & 600 & 0.4 \\
\hline cIS 0 & 586 & 14.5 & 0 & 0 & 597 & 2.9 & 600 & 0.4 \\
\hline $\operatorname{cDIV} 2 / 3$ & 269 & 6.67 & 10 & 52 & 399 & 1.33 & 462 & 0.45 \\
\hline cDIV 1/6 & 67.3 & 1.67 & 10 & 52 & 193 & 0.33 & 255 & 0.61 \\
\hline cDIV 1/30 & 13.5 & 0.33 & 10 & 52 & 138 & 0.07 & 200 & 0.69 \\
\hline cDIV 0 & 0 & 0 & 10 & 52 & 124 & 0 & 186 & 0.71 \\
\hline
\end{tabular}

\section{Wettability Measurements}

We used the same techniques as described in our previous work, with an added temperature control system. A cuvette containing oil and a mica slide was covered with a sheet copper casing to promote even heat distribution and placed in a small windowed chamber on top of a temperature control unit (TFC 100Pro). This unit was heated by water pumped through a water bath (Fig. 3.1). Through a hole in the top of the chamber, a $2 \mu \mathrm{l}$ drop was deposited on the mica surface. Contact angles were determined from optical images recorded using a contact angle goniometer (Dataphysics OCA 20L) and the accompanying SCA software. For each condition, we averaged the contact angle over 20 measurements from unique droplets. All contact angles reported 
throughout this manuscript are contact angles measured in the water phase. They are directly related to the corresponding contact angles in the oil phase by $\theta_{\text {oil }}=180^{\circ}-\theta_{\text {water }}$. In Fig. 3.2, we demonstrate for a specific example that this relation indeed holds in our system. Note that recording water-in-oil drops rather than oil-in-water has two practical advantages: first of all buoyancy facilitates water-in-oil measurements when the solid substrate in on the bottom of the chamber. Secondly and more importantly, in asymmetric partial wetting situation with one phase wetting the substrate better than the other, equilibration is much easier to achieve using the better wetting phase as the drop phase, i.e. for water droplets in oil in our experiments. For oil droplets in water in the presence of fatty acids, it is easy to entrap a metastable water layer underneath the oil droplet, which separates the oil from the substrate in a secondary minimum of the free energy landscape and induces erroneously small apparent water contact angles. This conclusion follows directly from the complex shapes of disjoining pressure curves is systems like ours, as discussed in detail by the work by Hirasaki. ${ }^{41}$

For all ASW dilutions, at 20,40 , and $60^{\circ} \mathrm{C}$, we also measured the oil/water interfacial tension by capturing pendant drop snapshots, and using the SCA software to extract the interfacial tension. All mentioned soft- and hardware was obtained from DataPhysics Instruments $\mathrm{GmbH}$. The densities of the brine and oil phases, which are required to calculate the interfacial tension from the droplet contours, were respectively: calculated using an equation of state for seawater, ${ }^{42}$ and taken from experimental data. ${ }^{43}$ 


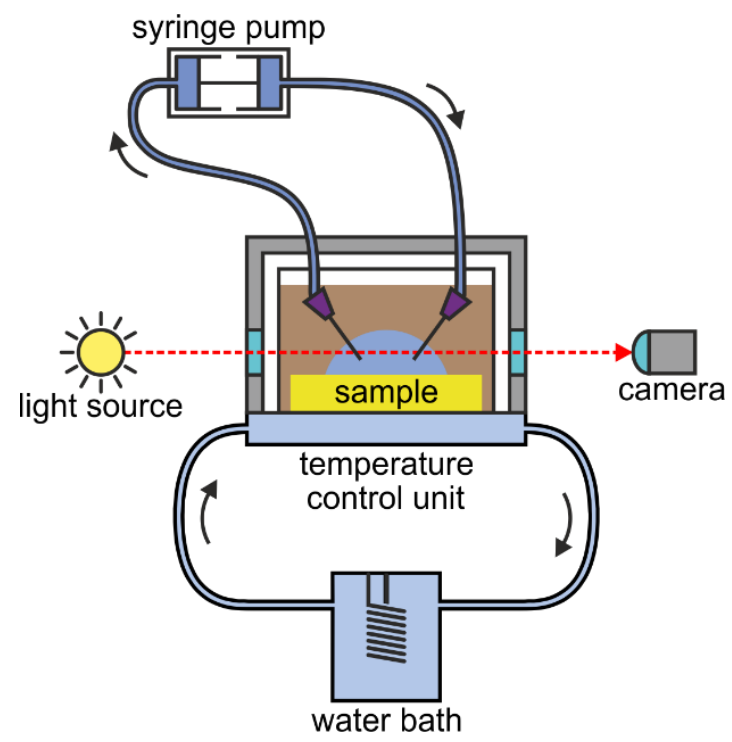

Figure 3.1. Schematic of the experimental setups used for contact angle measurements and fluid exchange at elevated temperatures.

This system was also used for dynamic, fluid exchange experiments. For these experiments, two needles, ending in thin glass capillaries (100 $\mu \mathrm{m}$ inner and $170 \mu \mathrm{m}$ outer diameter; VitroCom) were inserted into the droplet, and left for a minute to allow them to heat up to the experimental temperature. The needles were connected to a push/pull syringe pump (Fig. 3.1) that was used to exchange to droplet fluid at $10 \mu \mathrm{l} / \mathrm{min}$ for 15 minutes, in a droplet with a total volume of 20 $\mu 1$. The mica substrate was, only in these experiments, pretreated beforehand to ensure full coverage of a stearic acid monolayer. This was done by depositing a larger, $200 \mu$ droplet, which was then extracted at $50 \mu \mathrm{l} / \mathrm{min}$. In doing this, the contact line of this droplets had moved over the entire substrate, which results in the deposition of a self-assembled monolayer of $\mathrm{Ca} / \mathrm{Mg}$-bridged stearic acid. ${ }^{30,44}$ 

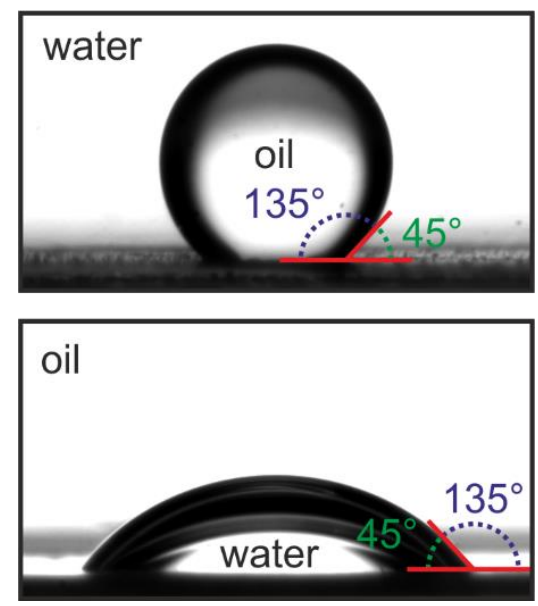

Figure 3.2. Snapshots comparing an $A S W(p H 8)$ droplet in ambient oil ( $n$ decane $+100 \mu M$ stearic acid), and an oil droplet in ambient ASW.

\subsection{Results}

\section{General Behavior}

We measured contact angles of ASW-based brine droplets to investigate the combined effect of temperature and salinity on the water-wettability of mica in an ambient $n$-decane phase. The brine droplets followed the similar behavior upon deposition as described in our previous work: rapid spreading in less than a second, followed by a slower contact line retraction to a higher contact angle within a few tens of seconds. The latter contact angle is reported as the final contact angle $\left(\theta_{f}\right)$ in the following. The contracting behavior has been termed autophobing. ${ }^{44}$ For our system, it has been explained with the transfer of stearic acid from the contact line to the mica surface. ${ }^{35,}{ }^{39}$ Cations, most prominently divalent species, can bind the negatively charged carboxylate group to the negatively charged mica surface. ${ }^{36,39}$ An oilin-ASW drop spreads instead of retracts, leading to a water contact angle outside the drop of $\approx 45^{\circ}$ (Fig. 3.2). This shows that we can assume the contact angles we measure are independent of which phase we choose to be the droplet phase. 
Droplets of ASW showed a clear, non-monotonic temperature dependence (Fig. 3.3). A minimum contact angle is reached at close to $40^{\circ} \mathrm{C}$, and a dramatic rise in contact angle is observed at higher temperatures (Fig. 3.4). We found a clear divide in autophobing kinetics between droplets at $40^{\circ} \mathrm{C}$ or lower, and those at higher temperatures. The former behaved, as described above, by contracting over the course of tens of seconds. The latter started out the same, and reached contact angles of $\approx 40^{\circ}$ after such a timespan, but continued to contract at a very slow pace, only reaching their final contact angles of $>100^{\circ}$ after around 15 minutes. We've found that, by omitting $\mathrm{NaHCO}_{3}$ from the brine, this second, slower, autophobing phase did not occur, and that when $\mathrm{CaCl}_{2}$ was omitted its effects were greatly reduced (supplementary information, Table 3.S1). We also studied a low salinity droplet variant of 30x diluted ASW (Fig. $3.3 \&$ \& 3.4). These showed lower contact angles, but followed qualitatively a similar temperature dependence as the pure ASW droplets, with two important differences. Firstly, the minimum at $40^{\circ} \mathrm{C}$ almost reaches $0^{\circ}$. It should be noted that complete wetting was not observed; well defined droplets could still be observed, but the contact angles were too low to measure. Secondly, above $40^{\circ} \mathrm{C}$ the aforementioned dramatic rise in contact angle and slow behavior were not observed. This discrepancy at higher temperatures results in a contact angle difference of up to $100^{\circ}$ between high and low salinity droplets. 


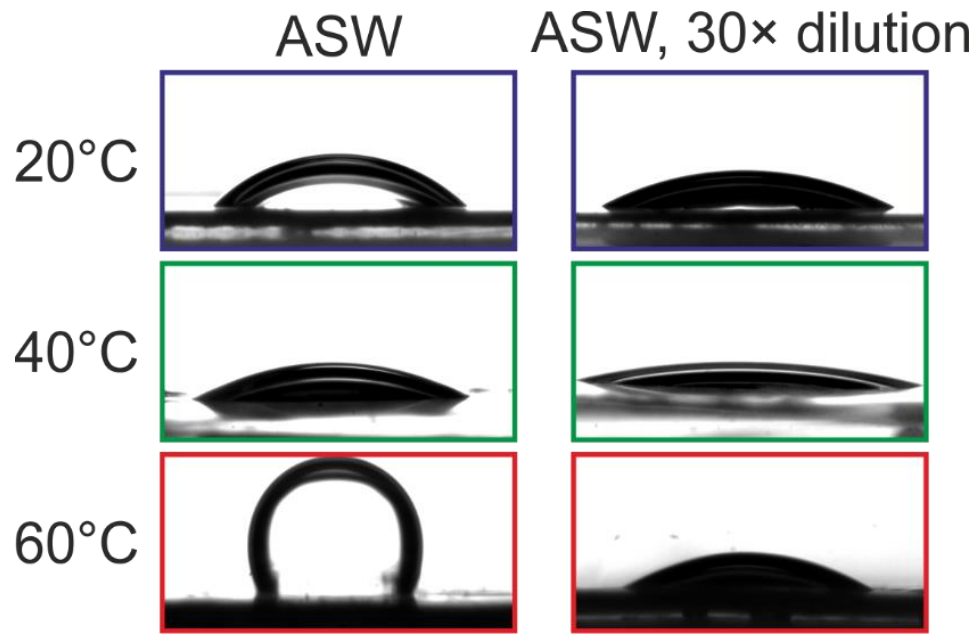

Figure 3.3. Final conformations of brine droplets in oil with $100 \mu \mathrm{M}$ stearic acid at varying temperatures and brine compositions: artificial seawater (ASW, pH 8), and $30 \times$ diluted ASW.

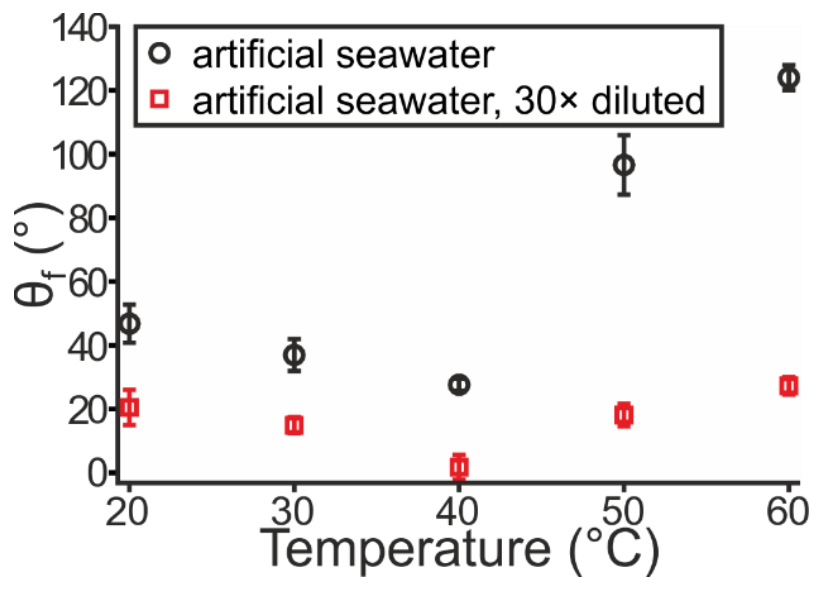

Figure 3.4. Final contact angles for $A S W(p H 8)$ droplets, in ambient oil with $100 \mu M$ stearic acid, showing the dependence on temperature. 


\section{Modified Artificial Seawater}

To investigate the effects of brine compositions, we have performed three ASW-based series of measurements: DIL, cIS, and cDIV (Table 3.1). Droplets in the DIL series (Fig. 3.5) consistently showed a lower contact angle at lower salinities, and the extent of contact angle reduction was strongly temperature dependent. At $20^{\circ} \mathrm{C}$ the contact angle decreases monotonically with increasing dilution from $\approx 45^{\circ}$ to $<2^{\circ}$. Temperatures of $40^{\circ} \mathrm{C}$ caused lower contact angles for the whole series. Here the contact angles start at $\approx 25^{\circ}$ and already reach $<2^{\circ}$ at a $30 \times$ dilution. At $60^{\circ} \mathrm{C}$ leads to an increase in the contact angles, i.e. a change in the opposite direction. These changes are so large that in most cases the contact angles become higher than they were at $20^{\circ} \mathrm{C}$. The effect is particularly dramatic for the highest salt concentrations, where contact angles of $\approx 125^{\circ}$ were reached. These were reached by the slow autophobing process mentioned earlier. For the other dilutions at $60^{\circ} \mathrm{C}$ the changes were less dramatic.

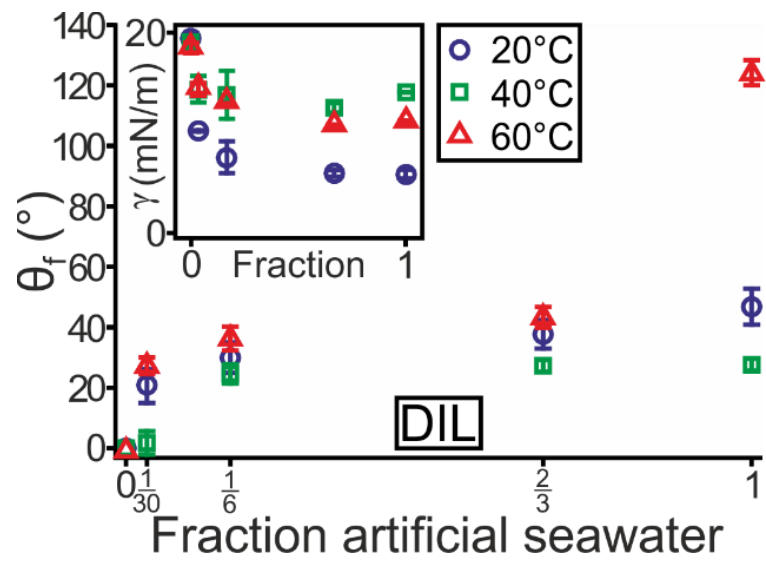

Figure 3.5. Final contact angles for simple dilution (DIL) scenario at varying temperatures. All brine droplets were at $\mathrm{pH} 8$, and the oil phase contains 100 $\mu M$ stearic acid.

To examine the origin of the temperature-induced changes in contact angle, we also measured the oil/water interfacial tensions ( $\gamma_{\mathrm{ow}}$ ) for the DIL series at the three temperatures. These data, presented in the 
inset of Fig. 3.5, show a dependence on both concentration and temperature as well. The interfacial tensions generally exhibit a decrease as the salinity is increased. The same salinity dependent trends were found by de Ruiter et al., ${ }^{45}$ and similarly, Brzozowska et al. ${ }^{46}$ have shown that stearic acid more strongly adsorbs to the oil/water interface at higher salinities. The $\gamma_{\text {ow }}$ values measured at 40 and $60^{\circ} \mathrm{C}$ lie close together (with a maximum difference of around $3 \mathrm{mN} / \mathrm{m}$ ) and are higher than the ones at $20^{\circ} \mathrm{C}$. It is noteworthy that the trends in $\gamma_{\text {ow }}$ alone are clearly insufficient for understanding the contact angle changes.

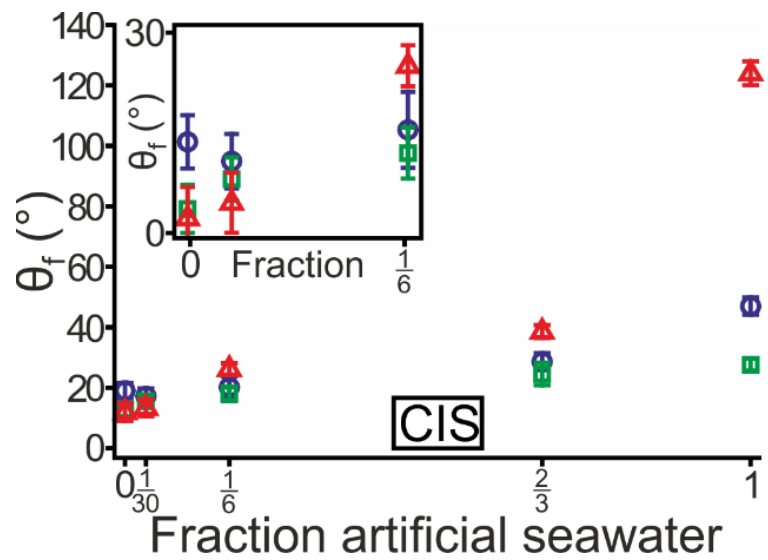

Figure 3.6. Final contact angles for a constant ionic strength (cIS) scenario at varying temperatures. All brine droplets were at $\mathrm{pH} 8$, and the oil phase contains $100 \mu \mathrm{M}$ stearic acid.

The cIS series (Fig. 3.6) showed the same quantitative trends as the DIL series at moderate dilution. But for stronger dilutions, two opposing shifts in contact angle occur. At $6 \times$ dilutions the contact angles are shifted down by about $10^{\circ}$, but for completely diluted solutions (the ' 0 ' data in the graphs, which stands for purified water in DIL and a purely monovalent-cation-salt brine in cIS) all contact angles are shifted up by 10 to $20^{\circ}$. Intermediate behavior is observed at $30 \times$ dilutions: the $20^{\circ} \mathrm{C}$ contact angles were the same as for DIL, at $40^{\circ} \mathrm{C}$ they shifted up by about $10^{\circ}$, and at $60^{\circ} \mathrm{C}$ they shifted down by about $5^{\circ}$. The temperature profile shifts as well at higher dilution factors. It 
starts, as in the DIL series, with a minimum contact angle at $40^{\circ} \mathrm{C}$, and transforms into a monotonic contact angle decrease with increasing temperature at $30 \times$ and complete dilutions.

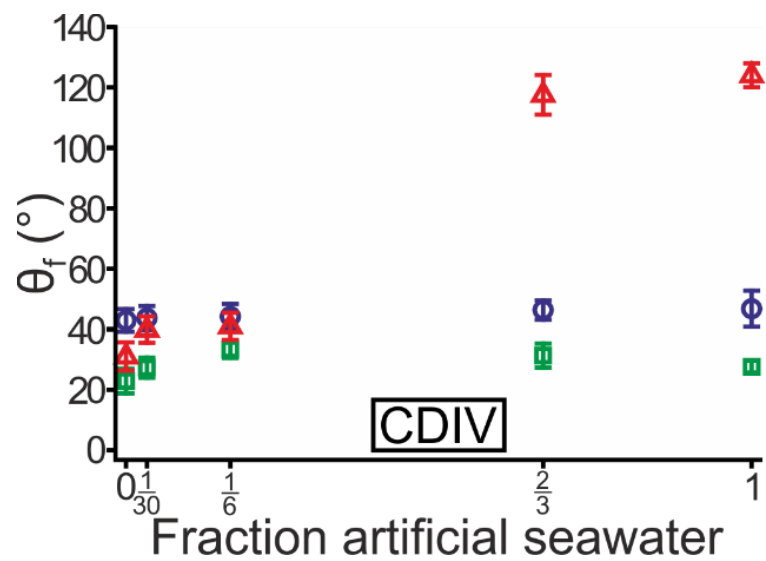

Figure 3.7. Final contact angles for a constant divalent cation concentration $(c D I V)$ scenario at varying temperatures. All brine droplets were at $\mathrm{pH} 8$, and the oil phase contains $100 \mu M$ stearic acid.

In contrast to the other two dilution scenarios, the contact angles of the cDIV series (Fig. 3.7) display a rather weak salinity dependence at 20 and $40^{\circ} \mathrm{C}$ temperature. At $20^{\circ} \mathrm{C}$ the contact angles are constant regardless of composition. At $40^{\circ} \mathrm{C}$ we found a slight salinity dependence. The average contact angle rose from $\approx 25^{\circ}$ to $\approx 30^{\circ}$ between ASW and the $6 \times$ dilution, and then sank again down to $\approx 20^{\circ}$ at a purely divalent-cation-salt brine. At $60^{\circ} \mathrm{C}$, however, we observed a stronger salinity dependence with two levels. At low dilutions we found a high contact angle level of $\approx 125^{\circ}$, which moved to a lower level of $\approx 30-40^{\circ}$ at $6 \times$ and $30 \times$ higher degrees of dilution.

In Fig. 3.8, we compare side-by-side the contact angle reductions for 30x dilution for the three different series (DIL, cIS, cDIV). The cDIV scenario, with the highest divalent cation concentrations, has the highest contact angle for all temperatures. cIS has the highest monovalent cation concentrations, and has the lowest contact angles, except for the somewhat irregular case of $40^{\circ} \mathrm{C}$. The cIS series also has 
the weakest temperature dependence, showing no significant trend at the $30 \times$ dilution condition.

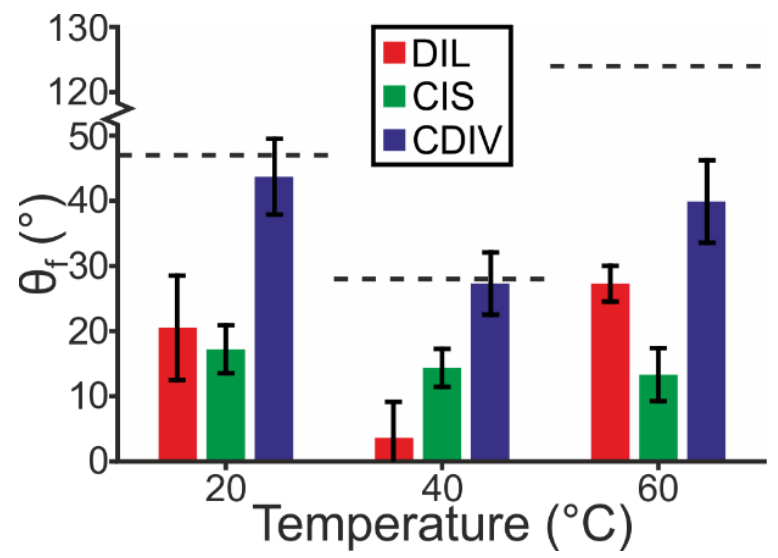

Figure 3.8. Final contact angles for different scenarios, $30 \times$ diluted. Red: simple dilution (DIL); green: constant ionic strength (cIS); blue: constant divalent cation concentration (cDIV). Dashed horizontal lines indicate final contact angles of pure artificial seawater droplets.

\section{Single Droplet Fluid Exchange}

In the experiments described above, the brine drops are deposited onto pristine surfaces of mica that are in contact with the ambient decane but not covered by surface-bound polar organic material in the initial state. This layer only forms in the course of the autophobing process, as described above and by Bera et al. ${ }^{35}$ During the actual oil recovery process, the solid surface has been exposed to crude oil for a long time and is therefore likely to be covered by a pre-existing layer of surfacebound polar oil components, which is desorbed during LSWF. Therefore, we should be able to desorb a stearate layer from mica by exposing it to low salinity water. In our previous work, we reported that this is indeed possible at room temperature for various types of salt solutions on a layer of acidic polar organic compounds. To test whether this is also the case for ASW dilutions at variable temperature, we pretreated the mica mica surfaces to form a self-assembled monolayer of $\mathrm{Ca} / \mathrm{Mg}$ stearate, as described in the experimental section, and performed 
so-called 'fluid exchange' experiments in which we changed the composition of sessile brine drops while keeping the volume constant. We started with ASW droplets deposited on stearate-pretreated mica substrates, and tracked their contact angle as we flushed the droplets (Fig. 3.9A) with: (i) purified water to represent the DIL series; (ii) a constant ionic strength brine without divalent cations to represent the cIS series; (iii) a constant divalent cation brine with no monovalent cations to represent the cDIV series. Initially, all drops display a high contact angle upon deposition without any autophobing. This is the expected consequence of the pretreatment, since a stearate monolayer is already present and does not need to be formed. There is some spread in the initial contact angle data, which we attribute to a certain imperfection and residual heterogeneity of the pretreatment. Upon exchanging the fluid, both the DIL and cIS showed a strong contact angle decrease over time (Fig. 3.9B). The cDIV droplet was seemingly unaffected by the reduction of its monovalent cation content, and retained an almost constant contact angle. The fact that the final contact angle at the highest dilutions is higher in the fluid exchange measurements as compared to the static experiments is presumably owing to the pretreatment of the substrates with stearate in the fluid exchange experiments. 


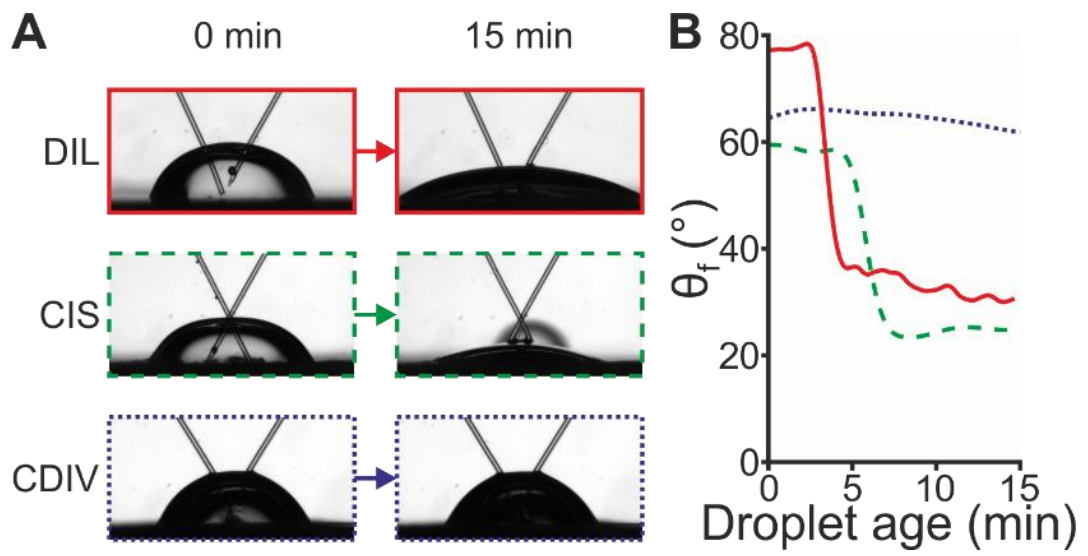

Figure 3.9. Single droplet fluid exchange for different scenarios Red continuous lines: simple dilution (DIL); green dashed lines: constant ionic strength (cIS); blue dotted lines: constant divalent cation concentration $(c D I V)$. a) Snapshots before and after 15 minutes of exchange. b) Contact angles during exchange.

\subsection{Discussion}

\section{Underlying Mechanisms}

The primary goal of the present study was to identify the underlying mechanism for wettability alteration in a simple oil/brine/silicate systems at elevated temperatures. In all experiments, the simple dilution series (DIL) and the dilution series with constant ionic strength (cIS) yield lower contact angles than the one with a constant divalent cation content (cDIV). In other words, reducing the $\mathrm{Ca}^{2+}$ and $\mathrm{Mg}^{2+}$ content reduces the contact angle while reducing the ionic strength by dilution has little effect. This suggests that indeed divalent cation bridging rather than EDL expansion is the primary cause of the observed wettability alteration at temperatures up to $40^{\circ}$. At higher temperatures this effect is diminished, but reducing the divalent cation content remains the most effective to alter the wettability. It should also be noted that for all brines, even for the $30 \times$ diluted ASW, the Debye screening length (according to the definition: $\lambda_{D}=\sqrt{\frac{\varepsilon_{0} \varepsilon_{W} k T}{2 N_{A} e^{2} I S}}$ remains in the order of one 
to two nanometers (see Table 3.1). This is the same order as that of the hydrated cations in our system, which, according to Volkov et al., ${ }^{47}$ have diameters of around 0.7 to $0.9 \mathrm{~nm}$. At these length-scales conventional EDL models do not accurately capture the short-range interactions. Therefore, it should not come as surprising that EDL expansion plays no significant role in this system.

The lower contact angles observed in the cIS series as compared to DIL at $6 \times$ and $30 \times$ dilution suggest that higher concentrations of monovalent cations can even contribute to a reduction of the water contact angle. In this sense a 'thinner' EDL can even be beneficial for enhancing water wettability. As we suggested in our previous work, this observation could be caused by the competition between monovalent and residual divalent cations in the ion-mediated binding process. Recently, Kobayashi et al. ${ }^{33}$ performed molecular dynamics (MD) simulations to model cation-mediated binding between mica and a carboxyl group in ambient aqueous electrolyte. According to their simulations, $\mathrm{Na}^{+}$and $\mathrm{Mg}^{2+}$ provide weak binding involving bridging water molecules. In contrast, $\mathrm{K}^{+}$and $\mathrm{Ca}^{2+}$ form very strong direct ion bridges between mica and deprotonated carboxyl groups reproducing some of the key findings of Mugele, Bera et al. ${ }^{30}$

However, the present experiments also display several unexpected features, which illustrate that the present understanding of the wettability alteration process is still incomplete, even for a simple model system as the present one. First, the absolute value of the water contact angles displays a curious minimum around $40^{\circ} \mathrm{C}$. Secondly, $\theta_{f}$ increases to very large values beyond $120^{\circ}$ at $60^{\circ} \mathrm{C}$. Moreover, the transition to these very large contact angles is accompanied by the appearance of a second much longer time scale of autophobing. At present, we do not have convincing explanations for these observations. Yet, a few general remarks and some specific speculations are in order.

First of all, it is well-known that hydration of both the mineralelectrolyte interfaces and the ions play a very important role in adsorption phenomena. A prominent example highlighting the role of hydration is the strong adsorption of $\mathrm{Ca}^{2+}$ and $\mathrm{Mg}^{2+}$ ions on the positively charged basal plane of gibbsite. ${ }^{31}$ In that system, short range 
forces mediated by shared hydration water between the substrate and the divalent cations supersedes the repulsive long range electrostatic forces. Hydrogen bridging between adjacent cations has also been shown to provide an attractive forces that promote the adsorption of heavier alkali cations on mica. ${ }^{48}$ Similarly, $\mathrm{x}$-ray reflectivity measurements, ${ }^{49}, 50$ surface $\mathrm{x}$-ray diffraction measurements, ${ }^{51}$ and a large variety of MD simulations confirm the presence and ordered hydration water at mica-electrolyte interfaces and its relevance for ion adsorption. ${ }^{32,34,52,53}$ All these findings suggest the presence of multiple competing adsorption configurations.

All these complex reactions involve hydration water and are likely to depend strongly on temperature. For instance, Katz et al. ${ }^{54}$ consistently found in a combined macroscopic titration and MD study an increased adsorption of divalent cations on gibbsite and an increasing preference for inner shell adsorption with increasing temperature. This process is believed to be driven by the gain in entropy as hydration water is released upon inner shell adsorption. While the overall degree of hydration of both the ions and the surface decreases with increasing temperature, its effect on bulk hydration of $\mathrm{Ca}^{2+}$ and $\mathrm{Mg}^{2+}$ is rather limited within the relatively narrow temperature range we investigated here. ${ }^{55,56}$ Nevertheless, it seems plausible that the complex competition between different processes might be at the origin of the observed non-monotonic temperature dependence of the contact angle.

Regarding the strong increase of the water contact angle at elevated temperatures, we note that this effect is consistent with various studies of rock wettability under crude oil. Several authors consistently reported increasing brine contact angles with increasing temperature attributed this observation to more pronounced adsorption of organic compounds, ${ }^{57,58,59}$ this could be caused by an increased ion adsorption to the substrate/water interface, as discussed above. Indeed, the mica water interface is known to become increasingly charged at higher temperatures, ${ }^{60}$ which is consistent with more ion adsorption. For the present model system, we propose the following specific scenario to explain our observations: we know that the intrinsic water contact angle 
of the oil/brine/mica system in the presence of divalent cations but in the absence of surface active stearic acid is at most of the order of $10^{\circ} .{ }^{30}$ Upon adding stearic acid, the characteristic contact angle increases to values of $30^{\circ}$ to $60^{\circ}$ owing to $\mathrm{pH}$-dependent divalent cation-mediated binding of stearate to the mica surface. This self-assembled surfacebound $\mathrm{Ca}$-stearate layer renders the mica surface more hydrophobic and gives rise to the enhanced water contact angle. Yet, absolute contact angles of $30^{\circ}$ to $60^{\circ}$ are lower than expected for a water-in-oil contact angle on a dense monolayer of hydrocarbons. Values of $\theta_{f} \approx 120^{\circ}$ as we observe them at $60^{\circ} \mathrm{C}$ are much more common for a dense selfassembled hydrocarbon monolayer. ${ }^{61}$ We've also shown that both $\mathrm{Ca}^{2+}$ and $\mathrm{HCO}_{3}{ }^{-}$need to be present in the brine to yield contact angles $>100^{\circ}$. This could be due to the stabilizing effect that potentially precipitated $\mathrm{CaCO}_{3}$ might have on the stearate monolayer, ${ }^{62}$ which could facilitate the formation of the aforementioned dense hydrophobic layers. I investigate this possibility in more detail in chapter 4 of this thesis.

\section{Relevance For Enhanced Oil Recovery}

Even though our system is very simplistic, it is still useful to translate our findings to what they would mean for LSWF. The choice of a simple model system allow to draw rather firm conclusions regarding the origin of the wettability alteration for the species investigated, namely, the binding of acidic oil components to silicate surfaces such as mica. The physical chemistry of actual oil recovery systems is obviously much more complex: sandstone rocks contain many types of minerals and clays, crude oil contains many types of polar components both acidic and basic, and the rock geometry is very complex and the thermodynamic conditions involve higher temperature and pressures than studied here. Therefore, the absolute values of our measurements cannot be used to predict the wettability at reservoir conditions, only the qualitative trends may.

We can look more specifically into what is currently known about the effects of the relevant parameters (e.g. type of substrate, contents of crude oil, and higher temperatures) on both the macroscopic wettability as well as the microscopic mechanisms. This knowledge can then be used to predict how well the qualitative trends we observed would hold 
up at reservoir conditions, and what that would imply for oil recovery. On the substrate side, we believe that our conclusion is rather generally valid. We demonstrated earlier that, just as in our current system, the adsorption of fatty acids is promoted by the presence of $\mathrm{Ca}^{2+}$ ions on both silica and the basal plane of gibbsite. ${ }^{63}$ The latter is representative of one of the facets of kaolinite, which is a common clay in rocks that display LSWF. ${ }^{64}$ As argued by Jackson et al., ${ }^{6}$ this indicates that the dependence on the specific type of clay is weaker than is sometimes assumed in the literature. Other polar oil components will of course bind in a different manner and may therefore be affected in a different manner by the brine composition. For instance, nitrogen-containing bases are expected to bind directly to a negatively charged silicate surface, and therefore to show a weaker response to salinity reduction. ${ }^{65}$ Generally, the simultaneous presence of several polar organic molecules should lead to poorer packing and more disordered adsorbed organic films. ${ }^{46}$ Taking this effect into account, the range of contact angle variation achieved upon divalent cation removal is expected to be smaller than it is in the present system. Yet, a smaller range than the tens of degrees of contact angle variation reported here is not necessarily a problem when concerning oil recovery. Substantial effects on the recovery rate are already expected for much weaker contact angle variations. Theoretical predictions and experimental observations suggest that in porous structures, ${ }^{1,2,3,4}$ a relatively small alteration in microscopic wetting properties can bring about a filling transition of the water phase. At higher temperatures than those used in our system the adsorption of organics can become even stronger, as reported in measurements with crude oil. ${ }^{22}$ Only at very high temperatures (> $100^{\circ} \mathrm{C}$ ) thermal energy is expect to cause desorption of organics, favoring water wettability. ${ }^{28}$. Pressure, on the other hand, seems to play a minor role. To the best of our knowledge, Xie et al. are the only to investigate the relation between LSWF effectiveness and pressure, and reported that it is negligible compared to its relation with temperature and salinity. ${ }^{58}$ Therefore, the qualitative wettability trends we observed in our system are expected to hold, yet diminished, at reservoir conditions. 
From the perspective of LSWF, the most important result of the present work is that our earlier conclusion that the removal of divalent cations is more important for improving water wettability than decreasing the overall salinity still holds up to temperatures of $60^{\circ}$. Another interesting finding in our experiments is that the lowest water contact angle at elevated temperature for a $30 \times$ dilution, typical of LSWF, is obtained for the constant ionic strength dilution series, see Fig. 7. It is not clear whether this observation is transferrable to actual LSWF oil production. If so, it would be very beneficial because water softening is less costly than desalination and because keeping high $\mathrm{NaCl}$ concentrations would reduce the risk of clay swelling and mobilization of fines. Despite earlier opposite conclusions, some recent experiments with spontaneous imbibition tests indeed suggest that this might be a viable strategy. ${ }^{66}$

\subsection{Conclusion}

The aim of our work was to investigate the underlying mechanisms of wettability alteration in a simplified oil/brine/silicate system containing fatty acids and the effects that temperature has on it. To this end, we have used contact angles as a macroscopic manifestation of water wettability and its underlying mechanisms. For all temperatures, the final water contact angles achieved upon diluting the artificial sea water in various manners were lowest for the scenarios in which divalent cations were removed. Reducing only the total salinity by removing the monovalent cations while keeping the divalent cation concentration constant results always resulted in higher contact angles. This suggests that the prominent role of divalent cations in binding carboxylates to mineral surfaces that was demonstrated earlier for pure salt solutions also holds for artificial sea water containing several ionic species at the same time.

At $20^{\circ} \mathrm{C}$ and $40^{\circ} \mathrm{C}$, the typical water contact angle reductions upon diluting the divalent cations are from $30-50^{\circ}$ down to $10-20^{\circ}$. As summarized in Fig. 3.8, at these lower temperatures decreasing the salinity by decreasing the monovalent cation concentration has no measurable effect on the contact angle at all. This demonstrates that the 
mere 'expansion of the double layer' is not relevant for the wettability, within the accessible range of Debye lengths from 0.4 to $2.2 \mathrm{~nm}$. At $60^{\circ} \mathrm{C}$, however, a substantial increase of the water contact angles to values around $120^{\circ}$ is observed in pure ASW. The mechanism underlying this additional contact angle increase is explored in further detail in chapter 4 , and involves the incorporation of $\mathrm{CaCO}_{3}$ into the hydrophobic layer, leading to an increase in coverage.

Notwithstanding these uncertainties, we also demonstrated the reversibility of the observed contact angle variations by showing that the initially high contact angle of a divalent cation containing brine droplet can be reduced in situ by exchanging the drop content with brine of lower divalent ion concentration (Fig. 3.9), mimicking the conditions of a tertiary water flooding experiment, in which the salinity of preexisting brine droplets is reduced. 


\section{References}

1. Jung, M.; Brinkmann, M.; Seemann, R.; Hiller, T.; de La Lama, M. S.; Herminghaus, S. Wettability Controls Slow Immiscible Displacement through Local Interfacial Instabilities. Physical Review Fluids 2016, 1 (7), 074202.

2. Singh, K.; Scholl, H.; Brinkmann, M.; Di Michiel, M.; Scheel, M.; Herminghaus, S.; Seemann, R. The Role of Local Instabilities in Fluid Invasion into Permeable Media. Scientific Reports 2017, 7.

3. Herminghaus, S. Universal Phase Diagram for Wetting on Mesoscale Roughness. Physical Review Letters 2012, 109 (23), 236102.

4. Sorbie, K. S.; Collins, I. A Proposed Pore-Scale Mechanism for How Low Salinity Waterflooding Works. Society of Petroleum Engineers, 2010.

5. Jadhunandan, P. P.; Morrow, N. R. Effect of Wettability on Waterflood Recovery for Crude-Oil/Brine/Rock Systems. SPE Reservoir Engineering (Society of Petroleum Engineers) 1995, 10 (1), 40-46.

6. Jackson, M.; Vinogradov, J.; Hamon, G.; Chamerois, M. Evidence, Mechanisms and Improved Understanding of Controlled Salinity Waterflooding Part 1: Sandstones. Fuel 2016, 185, 772-793.

7. Sheng, J. J. Critical Review of Low-Salinity Waterflooding. Journal of Petroleum Science and Engineering 2014, 120, 216-224.

8. Tang, G.-Q.; Morrow, N. R. Influence of Brine Composition and Fines Migration on Crude Oil/Brine/Rock Interactions and Oil Recovery. Journal of Petroleum Science and Engineering 1999, 24 (2-4), 99-111.

9. Song, W.; Kovscek, A. R. Functionalization of Micromodels with Kaolinite for Investigation of Low Salinity Oil-Recovery Processes. Lab on a Chip 2015, 15 (16), 3314-3325.

10. McGuire, P. L.; Chatham, J. R.; Paskvan, F. K.; Sommer, D. M.; Carini, F. H. Low Salinity Oil Recovery: An Exciting New Eor Opportunity for Alaska's North Slope. Society of Petroleum Engineers, 2005.

11. Morrow, N. R.; Tang, G. Q.; Valat, M.; Xie, X. Prospects of Improved Oil Recovery Related to Wettability and Brine Composition. Journal of Petroleum Science and Engineering 1998, 20 (3-4), 267-276.

12. Tang, C. Y.; Allen, H. C. Ionic Binding of $\mathrm{Na}+$ Versus $\mathrm{K}+$ to the Carboxylic Acid Headgroup of Palmitic Acid Monolayers Studied by Vibrational Sum Frequency Generation Spectroscopy. The Journal of Physical Chemistry A 2009, 113 (26), 7383-7393. 
13. Berg, S.; Cense, A.; Jansen, E.; Bakker, K. Direct Experimental Evidence of Wettability Modification by Low Salinity. Petrophysics 2010, 51 (05).

14. Al-Shalabi, E. W.; Sepehrnoori, K. A Comprehensive Review of Low Salinity/Engineered Water Injections and Their Applications in Sandstone and Carbonate Rocks. Journal of Petroleum Science and Engineering 2016, 139, 137-161.

15. Hilner, E.; Andersson, M.; Hassenkam, T.; Matthiesen, J.; Salino, P.; Stipp, S. The Effect of Ionic Strength on Oil Adhesion in Sandstone-the Search for the Low Salinity Mechanism. Scientific reports 2015, 5.

16. Ligthelm, D. J.; Gronsveld, J.; Hofman, J.; Brussee, N.; Marcelis, F.; van der Linde, $\mathrm{H}$. Novel Waterflooding Strategy by Manipulation of Injection Brine Composition. Society of Petroleum Engineers, 2009.

17. Austad, T.; Rezaeidoust, A.; Puntervold, T. Chemical Mechanism of Low Salinity Water Flooding in Sandstone Reservoirs. Society of Petroleum Engineers, 2010.

18. Lager, A.; Webb, K.; Black, C.; Singleton, M.; Sorbie, K. Low Salinity Oil Recovery-an Experimental Investigation. Petrophysics 2008, 49 (01).

19. Buckley, J.; Liu, Y.; Monsterleet, S. Mechanisms of Wetting Alteration by Crude Oils. SPE journal 1998, 3 (01), 54-61.

20. Buckley, J.; Morrow, N. In Characterization of Crude Oil Wetting Behavior by Adhesion Tests, SPE/DOE Enhanced Oil Recovery Symposium, 1990; Society of Petroleum Engineers.

21. Buckley, J.; Takamura, K.; Morrow, N. Influence of Electrical Surface Charges on the Wetting Properties of Crude Oils. SPE Reservoir Engineering 1989, 4 (03), 332-340.

22. Buckley, J. S.; Liu, Y.; Xie, X.; Morrow, N. R. Asphaltenes and Crude Oil Wetting-the Effect of Oil Composition. SPE journal 1997, 2 (02), 107-119.

23. Rueslatten, H.; Hjelmeland, O.; Selle, O. Wettability of Reservoir Rocks and the Influence of Organo-Metallic Compounds. North Sea oil and gas reservoir 1994, 3, 317-324.

24. Philippe, A.; Schaumann, G. E. Interactions of Dissolved Organic Matter with Natural and Engineered Inorganic Colloids: A Review. Environmental science \& technology 2014, 48 (16), 8946-8962. 
25. Feng, X.; Simpson, A. J.; Simpson, M. J. Chemical and Mineralogical Controls on Humic Acid Sorption to Clay Mineral Surfaces. Organic Geochemistry 2005, 36 (11), 1553-1566.

26. Lee, S. Y.; Webb, K. J.; Collins, I.; Lager, A.; Clarke, S.; apos; Sullivan, M.; Routh, A.; Wang, X. Low Salinity Oil Recovery: Increasing Understanding of the Underlying Mechanisms. Society of Petroleum Engineers, 2010.

27. Webb, K.; Black, C.; Edmonds, I. In Low Salinity Oil Recovery-the Role of Reservoir Condition Corefloods, IOR 2005-13th European Symposium on Improved Oil Recovery, 2005.

28. Aghaeifar, Z.; Strand, S.; Austad, T.; Puntervold, T.; Aksulu, H.; Navratil, K.; Storås, S.; Håms $\varnothing$, D. Influence of Formation Water Salinity/Composition on the Low-Salinity Enhanced Oil Recovery Effect in High-Temperature Sandstone Reservoirs. Energy \& Fuels 2015, 29 (8), 47474754.

29. Brady, P. V.; Krumhansl, J. L. A Surface Complexation Model of OilBrine-Sandstone Interfaces at $100{ }^{\circ} \mathrm{C}$ : Low Salinity Waterflooding. Journal of Petroleum Science and Engineering 2012, 81, 171-176.

30. Mugele, F.; Bera, B.; Cavalli, A.; Siretanu, I.; Maestro, A.; Duits, M.; Cohen-Stuart, M.; van den Ende, D.; Stocker, I.; Collins, I. Ion AdsorptionInduced Wetting Transition in Oil-Water-Mineral Systems. Scientific Reports 2015, 5, 10519.

31. Siretanu, I.; Ebeling, D.; Andersson, M. P.; Stipp, S. S.; Philipse, A.; Stuart, M. C.; Van Den Ende, D.; Mugele, F. Direct Observation of Ionic Structure at Solid-Liquid Interfaces: A Deep Look into the Stern Layer. Scientific reports 2014, 4, 4956.

32. Kobayashi, K.; Liang, Y.; Murata, S.; Matsuoka, T.; Takahashi, S.; Nishi, N.; Sakka, T. Ion Distribution and Hydration Structure in the Stern Layer on Muscovite Surface. Langmuir 2017, 33 (15), 3892-3899.

33. Kobayashi, K.; Liang, Y.; Murata, S.; Matsuoka, T.; Takahashi, S.; Amano, K.-i.; Nishi, N.; Sakka, T. Stability Evaluation of Cation Bridging on Muscovite Surface for Improved Description of Ion-Specific Wettability Alteration. The Journal of Physical Chemistry C 2017, 121 (17), 9273-9281.

34. Bourg, I. C.; Lee, S. S.; Fenter, P.; Tournassat, C. Stern Layer Structure and Energetics at Mica-Water Interfaces. The Journal of Physical Chemistry $C$ 2017, 121 (17), 9402-9412. 
35. Bera, B.; Duits, M. H. G.; Cohen Stuart, M. A.; van den Ende, D.; Mugele, F. Surfactant Induced Autophobing. Soft Matter 2016, 12 (20), 45624571.

36. Kumar, N.; Wang, L.; Siretanu, I.; Duits, M.; Mugele, F. Salt Dependent Stability of Stearic Acid Langmuir-Blodgett Films Exposed to Aqueous Electrolytes. Langmuir 2013, 29 (17), 5150-5159.

37. Hirasaki, G. J. Wettability: Fundamentals and Surface Forces. 1991.

38. Stocker, I. N.; Miller, K. L.; Welbourn, R. J.; Clarke, S. M.; Collins, I. R.; Kinane, C.; Gutfreund, P. Adsorption of Aerosol-Ot at the Calcite/Water Interface-Comparison of the Sodium and Calcium Salts. Journal of colloid and interface science 2014, 418, 140-146.

39. Haagh, M. E. J.; Siretanu, I.; Duits, M. H. G.; Mugele, F. SalinityDependent Contact Angle Alteration in Oil/Brine/Silicate Systems: The Critical Role of Divalent Cations. Langmuir 2017, 33 (14), 3349-3357.

40. Goebel, A.; Lunkenheimer, K. Interfacial Tension of the Water/NAlkane Interface. Langmuir 1997, 13 (2), 369-372.

41. Hirasaki, G. Wettability: Fundamentals and Surface Forces. SPE Formation Evaluation 1991, 6 (02), 217-226.

42. Millero, F. J.; Chen, C.-T.; Bradshaw, A.; Schleicher, K. A New High Pressure Equation of State for Seawater. Deep Sea Research Part A. Oceanographic Research Papers 1980, 27 (3), 255-264.

43. Banipal, T. S.; Garg, S. K.; Ahluwalia, J. C. Heat Capacities and Densities of Liquid N-Octane, N-Nonane, N-Decane, and N-Hexadecane at Temperatures from $318.15 \mathrm{~K}$ to $373.15 \mathrm{~K}$ and at Pressures up to $10 \mathrm{Mpa}$. The Journal of Chemical Thermodynamics 1991, 23 (10), 923-931.

44. Qu, D.; Suter, R.; Garoff, S. Surfactant Self-Assemblies Controlling Spontaneous Dewetting. Langmuir 2002, 18 (5), 1649-1654.

45. de Ruiter, R.; Tjerkstra, R. W.; Duits, M. H. G.; Mugele, F. Influence of Cationic Composition and $\mathrm{Ph}$ on the Formation of Metal Stearates at OilWater Interfaces. Langmuir 2011, 27 (14), 8738-8747.

46. Brzozowska, A. M.; Mugele, F.; Duits, M. H. G. Stability and Interactions in Mixed Monolayers of Fatty Acid Derivatives on Artificial Sea Water. Colloids and Surfaces A: Physicochemical and Engineering Aspects 2013, 433, 200-211. 
47. Volkov, A.; Paula, S.; Deamer, D. Two Mechanisms of Permeation of Small Neutral Molecules and Hydrated lons across Phospholipid Bilayers. Bioelectrochemistry and Bioenergetics 1997, 42 (2), 153-160.

48. Ricci, M.; Spijker, P.; Voïtchovsky, K. Water-Induced Correlation between Single lons Imaged at the Solid-Liquid Interface. 2014, 5, 4400.

49. Schlegel, M. L.; Nagy, K. L.; Fenter, P.; Cheng, L.; Sturchio, N. C.; Jacobsen, S. D. Cation Sorption on the Muscovite (001) Surface in Chloride Solutions Using High-Resolution X-Ray Reflectivity. Geochimica et Cosmochimica Acta 2006, 70 (14), 3549-3565.

50. Lee, S. S.; Fenter, P.; Nagy, K. L.; Sturchio, N. C. Real-Time Observation of Cation Exchange Kinetics and Dynamics at the MuscoviteWater Interface. 2017, 8, 15826.

51. Pintea, S.; de Poel, W.; de Jong, A. E. F.; Vonk, V.; van der Asdonk, P.; Drnec, J.; Balmes, O.; Isern, H.; Dufrane, T.; Felici, R.; Vlieg, E. Solid-Liquid Interface Structure of Muscovite Mica in Cscl and Rbbr Solutions. Langmuir 2016, 32 (49), 12955-12965.

52. Bourg, I. C.; Sposito, G. Molecular Dynamics Simulations of the Electrical Double Layer on Smectite Surfaces Contacting Concentrated Mixed Electrolyte ( $\mathrm{Nacl}-\mathrm{Cacl} 2)$ Solutions. Journal of Colloid and Interface Science 2011, 360 (2), 701-715.

53. Schwierz, N.; Horinek, D.; Netz, R. R. Anionic and Cationic Hofmeister Effects on Hydrophobic and Hydrophilic Surfaces. Langmuir 2013, 29 (8), 2602-2614.

54. Katz, L. E.; Criscenti, L. J.; Chen, C.-C.; Larentzos, J. P.; Liljestrand, H. M. Temperature Effects on Alkaline Earth Metal Ions Adsorption on Gibbsite: Approaches from Macroscopic Sorption Experiments and Molecular Dynamics Simulations. Journal of Colloid and Interface Science 2013, 399, 6876.

55. Afanasiev, V. N.; Ustinov, A. N. Solvation of Magnesium Chloride and Sulfate in Aqueous Solutions at 278.15-323.15 K. Journal of Structural Chemistry 2008, 49 (5), 881-888.

56. Zavitsas, A. A. Aqueous Solutions of Calcium lons: Hydration Numbers and the Effect of Temperature. The Journal of Physical Chemistry $B$ 2005, 109 (43), 20636-20640.

57. Alotaibi, M. B.; Nasralla, R. A.; Nasr-El-Din, H. A. Wettability Studies Using Low-Salinity Water in Sandstone Reservoirs. 2011. 
58. Xie, Q.; Brady, P. V.; Pooryousefy, E.; Zhou, D.; Liu, Y.; Saeedi, A. The Low Salinity Effect at High Temperatures. Fuel 2017, 200, 419-426.

59. Yu, L.; Buckley, J. S. Evolution of Wetting Alteration by Adsorption from Crude Oil. 1997.

60. Arif, M.; Jones, F.; Barifcani, A.; Iglauer, S. Electrochemical Investigation of the Effect of Temperature, Salinity and Salt Type on Brine/Mineral Interfacial Properties. International Journal of Greenhouse Gas Control 2017, 59, 136-147.

61. Grate, J. W.; Dehoff, K. J.; Warner, M. G.; Pittman, J. W.; Wietsma, T. W.; Zhang, C.; Oostrom, M. Correlation of Oil-Water and Air-Water Contact Angles of Diverse Silanized Surfaces and Relationship to Fluid Interfacial Tensions. Langmuir 2012, 28 (18), 7182-7188.

62. Maas, M.; Rehage, H.; Nebel, H.; Epple, M. A Detailed Study of Closed Calcium Carbonate Films at the Liquid-Liquid Interface. Langmuir 2009, 25 (4), 2258-2263.

63. Wang, L.; Siretanu, I.; Duits, M. H. G.; Stuart, M. A. C.; Mugele, F. Ion Effects in the Adsorption of Carboxylate on Oxide Surfaces, Studied with Quartz Crystal Microbalance. Colloids and Surfaces A: Physicochemical and Engineering Aspects 2016, 494, 30-38.

64. Kahr, G.; Madsen, F. T. Determination of the Cation Exchange Capacity and the Surface Area of Bentonite, Illite and Kaolinite by Methylene Blue Adsorption. Applied Clay Science 1995, 9 (5), 327-336.

65. Soraya, B.; Malick, C.; Philippe, C.; Bertin, H. J.; Hamon, G. Oil Recovery by Low-Salinity Brine Injection: Laboratory Results on Outcrop and Reservoir Cores. Society of Petroleum Engineers, 2009.

66. Nicolini, J. V.; Ferraz, H. C.; Borges, C. P. Effect of Seawater Ionic Composition Modified by Nanofiltration on Enhanced Oil Recovery in Berea Sandstone. Fuel 2017, 203, 222-232. 


\section{S Supplementary Information}

Table 3.S1. Contact angles of ASW based brines measured at $60^{\circ} \mathrm{C}$, showing the effects of omitting specific salts.

\begin{tabular}{cccccc}
\hline \multicolumn{7}{c}{ Salt concentration $(m M)$} & & Contact \\
$\mathrm{NaCl}$ & $\mathrm{KCl}$ & $\mathrm{CaCl}_{2}$ & $\mathrm{MgCl}_{2}$ & $\mathrm{NaHCO}_{3}$ & angle $\left(^{\circ}\right)$ \\
\hline 402 & 10 & 10 & 52 & 2 & 128 \\
0 & 0 & 10 & 0 & 2 & 113 \\
0 & 0 & 0 & 52 & 2 & 76 \\
402 & 10 & 10 & 52 & 0 & 31 \\
\hline
\end{tabular}




\section{4}

\section{CARBONATE EFFECT AT ELEVATED TEMPERATURE}

The contents of this chapter have also been published as:

'Wetting of Mineral Surfaces by Fatty-Acid-Laden Oil and Brine:

Carbonate Effect at Elevated Temperature'

M. E. J. Haagh, N. Schilderink, F. Mugele, and M.H.G. Duits;

Energy \& Fuels 2019, 33, 10, 9446-9456

We investigate in more detail a specific effect found in chapter 3: that $2 \mathrm{mM}$ bicarbonate (typical for seawater brines) has a strong influence at temperatures above $40^{\circ} \mathrm{C}$ (as in reservoirs), yielding water contact angles in ambient oil with stearic acid up to $160^{\circ}$. In this chapter, we found similar behavior for a variety of carboxylic acids. On increasing the (even) carbon number of simple fatty acids from 8 to 20, the contact angle becomes larger until it saturates at 16 carbon atoms. Similar hydrophobic layers are formed by pulling a sheet of mica through an oil/water interface at comparable velocities. By studying these dipcoated samples with AFM imaging, SEM, XPS and Raman spectroscopy, we can infer that the adsorbed layer is composed of alternating carboxylic acid bilayers, that are held together by a very thin intermediate layer containing calcium and (bi)carbonate ions. Exposure to low salinity water makes the multilayers disappear and the mineral surface become water-wet again, demonstrating that the presence of these structures can lead to a strong salinity-dependent wettability alteration. 


\subsection{Introduction}

Oil recovery from sandstone reservoirs by seawater flooding, also known as secondary water flooding, is an inefficient process, as typically 60 to $80 \%$ of the oil is left in the reservoir at the end of its economic lifetime. ${ }^{1}$ Significant improvements in oil recovery have been achieved by a tertiary low salinity water flooding (LSWF). ${ }^{2,3}$ Yet in spite of many core flooding experiments, it remains challenging to predict how much incremental oil can be obtained from a given reservoir using a certain flooding water composition. The reasons for this are manifold. Inherently, experiments on rock cores are not well suited to identify the pore- and mineral scale mechanisms underlying the LSWF effect, due to the difficult (optical) access. ${ }^{4}$ Also the complexity of the system in which oil release takes place, plays a major role. Rock, oil and brine typically have rich compositions, leading to a variety of (competing) interactions. Besides that, significant variations occur in geometry, oil/brine/rock chemistry and thermodynamic parameters within and between experiments. Because of these experimental and interpretive hurdles, a conclusive evidence of how LSWF works cannot be provided by core flooding experiments alone. Based on such experiments, it was possible to conclude that an improved water wettability of the sandstone is a key element of the low salinity effect. 5, 6,7 However, the details of this wettability alteration remain elusive.

A more comprehensive understanding of the low salinity effect could be obtained from direct observations of either the wettability alteration or of changes in the (chemistry of) microscopic films covering the rock. Each of these approaches still requires circumvention of problems: the lack of optical access to the rock in the former case, and the overwhelming chemical complexity of the fluids (in particular the oil) in the latter case. The challenge therefore lies in finding a model system that in spite of its simplified nature, can still capture the key elements which govern the wettability aspects. In the current work, we use brines and oils with simplified compositions and well-defined smooth mineral substrates to capture key elements of wettability changes. We combine macroscopic contact angle measurements with 
microscopic characterizations of modified mineral surfaces, and examine the link between the behaviors at these two length scales.

Several previous works followed this approach by studying the wetting of model mineral (mica and silica) substrates by droplets of simplified brine (1-4 dissolved salts) in an ambient of stearic acid laden alkane oil, at room temperature. In these model systems the wettability was found to depend strongly on the divalent cation concentration, ${ }^{8}$ and hardly on the ionic strength. ${ }^{9}$ The key role of the divalent cations was linked to their well-known tendency to bind to carboxylate groups, thereby forming organometallic complexes. ${ }^{10}$ Such (positively charged) complexes are known to adsorb on negatively charged solid/brine interfaces; ${ }^{11,12}$ a behavior that was confirmed in wetting experiments with brine droplets on the mica and silica substrates. ${ }^{13}$ Here, organic monolayers of (calcium) stearate were found around the contact line of droplets that contained $\mathrm{Ca}^{2+} .8,13$ Flushing such droplets with calciumdepleted brines led to removal of the adsorbed layers, ${ }^{9,} 14$ thereby revealing the reversible nature of the layer formation. Taking these various findings together, it appears that these model systems -in spite of their simplicity- are able to reproduce they key elements of wettability alteration via LSWF: the presence of an initial adsorbed organic layer, that showed an increased water wettability on exposure to 'low salinity' water.

However, the existing studies on this model system are still hampered by significant shortcomings. One of them is that the far majority of experiments was done at room temperature (RT). It is important to study effects of salinity on wettability also at elevated temperatures, since reservoir temperatures at intermediate depths typically range from 50 to $120^{\circ} \mathrm{C}{ }^{15}$ This recently prompted us to perform a first study on layer formation by fatty acids (using simple brines and oils) at temperatures up to $60^{\circ} \mathrm{C} .{ }^{14}$ In that work the divalent cation concentration was found to remain important for wettability. Additionally for $\mathrm{T} \geq 50^{\circ} \mathrm{C}$ a remarkable increase in water contact angle (from $30^{\circ}$ to $>120^{\circ}$ ) was observed, suggesting a change in the structure and/or composition of the adsorbing organo-metallic layer. This drastic effect required the additional presence of bicarbonate ions (at low 
concentrations as in seawater). The origin of this synergistic effect of bicarbonate ions and elevated temperature has however remained unclear. From biomineralization literature it is known that at room temperature templated growth of $\mathrm{CaCO}_{3}$ on carboxylate terminated monolayers is common, ${ }^{16,17}$ and that in this manner composite layers of fatty acids and $\mathrm{CaCO}_{3}$ can form. ${ }^{18}$ However, in wetting studies at room temperature, adding carbonate ions to the brine did not produce the strong wettability alteration. Hence it remains to be elucidated what type of hydrophobic layer gets formed, and how.

Another shortcoming of the model systems used so far is the oversimplified oil composition. Crude oils are well known to contain a large number of components, including several classes of compounds which show surface-activity: acidic, basic and aromatic ones. Even restricting to the acidic compounds, a range of carboxylic acids remains to be considered: saturated/unsaturated, aromatic, linear/branched. Changes in the molecular architecture of the hydrophobic chain could change the adsorption and self-assembly at the mineral/brine interface (and similarly for mixtures of carboxylic acids). Such effects have been studied for layers formed at brine/air interfaces, ${ }^{19,} 20$ but not systematically for carboxylic acids deposited directly on solid substrates by a moving contact line in a brine/oil/mineral system.

In the present paper we improve the model system along both lines (elevated temperature and enhanced oil complexity), and examine the ensuing changes in physico-chemical behavior. Using contact angle measurements, we study the effect of bicarbonate in brine droplets (in ambient oil with palmitic acid) on the wettability of mica and silica at temperatures up to $60^{\circ} \mathrm{C}$. Additionally, to examine the influence of the oil-dissolved molecules on the wetting properties, we explored several other carboxylic acids at high temperature. To better understand how the macroscopic wetting originates from the chemical and topographical structure at the microscale, we complement the contact angle measurements on brine drops with a microscopic imaging of the layers left behind by them, using atomic force microscopy (AFM). Additionally, we examine layers formed under a better control over the 
contact line velocity, via experiments where the mineral substrates are pulled across the brine/oil contact line.

\subsection{Experimental}

\section{Materials}

All chemicals are reaction grade and were purchased from Sigma. As oil phase we used $n$-decane, purified by flushing it $5 \times$ through a $5 \mathrm{~cm}$ column of aluminum oxide powder, removing most surface active impurities (verified by the surface tension decreasing $<0.1 \mathrm{mN} / \mathrm{m}$ per hour after treatment). ${ }^{21} \mathrm{~A}$ single type of carboxylic acid (C6=hexanoic acid, C8, C10, C12, C13, C14, C15, C16, C17, C18, C20, oleic acid, or 12-phenyl dodecanoic acid) was then dissolved in it at concentrations of $0.1 \mathrm{mM}, 1 \mathrm{mM}$, or $10 \mathrm{mM}$. The brine phase was made by dissolving $10 \mathrm{mM} \mathrm{CaCl} 2$ and $2 \mathrm{mM} \mathrm{NaHCO}_{3}$ in deionized water (Millipore, resistivity $18.2 \mathrm{M} \Omega \mathrm{cm}$ ), similar to their concentrations in seawater. It was then brought to the $\mathrm{pH}$ of choice at room temperature, by adding small amounts of $0.1 \mathrm{M} \mathrm{NaOH}$ or $\mathrm{HCl}$. As solid substrate we used sheets of the mica mineral muscovite (B \& M Mica Co., Inc.), or amorphous silica in the form of fused quartz (SPI Supplies). Clean mica surfaces were prepared by cleaving them right before submerging them in the oil, which results in an atomically smooth surface on a scale of hundreds of $\mu \mathrm{m}$ 's. ${ }^{22}$ Quartz substrates were cleaned by sonicating them for 10 minutes in a detergent solution (Mucasol, Sigma Aldrich), then in deionized water, and lastly in an ethanol and isopropanol 1:1 mixture. The sheets were then dried with nitrogen and cleaned in a UV ozone cleaner (BioForce Nanosciences, Inc.) for 15 minutes.

\section{Wettability Measurements}

Contact angles were measured from the water phase using a contact angle goniometer (Dataphysics OCA 20L, schematically shown in Fig. 4.1A) with droplet dispensing unit. The steel needle of the latter was filled with brine solution at RT $\left(20 \pm 1{ }^{\circ} \mathrm{C}\right)$, and immersed in a glass cuvette (Hellma Analytics) filled with oil at the measurement temperature. After a dwell time of 1 minute to allow thermal equilibration, the experiment was started by depositing a $2 \mu \mathrm{L}$ drop on the sample sheet. For elevated temperature measurements the cuvette 
was fitted with a copper casing and placed inside a windowed temperature control chamber (Dataphysics TFC 100Pro) which was heated from below by circulating water. The temperature was verified by a mercury thermometer in the oil. Due to the spontaneous evolution of the droplet shape (see below), advancing or receding contact angles could not be measured. Instead, we report (besides some transient data) the final contact angle of the droplet; i.e. after it had stopped receding. For each condition, final contact angles were measured and averaged over 20 separate droplets, with typically 3 to 5 droplets per pristine substrate, placed a few mm apart to prevent interaction.

Additional water contact angle measurements (in the same setup) were performed while the droplet composition was changed using a (mechanically gentle) fluid exchange technique which was earlier demonstrated. ${ }^{9}{ }^{14}$ Briefly, $20 \mu 1$ droplets were deposited by hand using a pipette at $60^{\circ} \mathrm{C}$. After the droplet had reached the final contact angle, two capillaries $(100 / 170 \mu \mathrm{m}$ inner/outer diameter, VitroCom) connected to a push-pull syringe pump (Legato, KD Scientific) were inserted, to exchange the brine with deionized water at $20 \mu \mathrm{l} / \mathrm{min}$, while keeping the droplet volume constant. The outlet needle was positioned close to the substrate, to extract the initial high-salinity phase preferentially. Since some mixing between the defending and invading liquids still takes place, the droplet volume was exchanged about 20 times.

\section{Surface Characterization}

Besides these droplet deposition experiments, we also exposed substrates to a forced moving contact line (Fig. 4.1B). The aim of the latter was to get a more homogeneous distribution of the deposited layers. These experiments were carried out in heated water bath. After thermal equilibration of the brine and oil in separate vials (in the same bath) for 30 minutes, the oil was carefully added to the brine. Hereafter the substrate slide was immersed, and the experiment started within 5 minutes. The substrate was pulled, at constant speed, through the oil/brine interface by a clamp attached to a motorized travel stage (Thorlabs). 


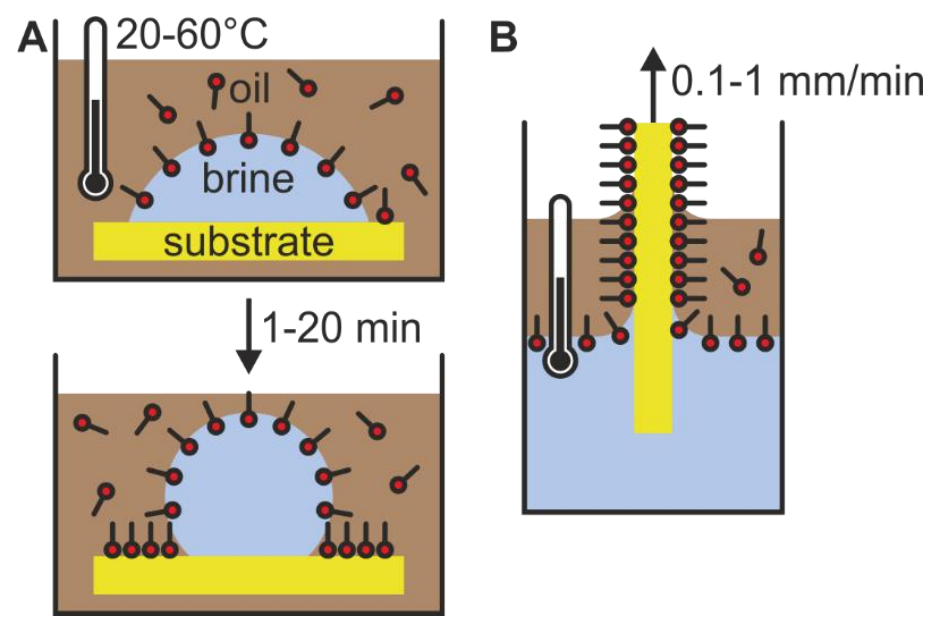

Figure 4.1. Schematics of setups for contact angle measurements (A), and dipcoating (B).

After the droplet deposition or dip-coating experiment, the sheet was taken out of the oil, and residual oil and water were blown off with nitrogen, such that no visible liquid remained on the substrate. Next, these sheets were dried with nitrogen, and kept in a nitrogen atmosphere until they were analyzed. AFM imaging was performed using amplitude modulation (20 $\mathrm{nm}$ amplitude, set point at $18 \mathrm{~nm}$ ) in air using NSC36 cantilevers (MikroMasch) in a Bruker Dimension Icon. SEM imaging was done using a Zeiss MERLIN HR-SEM. XPS measurement were performed using a PHI Quantera SXM. Confocal Raman spectroscopy was performed using a Witec alpha300 R, where each spectrum was averaged over 1500 accumulations at the same location with an integration time of $1 \mathrm{~s}$ per accumulation.

\section{Speciation Calculations}

Bulk speciation of the ions dissolved in the brine was determined using Visual MINTEQ 3.1, which performs equilibrium calculations using a database with all common equilibrium reaction constants for variable temperatures. To be consistent with our experimental procedure, we first calculated the amount of strong acid/base needed to reach the experimental $\mathrm{pH}$ as set at $20^{\circ} \mathrm{C}$. Then while keeping this composition 
fixed, we calculated the equilibrium speciation at varying temperatures. Equilibration with $\mathrm{CO}_{2}$ from the air was not taken into account, since we suppressed this in the experiments by not letting the brine phase age, and measuring under oil (see above). In most calculations, also precipitation was not taken into account. The exception was the $\mathrm{pH}$, which was calculated both with and without $\mathrm{CaCO}_{3}$ precipitation allowed, for comparative purposes. Further justification for neglecting $\mathrm{CO}_{2}$ equilibration and precipitation was obtained from ageing experiments (discussed in the SI, Fig. 4.S1) which showed no visible precipitation and negligible $\mathrm{pH}$ change during the timescale of our experiments.

\subsection{Results}

\section{Wetting Behavior}

To examine the wetting behavior, we placed droplets of brine onto mica sheets submerged in $n$-decane containing palmitic acid (C16), and measured water contact angles. A universal behavior was observed: regardless of the explored temperature, $\mathrm{pH}$ and liquid composition, the drops spread to contact angles of $\approx 10^{\circ}$ in about 1 second, and then retracted to higher contact angles over the course of 1 to 20 minutes. This 'self-hydrophobizing' phenomenon, also termed 'autophobing', ${ }^{23}$ has been described in detail for similar oil/brine/mineral systems at room temperature. ${ }^{8}$ It arises when amphiphilic molecules (here organometallic complexes), are formed at the brine/oil interface, get transported along that interface, and subsequently get deposited on the solid by the three-phase contact line. The retracting contact line then leaves behind a hydrophobic layer in the oil, while on the water side the hydrophilic substrate remains bare (see also Fig. 4.1A). Divalent cations and a sufficiently high $\mathrm{pH}$ in the brine are required for this effect to take place: the formation of the organo-metallic complexes requires deprotonation of the fatty acids, while the divalent cations that replace the protons also facilitate the subsequent binding to mica or silica substrates. Higher concentrations of the cations lead to a further increase of the contact angle. ${ }^{8}$ 
The effects of temperature and bicarbonate ions on the contact angle were examined using mica substrates and oil with $0.1 \mathrm{mM} \mathrm{C16}$. To avoid any possible $\mathrm{pH}$ effects, all solutions (with and without added bicarbonate) were adjusted to $\mathrm{pH} 8$, at room temperature (RT), shortly before the measurement. Results are shown in Fig. 4.2A. For the droplets without added bicarbonate, the autophobing effect is weak, resulting in water contact angles of about $20^{\circ}$. This is likely due to the low concentration of $\mathrm{CaCl}_{2}(10 \mathrm{mM})$ used, in comparison to earlier work. ${ }^{8}$ Without bicarbonate we also do not perceive any significant effect of temperature on the wetting properties. In contrast, in presence of $2 \mathrm{mM} \mathrm{NaHCO} 3$ in the brine, contact angles are markedly increased and continue to rise with increasing temperature: up to $150^{\circ}$ at $60^{\circ} \mathrm{C}$.

We also observe a change in the autophobing kinetics in presence of added bicarbonate: whereas it takes about 1 minute for droplets below $40^{\circ} \mathrm{C}$ to reach a stable conformation, at higher temperatures that time increases to about 20 minutes (Fig. 4.2B). The diameter of the droplets is $\approx 2 \mathrm{~mm}$ at maximal spreading, therefore the contact line moves with an average speed of $\approx 0.1 \mathrm{~mm} / \mathrm{min}$ (it starts out faster, and slows down over time). We observed that, when $1 \mathrm{mM} \mathrm{C} 16$ is present in the oil (instead of $0.1 \mathrm{mM}$ ), the final contact angle remains the same, but the contact line speed is increased about 10 times.

We also investigated the effects of the initial $\mathrm{pH}$ of the brine phase. The high contact angle found at $60^{\circ} \mathrm{C}$ appears to persist as the droplet $\mathrm{pH}$ gets lowered to 6.5 (Fig. 4.3A): it still reaches a value of about $120^{\circ}$. At $\mathrm{pH} 6$ the droplets only reach contact angles of about $40^{\circ}$, but a slow autophobing still occurs (Fig. 4.3B), meaning that there is still some effect of the bicarbonate present. 

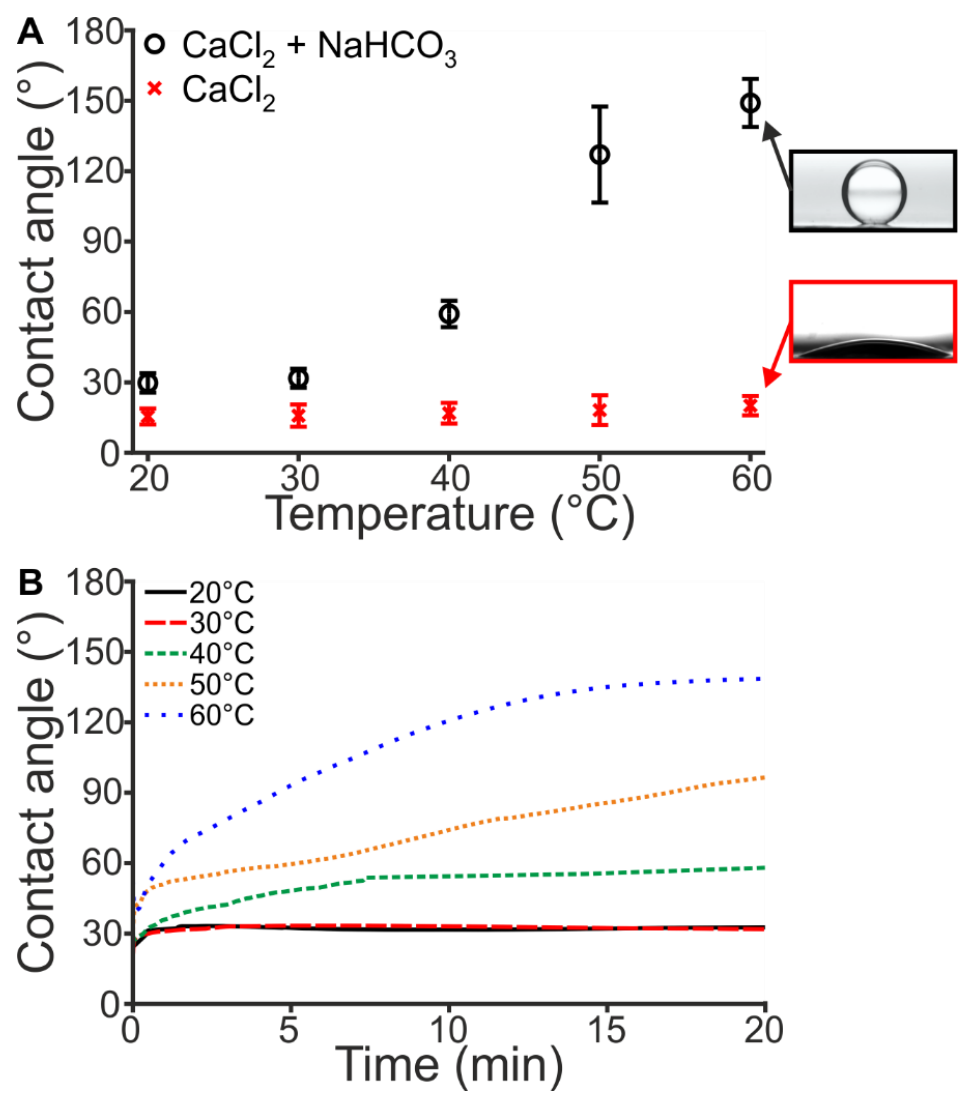

Figure 4.2. Temperature effect on wettability (i.e. water contact angle) of brine droplets on mica, immersed in decane with $0.1 \mathrm{mM} \mathrm{C16.} \mathrm{A)} \mathrm{Final} \mathrm{contact}$ angles and standard deviations for droplets with/out $2 \mathrm{mM} \mathrm{NaHCO}$, along with example pictures, $B$ ) time-dependence of the contact angle for the droplets with the $\mathrm{NaHCO}_{3}$. Brine composition: $10 \mathrm{mM} \mathrm{CaCl}_{2}$ (and $2 \mathrm{mM} \mathrm{NaHCO}_{3}$ when specified), $\mathrm{pH} 8$. 

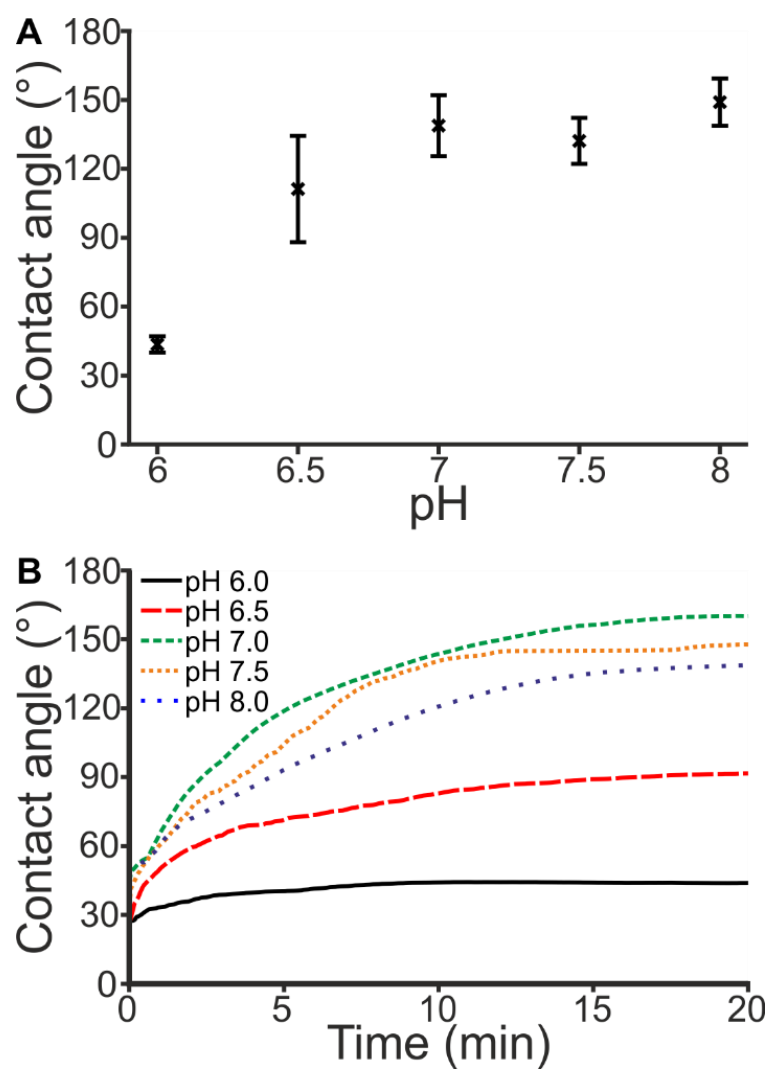

Figure 4.3. Effect of $p H$ (set at RT) on the wettability: A) final contact angles and standard deviations, $B$ ) time-dependent contact angles. Conditions: mica substrate, $0.1 \mathrm{mM} \mathrm{Cl6}$ in decane, $10 \mathrm{mM} \mathrm{CaCl} 2$ and $2 \mathrm{mM} \mathrm{NaHCO}_{3}$ in the brine, $60^{\circ} \mathrm{C}$. Note that $\mathrm{B}$ shows examples of measurements on individual drops; the final contact angles do therefore not necessarily match the averaged values shown in A.

At reservoir conditions a large variety of amphiphilic molecules, including weak acids, is present in the oil. ${ }^{4}$ This makes it relevant to examine how the molecular architecture of the carboxylic acid, affects the high-temperature bicarbonate effect. Fig. 4.4 shows the final contact angles obtained for 13 carboxylic acids. Eight of them have linear 
aliphatic tail groups with a different (even) number of carbon atoms (C6-C20). For these fatty acids, the final contact angle shows a monotonic increase with chain length. At the shortest chain length of 6 carbon atoms, we do not observe the strong, slow autophobing behavior described above. For $\mathrm{C} 10$, the autophobing effect starts to become apparent, and for C16 it levels off to a contact angle plateau of around $150^{\circ}$. For odd chain-lengths we find a different behavior, with a large spread of final contact angles. Only a fraction of the droplets showed a strong (and slow) autophobing behavior, while others showed a weak (and quick) autophobing. This indicates a large contact angle hysteresis, which could be associated with a chemically inhomogeneous substrate. Two carboxylic acids with a more complex architecture, oleic- and 12phenyl dodecanoic acid, still show the slow autophobing effect but with a diminished final contact angle of around $50^{\circ}$.

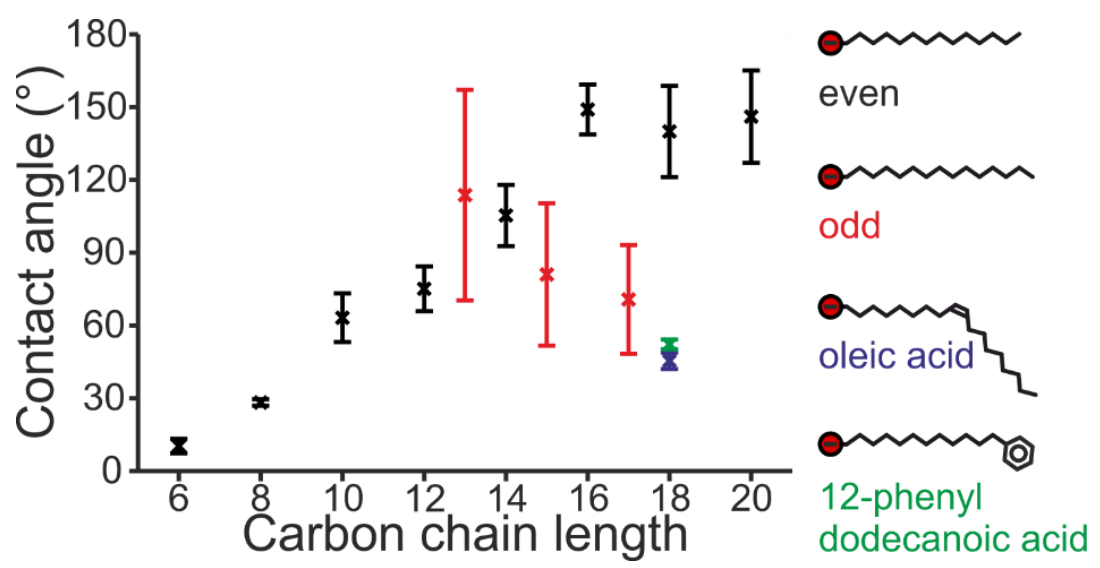

Figure 4.4. Effect of the molecular architecture of the carboxylic acid on the wettability: final water contact angles along with their standard deviations. Odd carbon chain length data has been split up in two populations (approximate percentage of data points is shown): slow, strong autophobing (high contact angle); and faster, weak autophobing (low contact angle). Conditions: mica substrate, $0.1 \mathrm{mM}$ carboxylic acid in decane, $10 \mathrm{mM} \mathrm{CaCl}_{2}$ and $2 \mathrm{mM} \mathrm{NaHCO}$ in brine at $\mathrm{pH} 8,60^{\circ} \mathrm{C}$. 


\section{Surface Topography}

The found relation between tail-group architecture and wetting phenomenology indicates that the self-assembly of the different carboxylic acids on the mica, leads to significant differences in the structure of the hydrophobic layer. We investigated these structures in more detail by ex situ AFM imaging in air. A drawback of studying substrates obtained after autophobing is that there was no control over the velocity of the contact line. Variations in this velocity were earlier found to cause an inhomogeneous deposition of material. ${ }^{24} \mathrm{We}$ observed this also in our samples: substrate coverage increased when approaching the final contact line from the outside of the droplet (compare Fig. 4.5B and 4.5C, left column). Anticipating a better insight into the layer formation process from experiments where this velocity is better controlled, we did experiments where the mica was dip-coated through the oil/brine interface. We chose velocities of 0.1 or $1 \mathrm{~mm} / \mathrm{min}$, reflecting the average contact line speed of autophobing droplets at 0.1 $\mathrm{mM}$ and $1 \mathrm{mM} \mathrm{C} 16$ respectively. To examine the layer homogeneity and to ensure representative images, we scanned three or more areas several millimeters apart, and in some cases also on different samples prepared at identical conditions. We found that dip-coating indeed resulted in a more homogeneous distribution of organic layers across and between samples. 

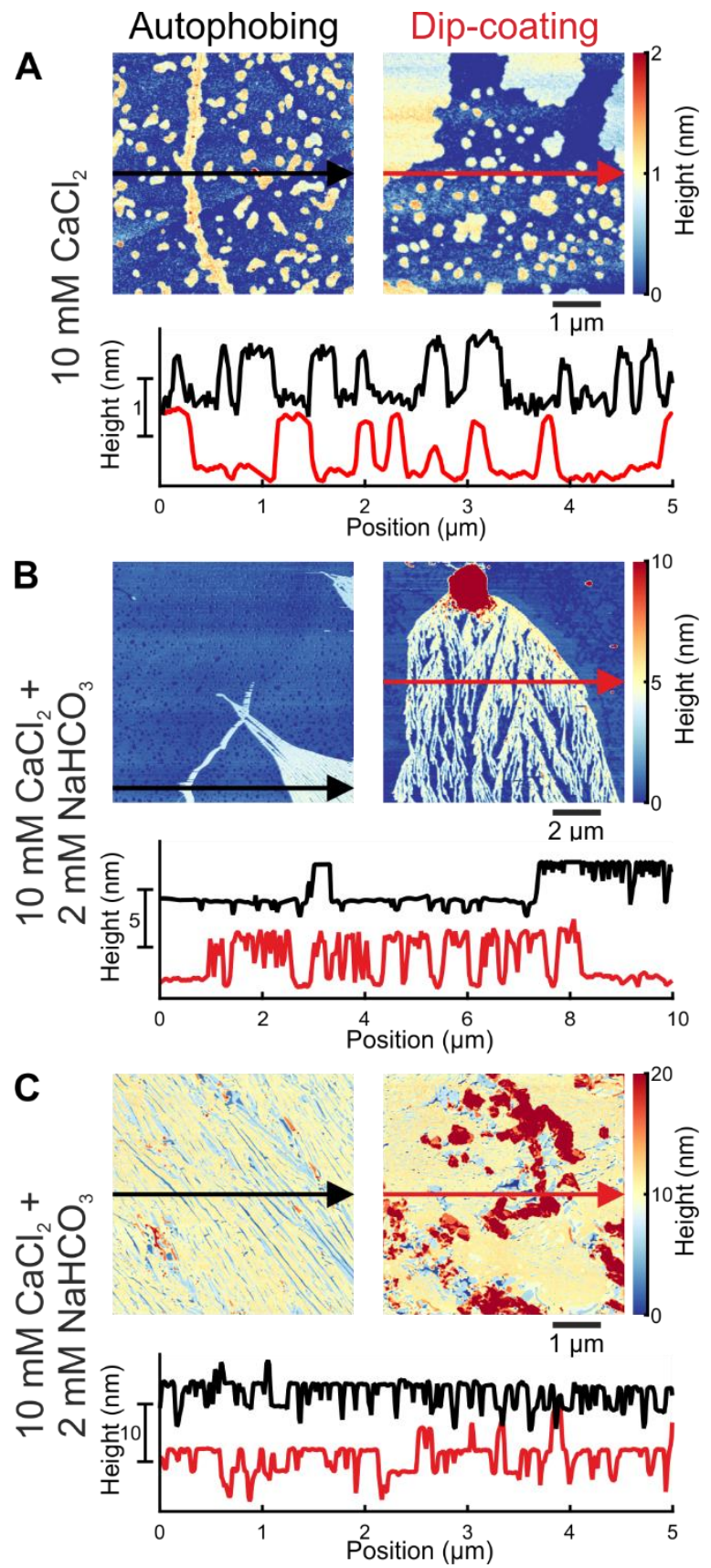
Figure 4.5. (opposite page) AFM height images and cross-sections of organic layers formed on mica by autophobing (left, black) and dip-coating (right, red): (A) without $\mathrm{NaHCO}_{3},(B)$ with $2 \mathrm{mM} \mathrm{NaHCO}_{3}$ at a mono- to multilayer transition region, $(C)$ with $2 \mathrm{mM} \mathrm{NaHCO}$ at a multilayer region. Note the height scale variation across subfigures. Line profiles in black have been shifted for clarity. Preparation conditions: $60^{\circ} \mathrm{C}$, mica substrate, decane

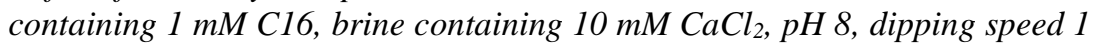
$\mathrm{mm} / \mathrm{min}$.

To illustrate the differences and similarities between the coating methods, we compare samples obtained under otherwise identical chemical conditions: $\mathrm{pH} 8,10 \mathrm{mM} \mathrm{CaCl}_{2}$ in the brine and $1 \mathrm{mM} \mathrm{C} 16$ in the oil. Two cases are considered: one in the absence (Fig. 4.5A), and one in the presence of an additional $2 \mathrm{mM}$ of $\mathrm{NaHCO}_{3}$ in the brine (Fig. $4.5 \mathrm{~B}$ and $4.5 \mathrm{C}$ ). Without the added bicarbonate, both autophobing and dip-coating experiments produce island-like structures with a distribution of lateral length scales ranging from $\approx 0.1$ to $\approx 1 \mu \mathrm{m}$. While there are some differences in lateral morphology, all islands have a height of around $1 \mathrm{~nm}$ (Fig. 4.5A), corresponding to a monolayer of C16 (see Eq. 4.1 below). It should be noted that the morphology of these islands is variable across the substrate, especially in the case of the autophobing droplet, but the thickness is always constant. In the presence of $2 \mathrm{mM} \mathrm{NaHCO} 3$ the structures look very different: both experiments now produce a much higher coverage, and also the layer thickness is much higher: from $\approx 5 \mathrm{~nm}$ (Fig. $4.5 \mathrm{~B}$ ) up to $\approx 20 \mathrm{~nm}$ (Fig. 4.5C). The layers appear to consist of units about $5 \mathrm{~nm}$, apparent from the cross-sections. Also the lateral geometry changes (for both methods), from disordered islands to a more lamellar structure with occasional branching (see also supplementary Fig. 4.S2). It thus appears that the effect of bicarbonate gets most strongly reflected in the coverage and layer thickness, while the dipping experiments can reproduce the trends as found with the autophobing droplets.

We therefore continue our investigation with dip-coating experiments. Decreasing the pulling speed from 1.0 to $0.1 \mathrm{~mm} / \mathrm{min}$ makes the layered-plateau structure more apparent (Fig. 4.6, in comparison to Fig. 4.5). Increasing the concentration of $\mathrm{C} 16$ present 
during dip-coating also makes the plateaus more pronounced: a comparison of samples prepared at $0.1,1$, and $10 \mathrm{mM}$ (Fig. 4.6A-C and D-F) shows increasing lateral extensions and better visible steps of the aforementioned $5 \mathrm{~nm}$ discrete layers; this is most noticeable in Fig. 4.6F. It is remarked here that, while AFM imaging was typically performed near the upper edge of the deposited layers (formed most quickly after the start of the experiment), also the lower edges were inspected. These layers, which were formed 2-3 hours later $(0.1$ $\mathrm{mm} / \mathrm{min}$ pulling speed, $1-2 \mathrm{~cm}$ long slides) showed no structural differences in the layering. This suggests the absence of aging effects.

\section{Discrete Layer Characterization}

To further study the discrete layering, we performed additional analysis on samples prepared under the same conditions as for Fig. 4.6C. Using AFM imaging at higher lateral resolution $(1024 \times 1024$ instead of $512 \times 512$ pixels, $20 \times 20 \mu \mathrm{m}$ ), we get a detailed picture with many discrete layer steps (Fig. 4.7A). An image of the same sample with SEM (Fig 4.7B) shows that the layers are mostly flat, with occasionally some larger structures of stacked platelets. The lack of contrast in the lower layers suggests that the entire surface is covered with an organic layer, meaning that what we indicate as 'zero' height in the AFM image is likely not the mica but rather the lowest organic layer.

By transforming the AFM height map into a histogram, the layering can be studied in more detail (Fig 4.7A). Taking the peak-to-peak distances of the histograms of this image, as well as the $2 \times 2 \mu \mathrm{m}$ image of this sample (see supplementary Fig. 4.S5F), we find a mean layer thickness of $4.6 \mathrm{~nm}$, with a standard deviation of $0.30 \mathrm{~nm}$. The same sample was also analyzed by confocal Raman spectroscopy, where we found, besides mica and palmitic acid, evidence for the presence of carbonate due to a weak peak at $\approx 1080 \mathrm{~cm}^{-1}$, corresponding to the symmetric stretching of carbonate (see supplementary Fig. 4.S3) ${ }^{25} \mathrm{~A}$ sample exposed to an autophobing droplet at the same conditions was also analyzed by XPS, showing both the presence of $\mathrm{Ca}$ and $\mathrm{C}=\mathrm{O}$ (see supplementary Fig. 4.S4), but the latter can be either from carbonate species or from the carboxylate group of the fatty acids. 


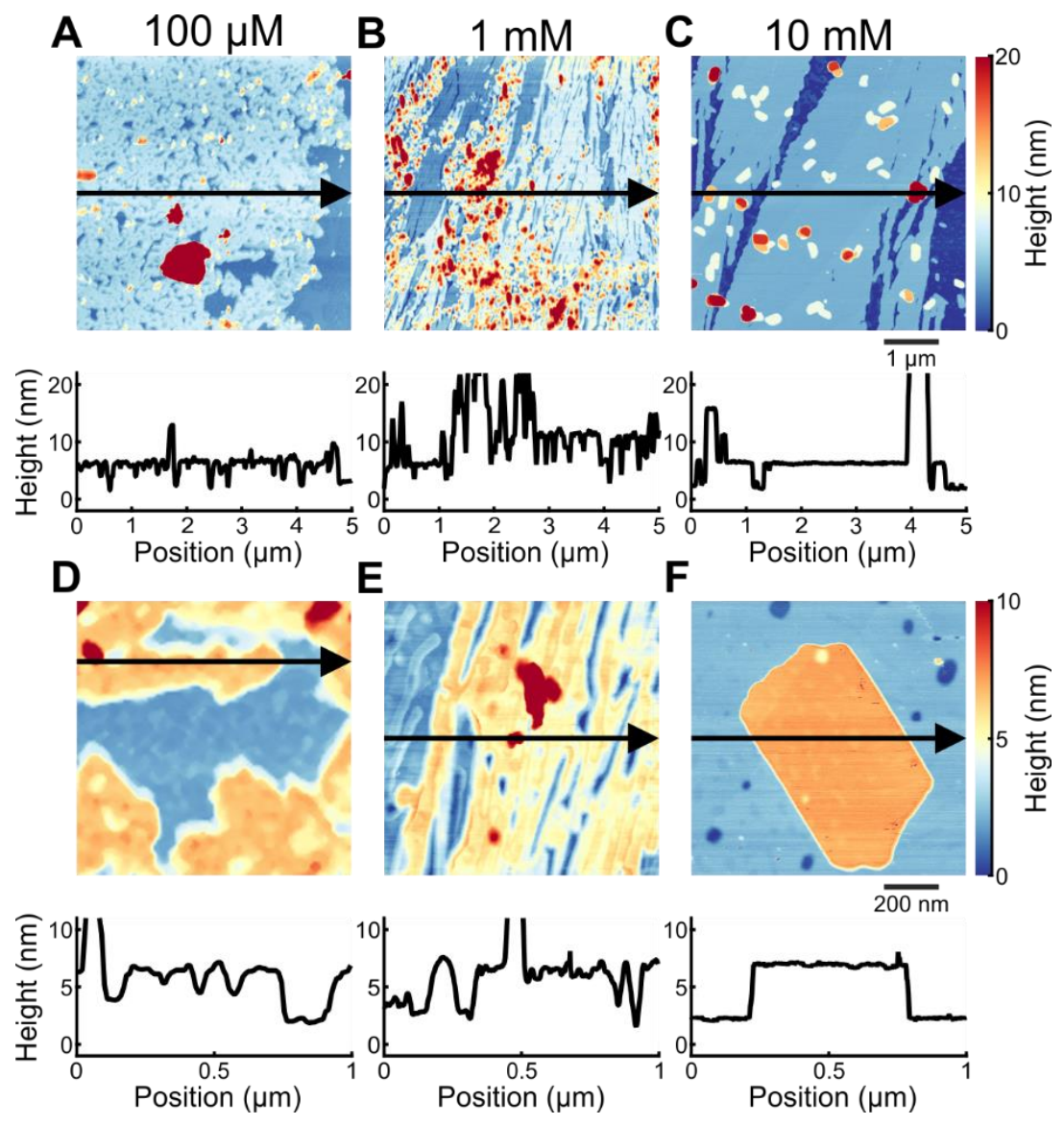

Figure 4.6. AFM height images and line profiles of organic layers formed on mica by dip-coating. Preparation conditions: varying [C16], $10 \mathrm{mM} \mathrm{CaCl}, 2$ $\mathrm{mM} \mathrm{NaHCO}, \mathrm{pH} 8,60^{\circ} \mathrm{C}$, dipping speed $0.1 \mathrm{~mm} / \mathrm{min}$. 

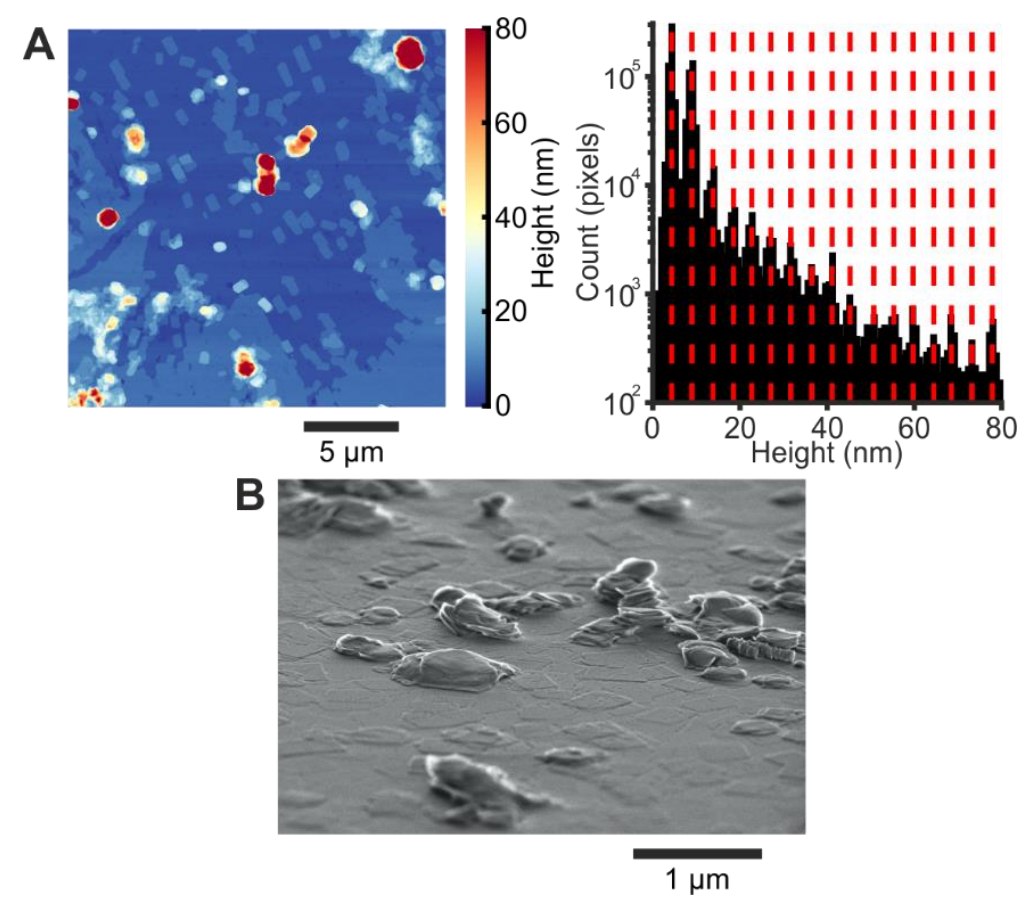

Figure 4.7. (A) AFM height image with corresponding histogram and (B) SEM image of organic layers formed on mica by dip-coating. Red dashed lines illustrate the periodicity of the histogram. Preparation conditions: $10 \mathrm{mM}$ Cl6, $10 \mathrm{mM} \mathrm{CaCl}, 2 \mathrm{mM} \mathrm{NaHCO}_{3}, \mathrm{pH} 8,60^{\circ} \mathrm{C}$, dipping speed $0.1 \mathrm{~mm} / \mathrm{min}$.

A similar analysis was performed using different linear fatty acids: C8, C12, and C20 (see supplementary Fig. 4.S5). C6 was excluded from this analysis since here the autophobing effect was weak, and the amount of deposited hydrophobic material was small. This might be related to the fact that this short-chain fatty acid can dissolve both in water and in oil. Recording and combining multiple AFM images on the same samples, at locations several $\mathrm{mm}$ apart, allowed us to conclude that the overall coverage of multilayers increased with increasing chain length: a rare occurrence with $\mathrm{C} 8$, more prominence with $\mathrm{C} 12$, and almost full coverage with $\mathrm{C} 16$ and $\mathrm{C} 20$. These inspections (not shown) also revealed that the inhomogeneities occurred on a length scale of $\mathrm{O}(1$ 
$\mathrm{mm})$, which is too large to address with AFM. As a consequence, the AFM analysis of the samples prepared with C8 and C12 involved a scrutiny of the images for regions with thick multilayer areas. AFM images presented in Fig. 4.S5 are hence not representative in all respects. Focusing on the histograms for the layer height, it turned out that all fatty acids (C8, C12, C16 and C20) show the same type of layering, where the thickness of the unit layer increases with chain length. Plotting the mean histogram peak-to-peak distances versus the carbon chain length, we find a linear relation with an extrapolated intercept ('no fatty acid') of $0.82 \mathrm{~nm}$ and a slope of $0.23 \mathrm{~nm}$ per carbon atom (Fig. 4.8).

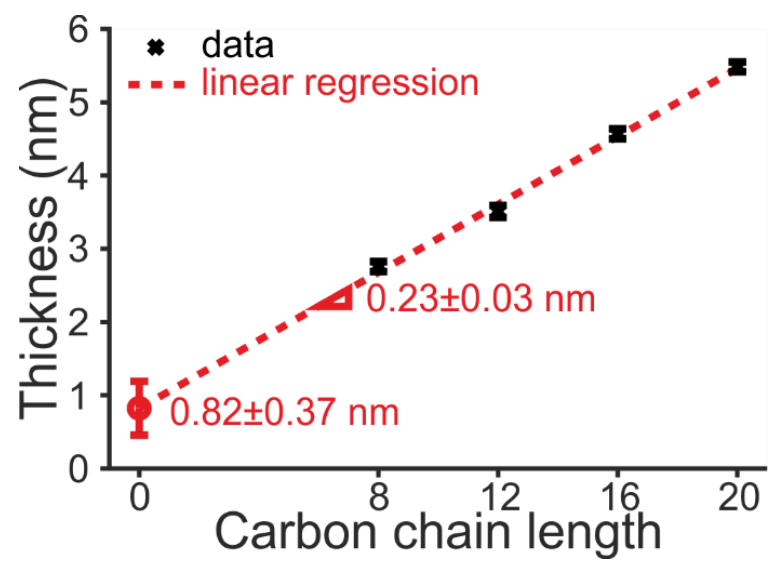

Figure 4.8. Thickness of the unit layer as a function of the carbon chain length for fatty acids deposited on mica slides by dip-coating at $60^{\circ} \mathrm{C}$. Thicknesses were obtained from AFM height histograms like Fig. 4.7A and 4.S5. Uncertainty ranges correspond to standard errors. Red dashed line is the result of linear regression. Other conditions: decane with $10 \mathrm{mM}$ fatty acid, brine with $10 \mathrm{mM} \mathrm{CaCl}, 2 \mathrm{mM} \mathrm{NaHCO}$, pH 8, dipping speed $0.1 \mathrm{~mm} / \mathrm{min}$.

\section{Reversibility}

The results presented up to this point describe the formation of organic (multi)layers. Since they are deposited on the oil-side of the contact line, it is plausible that the hydrophobic tails are sticking out. This is also corroborated by the increase in water contact angle after the layer 
deposition (Figs. 4.2 and 4.3). However, what matters for LSWF is not the formation but rather the removal of the hydrophobic organic layers. To examine this reverse process, we flushed a brine droplet, deposited on mica in $n$-decane with $1 \mathrm{mM} \mathrm{C16}$ at $60^{\circ} \mathrm{C}$, with deionized water. Within a few minutes this caused the droplet to spread again, indicating that the hydrophobic layer either desorbs or dissolves (Fig. 4.9A). The same behavior was found for brine droplets on a silica substrate (see supplementary Fig 4.S6, and videos).

To confirm that the hydrophobic layer had indeed disappeared, we also submerged a mica-slide which had been dip-coated at $1 \mathrm{~mm} / \mathrm{min}$ (under otherwise the same conditions as in the droplet experiment) in deionized water at $60^{\circ} \mathrm{C}$ for 30 minutes. Comparing AFM images from before and after the brine replacement (Fig. 4.9B), we found that the multilayers were mostly gone, leaving only a sparse coverage of monolayers and some larger aggregates.
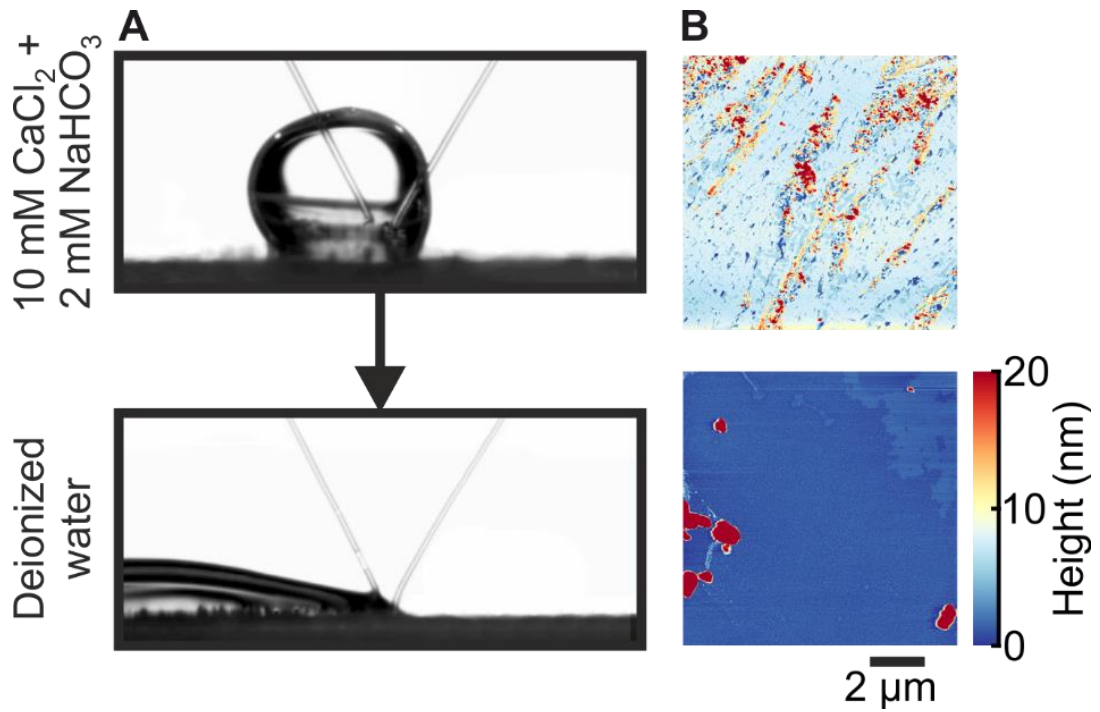

Figure 4.9. (A) Pictures of brine droplets on mica immersed in C16-laden decane at $60^{\circ} \mathrm{C}$, before (top) and after (bottom) replacing the droplet phase (10 $\mathrm{mM} \mathrm{CaCl} 2$ and $2 \mathrm{mM} \mathrm{NaHCO}$ ) by deionized water. (B) AFM images showing the distribution of organic material on the mica changes. 


\subsection{Discussion}

\section{Wettability Effects}

Even though our experimental system is very simple compared to reservoir conditions, it is still host to complex phenomena. Unexpectedly, we observed a vastly different wetting behavior after a slight increase in temperature. This behavior was found for various carboxylic acids, and could be attributed to synergistic effects of the presence of bicarbonate and elevated temperature. Given the complexity of real oil/brine/rock systems, it cannot be excluded that other, yet unidentified mechanisms play a role as well in real LSWF. Nonetheless, our current results are useful in gaining further insights in this EOR process.

From the macroscopic wettability experiments we found that low concentrations of bicarbonate ions have a strong effect on the wetting behavior in oil/brine/mineral systems at elevated temperatures up to $60^{\circ} \mathrm{C}$, where they cause the final contact angle (CA) to increase to $\approx 150^{\circ}$, likely the result of higher coverage of dense organic layers. The effect requires the presence of calcium ions and carboxylic acids with chain lengths $\geq 8$, and temperatures $\geq 40^{\circ} \mathrm{C}$. The CA increase gets stronger with higher temperature (Fig. 4.2), $\mathrm{pH}$ (levelling off at $\geq 7$, Fig. $4.3 \mathrm{~A}$ ), and carbon number of the fatty acid (plateauing at $\geq 16$, Fig. 4.4). All these trends are consistent with the explanation that $\mathrm{Ca}^{2+}$ and carbonate or bicarbonate ions get incorporated in the hydrophobic layers that are responsible for the CA increase. Raman spectroscopy data also indicate that some carbonate species are likely present in these layers (see supplementary Fig. 4.S3).

The importance of elevated temperature for bicarbonate to have an effect on wettability is not immediately obvious from bulk speciation. Although $\mathrm{CaCO}_{3}$ precipitation is known to increase with temperature, our speciation calculations show that a significant fraction of the carbonate species should already precipitate at $20^{\circ} \mathrm{C}, \mathrm{pH} \quad 8$ (supplementary Fig. 4.S8), where we find no strong wettability effects of the bicarbonate. Also in control experiments at $60^{\circ} \mathrm{C}, \mathrm{pH} 8$, aimed at revealing any solid formation in the aqueous phase, no such 
precipitation was observed (supplementary Fig. 4.S1). The MINTEQ calculations show no significant temperature dependence on the fraction of $\mathrm{CaHCO}_{3}{ }^{+}$. We also find that no bulk precipitation of $\mathrm{CaCO}_{3}$ is to be expected at $60^{\circ}$, pH 6-7 (supplementary Fig. 4.S7), whereas we do find a moderate to strong wettability effect under those conditions. This could still be consistent with $\mathrm{CaCO}_{3}$ formation taking place at the carboxylate groups at the oil-water interface. Whereas fatty acids in bulk are known to inhibit growth of $\mathrm{CaCO}_{3}$ through complexation, ${ }^{26,27}$ if they are present as ordered monolayers, e.g. at the oil-water interface, the same $\mathrm{Ca}^{2+}$-carboxylate interaction enhances $\mathrm{CaCO}_{3}$ growth. ${ }^{16}$

The observed $\mathrm{pH}$ dependence of the wetting behavior likely stems from the deprotonation of carboxylate groups, a requirement for their surface activity and cation complexation. Even though the effective $\mathrm{pKa}$ of the $\mathrm{C} 16$ head-group at the interface has been measured to be approximately $9,{ }^{28}$ it is also known that certain cations can significantly lower the effective $\mathrm{pKa}$ of carboxylic acids in monolayers by inducing deprotonation. ${ }^{29,30,31}$ Previous wetting studies in similar systems at room temperature have also shown a similar transition occurring around pH $6 .{ }^{8}$ The calcium ions thus appear to play a double role: both deprotonation of the carboxylic acids and binding to carbonate or bicarbonate ions.

The increase of the contact angle with chain length (for even numbers, C6-C20) could be explained by an increase in the lateral packing density, under the plausible assumption that predominantly the hydrophobic carbon chains will get exposed to the liquid phase. This denser packing would be driven by the well-known increased lateral interactions between the aliphatic chains. ${ }^{32}$ This point is corroborated by the odd-even effects (i.e. the deviating results for $\mathrm{C} 13, \mathrm{C} 15$ and $\mathrm{C} 17$ ) we observe, since odd and even fatty acids are known to orient in different lateral geometries, depending on the substrate, which can in turn affect macro-scopic wettability or crystal growth. ${ }^{33} 34$ The diminished wettability found with bent (oleic acid) or laterally more bulky (phenyl dodecanoic acid) tail groups, which are known to exhibit weaker intermolecular hydro-phobic interactions, ${ }^{19}$ also demonstrates the importance of a laterally dense and organized fatty acid layer. 


\section{Organic Hydrophobic Layers}

The AFM images clearly demonstrated that the presence of bicarbonate ions induces thicker layers with higher coverage (Fig. 4.5). The higher coverage could explain the higher contact angles, in a simplistic rationalization using Cassie's law. ${ }^{35}$ As will be argued below, it is quite conceivable that the presence of carbonate or bicarbonate ions has a positive influence on the stability of densely packed calcium-fatty acid complexes, thus causing the high coverage.

Dip-coating experiments offered a way to study the architecture of the formed multilayers in more detail. The lateral structures obtained via dip-coating are somewhat different from those formed via autophobing, but the unit layer thickness seems to be identical (Fig. 4.5). Slower contact line motion or higher fatty acid concentration generate on average thicker multilayers with a higher coverage (Fig. 4.6), but again the unit layer thickness remains the same (Fig. 4.7C and 4.S5). This suggests that the formation of the individual layers is governed by an equilibrium organizing principle that depends on chemical composition, but the number of layers that are formed does depend on kinetics.

An interesting aspect is that with multilayers, not all layers can reside at an interface. The point that additional layers are formed in the oil thus implies a thermodynamic driving force for taking ions from the brine, binding them to fatty acids and forming an insoluble layer in the oil. Also the observation that the multilayer gets removed upon dilution of the brine suggests that a certain dissociation equilibrium (involving species in different fluid phases) is involved in the formation/disintegration of the multilayers. In this picture, the fact that the multilayers tend to keep growing, implies that substantial depletion of the species involved in the equilibrium (fatty acid, $\mathrm{Ca}^{2+}$ and possibly also $\mathrm{HCO}_{3}{ }^{-}$) does not occur. Considering the amounts of mentioned species, the volume and area of the droplet, and the typical number of bilayers, a rough calculation indeed indicates that depletion should be insignificant.

The linear dependence of the unit thickness on the (even) carbon number for fatty acids (Fig. 4.8) is striking. It supports the picture that 
those layers are highly organized, with the hydrocarbon tails collectively sticking out in the same direction. Increases in the carbon number of the tail group will then result in a proportional increase of the unit layer thickness. In images where the organics do not completely cover the mica, such as Fig. 4.5B, the first layer seems slightly thicker than the subsequent ones (about 5-6 and $4 \mathrm{~nm}$ respectively); suggesting a difference in structure. The 1-2 nm extra in the lowest layer likely represents a template on top of which the additional layers grow. This is unlikely to be a film of $\mathrm{CaCO}_{3}$ grown directly on the mica, as the epitaxy for this configuration is known to be poor and therefore energetically unfavorable. ${ }^{36}$ More likely, this is the same $\mathrm{Ca}^{2+}$ complexed fatty acid monolayer that forms without added bicarbonate.

Combining the foregoing observations and interpretations, we speculate that the multilayer structure starts with a monolayer of fatty acid bound to the mica via $\mathrm{Ca}^{2+}$, which is followed by multiple units of alternating fatty acid bilayers, where the bilayers are internally held together by $\mathrm{Ca}^{2+}$ cations and carbonate or bicarbonate anions, such as $\mathrm{CaCO}_{3}$ as shown in Fig. 4.10A. $\mathrm{CaCO}_{3}$ is known to stabilize fatty acid bilayers in this manner. ${ }^{18}$ The underlying monolayer is likely formed at the oil/water interface through adsorption, and then deposited at the mica/oil interface. The subsequent multilayers must also be formed near the moving contact line, since the building blocks originate from different liquid phases. Our observation that the layer thickness depends on contact line speed is in agreement with this picture. 

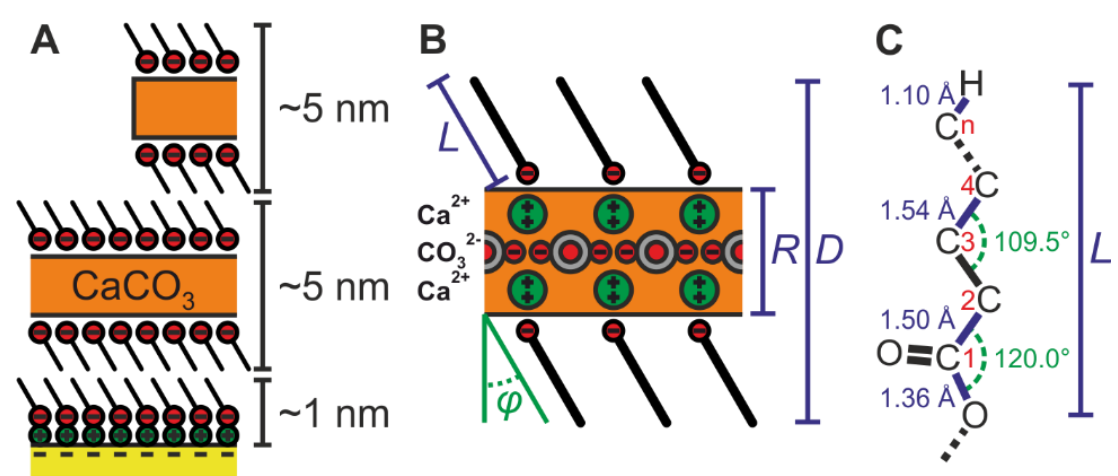

Figure 4.10. Speculative multilayer structure $(A)$, the geometry of a single discrete layer $(B)$, and the geometry of a single fatty acid molecule $(C)$.

We can gain further insight into the proposed intermediate $\mathrm{Ca}^{2+}$ and carbonate species layer by revisiting the linear relation $D(n)$ between unit layer thickness and aliphatic chain length (Fig. 4.8). Even though the obtained intercept and slope have significant standard errors, being $0.82 \pm 0.37$ and $0.23 \pm 0.03 \mathrm{~nm}$, they can be used to estimate the thickness $R$ of the intermediate layer under certain assumptions. We assume the geometry proposed in Fig. 4.10, with unit layer thickness $D$, and fatty acids as rigid rods of length $L$ under a tilt angle $\varphi$. These assumptions can be justified because densely packed layers are known to be composed of straightened tail-groups, ${ }^{37}$ which can be tilted depending on temperature and packing density. ${ }^{38}$ We can calculate $L$ as the distance from the furthest oxygen atom in the head-group to the furthest hydrogen atom in the tail-group (Fig. 4.10C), as a function of the carbon-number $n$. All the bond lengths and angles involved are known, ${ }^{39}$ so this can be worked out geometrically (in $\mathrm{nm}$ ):

$$
\begin{aligned}
& L(n)=0.08+0.13 n \\
& \quad \text { for } n \geq 2
\end{aligned}
$$

The solution is only valid for $n \geq 2$, because formic acid $(n=1)$ has no $\mathrm{sp}^{3}$-hybridized carbon, and therefore lacks some of the specific bond lengths and angles used in this calculation. Using this equation and 
accounting for a universal tilt, we find the linear relation $D(n)$, with an intercept at $R+0.24+0.16 * \cos \varphi \mathrm{nm}$, and a slope of $0.26 * \cos \varphi$ nm. Using the known values from Fig. 4.10 , we find $\varphi \approx 28^{\circ}$ and $R \approx$ $0.5 \mathrm{~nm}$. This remarkably small thickness suggests that the organizing effect of carbonate species on the layer structure is achieved by very few carbonate groups; too few to justify direct comparison with properties of bulk $\mathrm{CaCO}_{3}$ phases, as it's slightly smaller than the size of a unit cell (for calcite or aragonite). Considering the uncertainty in $\mathrm{R}$ an arrangement of planes of calcium and carbonate ions, as sketched in Fig. 4.10B might still be possible. In this context is noteworthy that $\mathrm{CaCO}_{3}$ is known to organize in this way when grown simultaneously with fatty acid monolayers, from molecular dynamics studies, ${ }^{40,41}$ and X-ray diffraction experiments. ${ }^{16,17}$

The value of $\varphi$ can be used to infer the lateral head-group spacing, which could correspond to the spacing between $\mathrm{Ca}^{2+}$ ions in the plane underneath (c.f. Fig. 4.10A). In dense fatty acid monolayers, tail-groups tend to pack in hexagonal geometries, due to their lateral affinity. The typical distance is then around $0.47 \mathrm{~nm} .{ }^{37}$ If the head-group spacing is larger than this, for instance if the fatty acids are grafted to a template, the tail-groups can tilt towards each other to maintain the tail-group spacing (Fig. 4.10B). The shortest distance between $\mathrm{Ca}^{2+}$-ions in crystalline $\mathrm{CaCO}_{3}$ is typically around $0.50 \mathrm{~nm}$. In the case of $\mathrm{CaCO}_{3}$ growth in presence of a fatty acid monolayer, the latter is known to act as a flexible template for $\mathrm{CaCO}_{3}$ nucleation. ${ }^{40,42}$ This flexibility could accommodate for the discrepancy between the mentioned spacing. Our inference of a tilt of around $28^{\circ}$ supports a scenario where the headgroup spacing is increased during the formation of a fatty acid- $\mathrm{CaCO}_{3}$ interface.

\section{Relevance For Enhanced Oil Recovery}

Considering some of the conditions explored, an extrapolation of our findings to the scope of real enhanced oil recovery might be possible. Bicarbonate ions are present at $\mathrm{mM}$ concentrations in some reservoir brines, ${ }^{43}$ and in seawater ${ }^{44}$ as used in secondary oil recovery. The explored pH-range of 6-8 (Fig. 4.3) corresponds to reservoir brine during waterflooding. ${ }^{45}$ From the temperature variation (Fig. 4.2) we 
found that the wettability change due to bicarbonate occurs from $40^{\circ} \mathrm{C}$ onwards, at least up to $60^{\circ} \mathrm{C}$, which corresponds to temperatures of lowto-intermediate depth reservoirs. ${ }^{15}$ Also the mineral substrates of our experiments, mica and silica, are similar to that of sandstone reservoirs: alumino-silicates and quartz.

However, some significant differences remain between the organic phase in our model system and real crude oil. Other than simple carboxylic acids, crude oils contain a large variety of naphthenic acids, aromatic acids, and asphaltenes that are known to play significant roles in surface adsorption and wettability. ${ }^{46}$ On the other hand, carboxylic acids, and particularly fatty acids, are known to be disproportionally produced from sandstone core floods with low salinity water, as compared to the other organic compounds. ${ }^{4}$ This suggests that the reversible adsorption and precipitation of fatty acids does likely play a key role in the salinity dependent wetting properties of the reservoir, as it does in our simplified model system. Hence even experiments on simple model systems can be valuable in elucidating some specific mechanisms involved in LSWF.

\subsection{Conclusion}

A model system for enhanced oil recovery through LSWF, containing brine, oil with carboxylic acid and mica surface was used to study wettability alterations at elevated temperatures up to $60^{\circ} \mathrm{C}$. Most experiments involved the deposition of hydrophobic organic layers, giving rise to increasing water contact angles. Above $40^{\circ} \mathrm{C}$ a remarkable enhancement of this effect was found, provided that besides $\mathrm{Ca}^{2+}$ ions, there were also bicarbonate ions in the brine (at $\mathrm{pH}$ 8). This same effect was found for a variety of carboxylic acids and was the strongest for fatty acids with even carbon numbers $\geq 16$. The hydrophobic organic layers appear to consist of stacked bilayers of carboxylic acids, bound together by very thin layers that contain $\mathrm{Ca}^{2+}$ and presumably also carbonate species. This new insight into wettability alteration might help in understanding the complex salinitydependent wetting behavior of sandstone reservoirs. In particular, since seawater contains around $2 \mathrm{mM}$ bicarbonate ions, allowing seawater to 
flood the sandstone reservoir could actually promote the formation of hydrophobic surface structures, especially if no carbonate species were present in the reservoir brine. 


\section{References}

1. Muggeridge, A.; Cockin, A.; Webb, K.; Frampton, H.; Collins, I.; Moulds, T.; Salino, P. Recovery Rates, Enhanced Oil Recovery and Technological Limits. Philosophical Transactions of the Royal Society A: Mathematical, Physical and Engineering Sciences 2014, 372 (2006), 20120320.

2. McGuire, P. L.; Chatham, J. R.; Paskvan, F. K.; Sommer, D. M.; Carini, F. H. Low Salinity Oil Recovery: An Exciting New Eor Opportunity for Alaska's North Slope. Society of Petroleum Engineers, 2005.

3. Webb, K. J.; Black, C. J. J.; Al-Ajeel, H. Low Salinity Oil Recovery - LogInject-Log. In SPE/DOE Symposium on Improved Oil Recovery; Society of Petroleum Engineers: Tulsa, Oklahoma, 2004, p 7.

4. Collins, I. R.; Couves, J. W.; Hodges, M.; McBride, E. K.; Pedersen, C. S.; Salino, P. A.; Webb, K. J.; Wicking, C.; Zeng, H. Effect of Low Salinity Waterflooding on the Chemistry of the Produced Crude Oil. In SPE Improved Oil Recovery Conference; Society of Petroleum Engineers: Tulsa, Oklahoma, USA, 2018, p 17.

5. Jackson, M.; Vinogradov, J.; Hamon, G.; Chamerois, M. Evidence, Mechanisms and Improved Understanding of Controlled Salinity Waterflooding Part 1: Sandstones. Fuel 2016, 185, 772-793.

6. Al-Shalabi, E. W.; Sepehrnoori, K. A Comprehensive Review of Low Salinity/Engineered Water Injections and Their Applications in Sandstone and Carbonate Rocks. Journal of Petroleum Science and Engineering 2016, 139, 137-161.

7. Myint, P. C.; Firoozabadi, A. Thin Liquid Films in Improved Oil Recovery from Low-Salinity Brine. Current Opinion in Colloid \& Interface Science 2015, 20 (2), 105-114.

8. Bera, B.; Duits, M. H. G.; Cohen Stuart, M. A.; van den Ende, D.; Mugele, F. Surfactant Induced Autophobing. Soft Matter 2016, 12 (20), 45624571.

9. Haagh, M. E. J.; Siretanu, I.; Duits, M. H. G.; Mugele, F. SalinityDependent Contact Angle Alteration in Oil/Brine/Silicate Systems: The Critical Role of Divalent Cations. Langmuir 2017, 33 (14), 3349-3357.

10. Cannan, R. K.; Kibrick, A. Complex Formation between Carboxylic Acids and Divalent Metal Cations. Journal of the American Chemical Society 1938, 60 (10), 2314-2320. 
11. Kobayashi, K.; Liang, Y.; Murata, S.; Matsuoka, T.; Takahashi, S.; Amano, K.-i.; Nishi, N.; Sakka, T. Stability Evaluation of Cation Bridging on Muscovite Surface for Improved Description of Ion-Specific Wettability Alteration. The Journal of Physical Chemistry C 2017, 121 (17), 9273-9281.

12. Wang, X.; Lee, S. Y.; Miller, K.; Welbourn, R.; Stocker, I.; Clarke, S.; Casford, M.; Gutfreund, P.; Skoda, M. W. A. Cation Bridging Studied by Specular Neutron Reflection. Langmuir 2013, 29 (18), 5520-5527.

13. Mugele, F.; Bera, B.; Cavalli, A.; Siretanu, I.; Maestro, A.; Duits, M.; Cohen-Stuart, M.; van den Ende, D.; Stocker, I.; Collins, I. Ion AdsorptionInduced Wetting Transition in Oil-Water-Mineral Systems. Scientific Reports 2015, 5, 10519.

14. Haagh, M. E. J.; Schilderink, N.; Duits, M. H. G.; Siretanu, I.; Mugele, F.; Collins, I. R. Salinity-Dependent Contact Angle Alteration in Oil/Brine/Silicate Systems: The Effect of Temperature. Journal of Petroleum Science and Engineering 2018, 165, 1040-1048.

15. Bjørlykke, K.; Jahren, J. Sandstones and Sandstone Reservoirs. In Petroleum Geoscience: From Sedimentary Environments to Rock Physics, Bjorlykke, K., Ed.; Springer Berlin Heidelberg: Berlin, Heidelberg, 2010, pp 113-140.

16. Travaille, A. M.; Kaptijn, L.; Verwer, P.; Hulsken, B.; Elemans, J. A. A. W.; Nolte, R. J. M.; van Kempen, H. Highly Oriented Self-Assembled Monolayers as Templates for Epitaxial Calcite Growth. Journal of the American Chemical Society 2003, 125 (38), 11571-11577.

17. Han, Y.-J.; Aizenberg, J. Face-Selective Nucleation of Calcite on SelfAssembled Monolayers of Alkanethiols: Effect of the Parity of the Alkyl Chain. Angewandte Chemie International Edition 2003, 42 (31), 3668-3670.

18. Damle, C.; Kumar, A.; Sainkar, S. R.; Bhagawat, M.; Sastry, M. Growth of Calcium Carbonate Crystals within Fatty Acid Bilayer Stacks. Langmuir 2002, 18 (16), 6075-6080.

19. Brzozowska, A. M.; Mugele, F.; Duits, M. H. G. Stability and Interactions in Mixed Monolayers of Fatty Acid Derivatives on Artificial Sea Water. Colloids and Surfaces A: Physicochemical and Engineering Aspects 2013, 433, 200-211. 
20. Shiao, S. Y.; Chhabra, V.; Patist, A.; Free, M. L.; Huibers, P. D. T.; Gregory, A.; Patel, S.; Shah, D. O. Chain Length Compatibility Effects in Mixed Surfactant Systems for Technological Applications. Advances in Colloid and Interface Science 1998, 74 (1), 1-29.

21. Goebel, A.; Lunkenheimer, K. Interfacial Tension of the Water/NAlkane Interface. Langmuir 1997, 13 (2), 369-372.

22. de Poel, W.; Pintea, S.; Drnec, J.; Carla, F.; Felici, R.; Mulder, P.; Elemans, J. A. A. W.; van Enckevort, W. J. P.; Rowan, A. E.; Vlieg, E. Muscovite Mica: Flatter Than a Pancake. Surface Science 2014, 619, 19-24.

23. Qu, D.; Suter, R.; Garoff, S. Surfactant Self-Assemblies Controlling Spontaneous Dewetting. Langmuir 2002, 18 (5), 1649-1654.

24. Bera, B. Ion and Surfactant Induced Wetting Transition. 2016.

25. Buzgar, N.; Apopei, A. I. The Raman Study of Certain Carbonates. Geologie Tomul L 2009, 2, 97-112.

26. Westin, K. J.; Rasmuson, A. C. Crystal Growth of Aragonite and Calcite in Presence of Citric Acid, Dtpa, Edta and Pyromellitic Acid. Journal of Colloid and Interface Science 2005, 282 (2), 359-369.

27. Wada, N.; Kanamura, K.; Umegaki, T. Effects of Carboxylic Acids on the Crystallization of Calcium Carbonate. Journal of Colloid and Interface Science 2001, 233 (1), 65-72.

28. Adams, E.; Allen, H. Palmitic Acid on Salt Subphases and in Mixed Monolayers of Cerebrosides: Application to Atmospheric Aerosol Chemistry. Atmosphere 2013, 4 (4), 315.

29. Le Calvez, E.; Blaudez, D.; Buffeteau, T.; Desbat, B. Effect of Cations on the Dissociation of Arachidic Acid Monolayers on Water Studied by Polarization-Modulated Infrared Reflection-Absorption Spectroscopy. Langmuir 2001, 17 (3), 670-674.

30. Kundu, S.; Langevin, D. Fatty Acid Monolayer Dissociation and Collapse: Effect of Ph and Cations. Colloids and Surfaces A: Physicochemical and Engineering Aspects 2008, 325 (1-2), 81-85.

31. Tang, C. Y.; Allen, H. C. Ionic Binding of $\mathrm{Na}+$ Versus $\mathrm{K}+$ to the Carboxylic Acid Headgroup of Palmitic Acid Monolayers Studied by Vibrational Sum Frequency Generation Spectroscopy. The Journal of Physical Chemistry A 2009, 113 (26), 7383-7393. 
32. Rakshit, A. K.; Zografi, G.; Jalal, I. M.; Gunstone, F. D. Monolayer Properties of Fatty Acids: Ii. Surface Vapor Pressure and the Free Energy of Compression. Journal of Colloid and Interface Science 1981, 80 (2), 466-473.

33. Tao, F.; Bernasek, S. L. Understanding Odd- Even Effects in Organic Self-Assembled Monolayers. Chemical reviews 2007, 107 (5), 1408-1453.

34. Tao, F.; Bernasek, S. L. Understanding Odd-Even Effects in Organic Self-Assembled Monolayers. Chemical Reviews 2007, 107 (5), 1408-1453.

35. Cassie, A.; Baxter, S. Wettability of Porous Surfaces. Transactions of the Faraday society 1944, 40, 546-551.

36. Stephens, C. J.; Mouhamad, Y.; Meldrum, F. C.; Christenson, H. K. Epitaxy of Calcite on Mica. Crystal Growth \& Design 2010, 10 (2), 734-738.

37. Chen, S.; Seidel, M. T.; Zewail, A. H. Atomic-Scale Dynamical Structures of Fatty Acid Bilayers Observed by Ultrafast Electron Crystallography. Proceedings of the National Academy of Sciences of the United States of America 2005, 102 (25), 8854.

38. Kaganer, V. M.; Osipov, M. A.; Peterson, I. R. A Molecular Model for Tilting Phase Transitions between Condensed Phases of Langmuir Monolayers. The Journal of Chemical Physics 1993, 98 (4), 3512-3527.

39. Fox, M. A.; Whitesell, J. K. Organische Chemie: Grundlagen, Mechanismen, Bioorganische Anwendungen; Spektrum Akad. Verlag1995.

40. Duffy, D. M.; Harding, J. H. Simulation of Organic Monolayers as Templates for the Nucleation of Calcite Crystals. Langmuir 2004, 20 (18), 7630-7636.

41. Côté, A. S.; Darkins, R.; Duffy, D. M. Modeling Calcite Crystallization on Self-Assembled Carboxylate-Terminated Alkanethiols. The Journal of Physical Chemistry C 2014, 118 (33), 19188-19193.

42. Duffy, D. M.; Harding, J. H. Growth of Polar Crystal Surfaces on Ionized Organic Substrates. Langmuir 2004, 20 (18), 7637-7642.

43. Tang, G. Q.; Morrow, N. R. Salinity, Temperature, Oil Composition, and Oil Recovery by Waterflooding. SPE Reservoir Engineering 1997, 12 (04), 269-276.

44. Dickson, A. G.; Goyet, C. Handbook of Methods for the Analysis of the Various Parameters of the Carbon Dioxide System in Sea Water. Version 2. 1994. 
45. Shi, L.; Olsson, M. H. M.; Hassenkam, T.; Stipp, S. L. S. A Ph-Resolved View of the Low Salinity Effect in Sandstone Reservoirs. Energy \& Fuels 2016, 30 (7), 5346-5354.

46. Buckley, J. S.; Wang, J. Crude Oil and Asphaltene Characterization for Prediction of Wetting Alteration. Journal of Petroleum Science and Engineering 2002, 33 (1-3), 195-202. 


\section{S Supplementary Information}

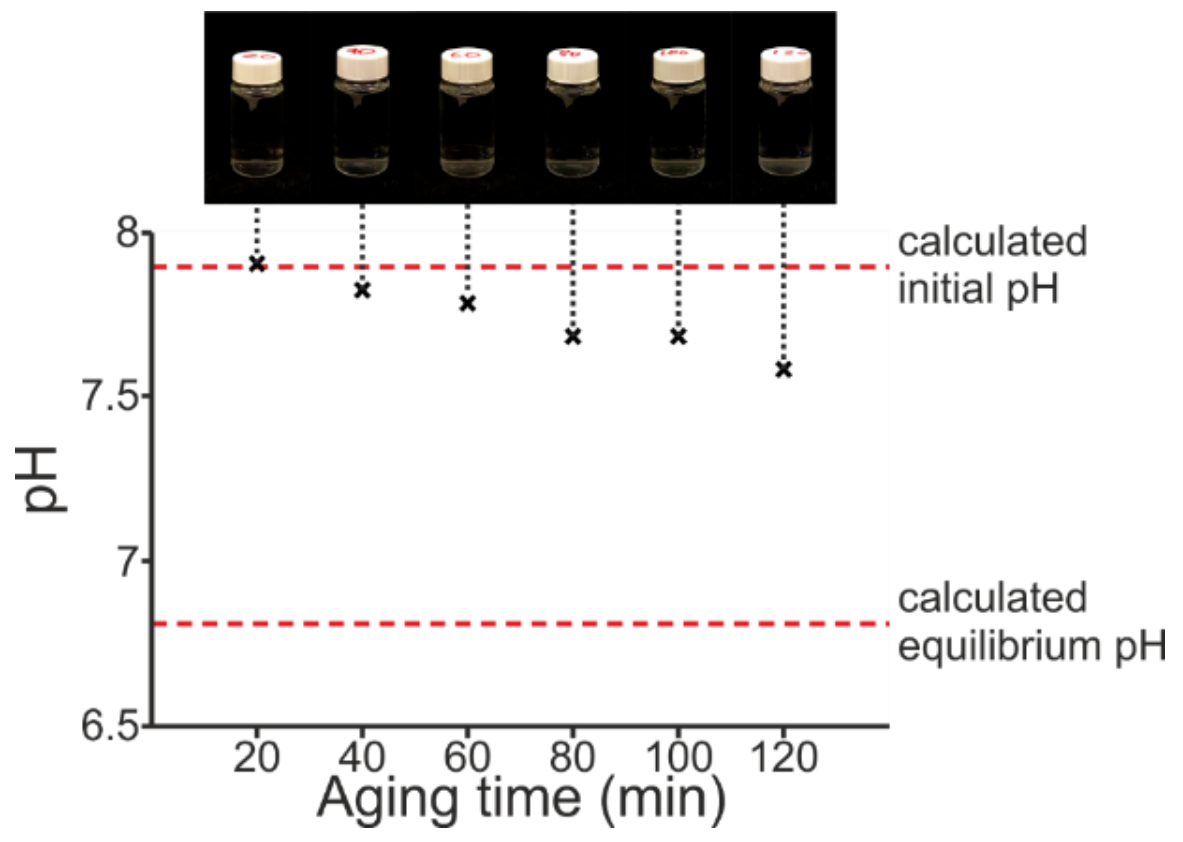

Figure 4.S1. Effect of aging an oil/brine system (similar to those used in the dip-coating experiments) at $60^{\circ} \mathrm{C}$. Brine contained $10 \mathrm{mM} \mathrm{CaCl}+2 \mathrm{mM}$ $\mathrm{NaHCO}_{3}$ while the oil was pure n-decane. Vials were left open to the atmosphere. Aliquots were taken every 20 minutes, allowed to cool down to room temperature (in closed vials) for $\approx 30$ minutes and then inspected for $\mathrm{pH}$ and visible signs of precipitation. No precipitation was observed for any of the samples, while the $\mathrm{pH}$ changed only slightly (and well after 20 minutes, the time needed for droplets to complete the autophobing process). The $\mathrm{pH}$ values are also compared to MINTEQ calculations, neglecting $\mathrm{CO}_{2}$ equilibration and either neglecting or accounting for precipitation. The close proximity of the measured $\mathrm{pH}$ data to the MINTEQ calculations without precipitation corroborates that precipitation is insignificant, especially in first 20-60 minutes. In absence of precipitation, $\mathrm{CO}_{2}$ equilibration would raise the $\mathrm{pH}$; this is not what is observed. 


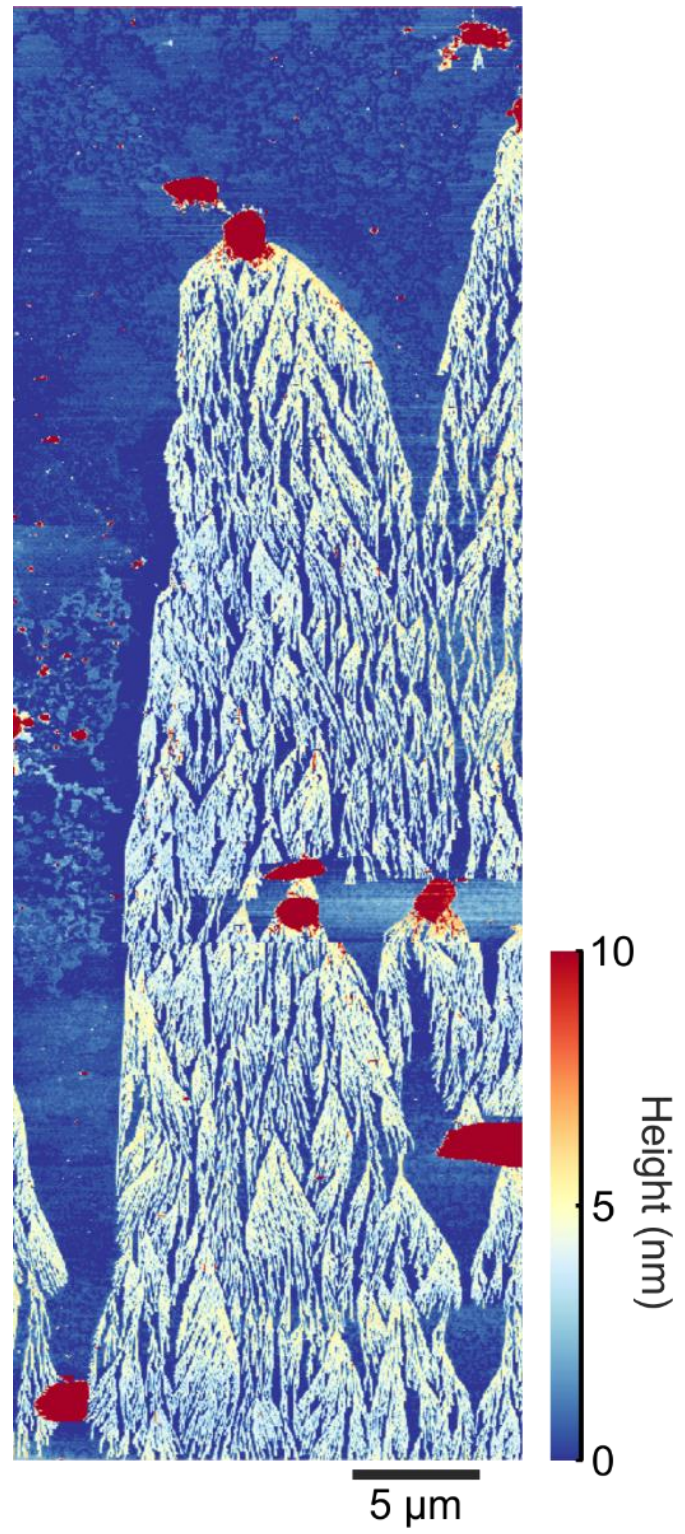

Figure 4.S2. Composite of three AFM height images of hydrophobic layers formed on mica by dip-coating ( $1 \mathrm{mM} \mathrm{Cl6,10} \mathrm{mM} \mathrm{CaCl}, 2 \mathrm{mM} \mathrm{NaHCO}_{3}, \mathrm{pH}$ $8,60^{\circ} \mathrm{C}, 100 \mu \mathrm{m} / \mathrm{min}$ ). 

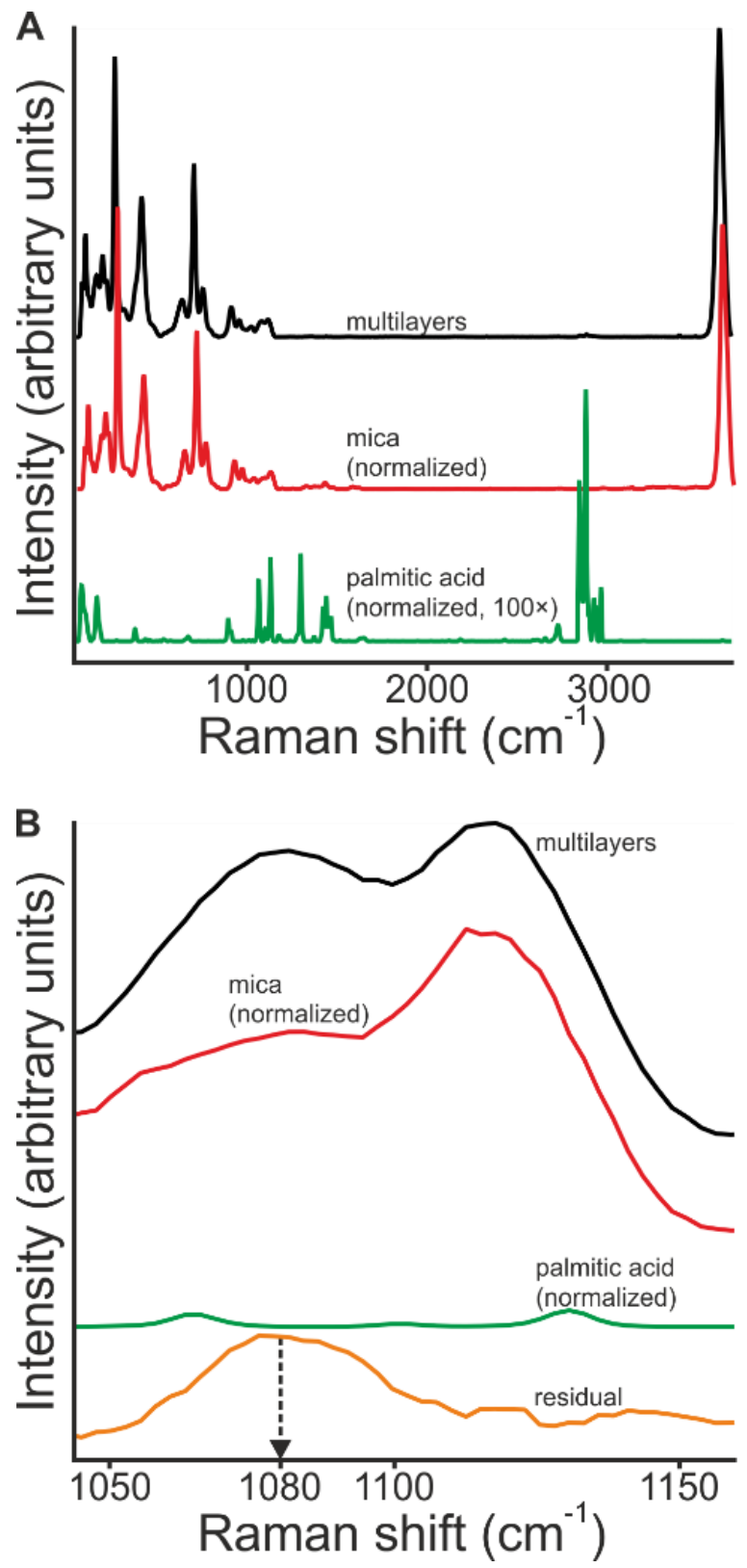
Figure 4.S3. (opposite page) Raman spectra (A), with a zoom in the 1045$1160 \mathrm{~cm}^{-1}$ range $(B)$, collected for a dip-coated mica substrate $(10 \mathrm{mM} \mathrm{C16}$, $10 \mathrm{mM} \mathrm{CaCl2}, 2 \mathrm{mM} \mathrm{NaHCO3}, \mathrm{pH} 8,60^{\circ} \mathrm{C}, 100 \mu \mathrm{m} / \mathrm{min}$ ), and pure mica and palmitic acid. The spectra have been normalized by equalizing specific peak intensities of the multilayer spectrum with identical peaks in the other spectra: for mica at $\approx 260 \mathrm{~cm}^{-1}\left(O\right.$-Si-O stretch), and for palmitic acid at $\approx 2880 \mathrm{~cm}^{-1}(C$ $H$ stretch). The latter normalization causes a very weak spectrum, the full spectrum has therefore been enhanced $100 \times$ in figure A. Figure B also shows the residual spectrum found by subtracting the normalized mica and palmitic acid spectra from the multilayer spectrum, which leaves a broad peak around $\approx 1080 \mathrm{~cm}^{-1}$ (where the $\mathrm{CO}_{3}{ }^{2-}$ symmetric stretch absorption is found).

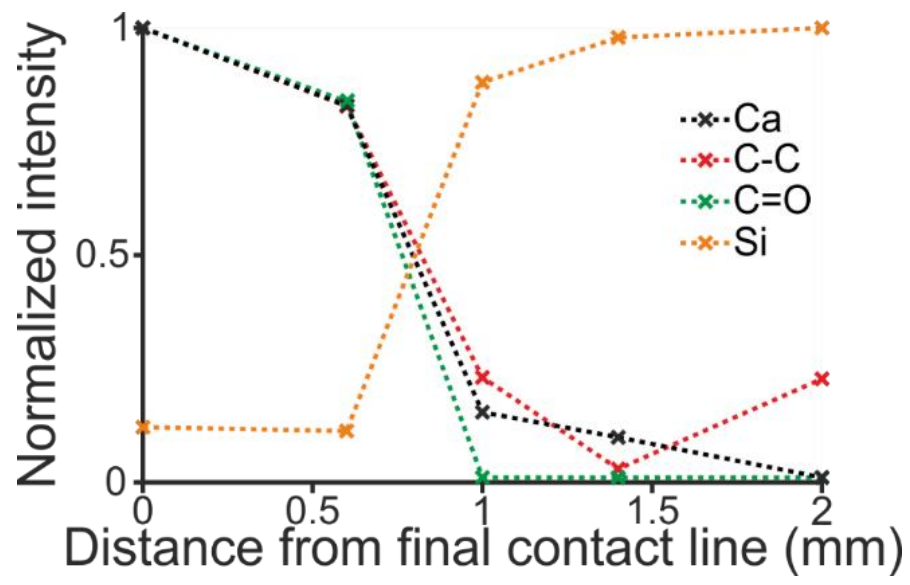

Figure 4.S4. XPS normalized intensity of several elements on a mica slide exposed to an autophobing droplet, at various positions outside the final contact line position, over an area corresponding roughly to the trail of the contact line (10 $\mathrm{mM} \mathrm{Cl6,10} \mathrm{mM} \mathrm{CaCl} 2$ and $2 \mathrm{mM} \mathrm{NaHCO}_{3}, \mathrm{pH} 8,60^{\circ} \mathrm{C}$ ). 


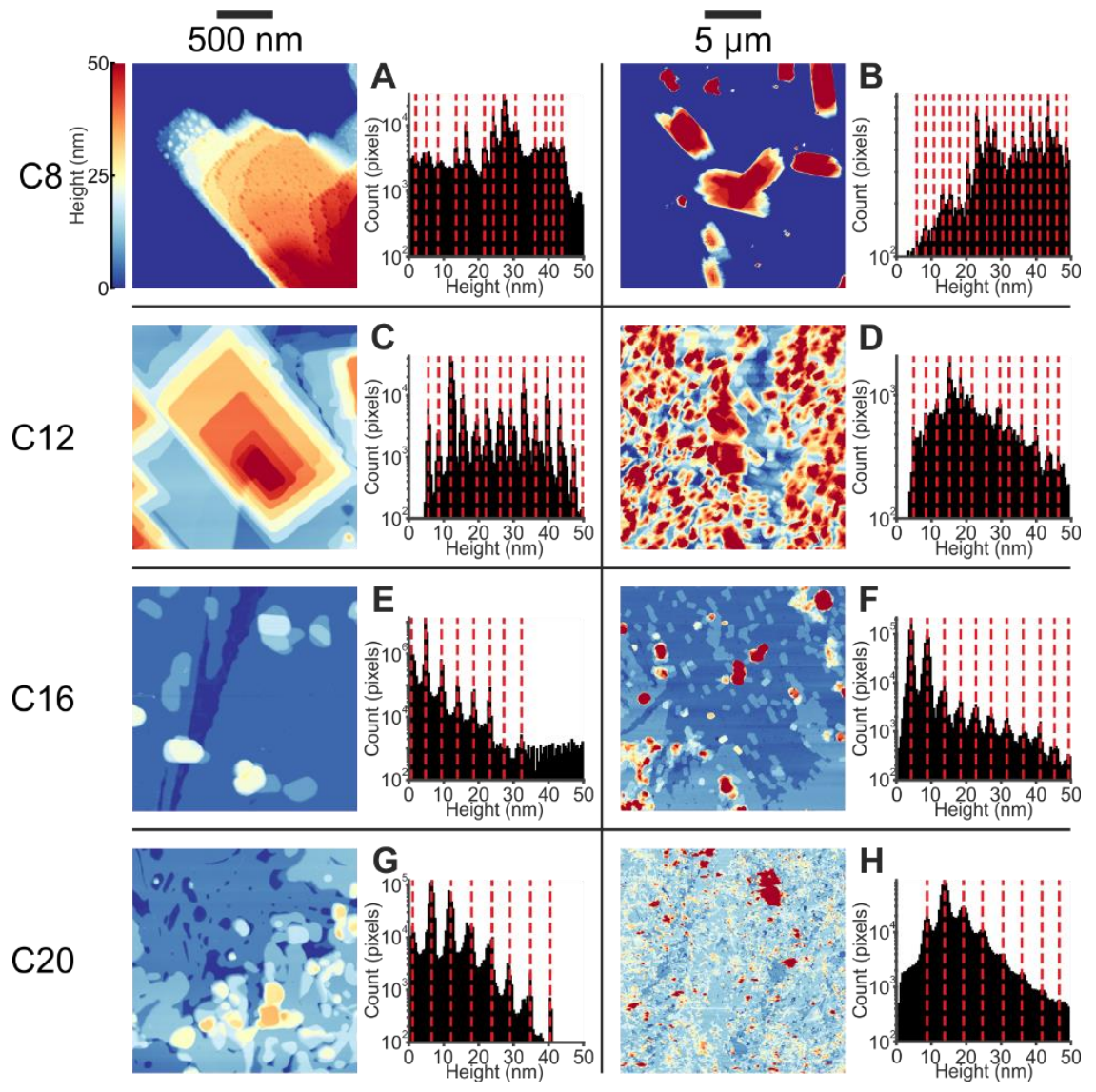

Figure 4.S5. AFM height images and corresponding histograms of hydrophobic layers formed on mica by dip-coating using varying fatty acids: $C 8(A, B), C 12(C, D), C 16(E, F)$ and $C 20(G, H)(10 \mathrm{mM}$ fatty acid, $10 \mathrm{mM}$ $\left.\mathrm{CaCl} 2,2 \mathrm{mM} \mathrm{NaHCO3}, \mathrm{pH} 8,60^{\circ} \mathrm{C}, 100 \mu \mathrm{m} / \mathrm{min}\right)$. 


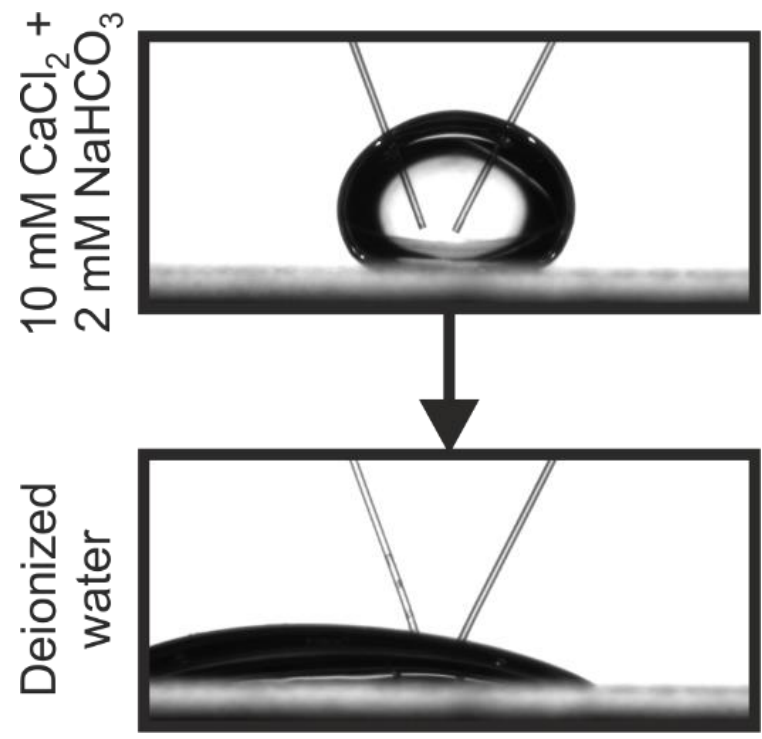

Figure 4.S6. Before-after picture of a fluid exchange experiment. An aqueous droplet containing $10 \mathrm{mM} \mathrm{CaCl}+2 \mathrm{mM} \mathrm{NaHCO}$ at $\mathrm{pH} 8$ gets its content displaced by deionized water (at $20 \mu \mathrm{l} / \mathrm{min}$ for 20 minutes) while maintaining droplet volume $(20 \mu \mathrm{L})$. Substrate is silica, ambient is decane with $1 \mathrm{mM} \mathrm{C16}$ at $60^{\circ} \mathrm{C}$. 

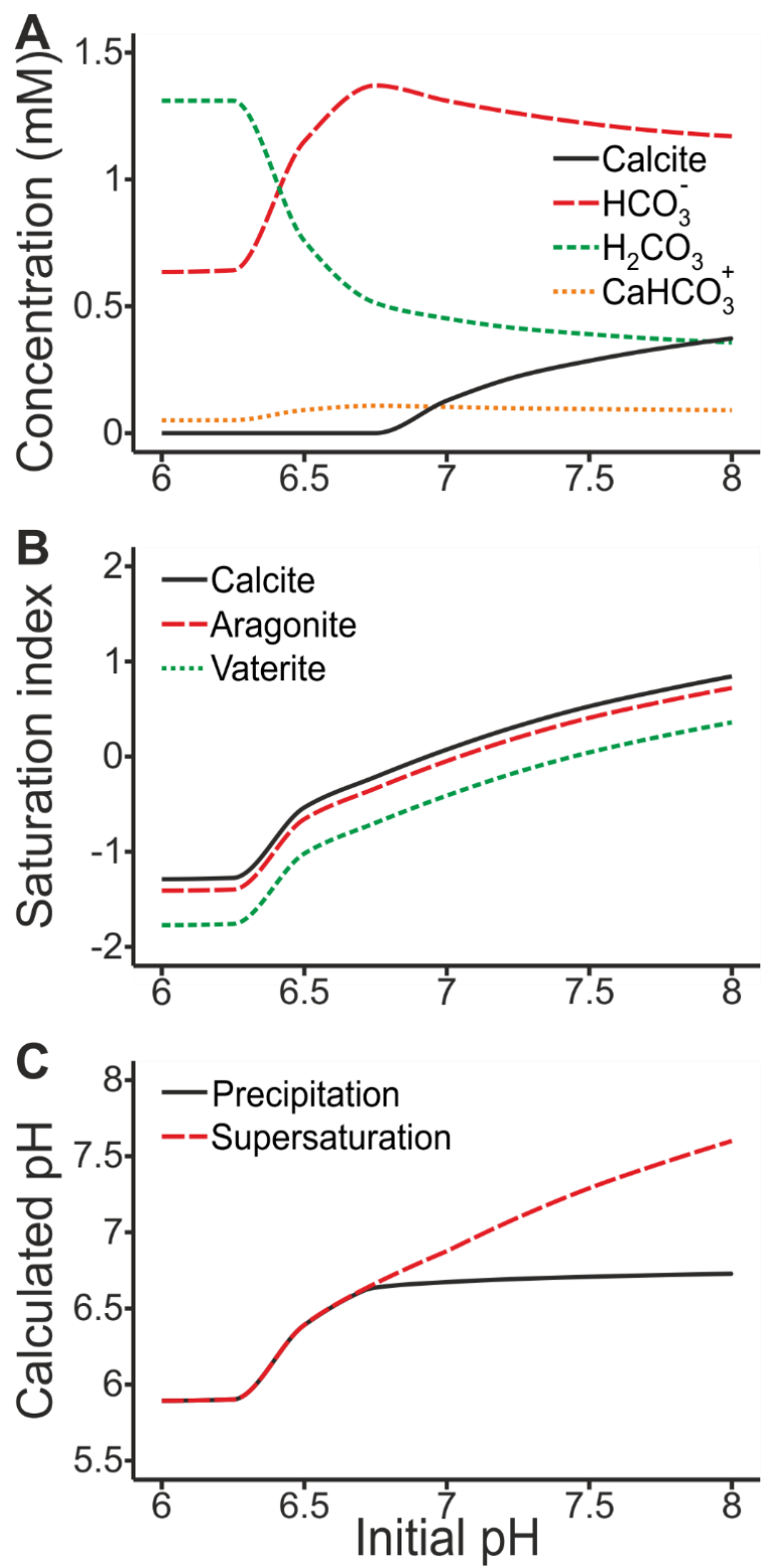
Figure 4.S7. (opposite page) MINTEQ calculation results: effect of initial pH, set at $20^{\circ} \mathrm{C}$, on various quantities at $60^{\circ} \mathrm{C}$ where most multilayer depositions took place. $\mathrm{CO}_{2}$ equilibration was not taken into account in view of timescales (see main text). A: carbonate speciation, total concentration $2 \mathrm{mM}$, only species with concentrations $>1 \mu M$ are shown. Precipitation was not taken into account, because it was not observed (see Fig. 4.S1). B: saturation index, defined as $\log \left(K_{\text {actual }} / K_{\text {eq }}\right)$ with $K_{\text {eq }}$ the solubility product. Values $>0$ indicate supersaturation of $\mathrm{CaCO}_{3}$ polymorphs. Below $\mathrm{pH} \approx 6.7$, no precipitation is expected even under equilibrium conditions. $C$ : final $\mathrm{pH}$ in scenarios with/out precipitation. Precipitation would lower the $\mathrm{pH}$ to $\approx 6.7$. 

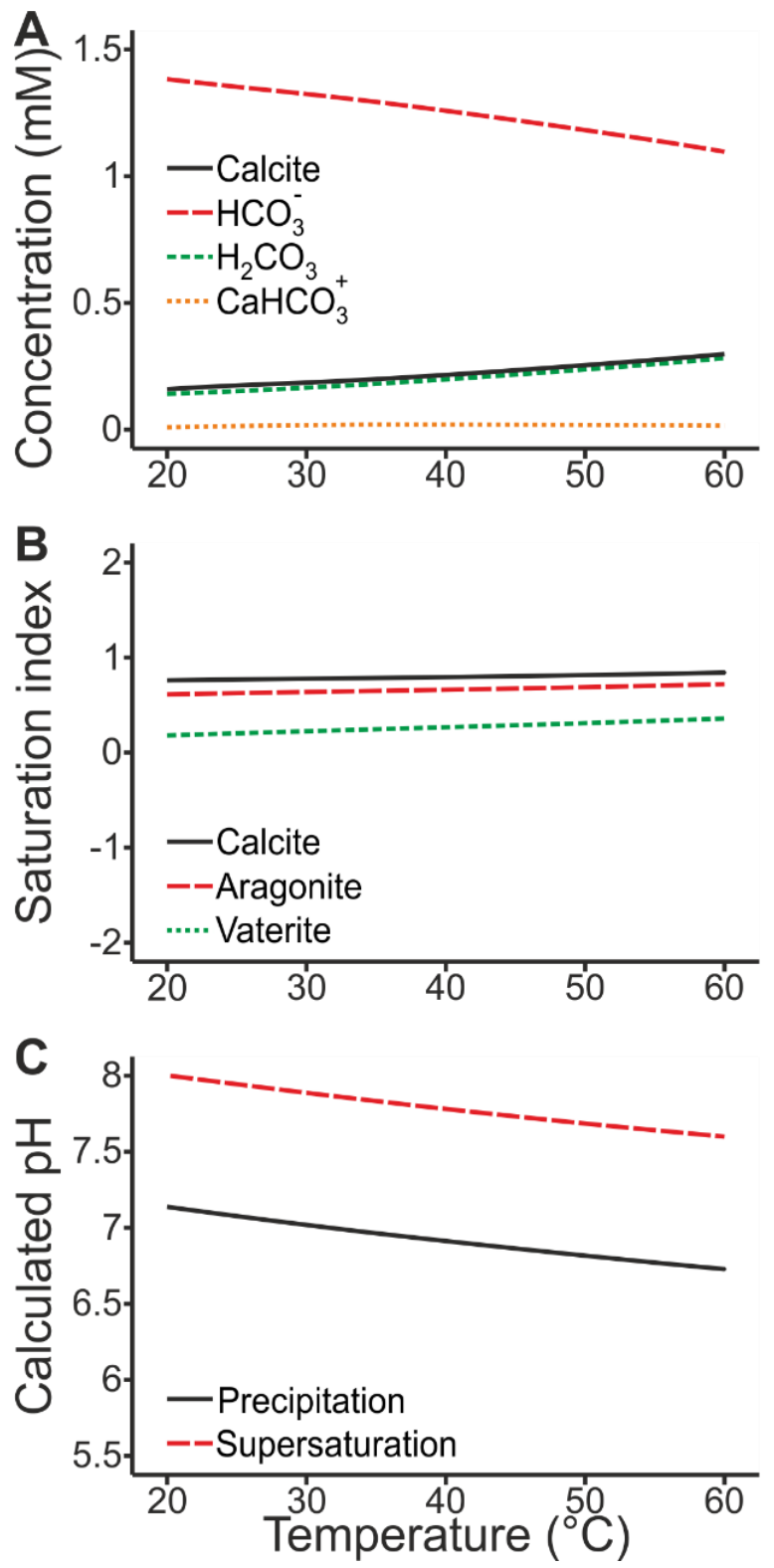
Figure 4.S8. (opposite page) MINTEQ calculation results: effect of temperature on various quantities, for a $\mathrm{pH}$ set to 8 at $20^{\circ} \mathrm{C}$. $\mathrm{CO}_{2}$ equilibration was not taken into account (as in Fig. 4.S7). A: carbonate speciation, total concentration $2 \mathrm{mM}$, only species with concentrations $>1 \mu M$ are shown. Precipitation was not taken into account (as in Fig. 4.S7). B: saturation index. The temperature dependence is very weak. C: final $\mathrm{pH}$ with-and without precipitation. The temperature dependence is weak, and precipitation to an equilibrium state would lower the $\mathrm{pH}$ by $\approx 0.8$ units. 



\section{5}

\section{CRUDE OIL SYSTEMS AND THE EFFECTS OF AGING}

The contents of this chapter are intended to be published as:

'Aging-Brine Dependent Deposition of Crude Oil onto Mica Substrates, and its Consequences for Wettability'

M. E. J. Haagh, N. Schilderink, M.H.G. Duits, P. Krawiec, I.R.

Collins, and F. Mugele

We use model mica substrates to investigate the impact of the composition of the brine used to prime the mineral surface before aging in crude oil at elevated temperature. After aging, oil contact angles are measured in ambient brines of high and low salinity to quantify the macroscopic wettability. Additionally, atomic force microscopy and confocal Raman microscopy are used to characterize morphology, thickness, stiffness, charge, and composition of the organic layer deposited onto the substrate during aging. In general, the variations in microscopic properties are found to be rather subtle. In contrast, the macroscopic contact angle can vary between values around $90^{\circ}$ and complete water wetting for variable aging brine composition. For the same crude oil, reducing the salinity of the ambient brine during the measurement can either increase or decrease the macroscopic oil contact angle, depending on the composition of the formation brine used during aging. These results clearly highlight the complex balance of interactions during brine-oil-rock aging and the subtle role of the connate water composition in extracting and binding different types of crude oil components and thereby setting the initial and boundary conditions for the oil recovery process. 


\subsection{Introduction}

The global average recovery factor from mature oil fields by conventional water flooding is somewhere between $20 \%$ and $40 \%{ }^{1}$ Enhanced oil recovery (EOR) techniques are employed in order to extract some of the remaining, 'trapped' oil. Low Salinity Water Flooding (LSWF) is an attractive EOR method that can improve the microscopic water-oil displacement efficiency by more than $20 \%$ in favorable cases. It is nowadays widely believed that this increase is caused by an improved water-wettability in mixed-wet sandstone reservoirs upon salinity reduction. ${ }^{2}, 3$ Wettability is generally considered as a macroscopic property that can be quantified by contact angle measurements on the millimeter scales, as we will do in this work. Yet, the origin of the macroscopic contact angle lies in the molecular interactions between rock, brine, and crude oil including all its components on the nanometer length scale. ${ }^{3,4,5}$ It is by shifting the subtle balance these interactions that LSWF can alter the macroscopic wettability of the system. Low salinity brine is typically only the last of a row different types of brines that interact with the rock throughout the life time of a reservoir from its diagenesis to the final stages of production. Initially, connate brine, rock, and crude oil together generate the typically mixed-wet initial state of the system as polar components from the crude oil adsorb onto the rock on geological time scales. Subsequently, seawater is injected in secondary mode and LSW is typically only injected in the final tertiary recovery phase. It has been conjectured that the injected brines do not interact with the rock directly, but instead with the thin organic layer strongly bound to it that has formed upon aging. ${ }^{6}$ LSWF is then thought to reduce the salinitydependent attractive interactions between the organic components and the rock and thereby turn the rock more hydrophilic again. ${ }^{7}$ Mechanistically, it is believed that this reduction of attraction is caused by primarily by multiple-ion-exchange, $\mathrm{pH}$ increase, electric double layer expansion, or a combination of these effects.

Notwithstanding an increasing consensus in the field favoring the just mentioned mechanisms, experimental results are still highly variable and the predictive power of existing models is rather poor, 
suggesting a lack of true fundamental insight. ${ }^{8}$ Probably, this failure has to be attributed to a combination of effects related to both variations in the composition of the fluids involved and variations of experimental procedures. An important aspect of the experimental procedures is the aging of the rock surface to reinstate conditions at the beginning of the laboratory experiment that mimic the initial conditions encountered in the reservoir. Aging protocols typically involve first exposure of the rock to a formation (or connate) brine and subsequently exposure of the rock to crude oil. While it is well-known that the initial aging in brine is crucial for the observation of enhanced recovery upon LSWF, systematic studies of the impact of the aging brine composition on crude oil aging and the subsequent wettability state of sandstone rock are remarkably sparse. Sharma and Filoco reported that the salinity of the connate water was the primary factor controlling oil recovery. ${ }^{9} \mathrm{Liu}$ et al. showed that an aging step with $\mathrm{Mg}^{2+}$ ions in combination with ionized organic acids in crude oil and negatively charged sand surfaces can change the wettability of a heavy oil/brine/sand system. ${ }^{10}$ Yang et al. found similar effects, but studied only the impact of the $\mathrm{Ca}^{2+}$ ion concentration in the connate water. ${ }^{11}$ Shehata and Nasr-El-Din showed that LSWF recovery was higher if the concentration of divalent cations $\left(\mathrm{Ca}^{2+}\right.$ and $\left.\mathrm{Mg}^{2+}\right)$ was increased in the connate water, ${ }^{12}$ presumably because of wettability differences induced by the increasing ion concentration. However, no systematic variation of the ionic composition was performed. A major difficulty contributing to the lack of systematic studies is certainly the fact that core flood experiments are time-consuming and costly. This compromises the ability to perform 'high-throughput' screening for optimized LSWF recipes. Moreover, it is notoriously difficult to access the interior of core samples for microscopic in situ characterization of structure and composition $^{13}$, typically requiring mechanical slicing or FIB (focused ion beam) dissection. Microscopic contact angles in porous media have recently become possible (e.g. in x-ray tomography) ${ }^{14}$, yet such measurements require specific fluid compositions that deviate from the complex fluids in EOR. 
In the present work, we study systematically the influence of the composition of the aging brine on the macroscopic contact angle of flat mica substrates representing a sandstone like mineral surface. While circumventing in this manner the complexity arising from the threedimensional pore structure, this approach allows us to retain the relevant surface chemistry ${ }^{3,4,15,16}$ while gaining access with a suite of surface characterization techniques including various manners of atomic force microscopy (AFM) imaging and spectroscopy, confocal Raman microscopy (CRM) and scanning electron microscopy (SEM). The mica slides are initially aged in connate brines of variable composition followed by aging in crude oil at elevated temperature. Subsequent measurements of advancing oil contact angles in ambient brines of variable salinity demonstrate a significant effect of the composition of the initial aging brine on the wettability of various crude oils in 'measurement' brines of variable salinity. To rationalize our macroscopic observations, we characterize the topography and chemical composition of the samples after aging in crude oil using AFM and CRM in ambient air. These measurements clearly reveal the presence of organic deposits on the mica surfaces. Yet, despite significant variations of the macroscopic wettability, the surface composition and topography display a remarkably weak response to systematic modifications of the aging brines such as depletion of divalent cations, bicarbonate ions and changes in temperature and $\mathrm{pH}$. In situ AFM spectroscopy in variable brine reveals changes of the local surface charge and elasticity for certain conditions.

\subsection{Experimental}

Four different types of crude oil (designated as A, B, C and D) were obtained from BP, Sunbury (UK). Acid and base number, saturated, aromatic, resin and asphaltene (SARA) contents are specified in Supplementary Table 5.S1. As solid substrate we used sheets of muscovite mica (B \& M Mica Co., Inc.). All other chemicals were reagent grade and purchased from Sigma. Brine phases (see Table 5.1 for the most commonly discussed brines in this paper, and Supplementary Table 5.S2 for an overview of all brines used in this 
work) were prepared by dissolving combinations of inorganic salts in deionized water (Millipore, resistivity $18.2 \mathrm{M} \Omega \mathrm{cm}$ ). A distinction is made between artificial connate brines (CB) and artificial sea water (ASW), where CBs mimic reservoir aging conditions, and (modifications of) ASW correspond to seawater-based compositions. The $\mathrm{pH}$ of the brines was adjusted at room temperature by adding small amounts of $0.1 \mathrm{M} \mathrm{NaOH}$ or $\mathrm{HCl}$.

The brines and crude oils used for aging were pipetted into glass vials and kept in an oven at $60^{\circ} \mathrm{C}$ unless indicated otherwise. Mica slides are cleaved in air and immediately immersed in the aging brine for 24 hours. After removal from the aging brine, the mica sheets are held vertically in the air and excess fluid is allowed to drain for $\approx 1$ minute. Before the samples dry out they are immersed in crude oil and placed back into the oven, where they are left to age for another 4 days at $60^{\circ} \mathrm{C}$. Subsequently, the samples are allowed to cool down for 30 minutes, removed from the crude oil and rinsed with toluene to remove all excess crude oil that is not strongly bound to the surface. This process produces a thin transparent organic film on top of the mica sheets. Finally, the samples are blown dry with nitrogen and stored under nitrogen atmosphere. 
Table 5.1. Ion concentrations, ionic strength, calculated Debye length, and measured $\mathrm{pH}$ of all the main brines used in this work (see Supplementary Table $S 2$ for a complete overview). Sample codes with a dash indicate depletion of a specific species (-c for bicarbonate, and $-\mathrm{M}^{2+}$ for divalent cations).

\begin{tabular}{|c|c|c|c|c|c|c|c|c|c|c|}
\hline & \multirow{2}{*}{$\begin{array}{l}\text { Brine } \\
\text { name }\end{array}$} & \multicolumn{6}{|c|}{ Ion concentration (mM) } & \multirow{2}{*}{$\begin{array}{c}I S \\
(m M)\end{array}$} & \multirow{2}{*}{$\begin{array}{c}\lambda D \\
(n m)\end{array}$} & \multirow{2}{*}{$p H$} \\
\hline & & $\mathrm{Na}^{+}$ & $\mathrm{K}^{+}$ & $\mathrm{Ca}^{2+}$ & $\mathrm{Mg}^{2+}$ & $\mathrm{Cl}^{-}$ & $\mathrm{HCO}_{3}^{-}$ & & & \\
\hline \multirow{4}{*}{ 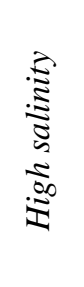 } & ASW & 404 & 10 & 13 & 112 & 660 & 2.3 & 792 & 0.3 & 8.8 \\
\hline & ASW-c & 402 & 10 & 13 & 112 & 660 & 0 & 786 & 0.3 & 6.0 \\
\hline & $\mathrm{ASW}_{-\mathrm{M}^{2+}}$ & 404 & 10 & 0 & 0 & 410 & 2.3 & 417 & 0.5 & 8.7 \\
\hline & CBA & 990 & 10 & 119 & 21 & 1280 & 0 & 1420 & 0.3 & 5.7 \\
\hline \multirow{2}{*}{ 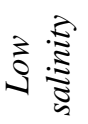 } & 1sASW & 13 & 0 & 0 & 4 & 21 & 0.1 & 25 & 1.9 & 8.7 \\
\hline & lsCBA & 14 & 0 & 2 & 0 & 17 & 0 & 20 & 2.2 & 6.3 \\
\hline
\end{tabular}

Contact angle measurements were performed with the mica slide attached to a quartz substrate and immersed horizontally in the measurement brine at $60^{\circ} \mathrm{C}$. A curved needle with oil was then inserted in the brine phase and allowed to thermally equilibrate with the ambient brine for 1 min before generating a $30 \mu \mathrm{L}$ oil droplet. The drop was brought in contact with the sample and the volume was increased and decreased, each over a period of $40 \mathrm{~min}$ (see Fig. 5.1). Advancing and receding contact angle (ARCA) measurements were performed on a Dataphysics OCA 20L goniometer equipped with a droplet dispensing unit, a temperature control stage (Dataphysics TFC 100Pro) and SCA20 Analysis Software. A home-made copper casing with a window for the optical path was mounted around the cuvette, and a thermometer in the brine was used to ensure the set temperature. Oil injection and retraction were carried out slowly because of the high oil viscosities. For each condition (aging brine, crude oil, ambient brine) 5-6 ARCA measurement series were done, with 2 measurements per sample. 

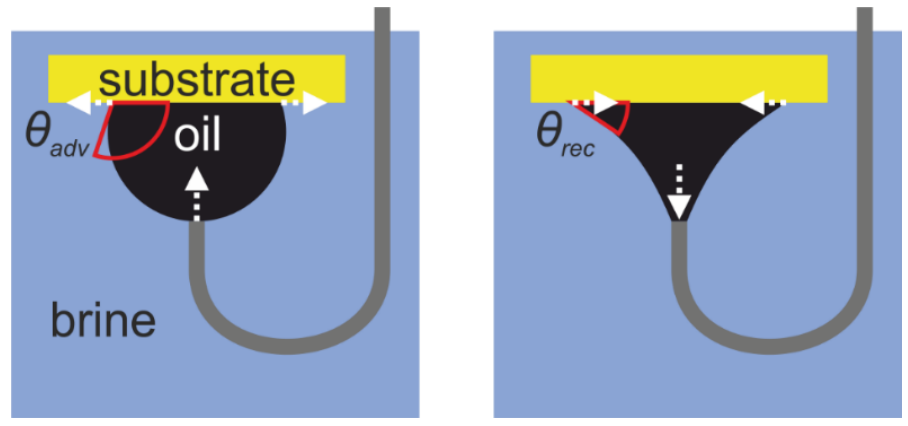

Figure 5.1. Captive droplet ARCA set-up schematic. Advancing and receding angles of a crude oil droplet are measured on an aged mica slide, immersed in either high or low salinity brine at a set temperature of $60^{\circ} \mathrm{C}$.

AFM imaging of dried substrates was performed using amplitude modulation ( $20 \mathrm{~nm}$ amplitude, set point at $18 \mathrm{~nm}$ ) in air using NSC36 cantilevers (MikroMasch) in a Bruker Dimension Icon. We also performed force volume measurements in ambient brine, using Scanasyst-Fluid cantilevers (Bruker), at room temperature. For the measurements in ambient brine, the substrates (aged in ASW, ASW-c, and $\mathrm{ASW}-\mathrm{M}^{2+}$ ) were placed in a glass petri dish and submerged together in $10 \mathrm{ml}$ brine. Forces were measured subsequently in ASW, lsASW, and finally in $1 \mathrm{mM} \mathrm{NaCl}$. The $\mathrm{pH}$ of these fluids was set to 6 by adding $\mathrm{HCl}$ to ensure a constant $\mathrm{pH}$ through the duration of the measurements $(\approx 8$ hours). Upon switching from one brine to another, the fluid in the measurement cell was exchanged three times while keeping the samples submerged. The latter allowed us to use the same AFM tip and substrate for several measurement conditions. For the force volume measurements, approach and retract curves were recorded on a grid of for $100 \times 100$ or $64 \times 64$ pixels with a maximum force upon closest approach of $5 \mathrm{nN}$. $F(z)$, force versus piezo displacement, curves were converted into $F(d)$, force vs. tip-sample separation, curves using standard procedures, see Supplementary Fig. 5.S1. Assuming that the indentation regime can be described by a force model where the cantilever and the substrate are two Hookean springs in series, the stiffness ('spring constant') of the substrate is extracted. 
The surface charge densities for each substrate in each of the different brines were calculated by fitting an electrostatic interaction model to the long-range $(d>5 \mathrm{~nm})$ part of the $F(d)$ approach curve. Experimental procedures and data analysis follow the principles described in references ${ }^{17,18}$. A simplified standard model was used to describe the interaction between two asymmetrically charged surfaces, the silica tip and the aged mica substrate, for weak overlap of the electric double layers: ${ }^{19}$

$$
F(d)=\frac{2 \pi r^{2} \sigma_{\text {tip }} \sigma_{\text {sample }}}{\varepsilon_{0} \varepsilon} e^{-\frac{d}{\lambda_{D}}}
$$

Here, $r$ is the interaction radius, $\sigma_{i}$ is the charge density of surface $i$ ( $\sigma_{\text {sample }}$ was used as a fit parameter, while $\sigma_{t i p}$ was extracted from a separate calibration measurement on a clean silica sample and was kept constant during fitting at $-0.08 \mathrm{e} / \mathrm{nm}^{2} \cdot{ }^{17} \varepsilon_{0} \varepsilon$ is the dielectric constant of water, and $\lambda_{D}$, the Debye screening length, was also used as a fit parameter. The tip-sample interaction radius was estimated to be $16 \mathrm{~nm}$ (corresponding well to the $20 \mathrm{~nm}$ tip radius given by the manufacturer) by fitting the function to a reference measurement on a silica substrate. In addition, it assumes that the tip geometry can be represented by a flat disk parallel to the surface. While the absolute values of the extracted surface charge densities are subject to errors due to the uncertainties and approximations involved in these calibration procedures, relative comparisons of $\sigma_{\text {sample }}$ between different samples are reliable because compared measurements were all performed with the same AFM tip.

Raman images of aged mica substrates were obtained in air using a WiTec alpha 300R Raman microscope, connected to a $532 \mathrm{~nm}$ laser via an optical fiber, the entrance of which acted as a pinhole. A $600 \mathrm{~g} / \mathrm{mm}$ grating was used, providing a spectral resolution of around $2.5 \mathrm{~cm}^{-1}$. An EMCCD camera $(1600 \times 200$ pixels, $16 \mu \mathrm{m}$ pixel size, Andor Newton) was used for detection. For high spatial resolution, a 100x objective (Zeiss, NA $=0.9$ ) was chosen. The laser power was measured at the sample using an optical power meter (ThorLabs). The integration time was $400 \mathrm{~ms} / \mathrm{pixel}$. Intensity maps for asphaltene compounds are obtained by integrating the area under the peaks at 1350 and $1580 \mathrm{~cm}^{-1}$ 
for every pixel (see Fig. 5.6). The baseline was subtracted using an algorithm developed by Zhang et al. ${ }^{20}$

\subsection{Results}

\section{Macroscopic Characterization}

The wettability of the aged mica substrates was examined by ARCA measurements using oil droplets, as illustrated in Fig. 5.2A. This typical experiment shows that after $\approx 10$ minutes of gradual inflation, the oil contact angle becomes fairly constant, while the base diameter is still increasing. The oil advancing contact angle, reflecting the most waterwet signature of the substrate, is thus measurable. The large angle of $\approx 140^{\circ}$ indicates that the oil drop has to overcome strongly hydrophilic regions on the substrate. We note that these regions might consist of rather small 'wetting defects' such as spots of bare mica on the otherwise organic layer-covered substrate. Upon deflating the droplet, the contact angle keeps decreasing for the majority of samples while the contact line remains pinned. A true receding contact angle is not reached in these cases, which is indicative of a very strongly oil-wet configuration. This ARCA signature with a strong contact angle hysteresis and very small receding contact angle was observed in most cases. Fig. 5.2B shows an exception to this picture, by displaying a finite receding c.a. of $\approx 90^{\circ}$ for case of crude oil $\mathrm{D}$ primed and characterized in ambient ASW. For a few other conditions, complete water wetting was observed (even on the crude oil-aged samples) with both advancing and receding contact angles close to $180^{\circ}$, indicating the presence of a stable water layer between the substrate and the oil. For each specific material composition and aging conditions the experiments were highly reproducible, as indicated by the error bars in Fig. 5.4. Occasional tests with samples that were aged for additional days in crude oil under the same conditions did not show any further evolution of the measured contact angles. 


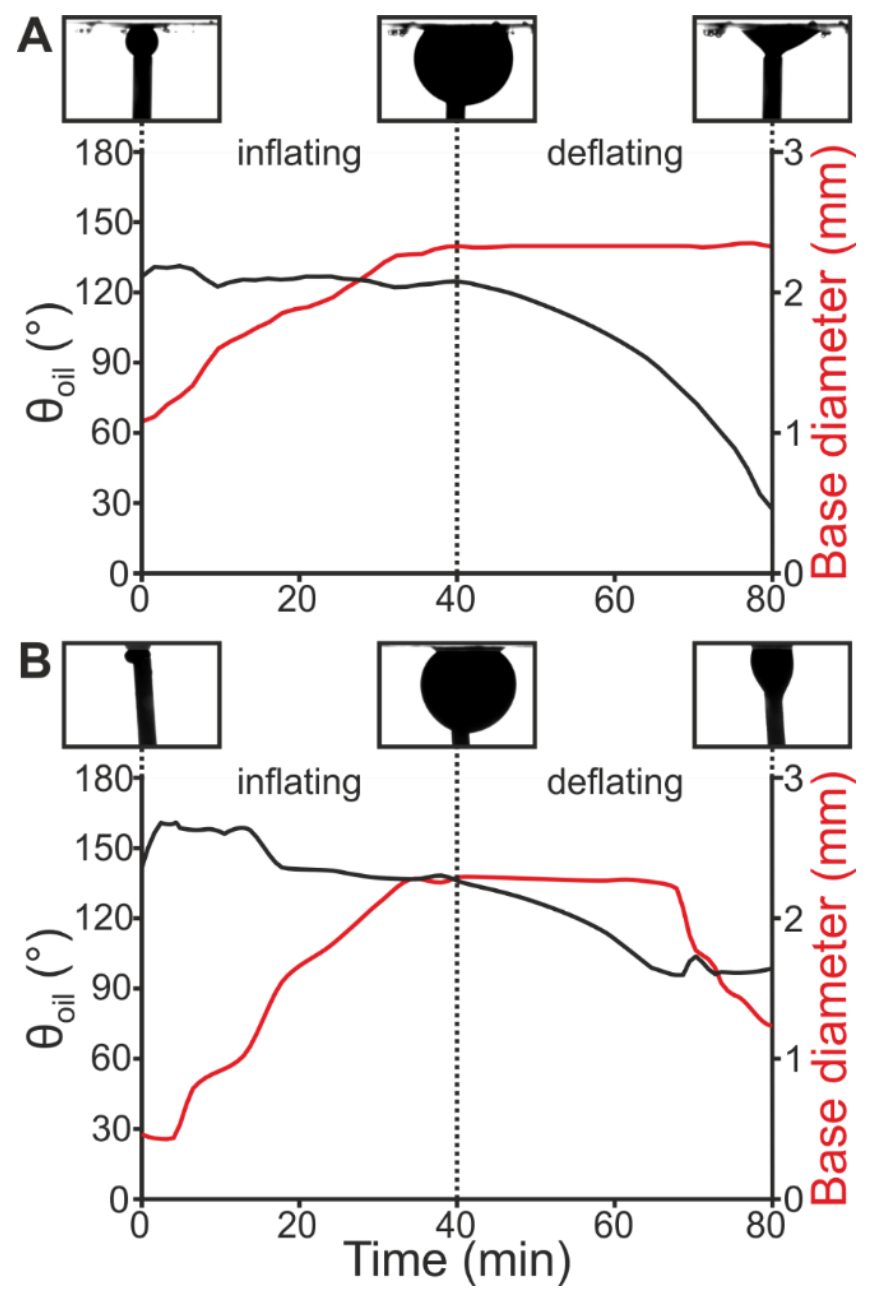

Figure 5.2. Example ARCA measurements showing two types of behavior: commonly, A) an advancing-, but no receding contact angle (crude oil A, aged and measured in $A S W)$, and rarely, $B$ ) showing both advancing- and receding contact angles ( $B$, crude oil D, aged with ASW, pH 6, measured in ASW). All aging and measurements performed with mica, at $60^{\circ} \mathrm{C}$; contact angles measured in the oil phase. 
Fig. 5.3 shows a comparison of advancing contact angles of crude oil A measured in high and low salinity brines on mica slides aged in the same crude oil but primed with variable aging brine. The snapshots clearly show the intriguing result that lowering the ambient salinity can result in both higher and lower contact angle (for the same crude oil and the same ambient measurement brine), depending on the composition, in this case the $\mathrm{pH}$, of the aging brine. Specifically, the aging brine had a pH of 8.8 in the middle row and $\mathrm{pH} 6.0$ (typical for injected seawater in sandstone reservoirs $)^{21}$ in the bottom row. Apparently, the aging brine, which plays the role of the connate brine affects the low salinity response observed in later stages of the experiment.

This strikingly strong dependence on the aging brine is not limited to the $\mathrm{pH}$ but is also observed upon changing the ion content of the aging brine, as shown in Fig. 5.4. Clearly, the variation of the advancing $\theta_{\text {oil }}$ is very wide, and includes situations of complete water wetting if the divalent cations are removed from the aging brine (ASW-M ${ }^{2+}$ ). The latter case implies that the crude oil drop remains separated from the aged mica surface by a thin but stable brine film. From the perspective of macroscopic phenomenology, the brine film gives rise to the same wetting behavior as freshly cleaved (i.e. non-aged) mica. Yet, as we will see in the AFM images below, the two types of surfaces are microscopically very different. Fig. 5.S2 shows a more extended set of contact angle data for various crude oils, aging and measurement brine compositions. From that overview, it becomes clear that that the strong dependence (of both the contact angles and the low salinity effect) on details of the aging brine composition should indeed be regarded as a rather general phenomenon. 


\title{
Aging brinel $\mathrm{pH}$ \\ ${ }_{\mathrm{pH}} 8.7$
}

High salinity

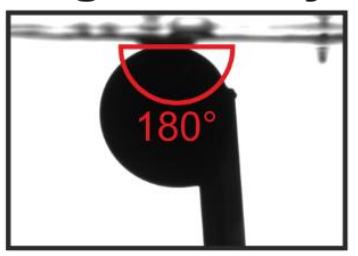

Low salinity

\author{
ASW \\ $\mathrm{pH} 8.8$
}
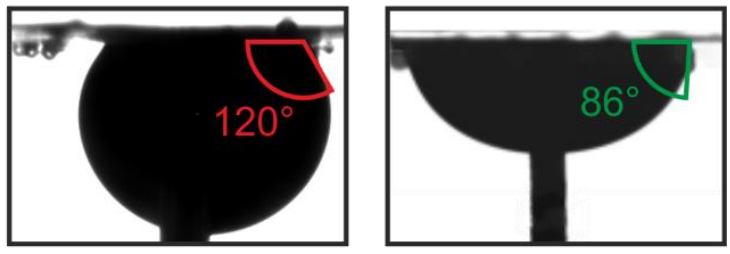

ASW
pH 6.0
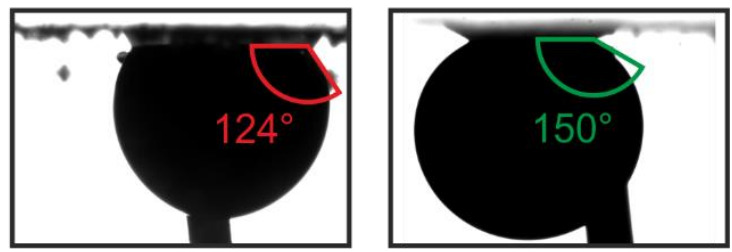

Figure 5.3. Illustration of advancing contact angles of crude oil A on aged mica slides for $T=60^{\circ} \mathrm{C}$ upon both aging and measurement. Top row: brines CBA (left) and lsCBA (right). Middle and bottom rows: ASW and lsASW. 


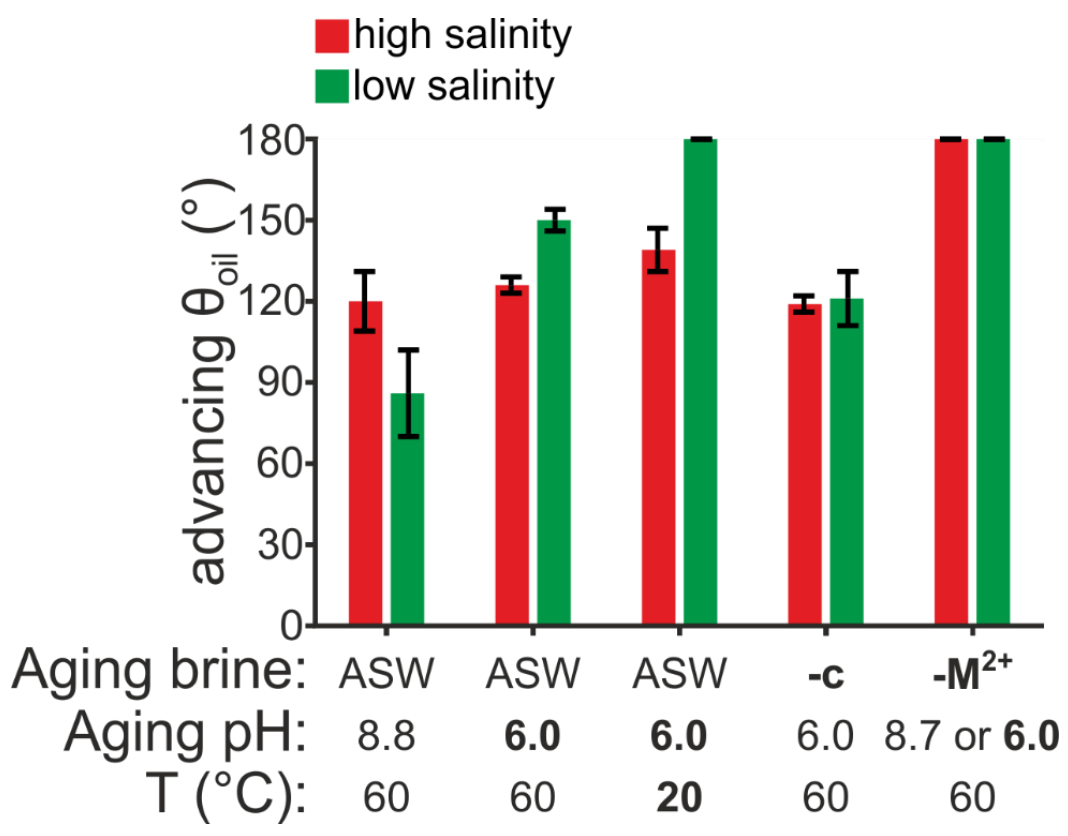

Figure 5.4. Advancing contact angles of crude oil drops on mica, measured in ambient brines of high-and low-salinity $A S W\left(p H \approx 8.8,60^{\circ} \mathrm{C}\right)$. The difference between the data sets lies in the aging brines, which were all based on ASW $\left(\mathrm{pH} \approx 8.8,60^{\circ} \mathrm{C}\right)$, but with different $\mathrm{pH}$, temperature or the depletion of certain ions. These deviations from standard ASW are emphasized in boldface. Error bars indicate standard deviations of advancing contact angles.

\section{Ex-Situ AFM Topography}

Aiming for a better understanding of the origin of these macroscopic phenomena, we proceeded to characterize the samples microscopically using tapping mode AFM. To this end, we dried the toluene-washed mica samples after the completion of the aging steps and imaged them in air. Optical inspection reveals occasional defects on the submillimeter scale but displays otherwise a rather homogeneous coating with apparently well-defined average properties. Fig. 5.5 provides an overview of the surface topography over several length scales recorded in these representative areas of mica surfaces aged in crude oil A after 
priming in variable aging brine as indicated. For each aging condition we captured at least two images per scan range, obtained from different substrates, and consistently found rather similar looking structures. Fig. 5.S3 shows similar data for other crude oils and aging conditions.

Despite the substantial variations of the response seen in the macroscopic contact angle, the surfaces look rather similar in AFM. All samples clearly display material that was deposited on the originally atomically flat mica surfaces during the aging procedure. The resulting surface roughness displays two characteristic length scales, namely a small scale roughness with a characteristic lateral length scale of several tens of nanometers and a height of the several nanometers that covers the entire surface rather homogeneously. These particles are reminiscent of earlier reports studying crude oil treated substrates. Some authors attributed these features to micelles or aggregates of asphaltenes. ${ }^{22,}{ }^{23}$ On top of this layer, additional protrusions with a lateral size of a few micrometers and a wide range of heights of the order of $100 \mathrm{~nm}$ can be seen. Figs. 5.S3 and 5.S4 provide an overview of the root-mean-square roughness and the average coverage of the larger protrusions for the AFM images of Figs. 5.5 and 5.S2. Notwithstanding the observed variations, no clear correlation between the topographic features of the surface and the macroscopic wettability could be identified. Only for crude oils C and D, the small scale asphaltene aggregates seemed distinctly less prominent (Fig. 5.S3). 


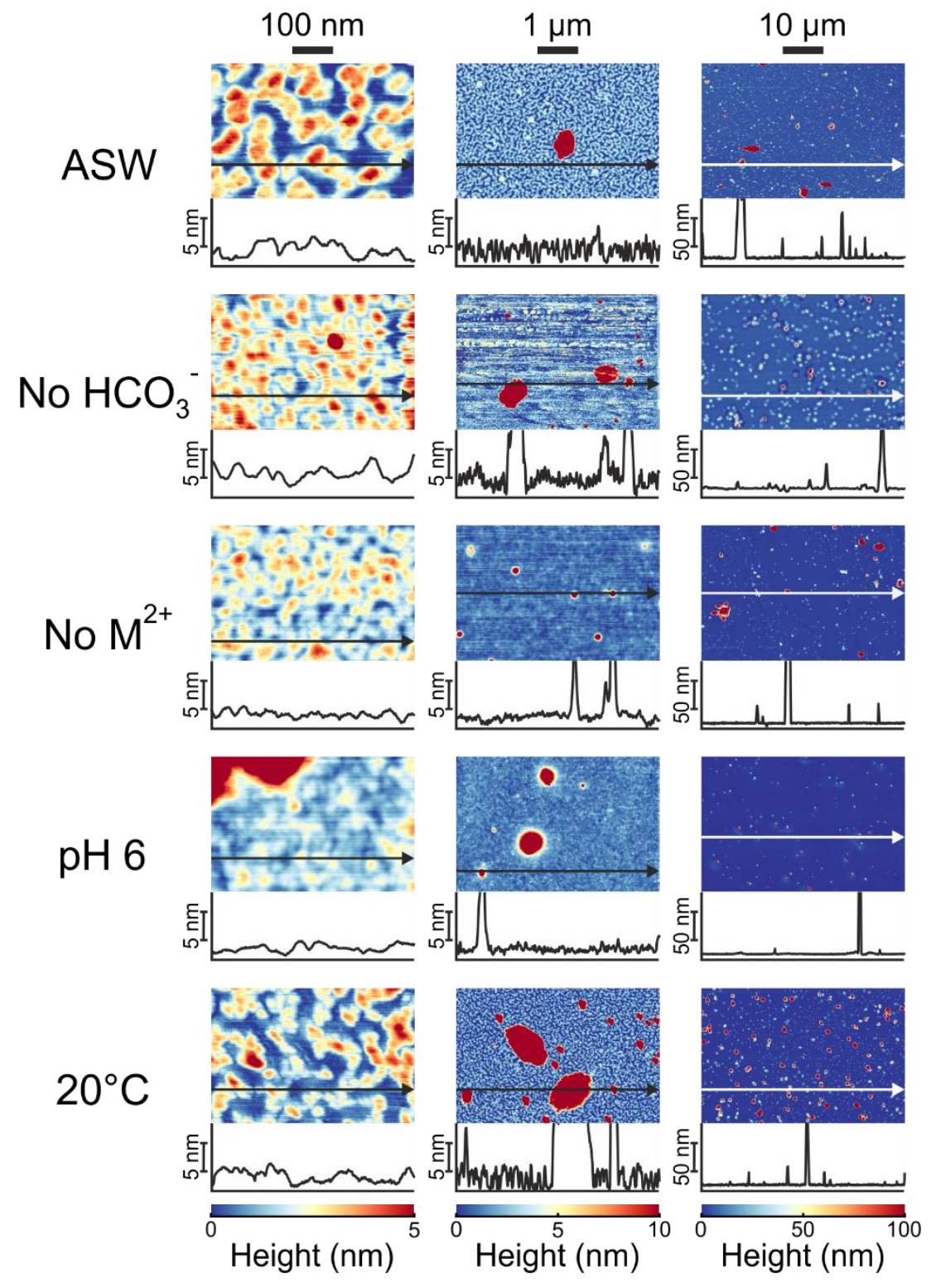


Figure 5.5. (opposite page) Substrate topography of dried deposits on mica, obtained using variations on ASW as the aging brine. Representative examples of AFM height images and cross-sections of dried aged mica substrates (ASW and crude oil $\mathrm{A}$ at $60^{\circ} \mathrm{C}$ ) at different lateral scan ranges: $0.5 \mu \mathrm{m}, 5 \mu \mathrm{m}$, and $50 \mu \mathrm{m}$.

\section{Ex-Situ Confocal Raman Microscopy}

Complementary information about the dry samples was obtained using CRM. While this technique is in principle capable of unraveling the chemical make-up of structures observed through a light microscope based on the specific vibrational fingerprint of each molecule, the material adsorbed from the various crude oils onto the mica substrates displays a very strong background fluorescence that overwhelms much of the vibrational information. To proceed, we first de-noised the CRM spectra using principal component analysis (see reference for a recent discussion $)^{24}$ and subsequently removed the fluorescent background as shown in Fig. 5.6. After this procedure, the well-known peaks of the G$\left(1580 \mathrm{~cm}^{-1}\right)$ and D- $\left(1350 \mathrm{~cm}^{-1}\right)$ bands associated with graphitic sheets are clearly visible and can be described by a superposition of four Gaussians. These peaks are known to be found in the presence of asphaltenes. They are attributed to their graphitic sheet-like structure and the defects such as broken bonds and substituted atoms therein. ${ }^{25}$ 

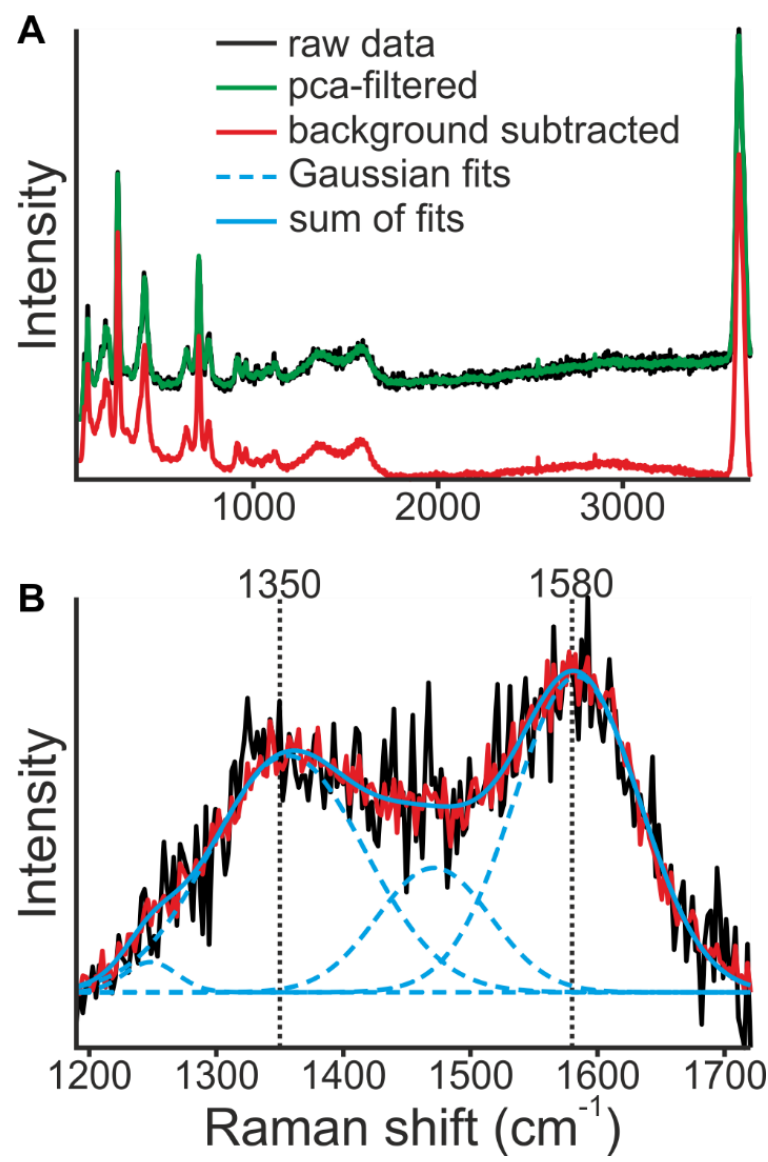

Figure 5.6. Raman spectrum captured from an aged mica substrate (ASW and crude oil A, $60^{\circ} \mathrm{C}$, same as in Fig. 5.7A, ASW): full spectrum + PCA noisefiltering and background subtraction (A), Gaussian fits showing the presence of $G^{-}\left(\approx 1580 \mathrm{~cm}^{-1}\right)$ and D1-bands $\left(\approx 1350 \mathrm{~cm}^{-1}\right)$ of noise-filtered background subtracted data, and two additional Gaussian curves needed to obtain a good fit (B).

Comparing the Raman and AFM topography maps taken at the same location on differently aged mica slides, we find a clear 
correspondence between topographic protrusions in the AFM maps and enhanced Raman scattering intensities in the range of the G- \& D-bands (see Fig. 5.7). This supports the notion that the structures observed in the AFM images contain asphaltenes. We also find slight differences in the D- and G-band intensities, both between samples of different aging conditions, and within each sample when comparing the spectra from protrusions to the ones from films, see Fig. 5.7C. The spectra shown in this figure are consolidated from approximately 50.000 curves. This implies that the differences, even though relatively subtle, are statistically relevant. They thus indicate significant chemical differences between the samples. For instance, slight differences in the intensity peak ratios between the D and G bands in Fig. 7C suggest that the average size of the asphaltenic aggregates in the protrusions is somewhat larger than in the adjacent film.

Remarkably, no evidence was found for a clear correlation between the microscopic structure and the macroscopic wettability. From Fig. 5.4, we know that the samples in the left and in the middle column of Fig. 5.7 display partial wetting, whereas the one aged in ASW-M ${ }^{2+}$ brine displays complete water wetting. Clearly, the modest differences between the microscopic images do not offer a basis for understanding the dramatic variations in contact angle. 

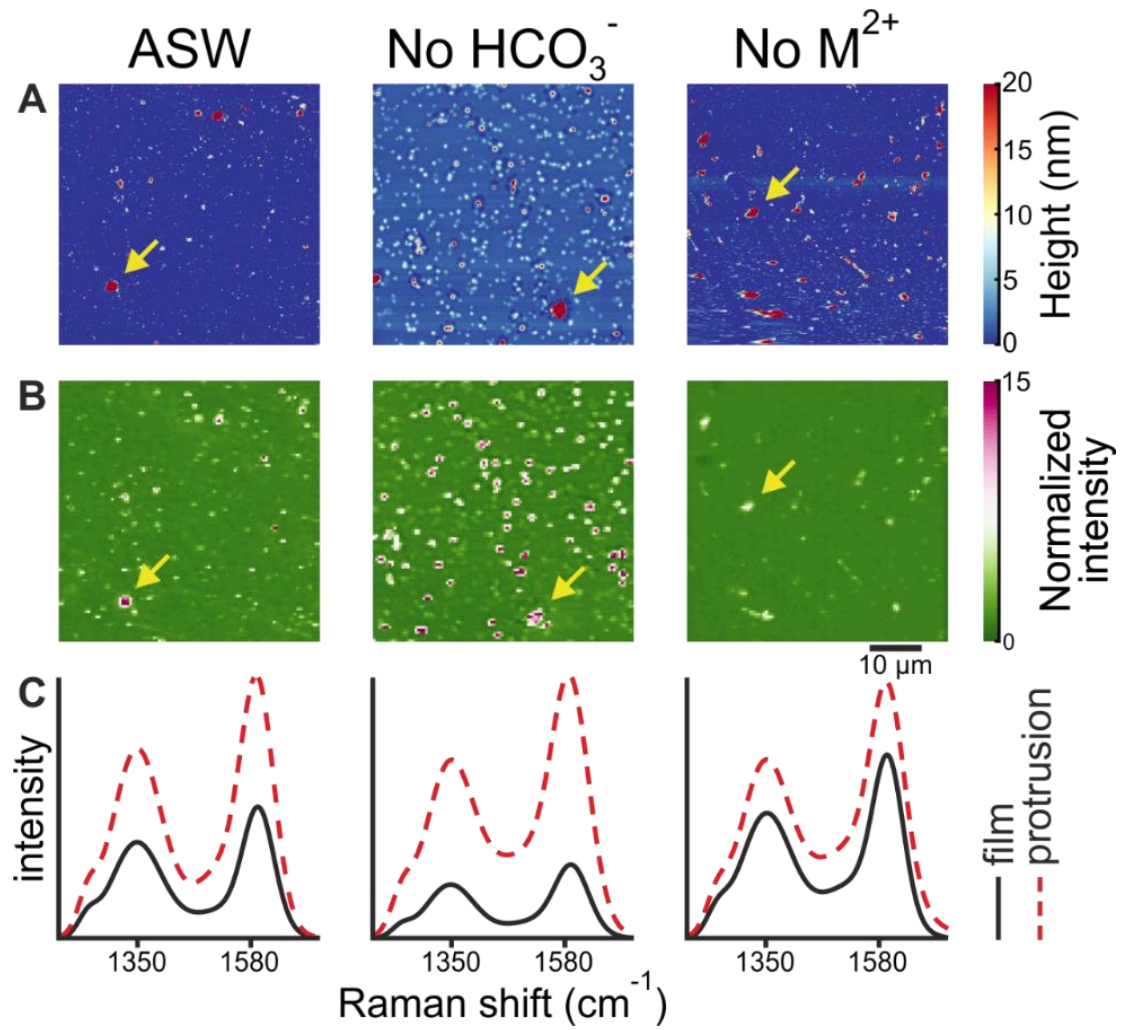

Figure 5.7. $50 \times 50 \mu \mathrm{m}$ images of dried aged mica substrates (crude oil and ASW-based brine, $60^{\circ} \mathrm{C}$ ): AFM height, $512 \times 512$ pixels (A), and Raman $G$ - \& $D$-band integrated intensities, normalized to the intensity in the film, $100 \times 100$ pixels (B). The Gaussian fits (see Fig. 5.6) to the median G-and D-band spectra of the film and protrusions from each map, normalized to the peak intensity of the protrusion G-band, are also shown $(C)$. Arrows indicate some major features for reference.

\section{In Situ AFM Characterization}

A major difference between the macroscopic contact angle measurements and the microscopic data discussed so far is obviously that the former are recorded in ambient brine while the latter were performed in air. It is conceivable that the lack of ability to discriminate 
between different wetting properties of the asphaltenic layers, arises from the fact that the layers simply look very similar in ambient air but reveal their different composition and response only upon exposure to brine. Hence, we continued to explore the properties of these layers by AFM imaging and spectroscopy, so-called force volume mapping, in ambient brine (using again conventional sharp AFM tips made from silica).

Force-volume mapping experiments can in principle reveal a wealth of information: relative height and stiffness of the layer, and nearcontact interactions such as electrostatic, adhesion or hydration forces. However a clean separation of these contributions can be challenging, and to limit the scope of this work we will look only at mechanical properties of the layers and their surface charge, since the former can be extracted from the 'direct contact' region of the force curve and the latter from the long-range region, with no overlap (see Fig. 5.S1). Measurements were performed on mica aged in ASW, ASW-c, and ASW-M ${ }^{2+}$. The topography and mechanical stiffness images $(500 \mathrm{~nm}$ scan size) for ASW-M ${ }^{2+}$ are shown in Fig. 5.8 (measured at $\mathrm{pH} 6$ in ASW and lsASW respectively). Also $50 \mu \mathrm{m}$ scan size images were measured; these are shown in Supplementary Fig. 5.S6. Median forcedistance curves of these measurements give a good impression of the interactions measured; these are shown in Supplementary Fig. 5.S7

From the topography images it is immediately clear that the structures appear much flatter than for the dry substrates, and no protrusions are visible in the $500 \mathrm{~nm}$ images for the standard, and no $\mathrm{HCO}_{3}{ }^{-}$samples (although sparse protrusions do exist for all conditions, as shown in the $50 \mu \mathrm{m}$ images). The substrates aged in ASW-M ${ }^{2+}$ brine also show features, that were not found on dry substrates: protrusions up to $30 \mathrm{~nm}$ cover the flatter structures below in a connected network (see Fig. 5.10A, right column for a $5 \mu \mathrm{m}$ image showing this network more clearly). Comparing the topography images taken in the ASW and the lsASW ambient brines, none of the samples show much difference. 

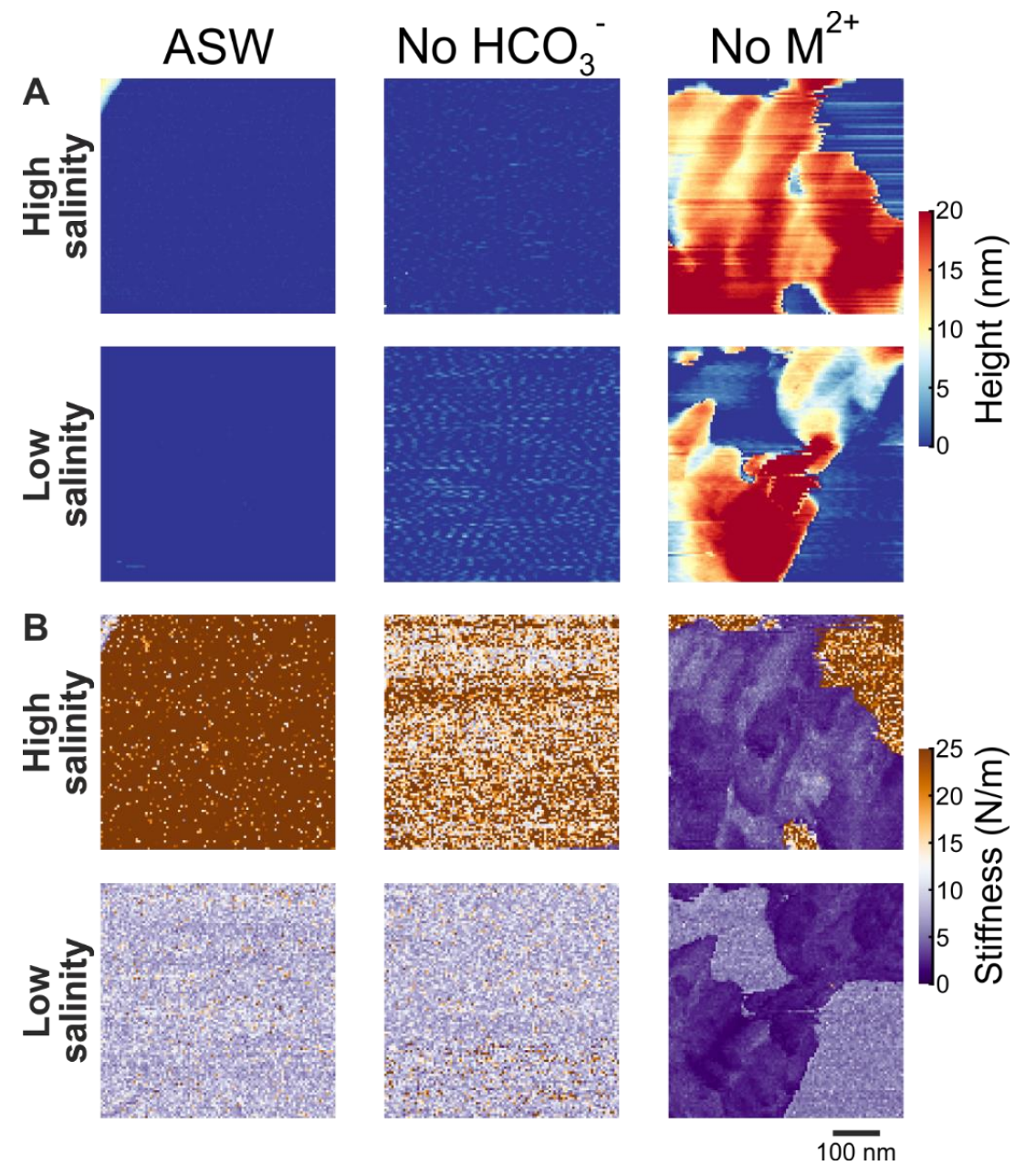

Figure 5.8. In-situ force volume AFM measurements at high salinity. $500 \times 500$ $n m$ images of aged mica substrates (crude oil and ASW-based brine, $60^{\circ} \mathrm{C}$ ) submerged in $A S W$, and lsASW, at pH 6: height (A), and substrate stiffness (B). 


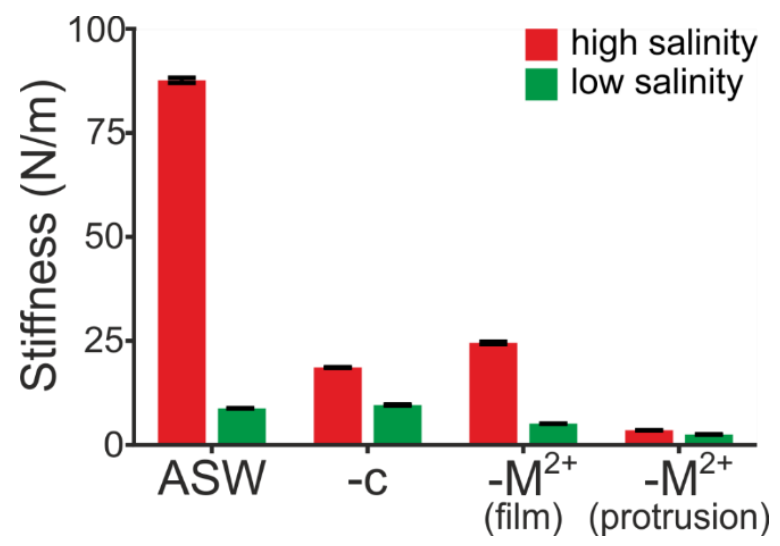

Figure 5.9. Mean substrate stiffness and standard errors extracted from $500 \times 500 \mathrm{~nm}$ force volume maps, measured in ASW and lsASW at pH 6 on mica substrate aged in crude oil $A$ and various ASW-based brines as indicated at $60^{\circ} \mathrm{C}$.

The calculated interaction stiffness on the different materials (Fig. 5.8B \& 5.9) show that all samples become softer at low salinity conditions, and that the aforementioned protrusions are much softer than the underlying film. As bare mica is expected to have a much higher stiffness (comparable to that of silica, ${ }^{26,27}$ which is here assumed to have infinite stiffness for cantilever calibration) which would not alter due to salinity conditions, these results indicate that the entire substrate is covered in a deformable organic film of unknown thickness. The changes in stiffness with salinity could be due to swelling of the organic film, or another form of structural reorganization. Upon drying, the substrates do not return to their original dry topography but do overall regain some detectable roughness (see Supplementary Fig. 5.S8).

Lastly we also measured the surface charge densities of the substrates, as these are indicative of exposed functional groups. Since the ionic strength felt by the submerged substrates is $26 \mathrm{mM}$ at low salinity conditions, the Debye length is only on the order of $1 \mathrm{~nm}$ (see Table 5.1), which is too small to extract any reliable electric double layer force (see the force curves in Supplementary Fig. 5.S7). 
Therefore, we also performed the force volume measurements on the same substrates, at $1 \mathrm{mM} \mathrm{NaCl}$ and used the exponentially decaying force at tip-sample separations $>5 \mathrm{~nm}$ to extract the surface charge (see Fig. 5.S9). Our analysis (see Fig. 5.10) shows that all samples are predominantly negatively charged, and notably, that the different aging conditions significantly affect the surface charge density. It also shows that surface charge, just like stiffness and chemistry, seems to correlate with topographical structures, indicating a salinity-induced . In this case, protrusions on the film generally show a more neutral charge, and areas of flat film a stronger, more negative charge.

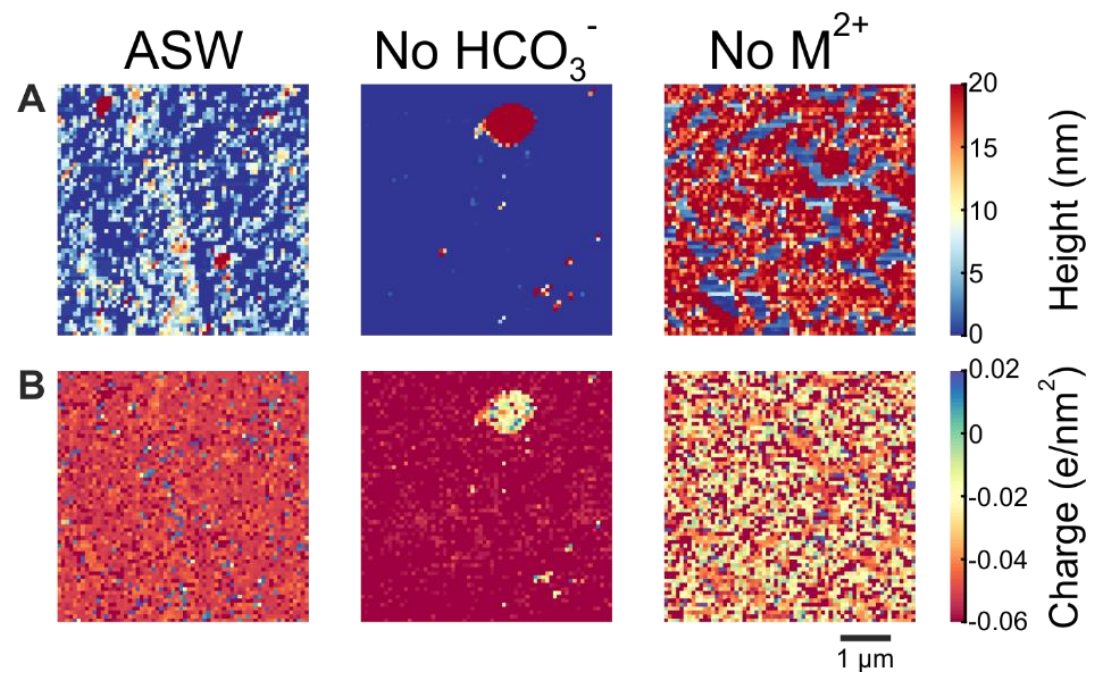

Figure 5.10. $5 \times 5 \mu \mathrm{m}$ images extracted from AFM force-volume measurements with a silica probe on aged mica (crude oil A and $A S W$-based brine, $60^{\circ} \mathrm{C}$ ), immersed in $1 \mathrm{mM} \mathrm{NaCl}$ at $20^{\circ} \mathrm{C}$. These images show that the brine content during aging can significantly affect the density of charged groups of the substrate.

\subsection{Discussion}

Our study into the influence of the aging brine on the wettability of mica mineral, involves several steps between the cause and the effect: the brine modifies the mica surface, which then changes the adsorption and 
assembly of components from the crude oil, which in turn alters the wettability of the finally obtained substrate. In the present work we looked at the overall effect, while also zooming in on the latter two steps. These steps involving adsorption from crude oil are well addressable with experiments, and were studied relatively little before, especially not in-situ. $5,28,29,30$

The overall effect of aging-brine composition on the wettability (measured via the oil contact angle) was found to be remarkably strong, i.e. differences of several tens of degrees for the same contact angle advancing or receding) in the same ambient brine. Comparing the (more reliable) advancing contact angles in high-and low-salinity ambient brines, also a diversity of 'low salinity effects' was observed: favorable (higher oil advancing contact angle), unfavorable and no effect. The fact that these behaviors were found for many combinations or crude oil and aging brine, suggests that (where possible) the conditions of reservoir aging should be taken into account when deciding to use low salinity water injection or not. The assumption that our mica substrates and the pristine reservoir rock behave similarly in this context, would still need to be experimentally verified.

The circumstance that the aging brine influences the wetting behavior indirectly via the adsorbed layer, combined with our microscopic characterization of the substrates, allows us to infer qualitatively what might happen during the several stages leading up to wettability alteration. Firstly, the ions in the aging brine must have a significant effect on the mica substrate before the latter gets submerged in the crude oil for further aging. In absence of high vacuum during the drying step, a thin aqueous film will be left behind on the mica, containing cations bound to the mica lattice and several other ions entrapped within the thin water film. Then, when crude oil is introduced, organic components are bound to the substrate via these ions. Due to the high salinities of the aging brines and the confined nature of the water film, the interactions binding these organic components are likely to be highly ion specific in nature, such as through coordination complexation. 
In analyzing the various aged substrates we found that these bound organic layers completely cover the substrate, with specific topographic regions correlating with chemical makeup. Differences in the ionic content of the aforementioned water films likely also seem to dictate the architecture of these films: although topographically most were similar, chemically and mechanically clear differences were found. Even though the exact chemical nature of the layers remains unknown, our CRM and surface charge measurements do indicate that the initial brine content likely dictates the adsorption behavior of the organic compounds, and thereby which chemical groups are exposed at the surface. The dry structure of the films as well as the CRM data indicate that these compounds are likely predominantly asphaltenes. This would not be unexpected considering the abundance of asphaltenes in most crude oils, and their tendency to adhere to substrates and to aggregate with each other. ${ }^{31,}{ }^{32}$ However also other (e.g. non-aromatic polar) components, which are more difficult to detect with CRM due to the strong background fluorescence, might be involved, as suggested by recent measurements on the salinity dependence of produced oil composition. ${ }^{33}$ When the films are brought in contact with brines, their topography radically changes, likely due to swelling and reorganization of the films. It therefore appears that some water may penetrate within these organic structures, which is not unlikely considering that the large advancing contact angles of the oil do indicate at least partially hydrophilic substrates.

The surface charge differences of the organic films are key to their effect on wettability and salinity response. The charges are indicative of exposed functional groups such as carboxylates (since we measure mostly negative charges), which can interact with other groups in bulk crude oil to either bind or release them, depending on salinity conditions. For example, no salinity effects were found for the samples aged without divalent cations, as oil droplets could not make direct contact with these substrates. It was also these samples that showed networks of protruded areas with a close to neutral charge, suggesting that the absence of divalent cations had promoted the adsorption of uncharged species. Samples that did allow for contact and did show 
salinity responses were found to be more negatively charged, suggesting the preferential adsorption of compounds with charged groups that facilitate interaction with the oil droplets. Jackson et al. have found that the polarity of the oil/water interface, which they show depends on the type of oil used, can strongly influence the effect of ionic content on oil recovery. ${ }^{34}$ We have now shown that this factor does not only depend on the oil, but can also be significantly altered by the contents of the connate brine.

Fig. 5.11 shows a speculative representation of how the asphaltenes might interact with both the crude oil droplets and the mica through cations of the brine. The organic layer is first bound to the mica through a brine film present during aging, where the ionic content is an important factor in the preferential adsorption of specific organic compounds. In order to bind the asphaltenes, this water film cannot be thicker than a few $\mathrm{nm}$, as this is the typical maximum range of interaction between mineral substrate and asphaltenes, ${ }^{35,}, 36$ which we also found in our silica probe-asphaltenic substrate interaction curves. When the aged substrate is submerged some brine can penetrate within it, further altering its structure. Then a crude oil droplet, also containing charged groups at its interface, is brought in contact with it. Here, again specific cation effects are likely an important factor controlling the oil/substrate interaction through specific binding with charged organic groups. 


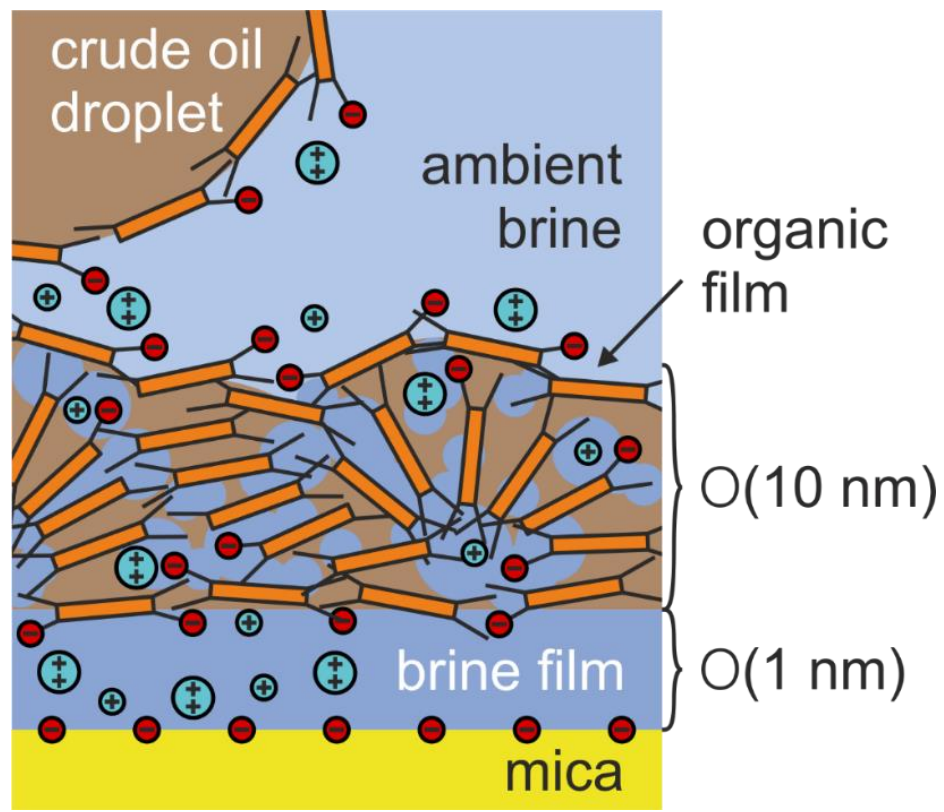

Figure 5.11. Schematic representation of a crude oil droplet contacting an aged mica substrate in ambient brine, showing cations interacting with negatively charged groups of asphaltenes and mica.

\subsection{Conclusion}

The aging conditions of mica substrates in brine and crude oil systems, was found to be of major importance to their macroscopic wetting properties and to the salinity response of those properties. We found that, through again, thin asphaltenic surface layers irreversibly adsorb, and that these layers are heterogeneous in terms of topographical, chemical, and mechanical properties. The latter two depend on the ionic content of the connate brine present during aging. We also found that this ionic content is more important in influencing the eventual wetting properties of the substrates than the type of crude oil used, even though only a very thin film of brine is present during the aging process. Very small amounts of specific ions (most prominently shown by the divalent cations) can apparently control which species from the crude oil adsorb 
to the substrate, and how. This, in turn, has major consequences for its wetting properties.

After these organic components have adsorbed, they completely coat the substrate, meaning that there is no direct interaction of the crude oil droplets with the underlying mineral substrate. It might therefore be that the mineral properties are only relevant for the initial adsorption of organic components, and are not directly causing the wetting properties. The wettability of the crude oil treated substrates by crude oil droplets thus seems most strongly related to the wet roughness geometry, as well as short-range cation-specific interactions due to adsorbed organic species. The implication of these findings is that the salinity response of reservoir systems will depend not only on the compositions of the crude oil and injected brine, but also on the history of the system and particularly its connate brine. 


\section{References}

1. Muggeridge, A.; Cockin, A.; Webb, K.; Frampton, H.; Collins, I.; Moulds, T.; Salino, P. Recovery Rates, Enhanced Oil Recovery and Technological Limits. Philosophical transactions. Series A, Mathematical, physical, and engineering sciences 2014, 372 (2006), 20120320.

2. Morrow, N.; Buckley, J. Improved Oil Recovery by Low-Salinity Waterflooding. 2011.

3. Morrow, N. R.; Tang, G. Q.; Valat, M.; Xie, X. Prospects of Improved Oil Recovery Related to Wettability and Brine Composition. Journal of Petroleum Science and Engineering 1998, 20 (3-4), 267-276.

4. Yu, L.; Buckley, J. S. Evolution of Wetting Alteration by Adsorption from Crude Oil. SPE Formation Evaluation 1997, 12 (01), 5-12.

5. $\quad$ Mugele, F.; Bera, B.; Cavalli, A.; Siretanu, I.; Maestro, A.; Duits, M.; Cohen-Stuart, M.; van den Ende, D.; Stocker, I.; Collins, I. Ion AdsorptionInduced Wetting Transition in Oil-Water-Mineral Systems. Scientific Reports 2015, 5, 10519.

6. Matthiesen, J.; Bovet, N.; Hilner, E.; Andersson, M. P.; Schmidt, D. A.; Webb, K. J.; Dalby, K. N.; Hassenkam, T.; Crouch, J.; Collins, I. R.; Stipp, S. L. S. How Naturally Adsorbed Material on Minerals Affects Low Salinity Enhanced Oil Recovery. Energy \& Fuels 2014, 28 (8), 4849-4858.

7. Tang, G.-Q.; Morrow, N. R. Influence of Brine Composition and Fines Migration on Crude Oil/Brine/Rock Interactions and Oil Recovery. Journal of Petroleum Science and Engineering 1999, 24 (2-4), 99-111.

8. Jackson, M.; Vinogradov, J.; Hamon, G.; Chamerois, M. Evidence, Mechanisms and Improved Understanding of Controlled Salinity Waterflooding Part 1: Sandstones. Fuel 2016, 185, 772-793.

9. Sharma, M.; Filoco, P. Effect of Brine Salinity and Crude-Oil Properties on Oil Recovery and Residual Saturations. SPE Journal 2000, 5 (03), 293-300.

10. Liu, Q.; Dong, M.; Asghari, K.; Tu, Y. Wettability Alteration by Magnesium lon Binding in Heavy Oil/Brine/Chemical/Sand Systems-Analysis of Electrostatic Forces. Journal of Petroleum Science and Engineering 2007, 59 (1-2), 147-156.

11. Yang, J.; Dong, Z.; Dong, M.; Yang, Z.; Lin, M.; Zhang, J.; Chen, C. Wettability Alteration During Low-Salinity Waterflooding and the Relevance of Divalent lons in This Process. Energy \& Fuels 2016, 30 (1), 72-79. 
12. Shehata, A. M.; Nasr-El-Din, H. A. Laboratory Investigations to Determine the Effect of Connate-Water Composition on Low-Salinity Waterflooding in Sandstone Reservoirs. SPE Reservoir Evaluation \& Engineering 2017, 20 (01), 59-76.

13. Boek, E. S.; Venturoli, M. Lattice-Boltzmann Studies of Fluid Flow in Porous Media with Realistic Rock Geometries. Computers \& Mathematics with Applications 2010, 59 (7), 2305-2314.

14. Singh, K.; Scholl, H.; Brinkmann, M.; Di Michiel, M.; Scheel, M.; Herminghaus, S.; Seemann, R. The Role of Local Instabilities in Fluid Invasion into Permeable Media. Scientific Reports 2017, 7.

15. Buckley, J. S.; Lord, D. L. Wettability and Morphology of Mica Surfaces after Exposure to Crude Oil. Journal of Petroleum Science and Engineering 2003, 39 (3-4), 261-273.

16. Kumar, K.; Dao, E.; Mohanty, K. K. Afm Study of Mineral Wettability with Reservoir Oils. Journal of Colloid and Interface Science 2005, 289 (1), 206217.

17. Ebeling, D.; Van den Ende, D.; Mugele, F. Electrostatic Interaction Forces in Aqueous Salt Solutions of Variable Concentration and Valency. Nanotechnology 2011, 22 (30), 305706.

18. Kumar, N.; Zhao, C.; Klaassen, A.; van den Ende, D.; Mugele, F.; Siretanu, I. Characterization of the Surface Charge Distribution on Kaolinite Particles Using High Resolution Atomic Force Microscopy. Geochimica et Cosmochimica Acta 2016, 175, 100-112.

19. Israelachvili, J. N. Intermolecular and Surface Forces: Revised Third Edition; Academic press2011.

20. Zhang, Z.-M.; Chen, S.; Liang, Y.-Z. Baseline Correction Using Adaptive Iteratively Reweighted Penalized Least Squares. Analyst 2010, 135 (5), 1138-1146.

21. Shi, L.; Olsson, M. H. M.; Hassenkam, T.; Stipp, S. L. S. A Ph-Resolved View of the Low Salinity Effect in Sandstone Reservoirs. Energy \& Fuels 2016, 30 (7), 5346-5354.

22. Joonaki, E.; Buckman, J.; Burgass, R.; Tohidi, B. Water Versus Asphaltenes; Liquid-Liquid and Solid-Liquid Molecular Interactions Unravel the Mechanisms Behind an Improved Oil Recovery Methodology. Scientific reports 2019, 9 (1), 11369-11369. 
23. Cadena-Nava, R. D.; Cosultchi, A.; Ruiz-Garcia, J. Asphaltene Behavior at Interfaces. Energy \& Fuels 2007, 21 (4), 2129-2137.

24. Nair, S.; Gao, J.; Yao, Q.; Duits, M. H.; Otto, C.; Mugele, F. AlgorithmImproved High Speed and Non-Invasive Confocal Raman Imaging of TwoDimensional Materials. National Science Review 2019.

25. Abdallah, W. A.; Yang, Y. Raman Spectrum of Asphaltene. Energy \& Fuels 2012, 26 (11), 6888-6896.

26. Engineering Toolbox: Young's Modulus - Tensile and Yield Strength for Common Materials. https://www.engineeringtoolbox.com/youngmodulus-d 417.html (accessed 30/12/2019).

27. Teich-McGoldrick, S. L.; Greathouse, J. A.; Cygan, R. T. Molecular Dynamics Simulations of Structural and Mechanical Properties of Muscovite: Pressure and Temperature Effects. The Journal of Physical Chemistry C 2012, 116 (28), 15099-15107.

28. Kobayashi, K.; Liang, Y.; Murata, S.; Matsuoka, T.; Takahashi, S.; Nishi, N.; Sakka, T. Ion Distribution and Hydration Structure in the Stern Layer on Muscovite Surface. Langmuir 2017, 33 (15), 3892-3899.

29. Siretanu, I.; Ebeling, D.; Andersson, M. P.; Stipp, S. S.; Philipse, A.; Stuart, M. C.; Van Den Ende, D.; Mugele, F. Direct Observation of Ionic Structure at Solid-Liquid Interfaces: A Deep Look into the Stern Layer. Scientific reports 2014, 4, 4956.

30. Mugele, F.; Siretanu, I.; Kumar, N.; Bera, B.; Wang, L.; de Ruiter, R.; Maestro, A.; Duits, M.; van den Ende, D.; Collins, I. Insights from lon Adsorption and Contact-Angle Alteration at Mineral Surfaces for Low-Salinity Waterflooding. 2016.

31. Buckley, J. S.; Liu, Y.; Xie, X.; Morrow, N. R. Asphaltenes and Crude Oil Wetting-the Effect of Oil Composition. SPE journal 1997, 2 (02), 107-119.

32. Buckley, J. S.; Wang, J. Crude Oil and Asphaltene Characterization for Prediction of Wetting Alteration. Journal of Petroleum Science and Engineering 2002, 33 (1-3), 195-202.

33. Collins, I. R.; Couves, J. W.; Hodges, M.; McBride, E. K.; Pedersen, C. S.; Salino, P. A.; Webb, K. J.; Wicking, C.; Zeng, H. Effect of Low Salinity Waterflooding on the Chemistry of the Produced Crude Oil. In SPE Improved Oil Recovery Conference; Society of Petroleum Engineers: Tulsa, Oklahoma, USA, 2018, p 17. 
34. Jackson, M. D.; Vinogradov, J. Impact of Wettability on Laboratory Measurements of Streaming Potential in Carbonates. Colloids and Surfaces A: Physicochemical and Engineering Aspects 2012, 393, 86-95.

35. Hu, X.; Yutkin, M. P.; Hassan, S.; Wu, J.; Prausnitz, J. M.; Radke, C. J. Asphaltene Adsorption from Toluene onto Silica through Thin Water Layers. Langmuir 2019, 35 (2), 428-434.

36. Gonzalez, V.; Taylor, S. E. Asphaltene Adsorption on Quartz Sand in the Presence of Pre-Adsorbed Water. Journal of Colloid and Interface Science 2016, 480, 137-145. 


\section{S Supplementary Information}

Table 5.S1. Composition of all crude oils used, as shown by SARA analysis, and acid-/base numbers.

\begin{tabular}{|c|c|c|c|c|c|c|}
\hline $\begin{array}{l}\text { Crude oil } \\
\text { name }\end{array}$ & Saturates & $\begin{array}{l}\text { Aromatics } \\
\qquad(w t \%\end{array}$ & $\begin{array}{l}\text { Resins } \\
\text { b) }\end{array}$ & Asphaltenes & $\begin{array}{c}\text { Acid } \\
\text { number } \\
\quad \text { (mg K }\end{array}$ & $\begin{array}{l}\text { Base } \\
\text { number } \\
\text { OH/g) }\end{array}$ \\
\hline $\bar{A}$ & 46.3 & 29.6 & 17.6 & 6.5 & 0.3 & 2.7 \\
\hline B & 40.2 & 29.4 & 19.0 & 11.4 & 0.1 & 2.4 \\
\hline $\mathrm{C}$ & 66.7 & 21.4 & 11.9 & 0.1 & 1.4 & 1.6 \\
\hline $\mathrm{D}$ & 51.0 & 30.3 & 15.3 & 3.4 & 0.6 & 2.3 \\
\hline
\end{tabular}

Table 5.S2. Ion concentrations, ionic strength, calculated Debye length, and measured $\mathrm{pH}$ of all brines used in this work, including an indication whether they were used for aging the substrates, as ambient phase during measurements, or both.

\begin{tabular}{|c|c|c|c|c|c|c|c|c|c|c|c|c|}
\hline \multirow{2}{*}{\multicolumn{2}{|c|}{ Brine name }} & \multirow{2}{*}{$\begin{array}{c}\text { Aging/ } \\
\text { measure- } \\
\text { ment }\end{array}$} & \multicolumn{7}{|c|}{ Ion concentration $(\mathrm{mM})$} & \multirow{2}{*}{$\begin{array}{c}I S \\
(m M)\end{array}$} & \multirow{2}{*}{$\begin{array}{c}\lambda_{D} \\
(\mathrm{~nm})\end{array}$} & \multirow{2}{*}{$p H$} \\
\hline & & & $\mathrm{Na}^{+}$ & $\mathrm{K}^{+}$ & $\mathrm{Ca}^{2+}$ & $\mathrm{Mg}^{2+}$ & $\mathrm{Sr}^{2+}$ & $\mathrm{Cl}^{-}$ & $\mathrm{HCO}_{3}^{-}$ & & & \\
\hline \multirow{7}{*}{ 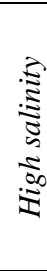 } & ASW & $y / y$ & 404 & 10 & 13 & 112 & 0 & 660 & 2.3 & 792 & 0.3 & 8.8 \\
\hline & ASW-c & $y / n$ & 402 & 10 & 13 & 112 & 0 & 660 & 0 & 786 & 0.3 & 8.7 \\
\hline & ASW-M ${ }^{2+}$ & $y / n$ & 404 & 10 & 0 & 0 & 0 & 410 & 2.3 & 417 & 0.5 & 6.0 \\
\hline & $\mathrm{CB}_{\mathrm{A}}$ & $y / y$ & 990 & 10 & 119 & 21 & 0 & 1280 & 0 & 1420 & 0.3 & 5.7 \\
\hline & $\mathrm{CB}_{\mathrm{B}}$ & $\mathrm{y} / \mathrm{y}$ & 471 & 7 & 3 & 4 & 0 & 492 & 0 & 498 & 0.4 & 5.6 \\
\hline & $\mathrm{CB}_{\mathrm{C}}$ & $\mathrm{y} / \mathrm{y}$ & 952 & 5 & 6 & 7 & 0 & 983 & 0 & 996 & 0.3 & 5.6 \\
\hline & $\mathrm{CB}_{\mathrm{D}}$ & $\mathrm{y} / \mathrm{y}$ & 2034 & 42 & 1651 & 415 & 35 & 6274 & 2.3 & 8382 & 0.1 & 8.7 \\
\hline \multirow{5}{*}{ 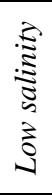 } & lsASW & $\mathrm{n} / \mathrm{y}$ & 13 & 0 & 0 & 4 & 0 & 21 & 0.1 & 25 & 1.9 & 8.7 \\
\hline & $1 \mathrm{sCB} A$ & $\mathrm{n} / \mathrm{y}$ & 14 & 0 & 2 & 0 & 0 & 17 & 0 & 20 & 2.2 & 6.3 \\
\hline & $1 \mathrm{sCB} B$ & $\mathrm{n} / \mathrm{y}$ & 24 & 0 & 1 & 1 & 0 & 26 & 0 & 28 & 1.8 & 6.3 \\
\hline & ${ }^{1 s C B} C_{C}$ & $\mathrm{n} / \mathrm{y}$ & 8 & 0 & 1 & 6 & 0 & 20 & 0.3 & 29 & 1.8 & 8.6 \\
\hline & $1 s \mathrm{CB}_{\mathrm{D}}$ & $\mathrm{n} / \mathrm{y}$ & 7 & 0 & 6 & 1 & 0 & 20 & 0 & 28 & 1.8 & 7.1 \\
\hline
\end{tabular}



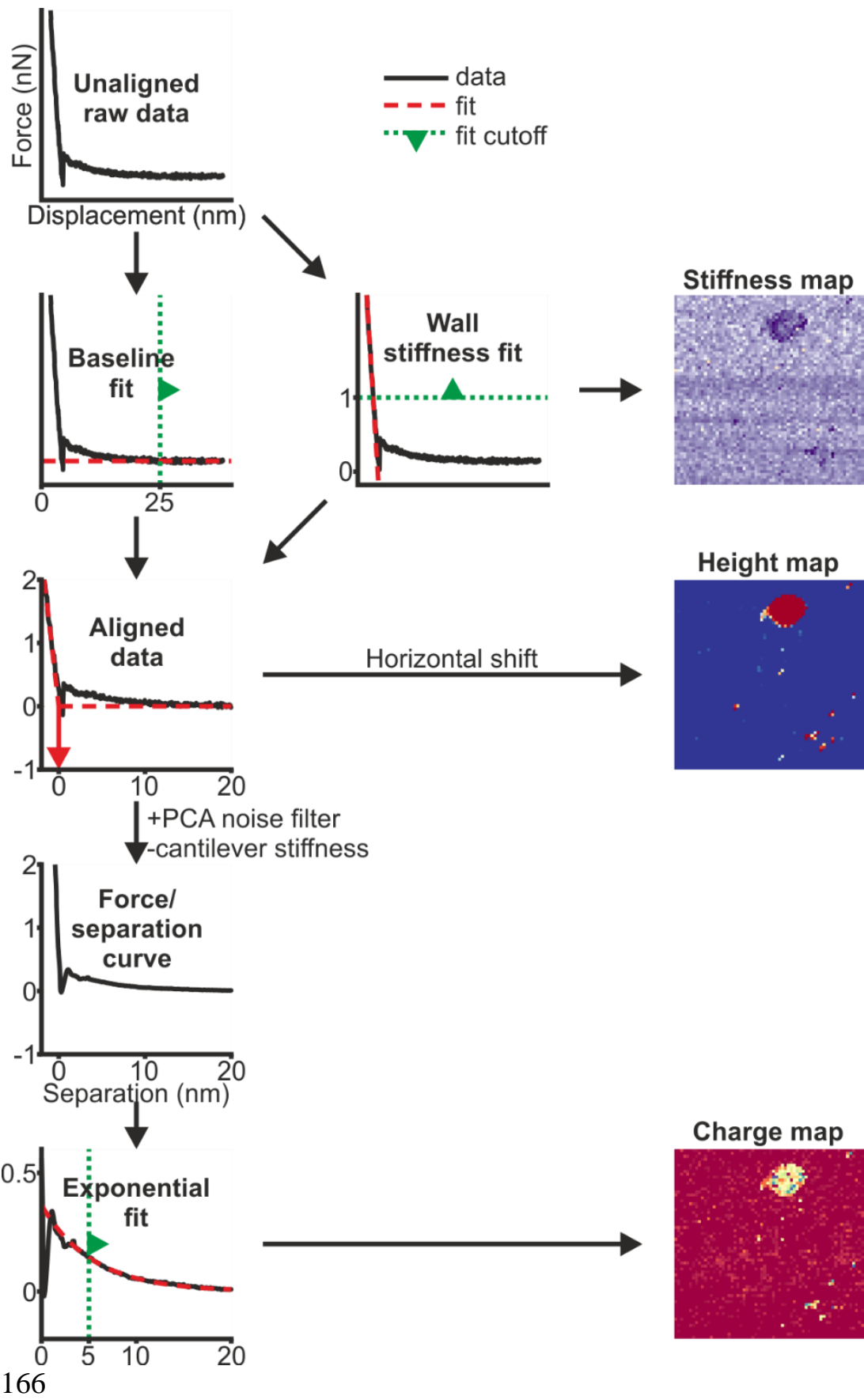

\section{Height map}

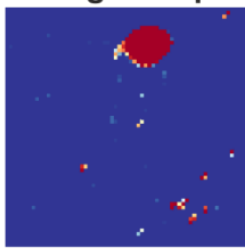

Charge map

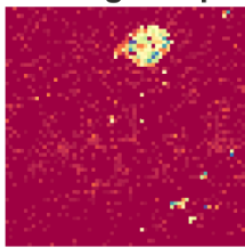


Figure 5.S1. (opposite page) Flowchart showing the different stages of processing done for the AFM force-volume data to extract three types of maps. The stiffness map was extracted using the slope of the linear part of the curve during tip/sample contact. The relative height map was extracted from the horizontal shift required to align all curves at their point of contact (defined as the point where the extrapolation of the aforementioned linear part crosses 0 force). The charge map was extracted by fitting the data to a model, see Fig. 5.S9. 
advancing, high salinity

advancing, low salinity

- receding
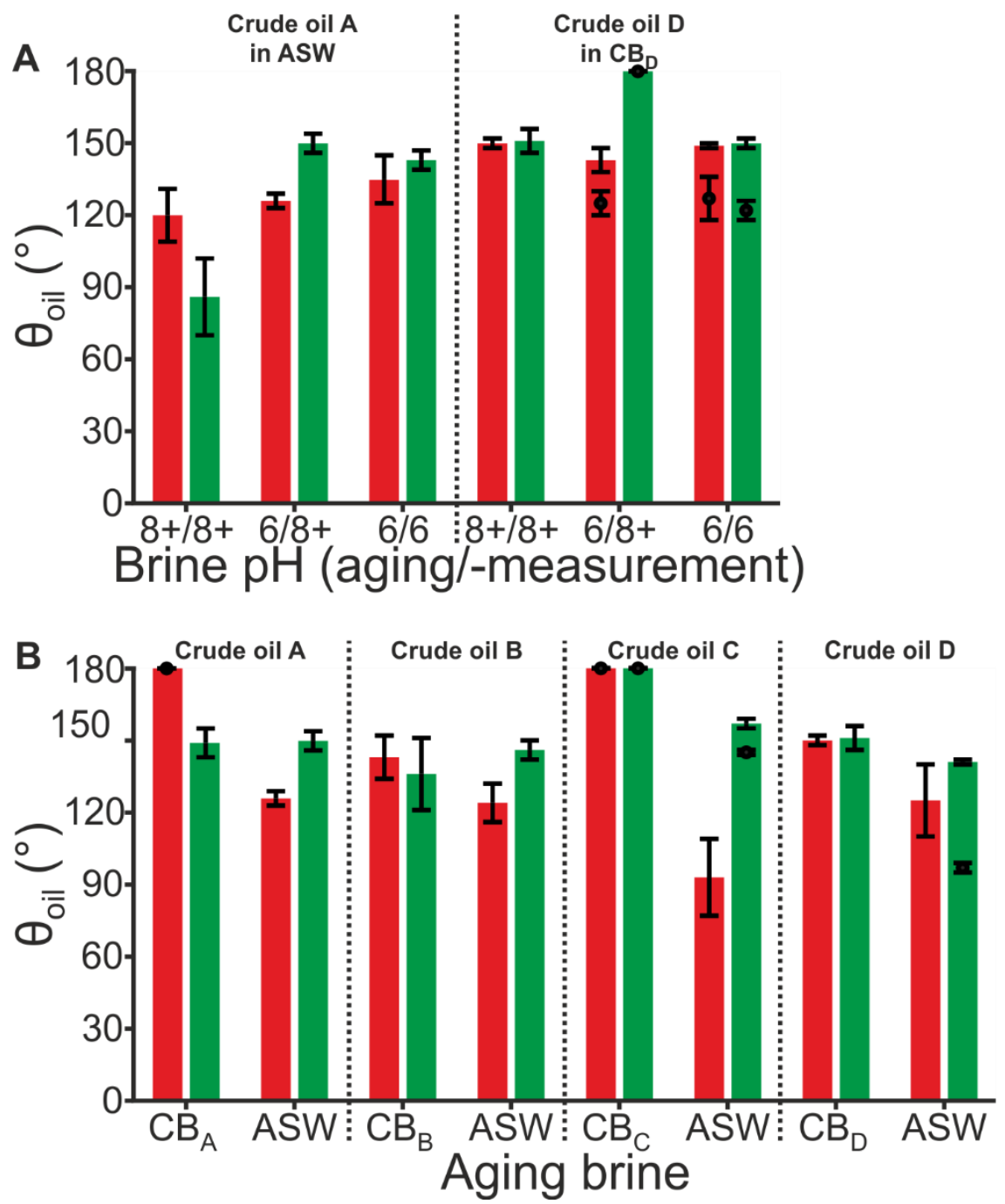
Figure 5.S2. (opposite page) Advancing and receding oil contact angles (where measureable) of different crude oils, on mica aged in different brines, at $60^{\circ} \mathrm{C}$.

A: variation of the $p H$ of the brines used in mica aging/ARCA measurements, the $\mathrm{pH}$ was either set to $\mathrm{pH} 6$ by adding $\mathrm{HCl}$ or left at $>8$. For crude oil $A$ aging and measurement was done in ASW/lsASW, while for crude oil D it was $C B_{D} / l s C B_{D}$.

$B$ : effects of different crude oils, aged with their corresponding $C B$, or with $A S W$ at pH 6. Measurements were performed in $C B / l s C B$ for samples aged in $C B$, and in $A S W / l s A S W(p H \approx 8.8)$ for samples aged in ASW. Compositions and $\mathrm{pH}$ (without added acid) of the various brines can be found in Table S2.

An increase in oil contact angle after lowering salinity would correspond to a wettability alteration that is favorable for LSWF EOR; this situation is found for all crude oils aged with $A S W, p H 6$, but only when the measurements were performed at $\mathrm{pH}>8$. 


\section{Crude oil $100 \mathrm{~nm}$}
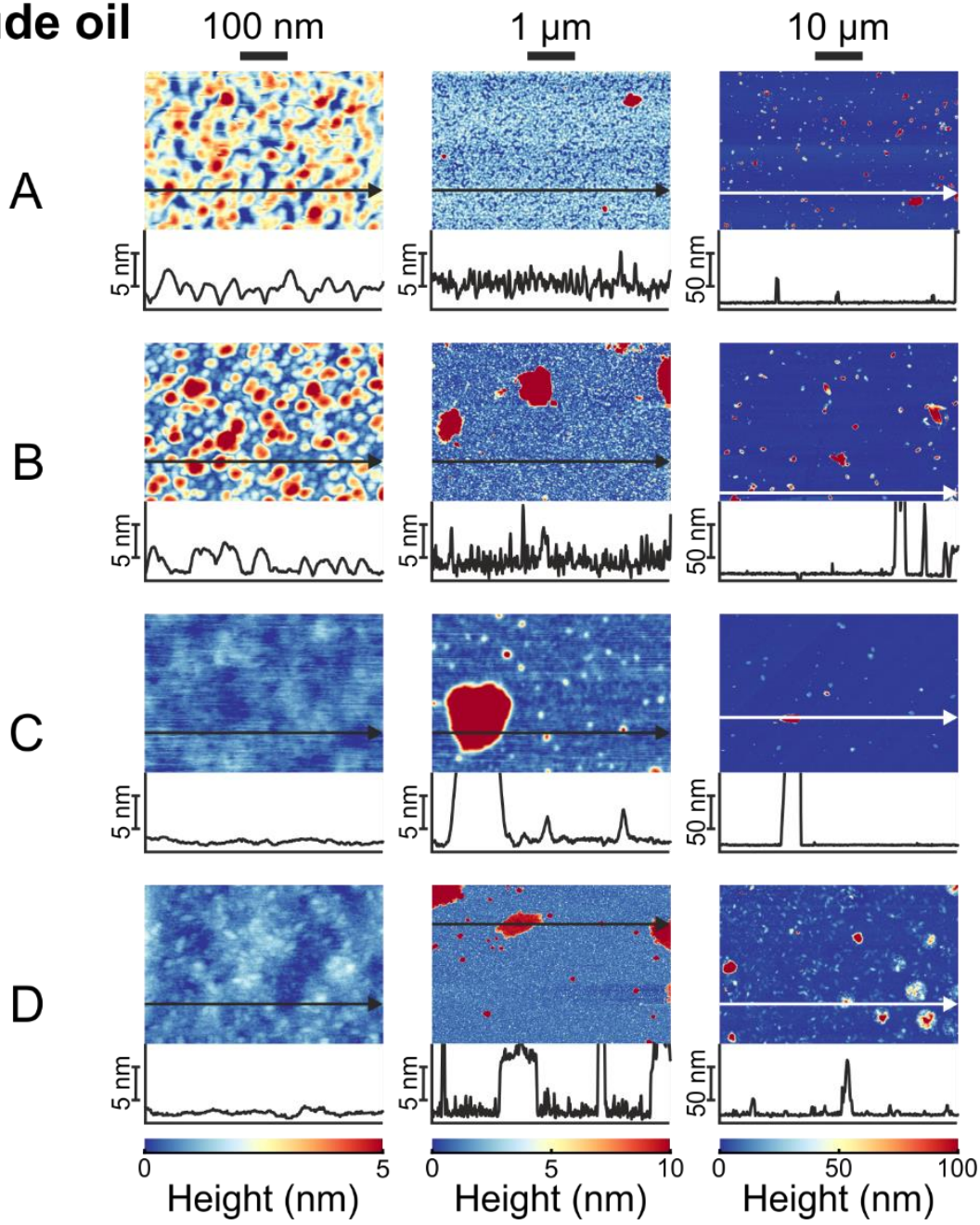

Figure 5.S3. Aging brine and crude oil dependence of substrate topography, using the respective $C B$ for each crude oil. Representative examples of $A F M$ height images and cross-sections of dried aged mica substrates $\left(\right.$ at $\left.60^{\circ} \mathrm{C}\right)$ at different lateral scan ranges: $50 \mu \mathrm{m}, 5 \mu \mathrm{m}$, and $500 \mathrm{~nm}$. 


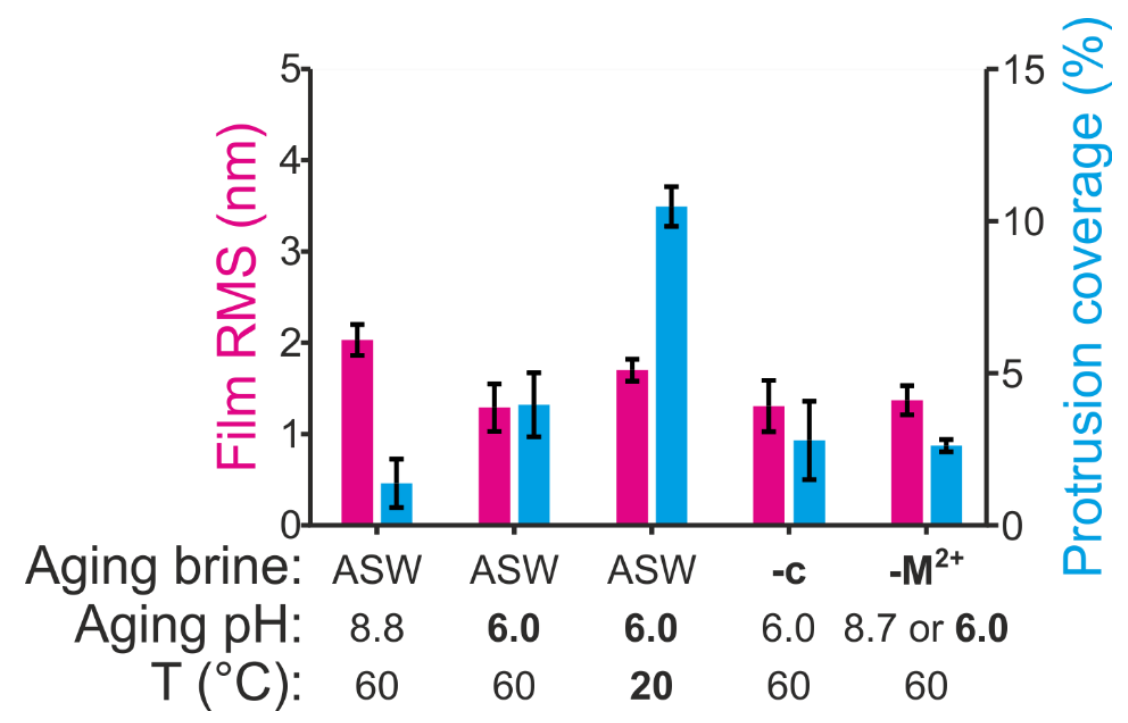

Figure 5.S4. Quantification of roughness of the films deposited on the mica during aging. Based on the AFM height images (in air) of Fig. 5.5, pixels with a height over $10 \mathrm{~nm}$, from the 5 \& 50 um lateral scan range images (at least 2 images of each scan size), were identified as protrusions. RMS roughness was also calculated based on the height signals, of all images. Error bars indicate the standard error. It shows that aging conditions do not seem to significantly affect these topographical parameters, other than the protrusion coverage of the $20^{\circ} \mathrm{C}$ aged substrate, which seems relatively high. 


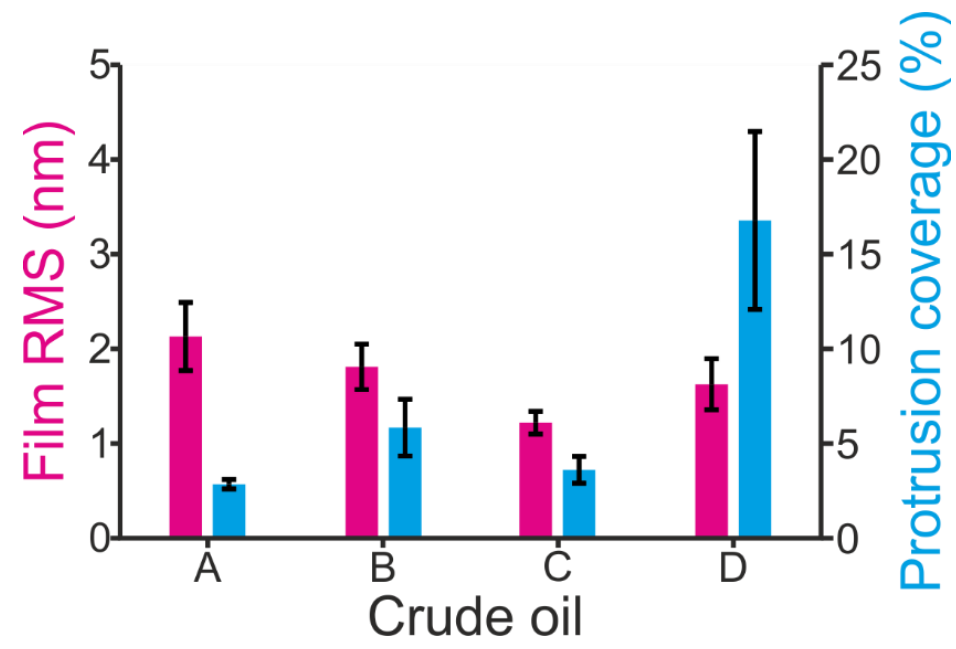

Figure 5.S5. Quantification of roughness of the films deposited on the mica during aging. Based on the AFM height images (in air) of Fig. 5.S3, pixels with a height over $10 \mathrm{~nm}$, from the 5 \& 50 um lateral scan range images (at least 2 images of each scan size), were identified as protrusions. RMS roughness was also calculated based on the height signals, of all images. Error bars indicate the standard error. It shows that aging conditions do not seem to significantly affect these topographical parameters, other than the protrusion coverage of the ' $D$ ' condition, which seems relatively high. 

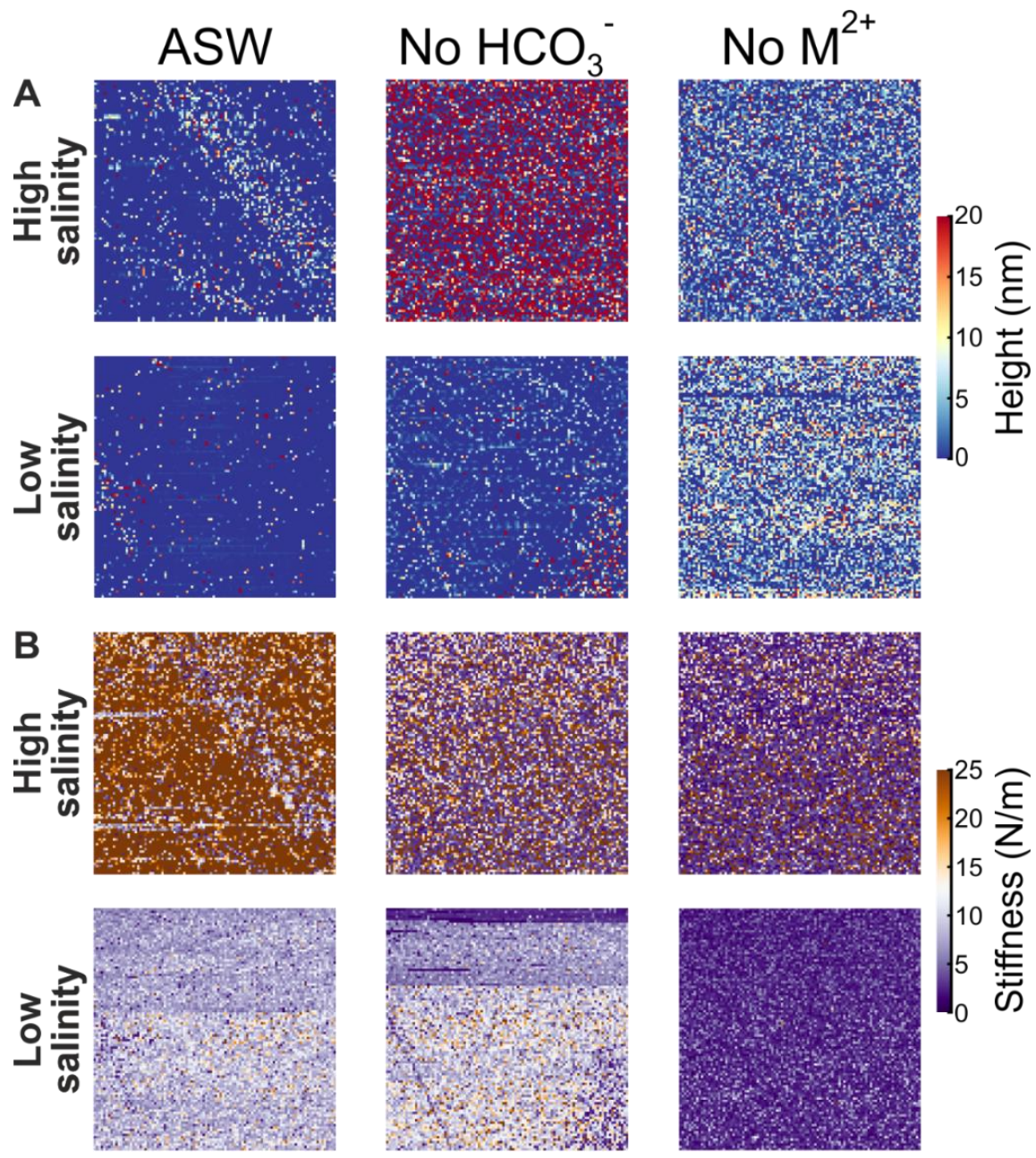

Figure 5.S6. In-situ force volume AFM measurements at high salinity. $50 \times 50$ $\mu \mathrm{m}$ images of aged mica substrates (crude oil and $A S W$-based brine, $60^{\circ} \mathrm{C}$ ) submerged in $A S W$, and lsASW, at pH 6: height (A), and substrate stiffness (B). 


\section{Aging brine High salinity Low salinity}

ASW
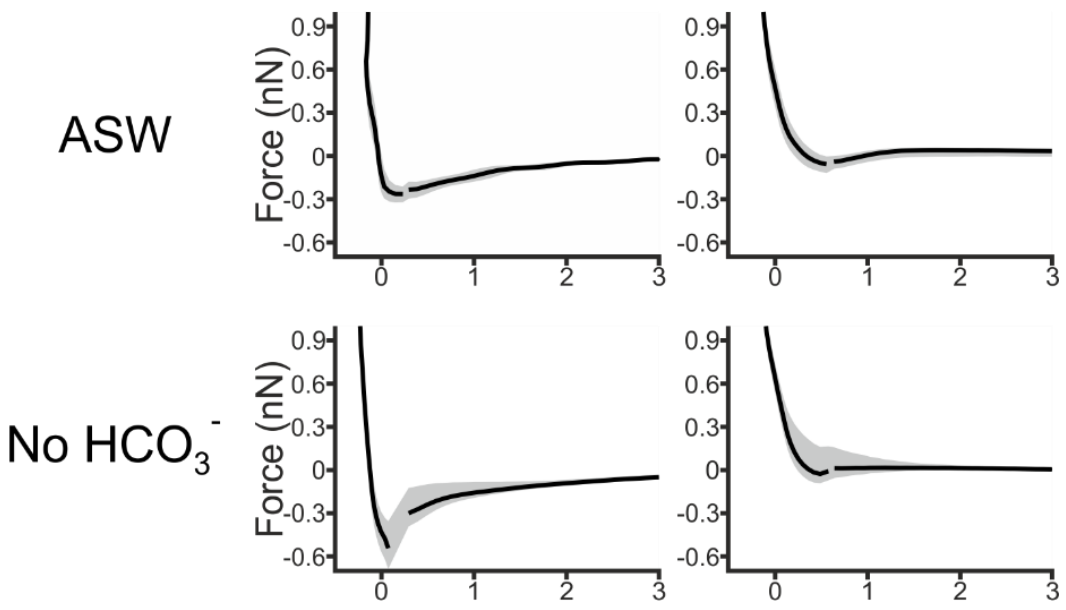

No $\mathrm{M}^{2+}$

(film)
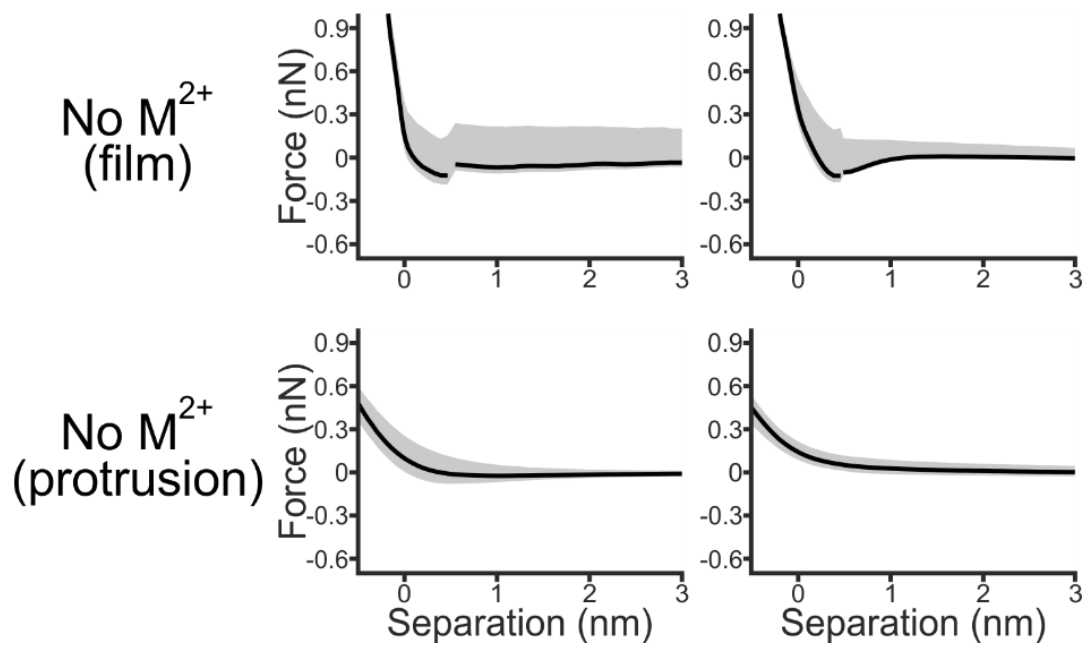

Figure 5.S7. Median force curves from the force volume maps of which some aspects are shown in Fig. 5.8, where each map consists of $100 \times 100=10000$ pixels. Grey area shows the confidence interval of 1 standard deviation around the mean. To prevent distortion of the curves by snap-in/snap-out effects, a gap is left between receding (left of gap) and the advancing (right of gap) curves. 


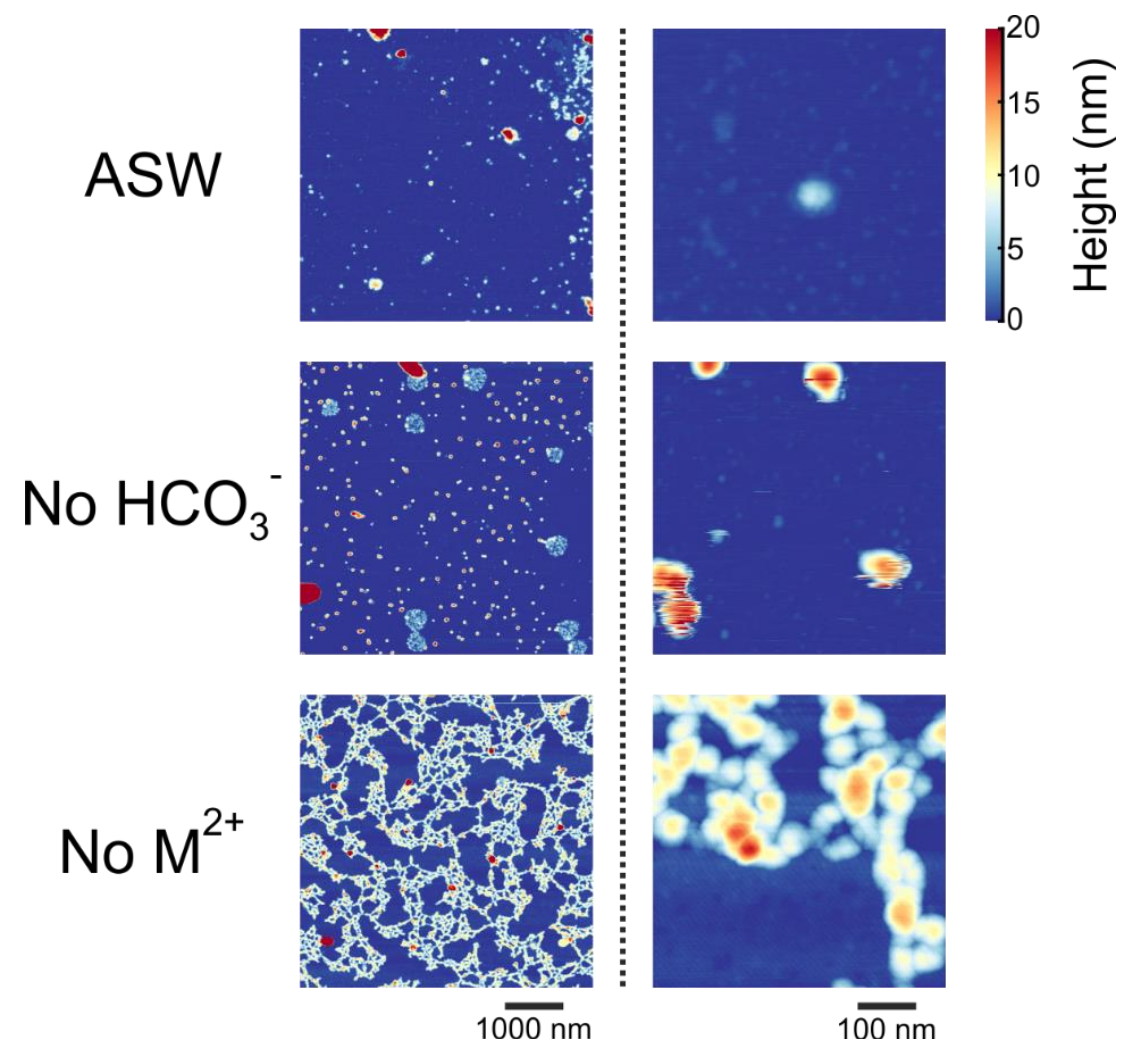

Figure 5.S8. AFM height images of dried aged mica substrates (crude oil A and $A S W$-Obased brines, $60^{\circ} \mathrm{C}$ ), subsequently exposed to ASW, lsASW (for the measurements shown in Fig. 5.8 \& 5.S6), then $1 \mathrm{mM} \mathrm{NaCL}$ (for the measurements shown in Fig. 5.10), and dried again. It shows that, exposure to brine can irreversibly alter the topography of the substrates, and that the height images measured in-situ might not accurately capture the topography. 

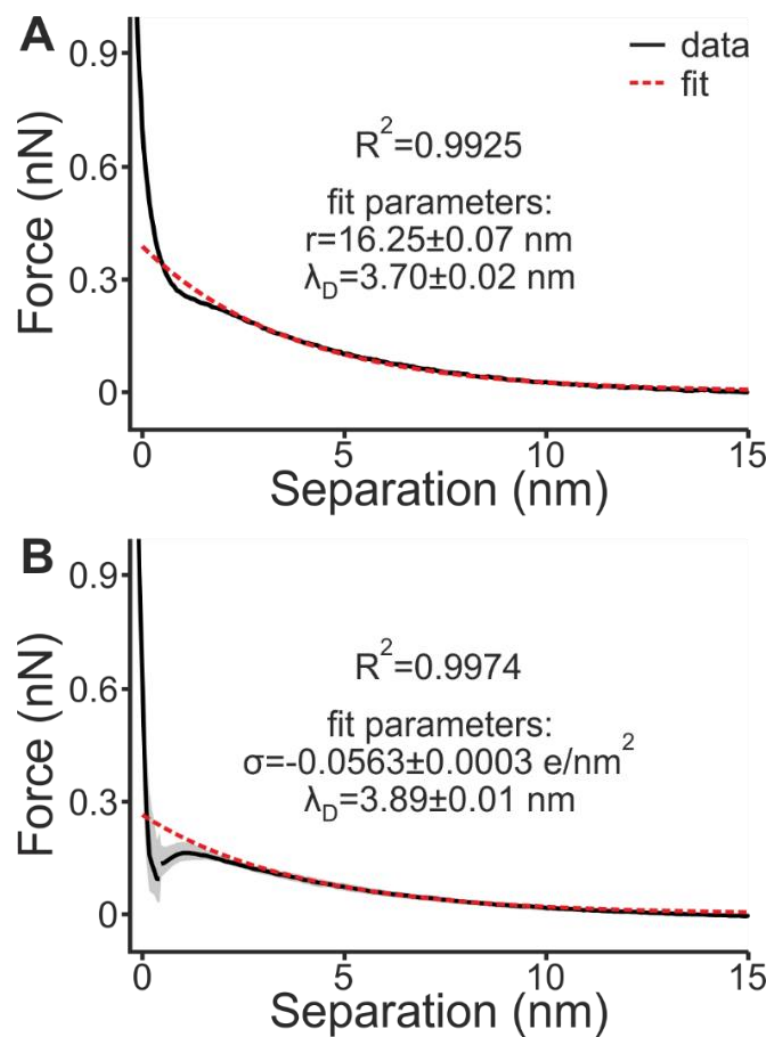

Figure 5.S9. Median force curves of $64 \times 64=4096$ pixel force volume maps, showing silica tip-silica substrate (A) and silica tip-ASW+crude oil A aged mica interaction (B, maps shown in Fig. 5.10, left column). The former was used to fit the tip radius, the latter is an example of how the charge is fit, both using only the data where separation $>5 \mathrm{~nm}$. 
6

\section{CONCLUSION \& OUTLOOK}

In the introduction I established that in order to adequately understand the mechanisms underlying the salinity-dependent wettability alteration of sandstone rock, as achieved in low salinity water flooding (LSWF), experimental data is required over a wide range of complexities, from real rock wetted by crude oil, to simple and less ambiguous model systems. The main aim has been to supplement existing data and increase understanding, by investigating model flat mineral substrates in simplified oil/brine ambient phases, focusing on the influence of different salts and simple amphiphilic organic components on the wettability.

In chapters $2 \& 3$, I found that, for realistic salinities, the ionic strength of the brine had no effect on the wettability of mica, in the presence of fatty-acid laden alkane oil. Instead, the concentration of divalent cations controlled the macroscopic wettability. This can be attributed to these cations binding with the organic molecules and subsequently adsorbing as weakly hydrophobic layers on the solid substrate. When temperatures were elevated to $40^{\circ} \mathrm{C}$ and above (in chapters $3 \& 4$ ), and bicarbonate was also present in the brine, I observed an additional effect, attributed to the additional incorporation of carbonate species in the aforementioned hydrophobic layers. This was found to enhance their effect to create hydrophobic and strongly oil-wet substrates. In all cases, removal of divalent cations from the brine was found to disrupt the organic surface layers and cause the system to change to a more water wet state. The underlying effects of LSWF are often associated with this type of wettability alteration.

Performing experiments with crude oil instead of a simple alkane oil with fatty acid, on substrates aged with brine and the crude oil (chapter 5), I found that the brine composition during 
aging had a strong influence on the wetting properties, including the response to lower ambient salinities. The aging steps caused a nanometer scale organic layer to irreversibly adsorb and cover the entire substrate, where the aging brine composition was found to influence the overall architecture of the film.
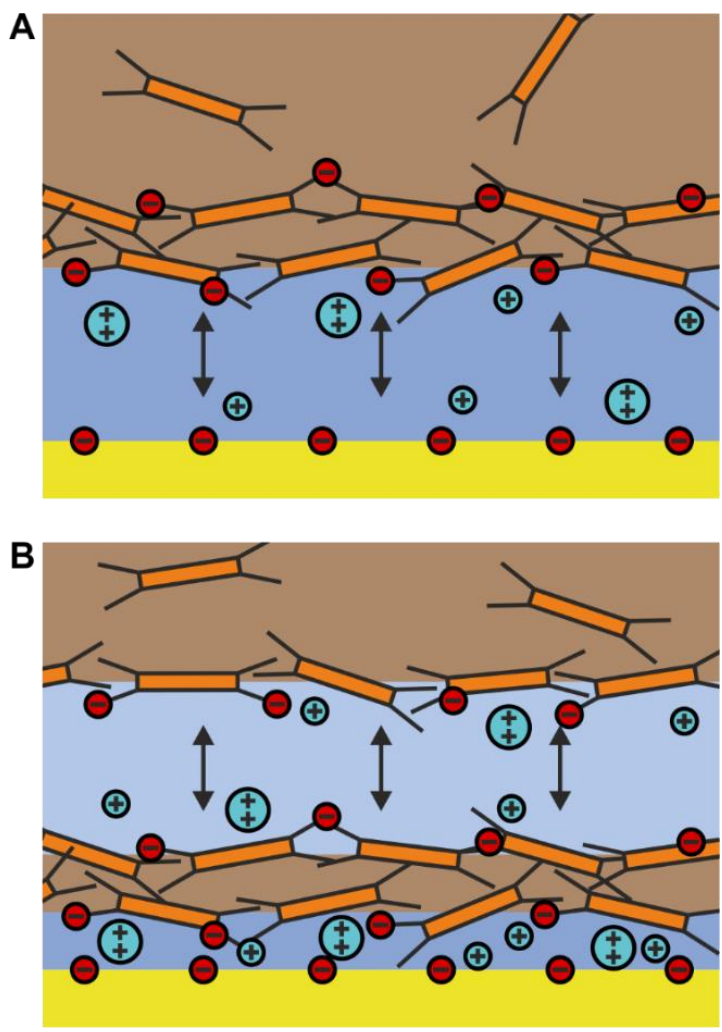

Figure 6.6. Schematic representation of the relevant thin-film interactions before and during LSWF: A) the initial organic film adsorption, B) the interactions of this film with bulk brine and crude oil. 
Although the conditions under which these crude oil experiments were performed are still far away from real reservoir conditions, they are nonetheless more representative than the simpler experiments from the earlier chapters. Their results are therefore likely also more reliable when trying to predict the wettability effects of LSWF and related core flooding experiments.

Our findings with the crude oils indicate that the microscopic mechanisms that directly control the wettability, occur at the surface of an organic thin film covering the mineral, and not at the mineral surface itself. At first glance, this might suggest that the results of the simpler experiments with clean mineral surfaces, are not (as they were set out to be) representative of relevant mechanisms under-lying LSWF. However, as stated above, the conditions at which the organic films are formed, were found to be ultimately decisive for wettability alteration by lowering salinity. Accordingly, the effects observed in the simpler, clean substrate experiments should be viewed more in light of the initial, ion-dependent, binding of organic components to the mineral surface, which has an indirect but important effect on the wetting properties of the system.

There appear to be two distinct stages in which the ionic content of the brine phase influences microscopic structure alteration at the solid surface. These structural changes can then influence the macroscopic wettability during core flooding, either directly or indirectly. The first stage involves the bare rock, interacting with the brine and invading oil phase to form a nanometer-scale thin film of surface-active crude oil components, possibly with some residual brine underneath (see Fig. 6.1A). The second stage involves the interactions occurring at the bulk liquid-exposed surface of this thin film, with the components of the formation brine, the invading brine, and the bulk oil phase (see Fig. 6.1B). Although I would not rule out the bulk oil directly interacting with the organic film components 
as an important wettability factor, it is likely that the thin film interactions described above are mostly responsible for the salinity response. Similar stages are likely to occur in a real reservoir, but the first would mostly occur during the formation of the reservoir over tens of millions of years. Therefore, it's pre-dominantly the second stage that is of relevance to LSWF, as these interactions are directly affected by invading brine composition. Nevertheless, a good understanding of the permanently adsorbed organic film architecture is essential to be able to predict the effects of LSWF.

The experiments with crude oil did not always display the same salinity-dependent wettability alterations as found for the simple systems. In other words: the results from the simple systems could not be consistently translated to the more realistic systems. I did generally find that divalent cations were important to the salinity responses, and that electric double layer expansion was not. Other than that I could not identify a more specific parameter or mechanism correlating to the wettability responses in all systems. Therefore, more research is required to link the simple model systems, which can reveal clear mechanistic pictures, with their more complex counterparts. As stated above, the experiments I performed with the simple systems are likely more relevant to the first stage of microscopic mechanisms, therefore, what is mostly lacking are simple model systems to test the second stage mechanisms in more detail, using an organic substrate.

To realize such a system, one should aim to further characterize the properties of the organic films formed by crude oil. Such as the characterization of asphaltene structures using AFM performed by Schuler et al. ${ }^{1}$ Based on this knowledge, model organic compounds can be selected, such as those compiled in a review article by Sjöblom et al., ${ }^{2}$ to create artificial organic films. In this way, relevant properties such as chemical groups and microscopic topography can be tuned to probe relevant specific effects. These artificial organic films can 
then also be used to directly measure microscopic interactions using functionalized AFM probes as has been done by Hassenkam et al. on real sandstone surfaces. ${ }^{3}$

Once the microscopic aspects of the crude oil systems are better understood, the crude oil wettability experiments can be made more complex and realistic to reservoir conditions, so that they may be used to predict and supplement core flooding experiments. A clear direction here would be a closer approach of the temperatures and pressures that occur in deeper reservoirs, i.e. up to about $160^{\circ} \mathrm{C}$ and up to $50 \mathrm{MPa}{ }^{4}$ Although the current literature indicates that the effects of pressure are likely negligible compared to that of brine composition, ${ }^{5}$ high pressures are still necessary for stable measure-ments at temperatures above the boiling point of the brine (but $1 \mathrm{MPa}$ will suffice to achieve this). The effects of geometry should also be investigated, as has been done in packed-bed systems by Jung et al., ${ }^{6}$ demonstrating that there exist critical transitions in flow patterns upon minor changes in surface wetting properties. By combining such pore flow systems with simple homogeneous surface chemistries, controllable brine compositions, and relevant organic components, an intermediate setup between wettability- and core flooding experiments could be realized.

What stands out from an overview of all experimental results in this thesis work is that, even when highly simplified systems were used, the interpretation of the outcomes can be very complex. Very small changes in environmental conditions, and the compositions of ions or organic components, can result in tremendous changes in surface specific mechanisms and macroscopic wettability.

When the system in this work were made more realistic, and thereby more complex, the origins of these effects also became less obvious, and more system-specific. It is to be expected that, if the systems were to be made even more complex, that would only be intensified. In the end, it seems unlikely that one single 
microscopic mechanism will ever be identified as the underlying factor of the 'low salinity effect'. Instead, as more data is collected, several important effects will likely be found, all relying on different environmental and chemical conditions. 


\section{References}

1. Schuler, B.; Meyer, G.; Peña, D.; Mullins, O. C.; Gross, L. Unraveling the Molecular Structures of Asphaltenes by Atomic Force Microscopy. Journal of the American Chemical Society 2015, 137 (31), 9870-9876.

2. Sjöblom, J.; Simon, S.; Xu, Z. Model Molecules Mimicking Asphaltenes. Advances in Colloid and Interface Science 2015, 218, 116.

3. Hassenkam, T.; Mitchell, A. C.; Pedersen, C. S.; Skovbjerg, L. L.; Bovet, N.; Stipp, S. L. S. The Low Salinity Effect Observed on Sandstone Model Surfaces. Colloids and Surfaces A: Physicochemical and Engineering Aspects 2012, 403, 79-86.

4. Bjørlykke, K.; Jahren, J. Sandstones and Sandstone Reservoirs. In Petroleum Geoscience: From Sedimentary Environments to Rock Physics, Bjørlykke, K., Ed.; Springer Berlin Heidelberg: Berlin, Heidelberg, 2015, pp 119-149.

5. Xie, Q.; Brady, P. V.; Pooryousefy, E.; Zhou, D.; Liu, Y.; Saeedi, A. The Low Salinity Effect at High Temperatures. Fuel 2017, 200, 419426.

6. Jung, M.; Brinkmann, M.; Seemann, R.; Hiller, T.; de La Lama, M. S.; Herminghaus, S. Wettability Controls Slow Immiscible Displacement through Local Interfacial Instabilities. Physical Review Fluids 2016, 1 (7), 074202. 



\section{DANKWOORD}

Lorem ipsum dolor sit amet, consectetur adipiscing elit. Vivamus vitae ligula feugiat, placerat erat vitae, ultricies tortor. Fusce tellus magna, efficitur hendrerit quam ac, viverra vehicula nibh. Donec nec metus in quam porta consequat. Fusce suscipit suscipit aliquet. Praesent gravida dapibus euismod. Suspendisse potenti. Ut erat justo, elementum sit amet nibh quis, fermentum semper felis. Donec rutrum nunc metus, eget suscipit mauris tempus quis. Proin a quam nunc. Donec sit amet pharetra libero. Phasellus sit amet vehicula erat. Pellentesque tincidunt sapien ac sagittis commodo. Nulla facilisi. Lorem ipsum dolor sit amet, consectetur adipiscing elit. Praesent facilisis diam at lectus pulvinar, sit amet congue quam consequat.

Cras eget pharetra elit, vel ultricies orci. Integer erat lectus, posuere sed enim ac, euismod scelerisque est. Fusce id commodo neque. Vestibulum aliquet, mauris quis finibus iaculis, nisl est consectetur nulla, eu faucibus dolor nisi vitae lacus. Sed pellentesque fermentum ex, ut sagittis sapien porta sagittis. Sed non massa ex. Cras eu sodales urna, sed accumsan purus. Suspendisse aliquet, elit non iaculis fermentum, dui magna hendrerit lorem, in luctus mauris mi id urna. Nulla facilisi. Curabitur mattis dui ac purus tristique convallis. Aenean eu porttitor sapien. Quisque convallis sollicitudin orci, vulputate sodales quam ornare in. Donec arcu metus, condimentum ut nisl ut, pulvinar auctor sapien. Nullam purus odio, pharetra finibus consequat nec, auctor sed dolor. Duis 
malesuada lorem nec arcu vestibulum, id mattis est ullamcorper. Quisque egestas non elit nec ornare.

Proin vestibulum odio nec risus viverra dapibus. Fusce nec tristique ante. Aenean in odio a turpis lobortis gravida. Lorem ipsum dolor sit amet, consectetur adipiscing elit. Phasellus dignissim cursus purus. Nullam pretium tortor a maximus commodo. Sed scelerisque ligula at ex imperdiet congue. Nullam libero quam, fermentum id massa sit amet, fringilla porttitor ex. Nunc a tellus hendrerit, mattis mi finibus, ullamcorper sem. In non dolor lacus. Fusce sit amet vulputate lectus, et malesuada dolor. 